$$
\begin{gathered}
\text { Universidade de Brasília } \\
\text { Instituto de Química } \\
\text { Programa de Pós-Graduação em Química }
\end{gathered}
$$

\title{
Avaliação da Qualidade dos Óleos Básicos Rerrefinados Brasileiros e a Determinação de Metais por Espectrometria de Fluorescência de Raios X
}

Maristela Lopes Silva Melo

Orientador: Prof. Dr. Jurandir Rodrigues de Souza

Brasília - 2015 


\section{COMUNICADO}

Comunicamos a aprovação da Defesa de Tese de Doutorado do (a) aluno (a) Maristela Lopes Silva Melo, matrícula no 10/0071678, intitulada "Avaliação da Qualidade dos Óleos Básicos Rerrefinados Brasileiros e a Determinação de Metais por Espectrometria de fluorescência de Raios X", apresentada no (a) Auditório Verde do Instituto de Química (IQ) da Universidade de Brasília (UnB) em 10 de julho de 2015.

Prof. Dr. Jurandir Rodrigues de Souza

Presidente de Banca (IQ/UnB)

Dr. Rossine Amorim Messias

Membro Titular (CPT / ANP)

Prof. Dr. Armando de Azevedo Caldeira Pires

Membro Titular (FT / UnB)

Prof. Dr. Alexandre Fonseca

Membro Titular (IQ/UnB)

Prof. Dr. Júlio Lemos de Macedo

Membro Titular (IQ/UnB)

Dr. Fábio da Silva Vinhado

Membro Suplente (CPT / ANP)

Em 10 de julho de 2015. 
Agradeço a Deus por tudo;

Ao meu anjo da guarda pela inspiração;

Aos meus pais, pela dedicação à minha formação como pessoa e profissional;

Ao meu marido Wilson, pela compreensão e paciência pela minha ausência nos momentos de dedicação total a este trabalho;

Aos meus colegas da Coordenação de Petróleo e Lubrificantes do CPT/ANP, pela colaboração e incentivo.

Aos colegas da Superintendências de Abastecimento, SAB, e de Fiscalização do Abastecimento, SFI. 


\section{Resumo}

O rerrefino do óleo lubrificante usado e contaminado é fortemente incentivado no Brasil por ser a única forma legal de tratar esse resíduo perigoso. No entanto, pouco se conhece sobre os processos utilizados no país e sobre a qualidade desses produtos, principalmente no que concerne à eliminação de contaminantes. Nesta pesquisa, dezoito instalações de rerrefino autorizadas para exercício da atividade de produtor foram visitadas e 39 amostras foram coletadas para avaliação da qualidade de acordo com a Portaria ANP $n^{\circ}$ 130/99 e para a avaliação da eficiência na eliminação de contaminantes. Um novo método de determinação de metais em óleos básicos utilizando a espectrometria de fluorescência de raios $X$ por energia dispersiva, FRX/EDX, foi estabelecido e validado. Os óleos básicos rerrefinados produzidos no Brasil são predominantemente do grupo I e o processo mais utilizado é uma combinação do termocraqueamento com ácido/argila. $O$ índice de não conformidades das amostras coletadas foi de $43,6 \%$, o que é considerado elevado. Dentre as amostras não conforme, a maioria é proveniente de duas empresas, cujos processos são muito simplificados. Dois espectrômetros de fluorescência de raios $X$ foram testados, um deles apresentou resultados promissores, mas o outro mostrou ser inadequado para a determinação de metais em óleos básicos rerrefinados. Os teores de metais encontrados em um terço das amostras foram superiores a $20 \mathrm{mg} / \mathrm{kg}$, o que evidencia a necessidade de se estabelecer método de análise rápido e que poderia ser utilizado rotineiramente no controle de qualidade das rerrefinadoras. 


\begin{abstract}
The re-refining of used lubricating oil is strongly encouraged in Brazil for being the only legal way of disposal of this hazardous waste. However, there is scant information about the processes used in the country and the quality of their products, especially in regard to the removal of contaminants. In this research, eighteen re-refining facilities authorized by ANP were visited and 39 samples were collected for quality assessment according to PANP $n^{\circ} 130 / 99$ and to determine the efficiency of contaminants removal. A new method for determination of metals in base oils by energy dispersive $\mathrm{X}$-ray fluorescence spectroscopy, EDXRF, was established and validated. The re-refined base oils produced in Brazil are predominantly group I and the most widely used process is a combination of thermocraking and acid/clay treatment. The index of noncompliance of the collected samples was $43.6 \%$, which is considered high. Among the non-compliant samples, the majority comes from two companies whose processes are very simplified. Two energy dispersive X-ray spectrometers were tested, one showed promising results, whereas the other proved to be inadequate for the determination of metals in re-refined base oils. The levels of metals found in one third of the samples exceeded $20 \mathrm{mg} / \mathrm{kg}$, which highlighted the need for a rapid analysis method that could be used routinely in quality control.
\end{abstract}




\section{Índice}

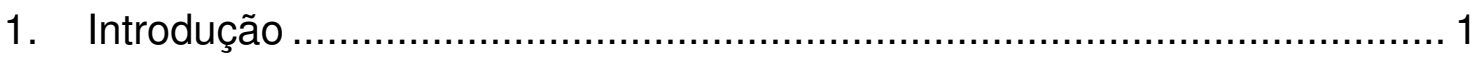

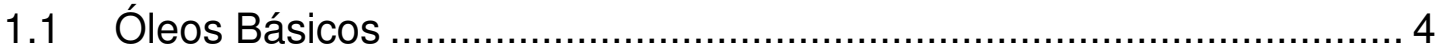

1.1.1 Conceito e Características Principais ........................................ 4

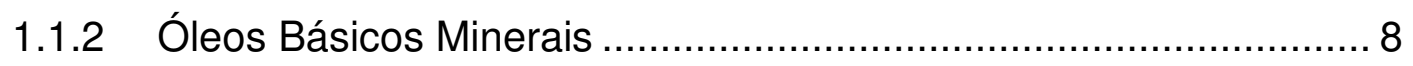

1.1.3 Óleos Básicos Sintéticos ..................................................... 16

1.1 .4 Óleos Básicos Vegetais .................................................... 18

1.1.5 Classificação dos Óleos Básicos .......................................... 19

1.2 Lubrificantes...................................................................... 20

1.2.1 Aditivos para Lubrificantes.................................................... 20

1.2.2 Classificação e Desempenho dos Óleos Lubrificantes ................. 23

1.3 Perspectivas Futuras para os Óleos Básicos ................................... 26

1.4 Óleo Lubrificante Usado e Contaminado e a Reciclagem .................. 28

1.5 Rerrefino ............................................................................ 34

1.6 A Fluorescência de Raios X e a Determinação de Metais em Óleos Lubrificantes ........................................................................................... 39

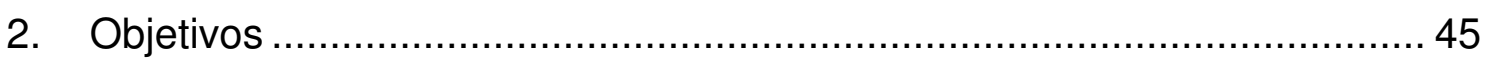

2.1 Objetivo Geral ................................................................... 45

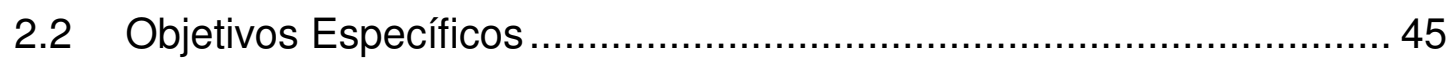

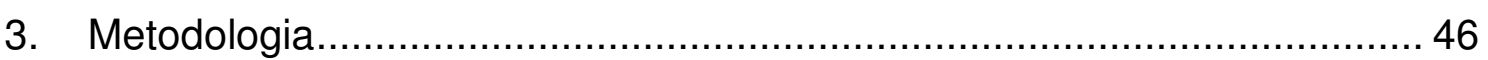

3.1 Visitas Técnicas, Coleta de dados e Amostras ................................. 46

3.2 Determinação de Características por Métodos Consolidados............. 47

3.3 Fluorescência de Raios X por Energia Dispersiva (FRX/EDX) .......... 51

3.3.1 Preparo dos Padrões e Soluções ............................................ 52

3.3.2 Condições de Análise por FRX/EDX ....................................... 52

3.3.3 Faixa Linear de Trabalho e Sensibilidade................................ 53

3.3.4 Seletividade e Efeito de Matriz ............................................ 59

3.3.5 Limites de Detecção e Quantificação ....................................... 60

3.3.6 Precisão e Exatidão ............................................................. 61

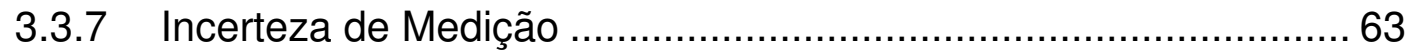

3.3.8 Testes em Equipamento com Tubo de Raios X de Prata ............. 65

3.4 Determinação dos metais........................................................ 66

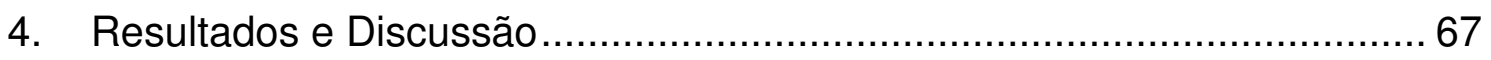

4.1 Visitas técnicas, Coleta de Dados e Amostras ..............................67 67 
4.1.1 Aspectos Gerais das Empresas Visitadas .................................. 67

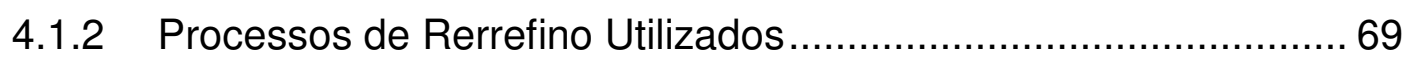

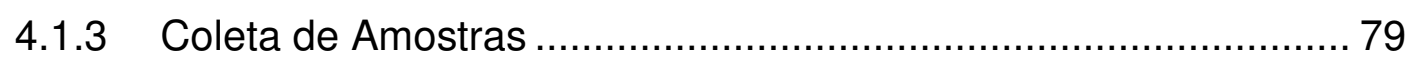

4.2 Determinação de Características por Métodos Consolidados.............. 80

4.3 Fluorescência de Raios X por Energia Dispersiva ............................ 101

4.3.1 Faixa Linear de Trabalho e Sensibilidade.................................. 101

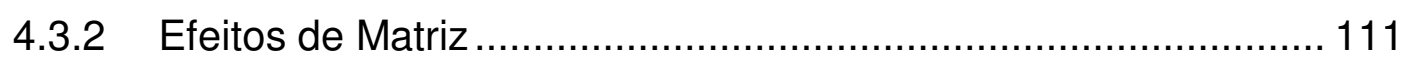

4.3.3 Limites de Detecção e Quantificação ........................................ 122

4.3.4 Precisão: Repetibilidade e Precisão Intermediária ...................... 124

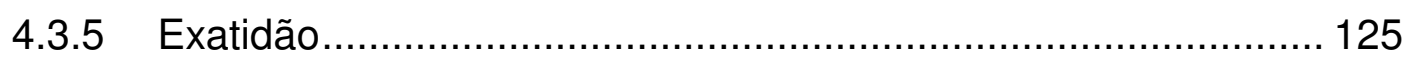

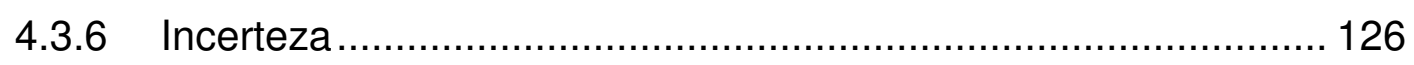

4.4 Determinação de Metais das Amostras Coletadas ........................... 127

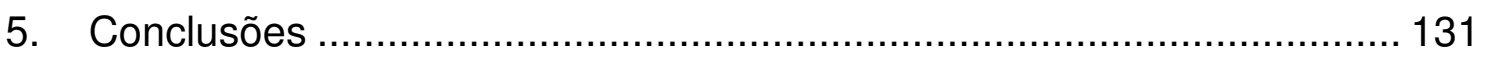

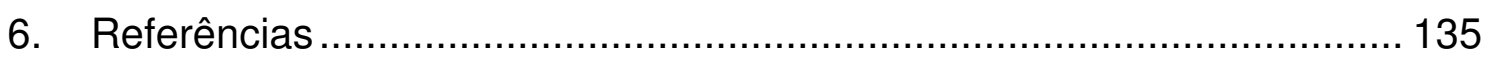

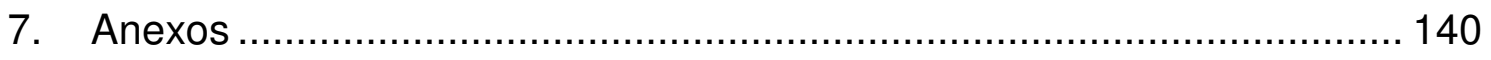

7.1 Anexo 1 - Espectros de infravermelho …………........................... 140

7.2 Anexo 2 -Linearidade do Método PNM1 para o Ferro ....................... 146

7.3 Anexo 3-Determinação do LD e LQ método PNM3 para o Ferro ... 151

7.4 Repetibilidade e Precisão Intermediária para o Ferro ........................ 152

7.5 Incerteza de medição para o Ferro método PNM3 ............................ 153 


\section{Lista de Abreviaturas}

ABNT - Associação Brasileira De Normas Técnicas

ANOVA - análise da variância,

ANP - Agência Nacional de Petróleo, Gás Natural e Biocombustíveis

API - American Petroleum Institute

ASTM - American Society For Testing And Materials

ATIEL - Association Technique de L'industrie Europeanne des Lubrifiants,

ATR - espectroscopia de reflectância total atenuada

CAP - cimento asfáltico de petróleo

CCS - simulador de partida a frio

CONAMA - Conselho Nacional do Meio Ambiente

CPT - Centro de Pesquisas e Análises Tecnológicas

EPA - Environmental Protection Agency

ETE - Estação de tratamento de efluentes

FRX/EDX - espectrometria de fluorescência de raios $X$ por energia dispersiva

HCC - hidrocraqueamento severo

HDT - hidrotratamento

HPLC - cromatografia líquida de alta eficiência

HVOC - compostos orgânicos halogenados voláteis

IAT - índice de acidez total

ICP-OES - espectrometria de emissão atômica de plasma indutivamente acoplado

IFP - Institut Français de Pétroleo

ISO - International Organization for Standardization

IV - índice de viscosidade

LD - limite de detecção do método

LQ - limite de quantificação do método

Lubnor - Lubrificantes do Nordeste

MIV - melhoradores do índice de viscosidade

MMQO - método dos mínimos quadrados ordinários

MRC - material de referência certificado

ND - não detectado

NMP - n-metilpirrolidona

OLUC - óleo lubrificante usado e contaminado

PAO - polialfaolefina 
PCB - policloreto de bifenila

PCR - principal componente regression

PIO - polinternalolefinas

PLS - partial least square

PNL - parafínico neutro leve

PNM - parafínico neutro médio

PNP - parafínico neutro pesado

PPD - abaixador do ponto de fluidez

PSP - parafínico spindle

SAE - Society of Automotive Engineers

UV - ultravioleta 


\section{Lista de Figuras}

Figura 1. Planos paralelos em movimento com um fluido entre eles ................5

Figura 2. Gráfico ilustrando a relação do índice de viscosidade, IV, com a

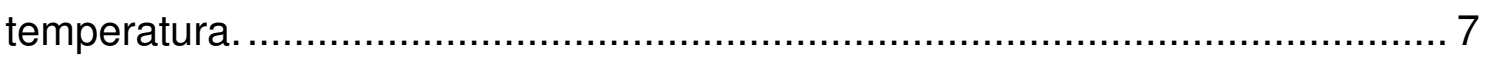

Figura 3. Esquema da destilação a vácuo. ............................................ 10

Figura 4. Esquema da desasfaltação a propano..................................... 11

Figura 5. Esquema representativo da desaromatização. .............................. 12

Figura 6. Esquema representativo da desparafinação ................................. 13

Figura 7. Esquema geral da rota convencional. ...................................... 14

Figura 8. Reações típicas de hidrogenação ............................................. 15

Figura 9. Oligômeros do 1-deceno. ....................................................... 16

Figura 10. Polímeros de dimetilsiloxano e de fenilmetilsiloxano...................... 17

Figura 11. Modelo explicativo do mecanismo de atuação dos melhoradores do índice de viscosidade. ................................................................. 21

Figura 12. Aditivos Melhoradores do Índice de Viscosidade......................... 21

Figura 13. Representações Estruturais de Alguns Aditivos Antioxidantes ....... 22

Figura 14. Representações Estrutural de um Aditivo detergente..................... 23

Figura 15. Demanda mundial de básicos por aplicação ............................... 27

Figura 16. Capacidade mundial prevista para 2014 e $2020 . \ldots \ldots \ldots \ldots \ldots \ldots \ldots . . . . . . . . . .28$

Figura 17. Esquema da extração a propano. .......................................... 36

Figura 18. Evaporador por película. Fonte Lwart Lubrificantes. ..................... 37

Figura 19. Processo safety kleen. ...................................................... 38

Figura 20. FRX/EDX, raios $X$ proveniente de (a) tubo de raios $X$ (b) substância radioativa..................................................................................... 41

Figura 21. Padrões comparativos para o teste de pingo do OLUC. ................. 70

Figura 22. Recebimento do OLUC: (a) e (b) caminhões coletores (c) e (d) descarregamento nas caixas receptoras............................................. 72

Figura 23. Exemplos de tanques para termocraqueamento.......................... 74

Figura 24. Processo de sulfonação (a) tanques de sulfonação, (b) tanques de sulfonação e tanques de ácido sulfúrico na horizontal. ................................ 75

Figura 25. Processo da empresa 5: a esquerda, na horizontal, destilador e a direita, na vertical, tanque de clarificação. .......................................... 75 
Figura 26. Purificação (a) filtro prensa e (b) filtros de 3, 10 e 25 mesh e filtro manga, da esquerda para a direita, respectivamente

Figura 27. Distribuição das não conformidades por parâmetros da Portaria ANP n०130/99.

Figura 28. Espectro da amostra RR8 em comparação com espectros de parafínico spindle e naftênico $\mathrm{NH} 140$, ambos de primeiro refino. 91

Figura 29. Espectro da amostra RR35 em comparação com espectros de parafínico spindle e naftênico $\mathrm{NH} 140$, ambos de primeiro refino. 92 Figura 30. Espectro da amostra RR7 em comparação com espectros de parafínico neutro médio, naftênico $\mathrm{NH} 140$ e de básicos contendo óleo vegetal.

Figura 31. Espectro da amostra RR17 em comparação com espectros de parafínico neutro médio e de parafínico contendo óleo vegetal. 93

Figura 32. Espectro da amostra RR21 em comparação com espectros de parafínico neutro médio e de parafínico contendo óleo vegetal. 94

Figura 33. Espectro da amostra RR7 em comparação com espectros de parafínico neutro médio, naftênico $\mathrm{NH} 140$ e de básicos contendo óleo vegetal.

Figura 34. Espectro da amostra RR17 em comparação com espectros de parafínico neutro médio e de parafínico contendo óleo vegetal. 96

Figura 35. Espectro da amostra RR38 em comparação com espectros de parafínico neutro médio e de parafínico contendo óleo vegetal e aditivo abaixador do ponto de fluidez, PPD......

Figura 36. Espectro da amostra RR38 em comparação com espectros de parafínico neutro médio e de parafínico contendo óleo vegetal e aditivo abaixador do ponto de fluidez, PPD.

Figura 37. Espectro da amostra RR36 em comparação com espectros de parafínico neutro médio e de parafínico contendo óleo vegetal e aditivo abaixador do ponto de fluidez, PPD. 98

Figura 38. Espectro da amostra RR37 em comparação com espectros de parafínico neutro médio e de parafínico contendo 0,25 \% em peso de água... 99 Figura 39. Espectro da amostra RR39 em comparação com espectros de parafínico neutro médio e naftênico $\mathrm{NH} 140$. 100 
Figura 40. Distribuição das não conformidades por parâmetros da Portaria ANP n॰130/99, excluindo a viscosidade cinemática e inserindo ATR. 101

Figura 41. Gráfico exploratório inicial obtido para o magnésio pelo método PNM1. 102

Figura 42. Gráficos exploratórios obtidos para o silício pelos métodos (a) PNM1 e (b) PNM3. 102

Figura 43. Gráfico exploratório inicial obtido para o silício utilizando o Epsilon 3 XL (método PNM2). 103

Figura 44. Gráfico da regressão linear obtida para o cádmio (a) e chumbo (b) pelo método PNM1. 104

Figura 45. Gráfico da regressão linear obtida para o cromo pelo método PNM1. 104

Figura 46. Gráfico da regressão linear obtida para o bário (a) e cálcio (b) pelo método PNM1. 105

Figura 47. Gráficos de regressão linear para ferro (a), zinco (b), cobre(c), molibdênio (d) e níquel (e) obtidos pelo método PNM1. 106

Figura 48. Gráfico da regressão linear obtida para o cálcio pelo método PNM3. 108

Figura 49. Gráfico da regressão linear obtida para o cobre pelo método PNM3. 109

Figura 50. Gráficos de regressão linear obtidos para cádmio, chumbo, cromo, cálcio e bário usando o equipamento Epsilon 3 XL (método PNM2). 110 Figura 51. Gráficos de regressão linear obtidos para ferro, zinco, cobre e níquel usando o equipamento Epsilon $3 \mathrm{XL}$

Figura 52. Gráfico de regressão linear das curvas de cálcio com os quatro tipos de básicos - método PNM3. 113

Figura 53. Gráfico de regressão linear das curvas de cádmio com os quatro tipos de básicos - método PNM1 114

Figura 54. Gráfico de regressão linear das curvas de zinco com os quatro tipos de básicos - método PNM1.

Figura 55. Gráfico de regressão linear das curvas de níquel com os quatro tipos de básicos - método PNM1. 115 Figura 56. Gráfico de regressão linear das curvas de cromo com os quatro tipos de básicos - método PNM1. 116 
Figura 57. Gráfico da regressão linear obtida para o zinco pelo método PNM3.

Figura 58. Gráfico da regressão linear das curvas em PNP para ferro (a) e bário (b) pelo método PNM3. 118

Figura 59. Gráfico de regressão linear das curvas de ferro com os quatro tipos de básicos - método PNM1. 118 Figura 60. Gráfico de regressão linear das curvas de bário com os quatro tipos de básicos - método PNM1. 119 Figura 61. Gráfico de regressão linear das curvas de chumbo com os quatro tipos de básicos - método PNM1 120

Figura 62. Gráfico de regressão linear das curvas de molibdênio com os quatro tipos de básicos - método PNM1 121

Figura 63. Gráfico de regressão linear das curvas de cobre com os quatro tipos de básicos - método PNM3. 121 Figura 64. Diagrama de Ishikawa com as fontes de incerteza avaliadas para os métodos 126

Figura 65. Distribuição das não conformidades por parâmetros da Portaria ANP n० 130/99, excluindo a viscosidade cinemática e inserindo ATR e teor de elementos. 129 


\section{Lista de Tabelas}

Tabela 1. Comparação entre características de óleos básicos parafínicos e

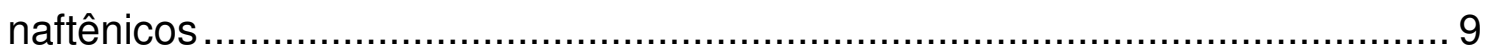

Tabela 2. Índices de viscosidade dos óleos básicos minerais e sintéticos....... 18

Tabela 3. Classificação ATIEL/API para óleos básicos..................................... 19

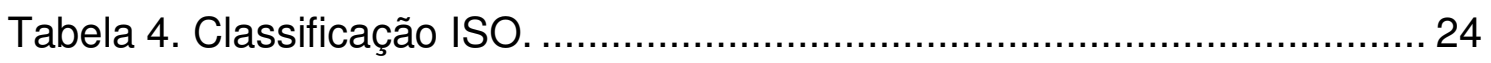

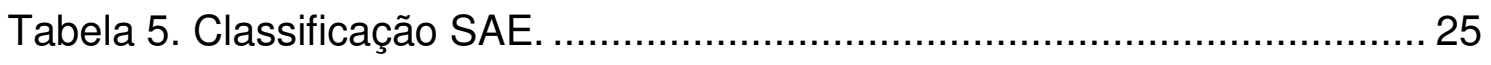

Tabela 6. Concentração dos constituintes do óleo usado................................ 29

Tabela 7. Volumes percentuais mínimos de OLUC a serem coletados pelos produtores e importadores de óleo lubrificante acabado.

Tabela 8. Empresas rerrefinadoras de OLUC autorizadas pela ANP no período avaliado.

Tabela 9. Normas Técnicas utilizadas para avaliação da qualidade dos óleos rerrefinados 48

Tabela 10. Condições de análise dos métodos PNM1 e PNM3 para cada elemento.

Tabela 11. Teste ANOVA da significância da regressão e do desvio da

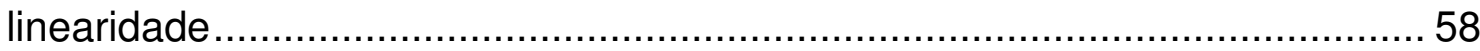

Tabela 12. Condições de análise do método PNM2 para cada elemento......... 66

Tabela 13. Processo de rerrefino adotado por cada empresa ......................... 76

Tabela 14. Nomenclatura das amostras coletadas por rerrefinador.................. 80 Tabela 15. Resultados para os ensaios aparência, cor ASTM, viscosidade cinemática a 40 e $100{ }^{\circ} \mathrm{C}$, índice de viscosidade e ponto de fulgor

Tabela 16. Resultados dos ensaios ponto de fluidez, índice de acidez total, resíduo de carbono ramsbottom, corrosividade ao cobre.

Tabela 17. Resultados para os ensaios espectroscopia no infravermelho, teor de enxofre e perda por evaporação Noack.

Tabela 18. Resultados do teste de Brown \& Forsythe obtidos para o cálcio método PNM1

Tabela 19. Resultados do teste ANOVA para o cobre - método PNM1 ........ 108

Tabela 20. Resumo dos resultados dos testes de efeito de matriz

Tabela 21. Resultados dos testes das três comparações das curvas de cálcio método PNM3 
Tabela 22. Resumo dos métodos adotados para cada elemento 122

Tabela 23. Limites de detecção e quantificação dos elementos para cada básico $(\mathrm{mg} / \mathrm{kg})$ 123

Tabela 24. Repetibilidade e precisão intermediária dos métodos avaliados $(\mathrm{mg} / \mathrm{kg})$ 125

Tabela 25. Incerteza expandida de medição dos métodos do equipamento FRX/EDX 720 ( $\mathrm{mg} / \mathrm{kg})$

Tabela 26. Teor de elementos nos óleos rerrefinados determinados por ICP $(\mathrm{mg} / \mathrm{kg})$ 128

Tabela 27. Teor de elementos nos óleos rerrefinados determinados por FRX/EDX (mg/kg). 130

Tabela 28. Teor de elementos nos óleos parafínicos neutro médio determinados com o Epsilon $3 \mathrm{XL}$ (mg/kg). 130 


\section{Introdução}

Atualmente, com o crescimento da população mundial e do consumo, o número de automóveis, ônibus, caminhões, motocicletas e outros tipos de veículos está aumentando, acarretando um maior consumo de combustíveis e lubrificantes.

Assim como os veículos automotivos, as máquinas industriais, em menor ou maior grau, necessitam de lubrificação. Dessa forma, o crescimento e a modernização industrial também possuem como consequência o aumento do consumo de lubrificantes.

Diferentemente dos combustíveis, os óleos lubrificantes não são totalmente consumidos com o uso. No entanto, independente do bom ou mau funcionamento do veículo ou equipamento, o lubrificante é contaminado e degradado, tornando-se um resíduo perigoso por conter substâncias orgânicas e metais tóxicos como chumbo, cádmio, cromo, cobre, etc.

O despejo de óleo lubrificante usado e contaminado, OLUC, no solo ou no esgoto é um problema ambiental muito sério, pois em curto prazo ocorre a contaminação do lençol freático e de cursos d'água como córregos e rios, sendo a recuperação desses difícil e onerosa. Além disso, a queima ou a utilização de OLUC para outros fins é prejudicial não só ao ambiente, mas também à saúde humana, pois quando queimado em condições precárias, esse resíduo pode liberar dioxinas e hidrocarbonetos policíclicos aromáticos.

Pelo fato do OLUC conter ainda óleo básico inalterado, foram desenvolvidas várias técnicas para recuperar e reciclar esse material, gerando óleo básico de qualidade comparável ao obtido pelo refino do petróleo. Essas técnicas são denominadas genericamente como rerrefino.

Na pesquisa bibliográfica realizada, não foi encontrado banco de dados de fácil acesso que informasse quais os processos de rerrefino utilizados na indústria nacional. A Agência Nacional de Petróleo, Gás Natural e Biocombustíveis, ANP, divulga apenas quais as empresas autorizadas a exercer a atividade de rerrefino. Existe, portanto, pouca informação disponível sobre como essas empresas realmente atuam no mercado. 
A fim de se estabelecer uma política nacional para a questão do óleo usado e contaminado, o Conselho Nacional do Meio Ambiente, CONAMA, definiu, por meio da Resolução $\mathrm{n}^{\circ} 9$ de $1993,{ }^{1}$ que todo o OLUC deveria ser recolhido e destinado à reciclagem por meio de rerrefino. Nos casos em que esse processo não pudesse ser aplicado, o OLUC deveria ser submetido à combustão com aproveitamento energético ou incineração, conforme legislações ambientais específicas.

Em 2005, a Resolução CONAMA n 9 de 1993 foi substituída pela Resolução CONAMA $n^{\circ} 362^{2}$, ainda vigente, que estabeleceu que todo o OLUC deve ser recolhido e destinado à reciclagem por meio do rerrefino e que a combustão e a incineração não são entendidas como forma de destinação adequada para esse resíduo.

Do ponto de vista econômico, o reaproveitamento de resíduo para gerar produtos anteriormente obtidos apenas a partir de um recurso não renovável é uma alternativa para o suprimento, sendo uma forma de garantir o abastecimento da sociedade em momentos de crise da indústria do petróleo.

No entanto, mais importante que garantir o abastecimento de óleo básico para a indústria de lubrificantes, é que o básico rerrefinado tenha a qualidade necessária ao que se destina e que se comprove que a presença dos contaminantes foi minimizada.

As Portarias ANP $n^{\circ} 129^{3}$ e $130^{4}$, ambas de 1999 , especificam as propriedades físico-químicas dos óleos básicos e dos óleos básicos rerrefinados, respectivamente. A segunda se esmera em comparar o óleo rerrefinado com o de primeiro refino, exigindo praticamente as mesmas análises físico-químicas que a primeira. Nela, não são previstos ensaios que comprovem a retirada de contaminantes como metais tóxicos.

Atualmente,, existem estudos comparativos entre processos diferentes de rerrefino, os quais se destinam a auxiliar na escolha entre um e outro. Esses estudos se baseiam na quantidade de óleo básico gerado pelo rerrefino e não necessariamente na qualidade do produto. Poucas pesquisas foram realizadas sobre a indústria nacional que comprovem que os óleos rerrefinados 
produzidos no Brasil atendem realmente ao especificado pela Portaria ANP $\mathrm{n}^{\circ}$ $130 / 99 .^{4}$

A princípio, isso não parece ser um grande problema, pois se trata de uma matéria-prima para formulação de outro produto, sendo assim, pode-se supor que a indústria realiza o controle de qualidade ao adquiri-lo. Essa pode ser a realidade das grandes empresas produtoras de óleo acabado, porém nas médias e pequenas a realidade é outra.

Além disso, é preciso investigar se apenas as propriedades físico-químicas exigidas pela ANP são suficientes para garantia da qualidade ou se é necessário estabelecer limites para alguns elementos químicos.

É importante ressaltar que não existem métodos normalizados nacionais para detecção e quantificação de traços de metais tóxicos em óleos básicos lubrificantes rerrefinados. O método internacional, ASTM D5185-09, utiliza espectrometria de emissão atômica de plasma indutivamente acoplado, ICPOES. ${ }^{5}$ Essa técnica é dispendiosa, no que se refere aos seus insumos, e exige a solubilização da amostra em um solvente orgânico, contendo um padrão interno de berílio, o que torna a análise demorada. Além disso, utiliza querosene de aviação ou xileno como solvente, os quais são tóxicos e apresentam odor persistente.

É necessário avaliar a qualidade dos óleos básicos rerrefinados produzidos no Brasil pela verificação da persistência ou ausência dos contaminantes do óleo usado e contaminado. Para tanto, serão propostos métodos de análise para os elementos $\mathrm{Ca}, \mathrm{Mg}, \mathrm{Zn}$, Ba, Fe, Mo, Cd, Cr, Pb, Si e Ni por espectrometria de fluorescência de raios $X$ por energia dispersiva, FRX/EDX, que serão comparados ao método ASTM D5185-09. ${ }^{5}$

As vantagens dessa técnica em relação à espectrometria de emissão atômica por plasma indutivamente acoplado, ICP-OES, quando se trata da análise de óleos básicos são: dispensar quaisquer métodos de separação ou diluição da amostra e o uso de solventes, não possuindo grandes insumos, diminuindo o volume de resíduos gerados e representando um menor risco à saúde dos analistas. Dessa forma, ela é mais barata, oferece menor risco e poupa tempo 
de análise. Como desvantagens, podemos citar a possibilidade de efeitos de matriz e limites de detecção e quantificação superiores.

Além da determinação dos metais por FRX/EDX e ICP, os básicos rerrefinados serão avaliados também quanto aos parâmetros já estabelecidos pela Portaria ANP $n^{\circ} 130$ de $1999^{4}$.

Assim, espera-se alcançar conhecimento suficiente para fazer um julgamento da política adotada pelo Brasil quanto à destinação de óleo usado e contaminado e da necessidade de revisão da Portaria ANP n 130 de 1999, ${ }^{4}$ bem como levantar sugestões para uma melhor especificação do óleo básico rerrefinado.

\section{1 Óleos Básicos}

\subsubsection{Conceito e Características Principais}

A norma norte-americana ASTM D $6074^{6}$, que é um guia para caracterização de óleos básicos lubrificantes hidrocarbonetos, apresenta dois conceitos importantes: base stock, sem tradução para o português, e base oil, óleo básico.

Segundo essa norma, base stock é um hidrocarboneto que compõe um lubrificante, além dos aditivos, o qual é produzido por um fabricante específico, sempre com as mesmas especificações (independe da origem da matériaprima ou da localização do fabricante), e que é identificado por um número de fórmula único ou número de identificação do produto, ou ambos. ${ }^{6}$

Ainda de acordo com essa norma, óleo básico é um base stock ou uma mistura de dois ou mais base stocks usados para produzir óleo lubrificante acabado, usualmente em combinação com aditivos. ${ }^{6}$

A diferenciação entre base stock e óleo básico não é usual no Brasil, sendo ambos indistintamente tratados como óleo básico. Neste contexto, óleo básico é o principal constituinte do óleo lubrificante, podendo ser um derivado de petróleo obtido pelo processo de refino ou substâncias sintéticas geradas por reações químicas ou, até mesmo, óleos de origem vegetal. 
As características físico-químicas de um óleo básico definem em que tipos de óleo lubrificante acabado eles podem ser utilizados, existindo diversos parâmetros a serem avaliados. Dentre estes, destacam-se a viscosidade, o índice de viscosidade, a volatilidade, o teor de saturados e o ponto de fluidez.

A lubricidade de um fluido está intimamente ligada à capacidade deste em formar uma película protetora entre as partes móveis de uma máquina ou equipamento, sendo essa característica relacionada à sua viscosidade.

A viscosidade de um fluido é a propriedade que determina o valor de sua resistência ao cisalhamento, que é a tensão gerada por duas ou mais forças atuando na mesma direção e em sentido igual ou oposto. A viscosidade é devida, primariamente, à interação entre as moléculas do fluido. ${ }^{7}$ A Figura 1 representa dois planos paralelos separados por uma distância $\mathrm{Y}$, sendo $\mathrm{O}$ espaço entre eles preenchido por um líquido. Uma força $F$ é exercida sobre o plano superior, que então se move a uma velocidade $\mathrm{V}$. O líquido aderido a ele também se moverá à mesma velocidade, enquanto o líquido aderido ao plano estacionário permanecerá imóvel em relação a este. Se a velocidade $V$ não for muito grande, as camadas intermediárias de líquido se moverão à velocidade $V_{1}$ e $V_{2}$, proporcionais ás distâncias $Y_{1}$ e $Y_{2}$.

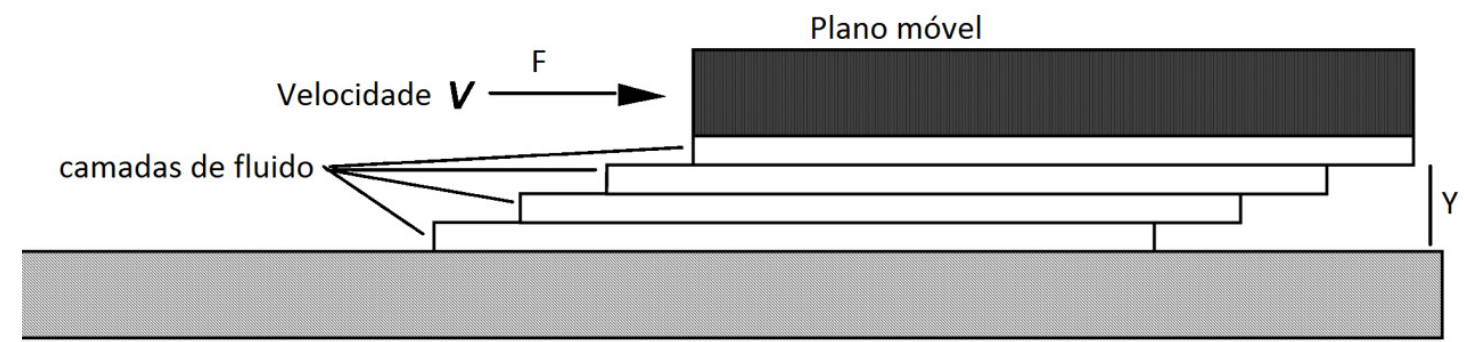

Plano estacionário

Figura 1. Planos paralelos em movimento com um fluido entre eles ${ }^{8}$

$A$ força $F$ é diretamente proporcional à área $A$ da placa móvel e à velocidade $V$ e inversamente proporcional à distância. $A$ força $F$ varia com a natureza do fluido. Sendo a viscosidade absoluta $\mu$, tem-se ${ }^{7}$ :

(1) $\mathrm{F}=\mu \frac{\mathrm{AV}}{\mathrm{Y}}$ ou $\mu=\frac{\mathrm{F} / \mathrm{A}}{\mathrm{V} / \mathrm{Y}}$ 
A viscosidade absoluta ou dinâmica é reportada comumente em poise $(P)$ ou centipoise (cP). No sistema internacional de medidas, um cP equivale a um $\mathrm{g} / \mathrm{cms}$ ou $10 \mathrm{P}$ equivalem a um Pascal Segundo- (Pa.s).

A viscosidade cinemática é o quociente da viscosidade dinâmica ou absoluta pela densidade, $\mu / d$, ambas à mesma temperatura ${ }^{7}$. Comumente, ela é expressa em centistokes (cSt). Um stoke (St) equivale a um $\mathrm{cm}^{2} / \mathrm{s}$ e um cSt a um $\mathrm{mm}^{2} / \mathrm{s}$.

É importante ressaltar que a viscosidade de um líquido depende da temperatura em que ele se encontra e, que, portanto, ao se reportar um valor para esta propriedade, é indispensável que fique claro em qual temperatura a medida foi obtida. A variação da viscosidade com a temperatura é um fator a ser avaliado, visto que é desejável que a lubrificação de um determinado sistema seja a mesma em todas as condições de operação. Existem diversas formas de expressar o comportamento da viscosidade em função da temperatura, sendo a mais usual, na indústria do petróleo, o índice de viscosidade, IV.

O índice de viscosidade, IV, definido por Dean e Devis, é baseado em uma escala empírica na qual foram atribuídos a padrões de óleos obtidos nos Estados Unidos da América os valores de IV iguais a 100 e zero. O IV de um dado óleo é calculado a partir das suas viscosidades a 40 e $100 \stackrel{\circ}{\circ}$ e das viscosidades a $40 \stackrel{\circ}{\circ}$ dos padrões que possuem viscosidade a $100 \stackrel{\circ}{\mathrm{C}}$ igual ao do produto cujo IV será determinado. Assim tem-se:

(2) IV $=\frac{L-U}{L-H} x 100$

Na qual:

IV é o índice de viscosidade;

L é a viscosidade cinemática a $40{ }^{\circ} \mathrm{C}$ de um padrão cujo IV é igual a zero, tendo a mesma viscosidade a $100 \stackrel{\circ}{\circ} \mathrm{C}$ que o óleo em estudo;

H é a viscosidade cinemática a $40{ }^{\circ} \mathrm{C}$ de um padrão cujo IV é igual a 100 , tendo a mesma viscosidade a $100^{\circ} \mathrm{C}$ que o óleo em estudo; 
U é a viscosidade cinemática a $40{ }^{\circ} \mathrm{C}$ do óleo em estudo.

Existem Tabelas para determinação do IV partindo-se das viscosidades cinemáticas a 40 e $100{ }^{\circ} \mathrm{C}$ do produto em avaliação. ${ }^{9,10}$

A norma ABNT 14358 estabelece que, nos casos em que a viscosidade cinemática a $40{ }^{\circ} \mathrm{C}$ do produto é inferior ou igual a $\mathrm{H}$, o IV deve ser calculado de acordo com a Equação abaixo: ${ }^{10}$

(3) $I V=\left\{\frac{[(\operatorname{artilog} N)-1]}{0,00715}\right\}+100$

Na qual:

$$
N=(\log H-\log U) / \log Y
$$

$\mathrm{Y}=$ é a viscosidade cinemática $\mathrm{em} \mathrm{mm}^{2} / \mathrm{s}$ a $100{ }^{\circ} \mathrm{C}$ do produto cujo índice e viscosidade se deseja calcular.

Em síntese, o índice de viscosidade de um fluido informa o quanto a viscosidade deste varia com a temperatura, sendo menor a variação quando 0 IV é maior. A Figura 2 mostra um gráfico do índice de viscosidade que ilustra bem esse comportamento. Percebe-se que a inclinação da reta do fluido de IV igual a zero é maior que a daquele de IV igual a 100, indicando que a influência da temperatura na viscosidade é maior no primeiro caso que no segundo.

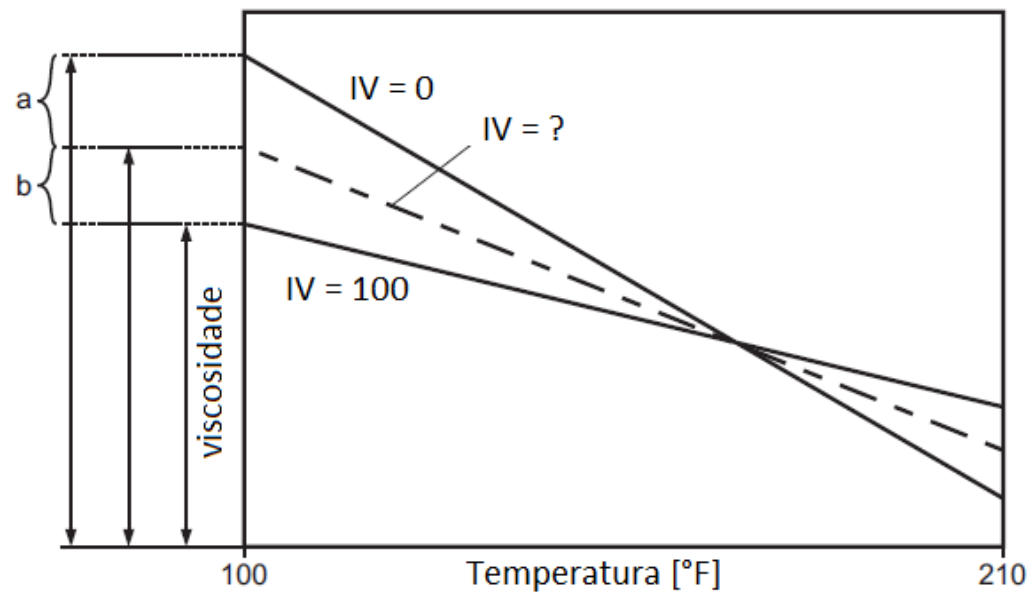

Figura 2. Gráfico ilustrando a relação do índice de viscosidade, IV, com a temperatura ${ }^{11}$. 
A capacidade de escoamento a baixa temperatura é outra propriedade crítica na aplicação de um óleo lubrificante, pois, para que ocorra a lubrificação, ele deve estar fluido. Ela é avaliada pela determinação do ponto de fluidez do óleo, que é a temperatura mínima na qual este ainda flui.

Apesar de serem oriundos das frações mais pesadas do petróleo cru, os óleos básicos possuem em sua composição substâncias voláteis. Quando utilizados em temperaturas elevadas, pode ocorrer a perda dessas frações leves dos lubrificantes, levando à diminuição do nível do óleo e prejudicando a lubrificação do equipamento/veículo. A volatilidade dos básicos é medida principalmente pelos ensaios de ponto de fulgor e perda por evaporação noack.

No ensaio de perda por evaporação noack, uma amostra do básico, cuja massa é conhecida, é submetida à temperatura de $250{ }^{\circ} \mathrm{C}$, por um tempo determinado. Mede-se a massa final e calcula-se a perda por evaporação.

O ponto de fulgor de um óleo é a menor temperatura na qual o vapor desprendido deste, em presença do ar, inflama-se momentaneamente ao se Ihe aplicar uma chama, formando um lampejo (flash). O conhecimento desta característica permite avaliar as temperaturas de serviço que um óleo lubrificante pode suportar com absoluta segurança ${ }^{7}$.

\subsection{2 Óleos Básicos Minerais}

Os óleos básicos minerais são aqueles obtidos através do petróleo, sendo constituídos de hidrocarbonetos parafínicos (alcanos) e naftênicos (cicloalcanos), com menor proporção de aromáticos, produzidos a partir de gasóleos da destilação a vácuo ou de óleos desasfaltados, originários de petróleos específicos. ${ }^{12}$ A classificação desses óleos se baseia no tipo de hidrocarboneto predominante, sendo os básicos minerais divididos em óleos básicos parafínicos e óleos básicos naftênicos. Para alguns autores ${ }^{8}$, essa classificação não é clara porque os básicos são fabricados de acordo com a viscosidade e não com a composição estrutural, não sendo nenhum óleo puramente parafínico, naftênicos ou aromático, mas sim uma mistura desses hidrocarbonetos. A Tabela 1 apresenta uma comparação entre as principais características dos óleos básicos parafínicos e naftênicos. 
Tabela 1. Comparação entre características de óleos básicos parafínicos e naftênicos ${ }^{12}$

\begin{tabular}{ccc}
\hline Propriedades & Parafínicos & Naftênicos \\
\hline Índice de viscosidade (IV) & Alto & Baixo \\
Ponto de fluidez & Alto & Baixo \\
Volatilidade & Baixa & Alta \\
Resistência a oxidação & Boa & Média \\
Carbono naftênico, \% típico & 20 & 40 \\
\hline
\end{tabular}

O processo a ser adotado na produção de óleo básico mineral depende do tipo de petróleo utilizado e da qualidade requerida para o produto final, sendo possível a adoção da rota convencional (ou rota solvente) ou da rota hidrorrefino.

A rota convencional ou rota solvente se baseia na separação física dos diversos componentes do petróleo cru, embora, atualmente, exista uma etapa final em que ocorrem também reações químicas para eliminação de heteroátomos presentes nas cadeias de hidrocarbonetos. Essa rota possui os seguintes passos: preparo da carga (matéria-prima) por destilação atmosférica, destilação a vácuo, desasfaltação a propano, desaromatizarão, desparafinação e hidroacabamento.

A destilação atmosférica em uma refinaria que se destina a produção de lubrificantes objetiva unicamente preparar a carga (matéria-prima) para as etapas seguintes. O petróleo é destilado, sendo gerados combustíveis e o resíduo atmosférico. Este último é, então, destilado a vácuo em duas etapas, como pode ser visto na Figura 3, sendo extraídos, na primeira torre, os cortes denominados spindle, neutro leve e neutro médio e, na segunda torre, o neutro pesado. O resíduo de vácuo da segunda torre é encaminhado para a desasfaltação a propano. 


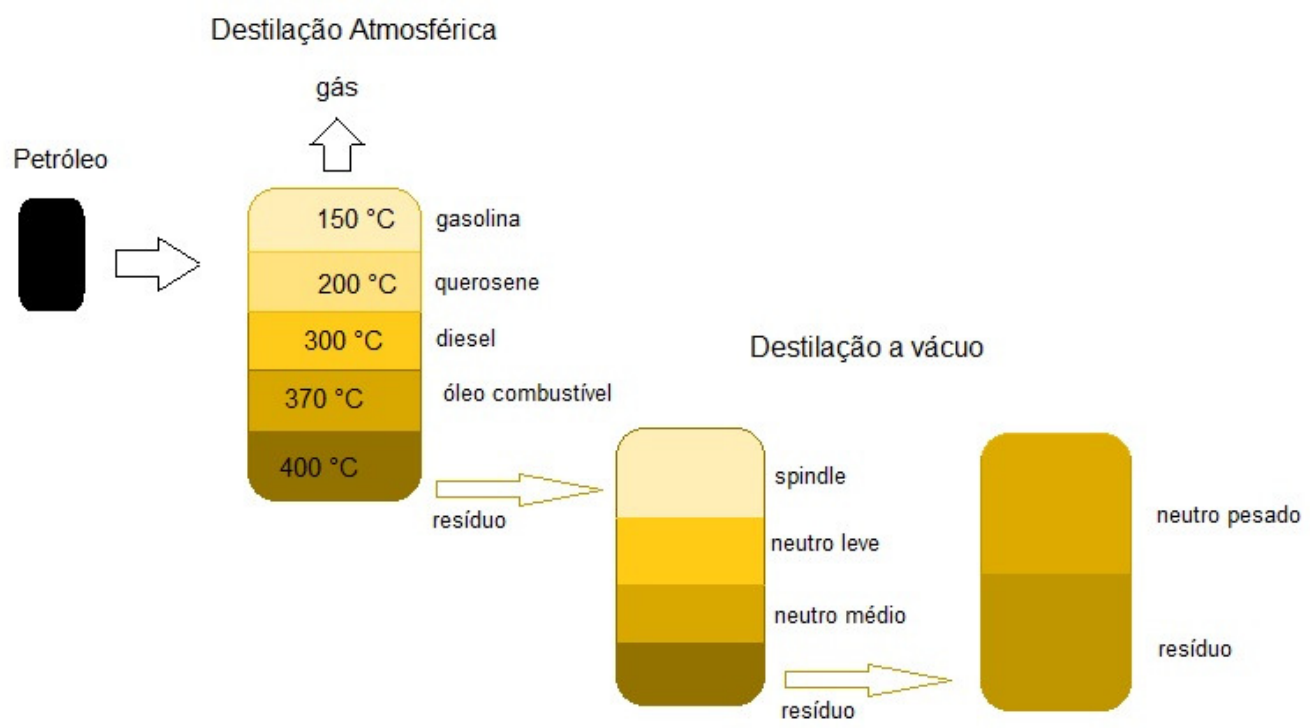

Figura 3. Esquema da destilação a vácuo.

Na desasfaltação a propano, o resíduo de vácuo é inserido na parte superior da torre de extração, enquanto o propano entra pela parte inferior, em contracorrente. $O$ contato entre os dois líquidos gera duas fases líquidas distintas, uma rica em solvente e contendo o óleo desasfaltado e outra pobre em solvente, de alta densidade e composta de resíduo asfáltico. A primeira é retirada pelo topo da torre e a segunda pela base. Ambas são submetidas à recuperação do solvente, que retorna ao processo. Pela desasfaltação a propano são produzidos os básicos denominados bright stock e cilindro, dependendo da densidade do resíduo de vácuo utilizado. O cimento asfáltico de petróleo, CAP, é um subproduto obtido pela recuperação do solvente. A Figura 4 apresenta um esquema da desasfaltação a propano. 


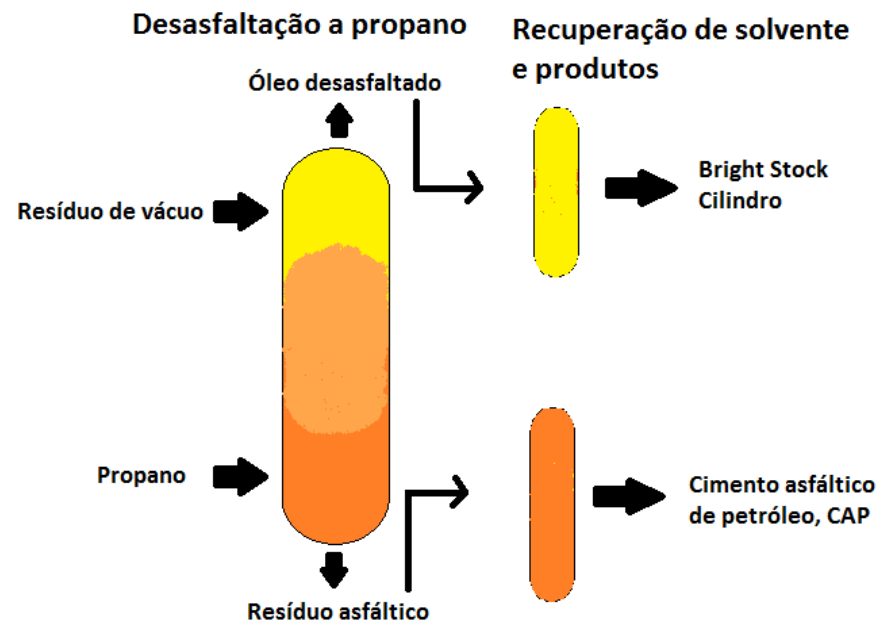

Figura 4. Esquema da desasfaltação a propano.

Os óleos básicos obtidos na destilação a vácuo e na desasfaltação já possuem viscosidade cinemática que atende aos parâmetros estabelecidos para cada corte. No entanto, outras características desses óleos precisam ser melhoradas para que estes possam atender às especificidades dos óleos lubrificantes acabados para os quais serão matérias-primas.

Em pesquisas realizadas sobre o índice de viscosidade, descobriu-se que os diversos tipos de hidrocarbonetos não reagem da mesma maneira a esta propriedade. Carreteiro e Belmiro ${ }^{7}$ afirmam, por exemplo, que óleos de processamento com componentes aromáticos possuem índice de viscosidade inferior a zero, óleos minerais de base naftênica preponderante possuem índice de viscosidade entre 0 e 40, enquanto óleos de base predominantemente parafínica tem índice de viscosidade entre 80 e 120.

A desaromatização é realizada com o objetivo de aumentar o IV dos óleos básicos obtidos nas etapas anteriores, sendo um processo similar à desasfaltação a propano.

O processo consiste em submeter o óleo básico a um solvente capaz de dissolver compostos aromáticos. No contato entre eles, surgem duas fases. Uma de menor densidade, contendo $90 \%$ de óleo desaromatizado e $10 \%$ de solvente, e outra de maior densidade, contendo cerca de $90 \%$ de solvente e 
10\% de resíduo aromático. A primeira fase, denominada rafinado, é retirada no topo da torre e a segunda, extrato, na base. O solvente é posteriormente recuperado de ambas e purificado para reutilização no processo. A Figura 5 mostra um esquema da desaromatização.

Os solventes mais comumente utilizados são o furfural, o fenol e a $n$ metilpirrolidona (NMP). O furfural é um dos solventes mais utilizados porque se aplica a uma ampla faixa de óleos, já que não reage quimicamente com estes. Por sua vez, o fenol é pouco utilizado devido à sua toxicidade e, a NMP, devido ao seu maior custo. ${ }^{12}$

O extrato aromático é um subproduto desta etapa da obtenção de óleos lubrificantes, sendo utilizado como agente rejuvenescedor de asfaltos ou óleo extensor para a indústria de borrachas. No entanto, devido à sua toxicidade, está sendo banido dessas aplicações.

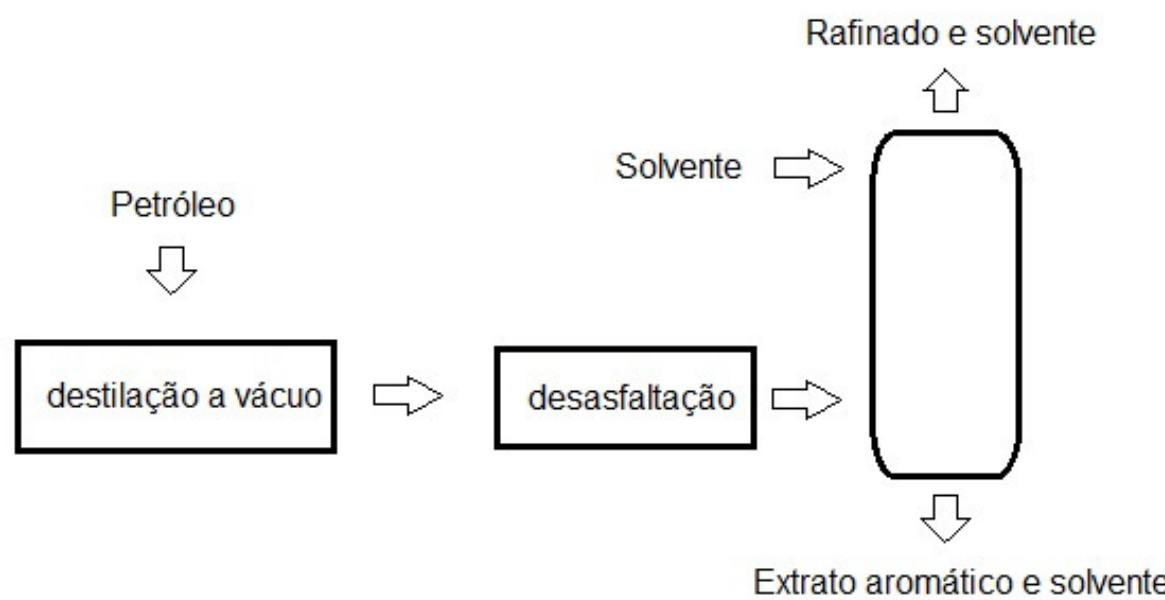

Figura 5. Esquema representativo da desaromatização.

$\mathrm{Na}$ desparafinação, são removidas as $n$-parafinas, caracterizadas por possuírem altos pontos de fluidez. Estes compostos acarretariam dificuldades no escoamento do óleo lubrificante, quando de seu uso a baixas temperaturas, que ocorre durante a partida de um equipamento em climas frios.

A carga é dissolvida em uma mistura de metil-etil-cetona e tolueno na proporção $1: 1$, sendo aquecida para total solvência e, em seguida, resfriada para cristalização da parafina. A mistura de óleo, solvente e parafina 
cristalizada é, então, filtrada em tambores rotativos, sendo obtidas duas fases: parafina oleosa e óleo+solvente, que seguem para recuperação do solvente. A parafina oleosa segue para a desoleificação e o óleo para o hidroacabamento. A Figura 6 apresenta um esquema da desparafinação.

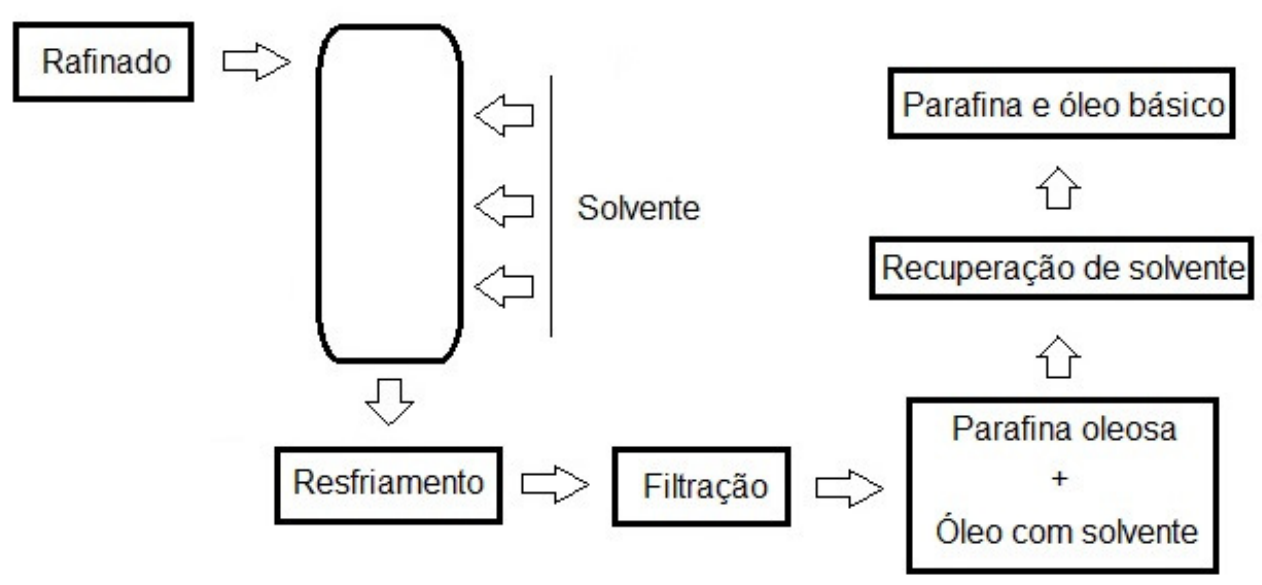

Figura 6. Esquema representativo da desparafinação

O óleo obtido após desaromatização e desparafinação ainda possui alta corrosividade, devido a compostos de enxofre, e baixa estabilidade, devido à presença de olefinas e compostos contendo nitrogênio, oxigênio e enxofre. $O$ hidroacabamento visa remover esses compostos por meio da adição de $\mathrm{H}_{2}$.

O óleo é submetido a uma corrente de hidrogênio na presença de um catalisador sob temperatura e pressão controladas. Após a reação, o excesso de hidrogênio é retirado por arraste e os gases $\mathrm{H}_{2} \mathrm{~S}$ e $\mathrm{NH}_{3}$ por injeção de vapor de água. $\mathrm{O}$ óleo sofre, então, uma secagem a vácuo.

A Figura 7 mostra um esquema geral da produção de óleo lubrificante pela rota convencional. 


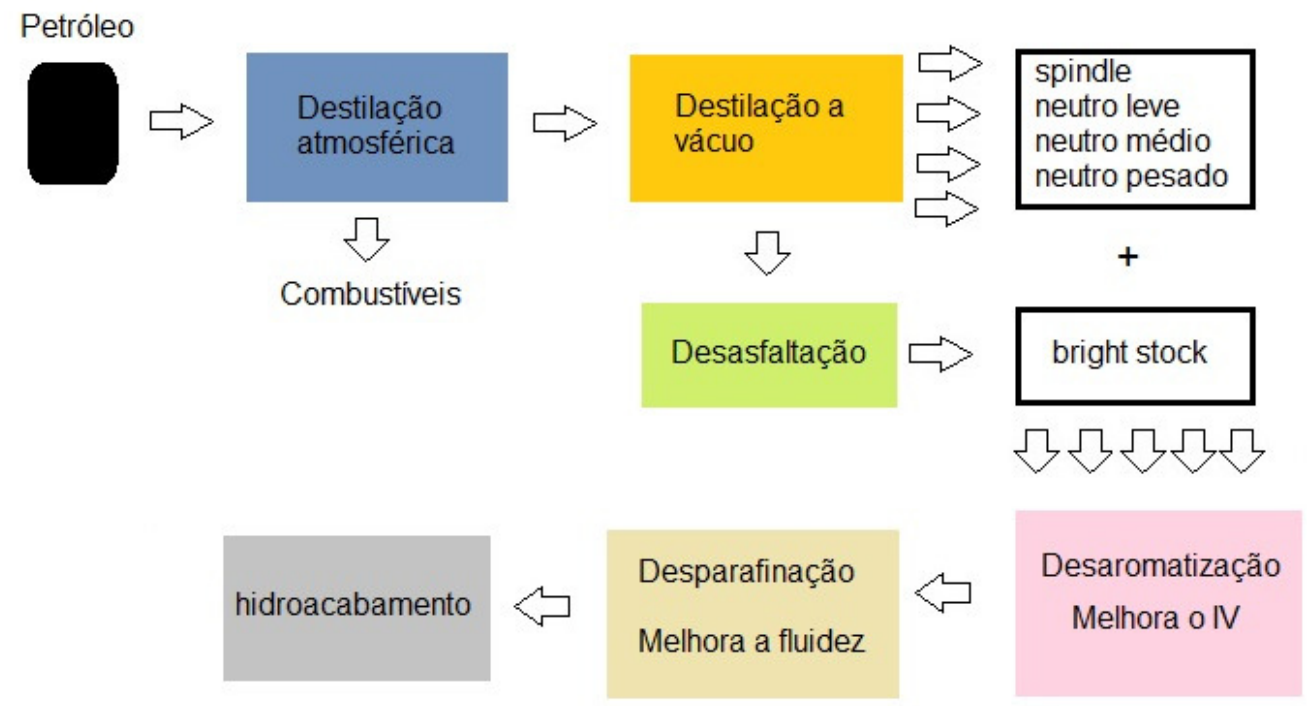

Figura 7. Esquema geral da rota convencional.

A produção de óleos básicos por hidrorrefino se baseia na conversão das moléculas indesejáveis presentes no petróleo cru em outras mais adequadas à finalidade do produto pela adição de hidrogênio na presença de um catalisador. Uma das vantagens do hidrorrefino é a baixa dependência que este possui em relação à origem do petróleo cru processado. A Figura 8 apresenta exemplos de modelos para as reações de hidrogenação que podem ocorrer no hidrorrefino.

Existem diversos esquemas possíveis, dependendo de quais moléculas se deseja eliminar e do quanto se deseja converter em novas substâncias. Dentre eles, se destacam a rota de hidrotratamento, HDT, e a rota de hidrocraqueamento severo, HCC. Ambas operam em temperaturas entre $285 \mathrm{e}$ $400{ }^{\circ} \mathrm{C}$ e utilizam catalisadores à base de combinações de cobalto e molibdênio ou níquel e molibdênio em leito de alumina ou à base de metais nobres, sendo a diferença principal entre elas a pressão parcial do hidrogênio ${ }^{8}$.

No HDT, os compostos aromáticos presentes na carga (gasóleos de vácuo ou óleos desaromatizados) são convertidos em hidrocarbonetos naftênicos ou parafínicos, ocorrendo também a retirada de compostos de enxofre, nitrogênio e oxigênio. A qualidade do produto final é melhorada nos parâmetros IV, cor e estabilidade a oxidação. No caso da produção de óleos básicos naftênicos, não é necessária nenhuma outra etapa. Para produção de óleos parafínicos, no 
entanto, ainda é necessária a desparafinação. A refinaria Lubnor, em Fortaleza/CE, produz óleos básicos naftênicos utilizando a rota HDT.

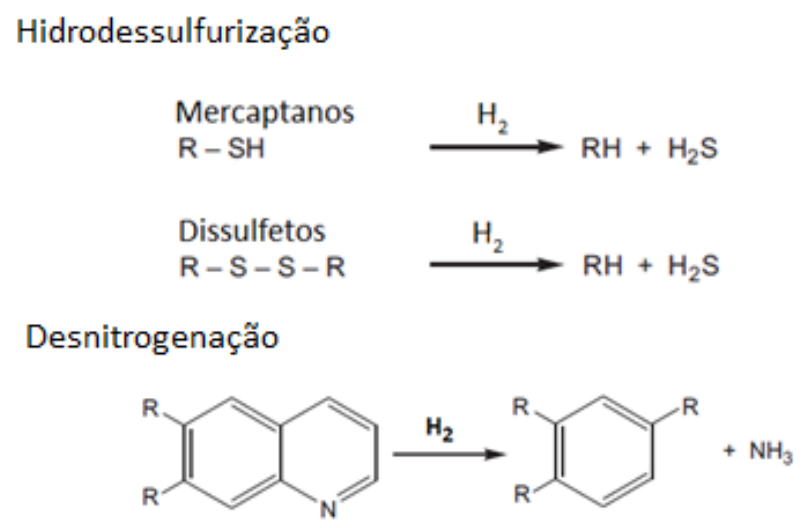

Saturação de poliaromáticos

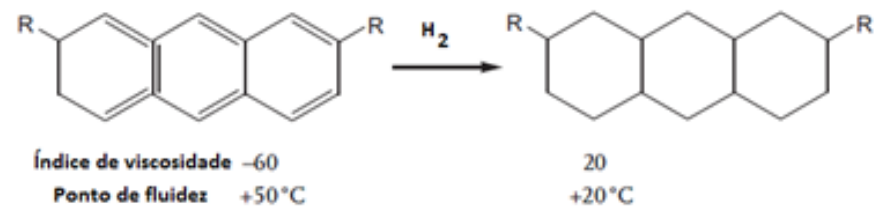

Abertura de anel naftênico
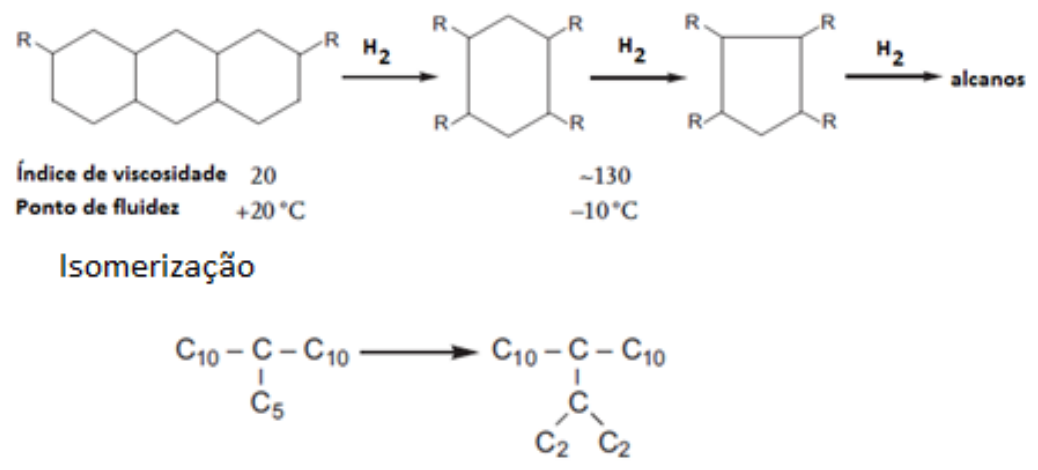

Índice de viscosidade $125 \quad 125$

Ponto de fluidez $\quad+20^{\circ} \mathrm{C} \quad-40^{\circ} \mathrm{C}$

Figura 8. Reações típicas de hidrogenação ${ }^{11}$

A pressão do hidrogênio no reator para HCC é maior que no caso do HDT. A carga pode ser gasóleo da destilação a vácuo e/ou óleo desasfaltados após passagem pelo HDT, pois os compostos aromáticos e os asfaltenos podem levar à formação de coque, envenenando o catalisador e diminuindo o rendimento do processo. No HCC, ocorre a desciclização dos hidrocarbonetos naftênicos e o craqueamento catalítico controlado da carga. ${ }^{12}$ Após o HCC, é necessário que a carga passe por outra destilação atmosférica para retirada dos combustíveis e por outra destilação a vácuo para retirada das frações 
lubrificantes. Cada fração de óleo básico passa ainda pela hidroisomerização e hidroacabamento. $\mathrm{Na}$ hidroisomerização, os alcanos lineares são transformados em ramificados através da reação com hidrogênio na presença de catalisador Pt-Pd. A rota HCC permite a obtenção de produtos de alto IV e baixo ponto de fluidez, sendo comparáveis aos básicos sintéticos. A não produção do básico bright stock é a desvantagem apresentada por ela. Não existem no Brasil refinarias que utilizem o HCC para produção de lubrificantes.

\subsection{3 Óleos Básicos Sintéticos}

Os óleos básicos sintéticos são aqueles obtidos por meio de reações químicas de síntese, possuem alta pureza e características químicas bem definidas. Eles apresentam como vantagens, em relação aos minerais, uma boa estabilidade química, alta resistência a temperaturas extremas, resistência à oxidação, maior vida útil e maior índice de viscosidade. A principal desvantagem é o custo, que pode ser muito maior que o de um óleo mineral. ${ }^{11}$ Existem vários tipos de óleos básicos sintéticos, a seguir serão abordados os principais.

Os oligômeros de olefina ou polialfaolefinas (PAOs) são hidrocarbonetos saturados formados a partir da reação de polimerização de olefinas contendo uma ligação dupla terminal (a-olefinas). Os oligômeros do 1-deceno são os mais comuns. Atualmente, PAOs são as bases sintéticas mais usadas na formulação de lubrificantes por possuírem ponto de fluidez muito baixo, alto índice de viscosidade e boa estabilidade térmica. A Figura 9 apresenta alguns exemplos desses oligômeros.
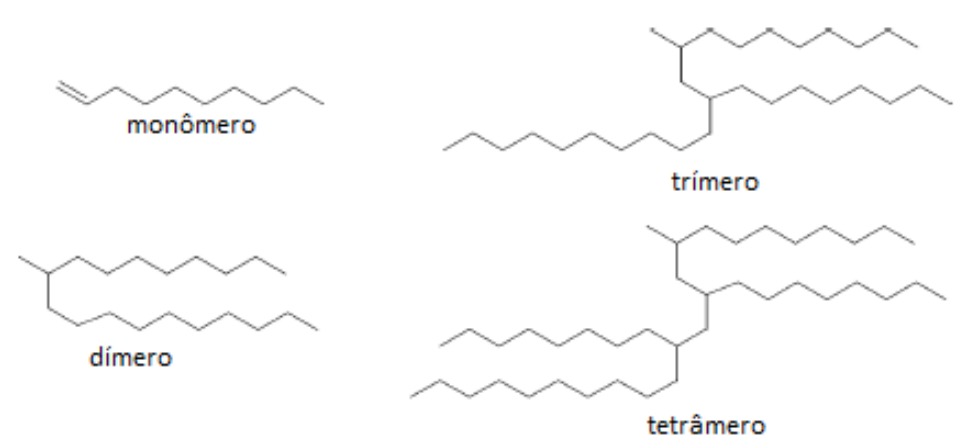

Figura 9. Oligômeros do 1-deceno. ${ }^{8}$ 
As polinternalolefinas (PIOs) também são oligômeros de olefinas, sendo similares às polialfaolefinas (PAOs), no entanto, são produzidas pelo craqueamento de óleos básicos parafínicos. De uma forma geral, as PIOs possuem IV de 10 a 20 unidades menores que os índices de viscosidade das PAOs de mesma viscosidade cinemática a $100{ }^{\circ} \mathrm{C}^{11}$.

Os ésteres de ácidos carboxílicos são utilizados como base lubrificante porque o grupo carboxila, devido ao forte momento de dipolo, reduz a volatilidade e aumenta o ponto de fulgor na mesma proporção em que afeta positivamente a estabilidade térmica, solvência, lubricidade e biodegradabilidade. Por outro lado, o grupo carboxila afeta negativamente a estabilidade hidrolítica e a reatividade com ligas que contenham cobre ou chumbo. ${ }^{11}$ Dentre os ésteres utilizados, destacam-se os ésteres de ácidos dibásicos e os poliolésteres.

O termo silicone é usado para polissiloxanos, que são polímeros lineares que contem Si-O-Si ligados a ramificações de hidrocarbonetos, sendo o grupo metil o mais comum dentre os grupos alquila e o fenil, o mais comum dentre os arila. ${ }^{8}$ Alguns exemplos constam na Figura 10. O peso molecular do silicone pode variar muito, dependendo do tamanho da cadeia. Basicamente, esse óleo básico possui baixa volatilidade, alto índice de viscosidade, alta resistência à oxidação e alta estabilidade térmica.

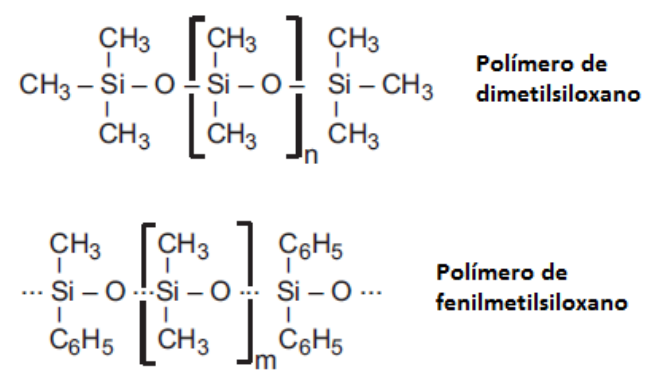

Figura 10. Polímeros de dimetilsiloxano e de fenilmetilsiloxano. ${ }^{11}$

A Tabela 2 apresenta os índices de viscosidades dos óleos minerais e sintéticos. Observa-se que os óleos naftênicos apresentam o menor IV e o silicone o maior. 
Tabela 2. Índices de viscosidade dos óleos básicos minerais e sintéticos. ${ }^{7}$

\begin{tabular}{cc}
\hline Óleo básico & IV \\
\hline Mineral naftênico & $50-60$ \\
Mineral parafínico & $80-120$ \\
polialfaolefinas & $120-170$ \\
diésteres & $120-180$ \\
silicone & $80-400$ \\
\hline
\end{tabular}

\subsection{4 Óleos Básicos Vegetais}

Os óleos vegetais são compostos principalmente de triacilgliceróis com ácidos graxos insaturados. Os triacilgliceróis são compostos por três moléculas de ácido graxo unidas por ligação éster a uma única molécula de glicerol. ${ }^{13}$

Segundo Rizvi ${ }^{8}$, além de serem biodegradáveis, os óleos vegetais apresentam outras vantagens como uma excelente lubricidade, boa relação viscosidadetemperatura, baixa volatilidade, não são tóxicos e não são carcinogênicos. Mas apresentam, como desvantagens, baixa estabilidade oxidativa e propriedades a baixa temperatura aquém do desejado.

Matos ${ }^{14}$ estudou a viabilidade de utilização de vários óleos vegetais produzidos no Brasil, analisando-os com relação a diversos parâmetros, dentre eles, viscosidade cinemática, índice de viscosidade, ponto de fluidez, ponto de fulgor e estabilidade oxidativa, comparando os resultados com os de óleos minerais e sintéticos por meio de análise de componentes principais. Ele concluiu que a maioria dos óleos vegetais avaliados possuía índice de viscosidade igual ou superior aos dos óleos sintéticos e ponto de fulgor superior ao de óleos parafínicos e sintéticos. Os resultados de ponto de fluidez foram variáveis, sendo o do óleo de mamona comparável aos de óleos sintéticos e os dos óleos de macaúba, algodão e maracujá, comparáveis aos minerais, enquanto os demais óleos avaliados apresentaram valores superiores ao de óleos parafínicos. Com relação à estabilidade oxidativa, apenas o óleo de mamona foi aprovado. O ponto de fluidez e a estabilidade oxidativa dos óleos reprovados foram reavaliados após utilização de aditivos próprios para melhoria dessas propriedades, sendo verificado um ganho de desempenho. 
Ainda são necessárias pesquisas para que os óleos vegetais sejam utilizados na fabricação de lubrificantes de alta performance, como os para motor automotivos, mas eles já são empregados em uma série de aplicações em que as suas desvantagens não são sentidas, como, por exemplo, fabricação de alguns tipos de graxa.

\subsubsection{Classificação dos Óleos Básicos}

Os óleos básicos obtidos por diferentes refinarias não são quimicamente idênticos e isso, no passado, era um empecilho para que os fabricantes de lubrificantes acabados conseguissem padronizar a sua produção e especificar corretamente os seus produtos.

Para solucionar esse problema, o American Petroleum Institute, API, nos Estados Unidos, e a Association Technique de L'industrie Europeanne des Lubrifiants, ATIEL, na Europa, adotaram um sistema de classificação único, no qual os parâmetros teor de enxofre, teor de saturados e índice de viscosidade são tomados como base. Essa classificação é apresentada na Tabela 3.

Tabela 3. Classificação ATIEL/API para óleos básicos. ${ }^{7}$

\begin{tabular}{ccc}
\hline Grupo I & Grupo II & Grupo III \\
\hline $\begin{array}{c}\text { Saturados }<90 \% \\
\text { Enxofre }>0,03 \% \\
80<\text { IV }<120\end{array}$ & $\begin{array}{c}\text { Saturados }>90 \% \\
\text { Enxofre }<0,03 \%\end{array}$ & $\begin{array}{c}\text { Saturados }>90 \% \\
\text { Enxofre }<0,03 \% \\
\text { IV }>120\end{array}$ \\
\hline Grupo IV & Grupo V & Grupo VI \\
\hline $\begin{array}{c}\text { Polialfaolefinas } \\
\text { PAOs }\end{array}$ & $\begin{array}{c}\text { Naftênicos, ésteres, } \\
\text { silicones, etc. }\end{array}$ & $\begin{array}{c}\text { Polinternalolefinas } \\
\text { PIOs }\end{array}$ \\
\hline
\end{tabular}

Os básicos do grupo I são os minerais parafínicos obtidos pela rota solvente. Os do grupo II e III são aqueles obtidos pelas rotas de hidrorrefino, como HDT e HCC. Os básicos do grupo IV são as polialfaolefinas (PAOs), primeiros sintéticos utilizados como básicos lubrificantes. Os básicos do grupo $V$ são todos os outros não contemplados, como os naftênicos e os demais sintéticos. Recentemente foi acrescentado o grupo $\mathrm{VI}$, que contemplam as polinternalolefinas (PIOs). Existem refinarias que produzem os grupos I, II e III com índice de viscosidade elevado, mas ainda dentro das respectivas faixas, 
sendo assim considerados como de qualidade superior aos de outros óleos dentro do mesmo grupo e, por isso, são designados como pertencentes aos grupos $\mathrm{I}_{+}, \mathrm{II}+, \mathrm{III}$.

\subsection{Lubrificantes}

A principal função do lubrificante é reduzir o atrito entre duas superfícies móveis de um determinado objeto. Em alguns casos, possui também a função de refrigerar, limpar as partes móveis, transmitir força mecânica, vedar e isolar.

Os lubrificantes podem ser sólidos ou fluidos. Entretanto, o mais usual é a lubrificação fluida, sendo usado um óleo mineral de petróleo. Embora de pouco emprego prático, diversos outros fluidos podem ser usados, inclusive ar ou água, em casos especiais. ${ }^{7}$

Segundo a Resolução ANP N¹6/2009 ${ }^{15}$, o óleo lubrificante acabado, ou seja, pronto para ser utilizado, é um produto formulado a partir de óleo lubrificante básico ou de misturas de óleos lubrificantes básicos, podendo ou não conter aditivos.

\subsubsection{Aditivos para Lubrificantes}

Os aditivos são substâncias químicas utilizadas para melhorar as características do óleo básico, conferir novas propriedades a ele ou eliminar aquelas indesejáveis. Segundo Carreteiro e Belmiro ${ }^{7}$, eles podem ser divididos em dois grupos: aqueles que modificam certas características físicas e aqueles cujo efeito final é de natureza química.

O primeiro grupo é usualmente constituído de materiais poliméricos e atuam como melhoradores do índice de viscosidade, abaixadores do ponto de fluidez e antiespumantes. Neste texto, serão abordados apenas os dois primeiros.

Os melhoradores do índice de viscosidade, MIV, são polímeros de estrutura linear que modificam o comportamento da viscosidade do óleo básico frente a variações de temperatura. A solvência desses aditivos no óleo básico aumenta proporcionalmente à temperatura. A Figura 11 ilustra a forma de atuação do MIV. 


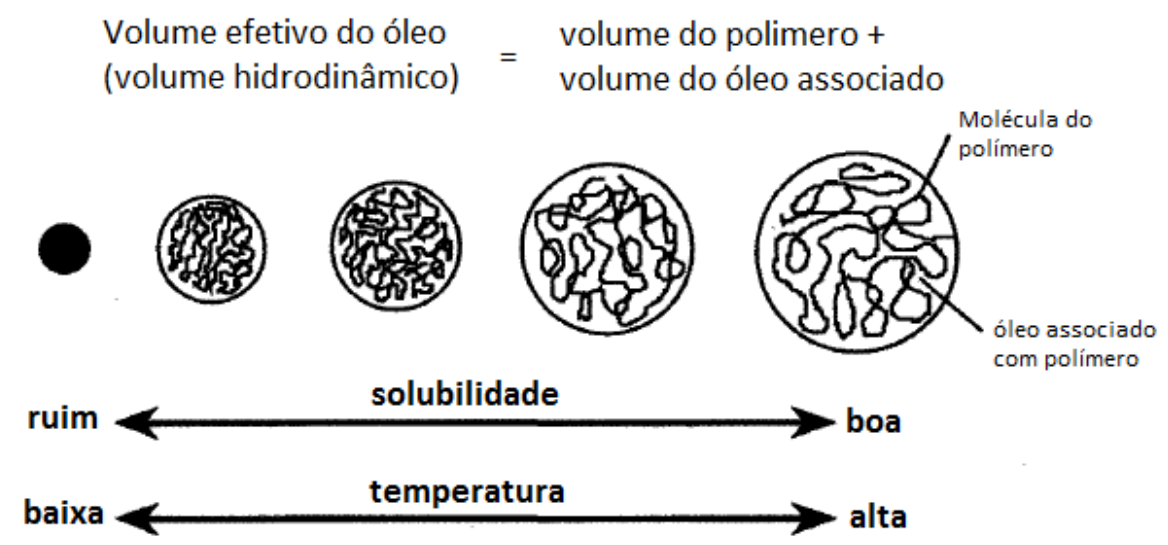

Figura 11. Modelo explicativo do mecanismo de atuação dos melhoradores do índice de viscosidade. ${ }^{16}$

Ao serem dissolvidos no óleo em temperaturas brandas, eles apresentam uma forma contraída, na qual suas moléculas se atraem, não havendo grande modificação da viscosidade do óleo básico. Quando a temperatura é elevada, no entanto, assumem uma forma descontraída, na qual as suas moléculas envolvem-se em um novelo solubilizado e podem desenrolar-se, aumentando 0 seu volume e a viscosidade da mistura. ${ }^{7}$ Esse aumento de viscosidade ocasionada pelo MIV compensa a diminuição da viscosidade do básico em virtude da alta temperatura. A Figura 12 apresenta alguns exemplos de MIV.

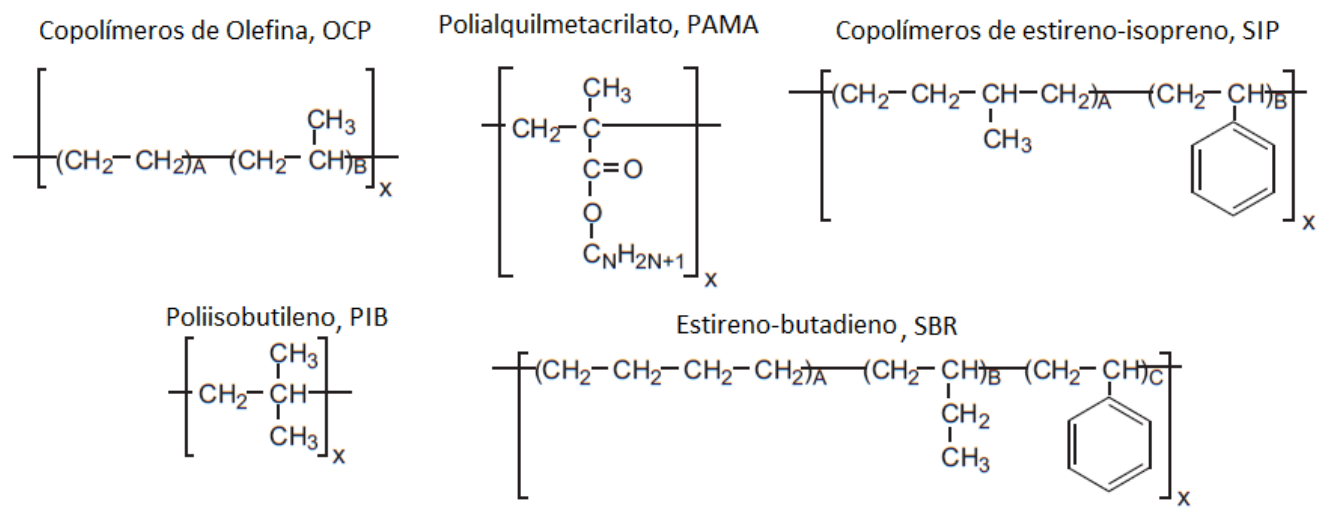

Figura 12. Aditivos Melhoradores do Índice de Viscosidade. ${ }^{11}$

Os abaixadores do ponto de fluidez, PPDs (do inglês pour point depressor), formam uma película protetora ao redor dos cristais de parafina que se formam a baixas temperaturas, inibindo o seu crescimento e mantendo o óleo líquido. Alguns exemplos são: polimetacrilatos, poliacrilamidas e copolímeros de vinilcarboxilato-dialcoil-fumaratos. 
O segundo grupo de aditivos compreende os antioxidantes, detergentes e dispersantes, antiferrugem, anticorrosivos, antidesgaste, etc. Apenas os dois primeiros serão abordados.

Os antioxidantes e os passivadores de metais são aditivos que visam eliminar os radicais orgânicos formados nas reações de oxidação ou decompor os peróxidos formados nessas reações. O óleo lubrificante durante o uso sofre reações de oxidação por exposição ao oxigênio do ar e de craqueamento térmico, ocasionadas pelas temperaturas elevadas. Os produtos típicos dessas reações de oxidação são peróxidos, ácidos carboxílicos, cetonas, álcoois e ésteres. ${ }^{7}$ Ao serem formados, esses produtos permanecem no óleo lubrificante, ocorrendo a policondensação e a polimerização destes, formando borra e verniz. ${ }^{11}$ Os fenóis e o ditiofosfato de zinco são exemplos desses aditivos. A Figura 13 mostra algumas representações estruturais desses aditivos.

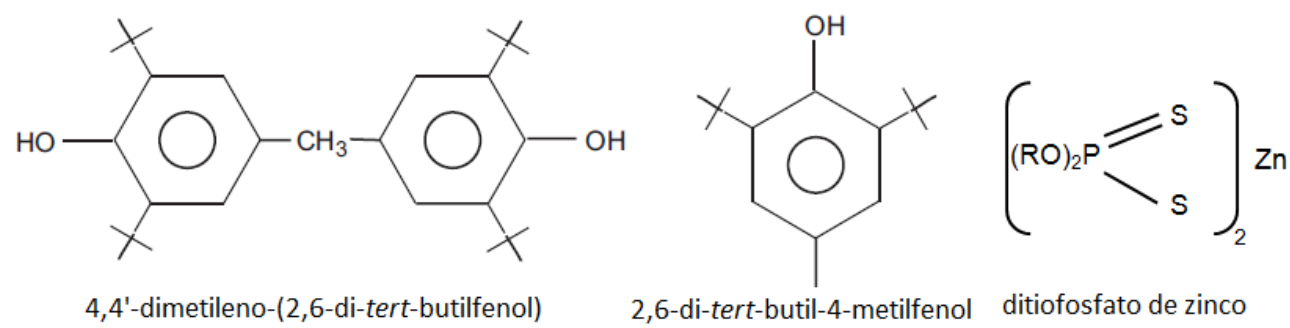

Figura 13. Representações Estruturais de Alguns Aditivos Antioxidantes. ${ }^{11,7}$

Os detergentes são substâncias que contem uma cadeia longa de hidrocarbonetos, apolar, e um grupamento polar na extremidade, chamado cabeça. A parte apolar permite que o detergente se dissolva no óleo, enquanto o grupo polar atrai partículas contaminantes do óleo, como, por exemplo, ácidos gerados na oxidação. Os mais utilizados comercialmente são os sulfonatos e os salicilatos alcoil-substituídos.

Os detergentes alcalinos são produzidos através da utilização de excesso de base metálica sobre as quantidades estequiométricas requeridas para a formação dos produtos. ${ }^{7}$ Os metais mais comuns são o cálcio e o magnésio. Como vantagem em relação aos detergentes, eles apresentam a maior capacidade de neutralização dos ácidos formados e uma maior dispersão dos 
contaminantes. A Figura 14 representa o salicilato, um dos mais utilizados na fabricação de lubrificantes.

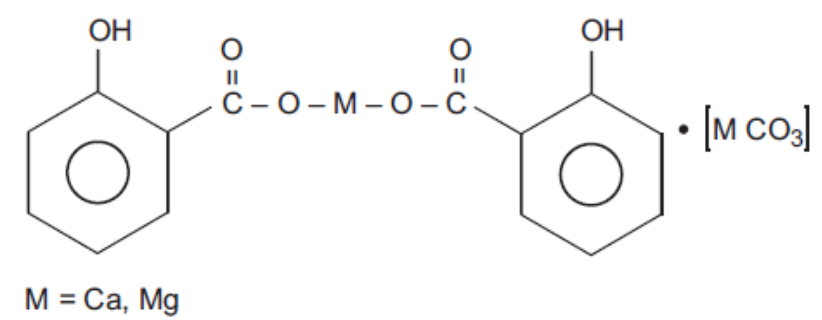

Figura 14. Representações Estrutural de um Aditivo detergente. ${ }^{11}$

\subsubsection{Classificação e Desempenho dos Óleos Lubrificantes}

Os óleos lubrificantes são classificados de acordo com sua viscosidade. No caso dos óleos industriais, a viscosidade cinemática é medida a $40{ }^{\circ} \mathrm{C}$ e a classificação é feita de acordo com o estabelecido pela International Organization for Standardization, ISO. Essa organização criou um padrão onde cada grau ISO representa o ponto médio de uma faixa de viscosidade cinemática a $40{ }^{\circ} \mathrm{C}$, e as faixas mínima e máxima são exatamente $10 \%$ abaixo ou acima desse ponto. A Tabela 4 apresenta a classificação ISO para os óleos industriais. 
Tabela 4. Classificação ISO. ${ }^{17}$

\begin{tabular}{c|c|c|c}
\hline \multirow{2}{*}{ Grau ISO } & \multirow{2}{*}{ Viscosidade Média } & \multicolumn{2}{|c}{ Limites de Viscosidade Cinemática a $40{ }^{\circ} \mathrm{C}$} \\
\cline { 3 - 4 } & & Mínima & Máxima \\
\hline 2 & 2,2 & 1,98 & 2,42 \\
\hline 3 & 3,2 & 2,88 & 3,52 \\
\hline 5 & 4,6 & 4,14 & 5,06 \\
\hline 7 & 6,8 & 6,12 & 7,48 \\
\hline 10 & 10 & 9,00 & 11,0 \\
\hline 15 & 15 & 13,5 & 16,5 \\
\hline 22 & 22 & 19,8 & 24,2 \\
\hline 32 & 32 & 28,8 & 35,2 \\
\hline 46 & 46 & 41,4 & 50,6 \\
\hline 68 & 68 & 61,2 & 74,8 \\
\hline 100 & 100 & 90,0 & 110 \\
\hline 150 & 150 & 135 & 165 \\
\hline 220 & 220 & 198 & 242 \\
\hline 320 & 320 & 288 & 352 \\
\hline 460 & 460 & 414 & 506 \\
\hline 680 & 680 & 612 & 748 \\
\hline 1000 & 1000 & 900 & 1100 \\
\hline 1500 & 1500 & 1350 & 1650 \\
\hline & & & \\
\hline
\end{tabular}

No caso dos óleos para motor, a Society of Automotive Engineers, SAE, estabeleceu uma classificação baseada na viscosidade cinemática a $100{ }^{\circ} \mathrm{C}$ e na viscosidade dinâmica a frio pelo simulador de partida, CCS (do inglês, cold craking simulator). Os diversos graus são identificados com números baseados nos dois primeiros dígitos da viscosidade saybolt dos óleos, sendo acrescentada a letra $\mathrm{W}$, de winter, aos graus de viscosidade a frio. A viscosidade saybolt é dada pelo tempo de escoamento, em segundos, de 60 $\mathrm{mL}$ de amostra fluindo através de um orifício Universal calibrado sob condições específicas ${ }^{7}$. Segundo a classificação SAE, um óleo pode possuir um grau a quente e um frio, sendo chamado multiviscoso. Assim, por exemplo, um óleo $5 \mathrm{~W} 30$ possui classificação a frio $5 \mathrm{~W}$ e a quente 30 . A Tabela 5 apresenta a classificação SAE J300, como foi chamada, para os óleos de motor. 
Tabela 5. Classificação SAE. ${ }^{17}$

\begin{tabular}{|c|c|c|c|c|}
\hline \multicolumn{5}{|c|}{ SAE J300 Graus de Viscosidade para Óleos de Motor - dezembro de 1999} \\
\hline \multirow{2}{*}{$\begin{array}{l}\text { Grau } \\
\text { SAE }\end{array}$} & \multirow{2}{*}{$\begin{array}{l}\text { Baixa temperatura, }{ }^{\circ} \mathrm{C} \\
\text { Viscosidade } \mathrm{CCS}, \mathrm{cP} \text {, } \\
\text { máx }\end{array}$} & \multirow{2}{*}{$\begin{array}{l}\text { Baixa temperatura, }{ }^{\circ} \mathrm{C} \\
\text { Viscosidade de } \\
\text { bombeamento, } \mathrm{CP} \text { máx }\end{array}$} & \multicolumn{2}{|c|}{ Viscosidade cinemática, $100^{\circ} \mathrm{C}$} \\
\hline & & & Mín & Máx \\
\hline OW & 6200 a -35 & 60000 a -40 & 3,8 & - \\
\hline $5 \mathrm{~W}$ & 6600 a -30 & 60000 a -35 & 3,8 & - \\
\hline $10 \mathrm{~W}$ & 7000 a -25 & 60000 a -30 & 4,1 & - \\
\hline $15 \mathrm{~W}$ & 7000 a -20 & 60000 a -25 & 5,6 & - \\
\hline $20 \mathrm{~W}$ & $9500 a-15$ & 60000 a -20 & 5,6 & - \\
\hline $25 \mathrm{~W}$ & $13000 \mathrm{a}-10$ & 60000 a -15 & 9,3 & - \\
\hline 20 & - & - & 5,6 & $<9,3$ \\
\hline 30 & - & - & 9,3 & $<12,5$ \\
\hline 40 & - & - & 12,5 & $<16,3$ \\
\hline 50 & - & - & 16,3 & $<21,9$ \\
\hline 60 & - & - & 21,9 & $<26,1$ \\
\hline
\end{tabular}

A classificação SAE nada diz sobre o desempenho de um determinado lubrificante, pois este está relacionado com outras propriedades dos óleos básicos e dos aditivos utilizados na sua formulação. Em trabalho conjunto, a API, a SAE e a ASTM definiram as categorias de óleos para motor diesel e gasolina. A SAE definiu as necessidades de qualidade, a ASTM os testes a serem realizados e a API a linguagem a ser adotada. Para as categorias de motores ciclo otto foi adotado o prefixo $\mathrm{S}$ e, para as de motores a diesel, o prefixo $C$. As classes foram designadas por letras, em ordem alfabética. Assim, tem-se, para motores a gasolina SA, SB, SC etc e, para diesel, CA, CB etc. Os primeiros lubrificantes, SA e CA, eram óleos básicos não aditivados e se tornaram obsoletos, assim como muitos outros com o passar do tempo. Atualmente, os níveis de desempenho mais avançados são o $\mathrm{SN}$ e o CJ. No Brasil, a Resolução ANP $n^{\circ} 22 / 2014^{18}$ estabelece que os níveis de desempenho mínimo que podem ser comercializados no país são o SJ e CG-4, sendo todos os anteriores considerados obsoletos. Além disso, essa Resolução estabelece que em primeiro de janeiro de 2017 os níveis mínimos serão SL e $\mathrm{CH}-4$. 


\subsection{Perspectivas Futuras para os Óleos Básicos}

O mercado de óleos básicos é movimentado pelas indústrias automobilísticas e de fabricação de equipamentos industriais. Novos motores veiculares e máquinas requerem lubrificantes específicos que, por sua vez, vão necessitar de óleos básicos de qualidade e de aditivos que possam melhorar suas performances. Nesses quesitos, a indústria automobilística tem um peso maior, principalmente com relação aos óleos lubrificantes para motor. Em 2008, estimava-se que, no Brasil, $60 \%$ dos óleos básicos foram destinados à fabricação de óleos automotivos, $28 \%$ à de óleos industriais e o restante a outras aplicações, como produção de graxas, fluidos de refrigeração etc. ${ }^{19}$

As exigências ambientais de diminuição de emissão de poluentes e de economia de combustíveis, bem como a necessidade de se aumentar os períodos de troca, têm levado os produtores de lubrificantes automotivos a buscar óleos básicos com boas propriedades a baixa temperatura (viscosidade dinâmica a baixa temperatura) e menor volatilidade. Segundo Henderson ${ }^{20}$, o índice de viscosidade é a característica chave para cobrir ambas, pois para uma dada viscosidade cinemática, a viscosidade a baixa temperatura varia diretamente com o IV do óleo e a volatilidade melhora com o aumento do IV. A melhor relação entre essas propriedades é obtida com básicos dos grupos II e III.

As formulações modernas de óleos lubrificantes para motor, API SM e SN, possuem em sua especificação limites rigorosos para a viscosidade dinâmica a baixa temperatura, dessa forma, apenas graus SAE 0Wxx, 5Wxx e 10Wxx ( $x x$ $=20,30,40$ etc) são admitidos. ${ }^{21}$ Esses graus de viscosidade são atingidos com básicos sintéticos ou do grupos III e, em alguns casos, com misturas dos grupos II e III. A Figura 15 mostra a distribuição da demanda mundial de óleos básicos por aplicação. Percebe-se que os óleos automotivos correspondem a uma parcela considerável do uso de básicos e, por isso, pode-se prever um grande impacto na produção devido à tendência da indústria automobilística em aumentar o uso de básicos do grupo II e III em detrimento do grupo I. 


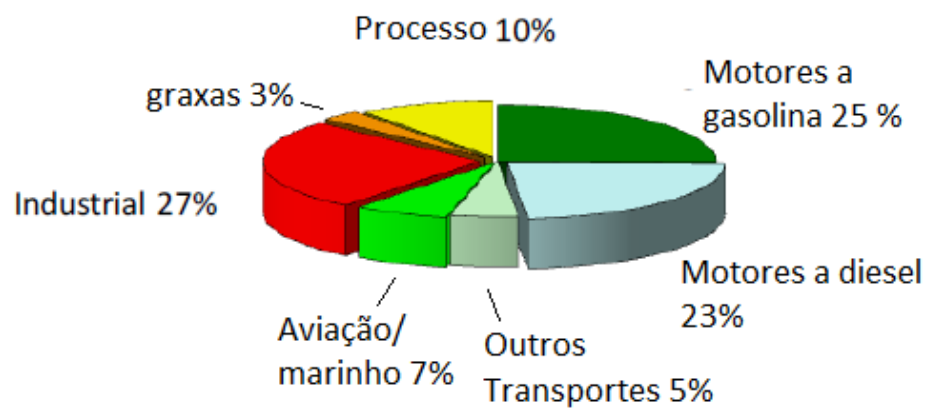

Figura 15. Demanda mundial de básicos por aplicação. ${ }^{22}$

Atualmente, no Brasil, são produzidos apenas básicos parafínicos do grupo I e naftênicos e um pequeno volume de grupo II, oriundo do rerrefino. Grande parte do básico grupo II e todo o óleo básico do grupo III e sintéticos consumidos no país são importados. Estima-se que, no primeiro semestre de 2010, o volume de importações de básico chegou a 276 milhões de litros, o que equivale a um aumento de $100 \%$ em relação ao mesmo período do ano anterior. ${ }^{23}$ Segundo a revista Lubes em Foco, em 2014, as importações sofreram uma queda de $19,3 \%$ sobre o volume de 2013 , atingindo um total aproximado de 486 milhões de litros. A revista destaca que o volume de básicos dos grupos II e III importados em 2014 foi maior que o dobro do importado em 2013. ${ }^{24}$

Segundo Serra-Holm ${ }^{25}$, a maioria dos analistas concorda que, por volta de 2015, os básicos do grupo I representarão apenas cerca de metade dentro dos grupos de básicos parafínicos e somente $40 \%$ da capacidade global de óleo básico por volta de 2020, o que acarretaria uma perda na capacidade do grupo I estimada entre 8 a 10 milhões de toneladas métricas. A Figura 16 apresenta uma expectativa da capacidade de básicos minerais para 2014 e 2020. 

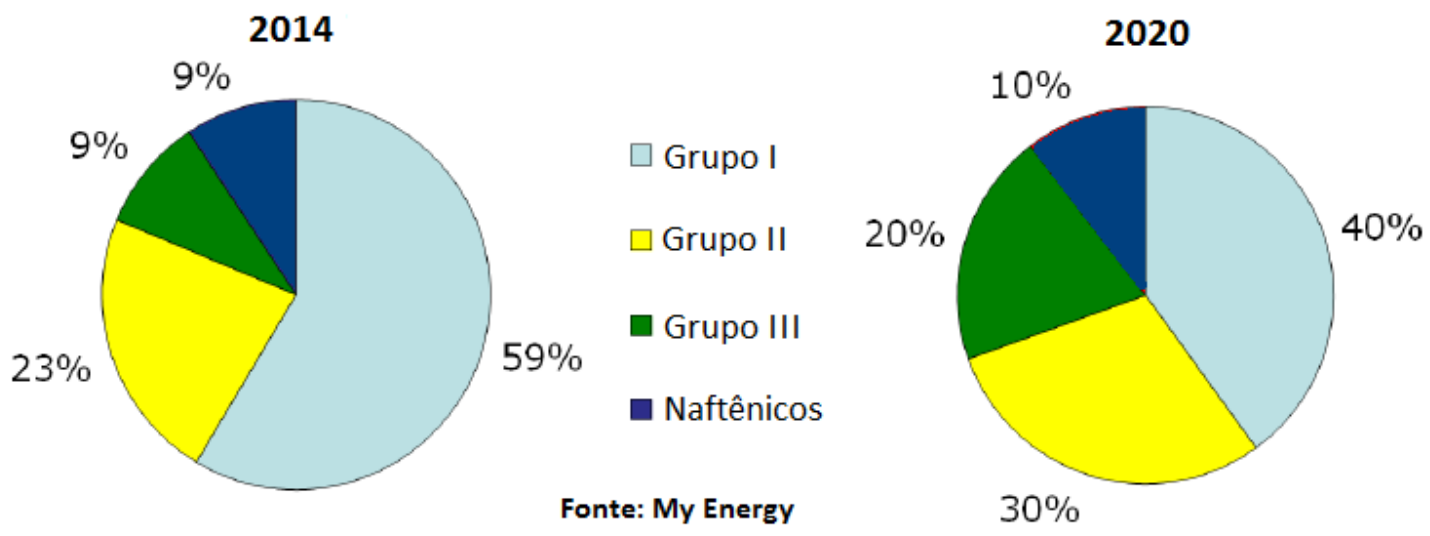

Figura 16. Capacidade mundial prevista para 2014 e $2020 .^{22}$

Todos os levantamentos que levam ao aumento da demanda por básicos grupo II e III são baseados na indústria automobilística e não consideram o uso industrial. Algumas características dos grupos II e III, como o alto IV e a baixa volatilidade, são irrelevantes para alguns óleos industriais. Serra-Holm ${ }^{25}$ aponta para o fato de que óleos com boa solvência e altas viscosidades serão escassos nesse novo cenário e que óleos pesados como o bright stock praticamente não serão produzidos. A boa solvência é uma propriedade indispensável para os básicos utilizados na fabricação de óleos industriais, pois estes frequentemente requerem que os seus aditivos se dissolvam por completo, formando soluções estáveis.

Os óleos minerais naftênicos representam uma alternativa aos básicos parafínicos, pois possuem boa solvência, ampla faixa de viscosidade e boa separação da água. Por serem pouco tóxicos, tem sido estudada a possibilidade de usá-los como substitutos do extrato aromático obtido como subproduto na rota solvente. ${ }^{22}$ Atualmente, esses óleos são utilizados na produção de graxas, fluidos hidráulicos, óleos de transformador e outros.

\section{4 Óleo Lubrificante Usado e Contaminado e a Reciclagem}

De uma forma geral, é denominado óleo lubrificante usado ou contaminado, OLUC, aquele óleo que, em decorrência de seu uso normal ou por motivo de contaminação, tenha se tornado inadequado à sua finalidade original. ${ }^{26,27}$

Segundo Duarte ${ }^{28}$, em pesquisa divulgada em 1981, os contaminantes geralmente presentes no OLUC são: 
1 - água, proveniente da condensação de umidade existente no ar ou de infiltrações;

2 - produtos voláteis (combustíveis líquidos tais como gasolina, álcool e óleo diesel), decorrentes de misturas ricas de combustíveis/ar, partidas repetidas com motor a frio, possíveis folgas nos cilindros, vazamento ou má combustão;

3 - compostos solúveis em óleo (geralmente produtos de combustão de hidrocarbonetos instáveis), presentes devido ao calor, podendo sofrer polimerização com conversão em matérias asfálticas e polímeros. Também podem estar presentes aditivos não degradados.

4 - Compostos insolúveis em óleo, tais como fuligem, poeira, partículas metálicas e aditivos degradados etc.

Atualmente, a Environmental Protection Agency dos EUA, EPA, afirma que estão presentes no OLUC contaminantes, como produtos de oxidação e degradação, poeira, cavacos metálicos, água e espécies ácidas devido à oxidação dos lubrificantes. ${ }^{29}$

Boughton e Horvath ${ }^{30}$ compararam os resultados de análise quantitativa dos elementos $\mathrm{Ba}, \mathrm{Pb}, \mathrm{Cd}, \mathrm{Cr}, \mathrm{Cu}, \mathrm{Ni}, \mathrm{Zn}, \mathrm{Cl}, \mathrm{P}$ e $\mathrm{S}$ e de cinzas em óleos usados de diversas fontes obtidos na Califórnia, EUA, com os analisados por outros pesquisadores em Vermont, EUA, e pela EPA. Os resultados são apresentados na Tabela 6 . Nota-se que os teores de $\mathrm{Zn}, \mathrm{P}$ e $\mathrm{S}$ são os mais altos nos três casos. Esses elementos, provavelmente, são oriundos da aditivação.

Tabela 6. Concentração dos constituintes do óleo usado. ${ }^{30}$

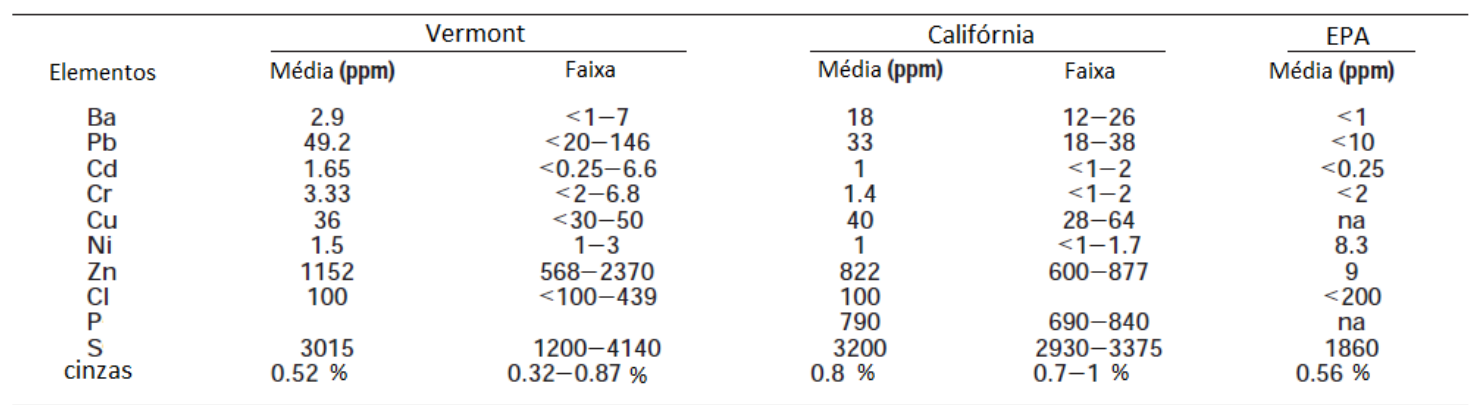

Brinkman \& Dickson ${ }^{31}$ analisaram óleos usados obtidos de fontes variadas (24 de cárter automotivo, 16 de troca rápida, 25 de indústria, 21 coletores e 9 
tanques de alimentação de uma rerrefinaria). Os parâmetros analisados foram: solventes clorados (cromatografia gasosa com detector de captura de elétrons); metais cádmio, cromo e chumbo (espectrometria de emissão atômica por ICP) e hidrocarbonetos policíclico aromáticos (cromatografia líquida de alta eficiência, HPLC, com detector de ultravioleta, UV). Os resultados de hidrocarbonetos policíclico aromáticos foram similares nos diferentes tipos de amostras para muitos componentes. No geral, o óleo industrial mostrou uma tendência a apresentar um nível mais baixo desses compostos, provavelmente devido ao menor estresse térmico. Uma variação maior foi observada no caso dos compostos orgânicos halogenados voláteis (HVOC). As amostras automotivas quase não apresentaram HVOC, enquanto que as amostras industriais apresentaram baixos níveis. Com relação aos metais, o cádmio foi quase inexistente, o cromo estava presente em níveis próximos àqueles de interesse regulatório americano (5 ppm), e o chumbo foi encontrado em concentrações acima de 265 ppm (limite de 5 ppm) em 75\% das amostras. A maior parte das amostras livres de chumbo era de origem industrial.

Segundo Cherednichenko et $a{ }^{\beta 2}$, os óleos usados são heterogêneos quanto a composição, os teores de água e material particulado, por exemplo, podem variar entre 0 a $40 \%$ e de 0,01 a $3 \%$ em peso, respectivamente. Ainda segundo os autores, essa heterogeneidade se deve, principalmente, às diferenças existentes na forma de coleta de amostras para análise, por isso, propuseram uma metodologia para realização da amostragem de OLUC em diferentes pontos dos tanques de armazenagem.

Em estudo comparativo da composição do OLUC europeu ao longo do tempo, Audibert ${ }^{33}$ verificou que, embora os requisitos dos motores automotivos e dos lubrificantes para esses motores sejam cada vez mais exigentes, as características dos resíduos presentes nesses óleos não mudaram muito com o tempo. Porém, o autor destaca o desaparecimento do bário nos últimos 20 anos, o aumento de magnésio, boro, sílica, zinco e fósforo e o progressivo declínio de cloro e chumbo até a sua extinção. 
Apesar do OLUC não ter sofrido grandes variações ao longo do tempo quanto aos tipos de contaminantes, percebe-se, pelos exemplos acima, que as quantidades desses contaminantes são dependentes da sua origem.

Existem diversas formas de tratar e/ou dispor o OLUC e cada país adota medidas adequadas à sua realidade. De uma forma genérica, o termo reciclagem designa os processos em que o OLUC é tratado e reutilizado, seja como combustível, lubrificante ou básico.

A reciclagem energética é a incineração com o reaproveitamento da energia gerada em um processo industrial ou para gerar energia elétrica. O OLUC pode passar por um pré-tratamento (sedimentação e filtração) para retirada de sólidos e minimização dos poluentes emitidos com a queima.

Casos em que o OLUC é convertido em óleo lubrificante acabado incluem o recondicionamento ou reprocessamento e a regeneração. $O$ recondicionamento/reprocessamento envolve operações físicas, como a remoção de impurezas sólidas (material particulado) por meio de filtração e, em alguns casos, a aditivação, prolongando a vida útil do óleo. É mais comum em óleos industriais usados que não sofreram oxidação. Normalmente, é realizado in situ.

A regeneração envolve um grau de processamento maior e é usada para óleos industriais, como os hidráulicos, para engrenagem e fluidos de usinagem. As regeneradoras empregam uma série de análises físico-químicas para definir o grau de tratamento requerido e o óleo regenerado possui qualidade igual ou inferior ao óleo lubrificante antes do uso. Nesse tipo de processo, o OLUC passa pelos seguintes passos: ${ }^{8}$

1 - Sedimentação, centrifugação e filtração para remover os sólidos;

2 - Tratamento com argila e base alcalina para remover contaminantes ácidos, seguido por lavagem para remoção de algum sabão formado;

3 - Aquecimento brando ou destilação para remoção de compostos voláteis;

4 - Aeração, ou outro tratamento biológico, para eliminação de bactérias; 
5 - Aditivação para complementar os aditivos que tenham sido eliminados.

O rerrefino inclui os processos em que o OLUC é convertido em óleo básico. Ele utiliza técnicas de refino de petróleo, como destilação a vácuo e hidrotratamento e resulta em óleos básicos de qualidade. No próximo subcapítulo, as diversas rotas adotadas serão abordadas com mais detalhes.

Segundo Raldenes et $a l,{ }^{34}$ o rerrefino é o tratamento do óleo lubrificante usado em uma sequência de processos que remove todos os contaminantes, incluindo água, partículas sólidas, produtos de diluição, produtos de oxidação e os aditivos previamente incorporados ao óleo básico.

Sendo este o conceito aceito oficialmente no Brasil, o recondicionamento, a regeneração e o rerrefino são denominados genericamente como rerrefino.

A Resolução CONAMA n 362/2005 estabelece ainda que os produtores e importadores de óleo lubrificante acabado são responsáveis pela coleta e destinação de um valor mínimo de óleo usado e contaminado, o qual é proporcional ao volume de óleo acabado vendido. A fixação desse valor mínimo a ser recolhido anualmente cabe ao Ministério de Minas e Energia, em conjunto com o Ministério do Meio Ambiente.

Esses valores mínimos de coleta anual por região nacional foram estabelecidos pela Portaria Interministerial do Ministério de Minas e Energia e do Ministério do Meio Ambiente $n^{\circ} 59 / 2012^{35}$, conforme consta na Tabela 7.

Tabela 7. Volumes percentuais mínimos de OLUC a serem coletados pelos produtores e importadores de óleo lubrificante acabado. ${ }^{35}$

\begin{tabular}{ccccccc}
\hline \multirow{2}{*}{ Ano } & \multicolumn{5}{c}{ Regiões } & \multirow{2}{*}{ Brasil } \\
\cline { 2 - 6 } & Nordeste & Norte & Centro-Oeste & Sudeste & Sul & \\
\hline 2012 & $26 \%$ & $26 \%$ & $32 \%$ & $42 \%$ & $36 \%$ & $36,90 \%$ \\
2013 & $28 \%$ & $28 \%$ & $33 \%$ & $42 \%$ & $36 \%$ & $37,40 \%$ \\
2014 & $30 \%$ & $30 \%$ & $34 \%$ & $42 \%$ & $37 \%$ & $38,10 \%$ \\
2015 & $32 \%$ & $31 \%$ & $35 \%$ & $42 \%$ & $37 \%$ & $38,50 \%$ \\
\hline
\end{tabular}

As Resoluções ANP $n^{\circ} 17 / 09^{36}$ e $18 / 09^{37}$, que tratam respectivamente das atividades de importação e produção de óleos lubrificantes acabados, 
estabelecem que importadores e produtores devem informar mensalmente à Agência Nacional do Petróleo, Gás Natural e Biocombustíveis, ANP, os volumes de óleos lubrificantes básico e acabado por eles movimentados, bem como o de OLUC a ser coletado por coletores contratados. Dessa forma, a ANP possui subsídios para o cálculo de volume a ser coletado por cada empresa. Além disso, são exigidos contratos com coletores autorizados e documentos que comprovem a coleta do OLUC.

Segundo dados disponíveis no site da $\mathrm{ANP}^{38}$, a meta de coleta nacional foi atingida em 2012 e 2013. Em 2014, as metas na região nordeste e a nacional não foram atingidas.

As atividades de coleta e rerrefino são regulamentadas pelas Resoluções ANP no $19 / 09^{26}$ e 20/09 ${ }^{27}$, existindo à época da realização desta pequisa 19 rerrefinadoras autorizadas pela ANP. Também há a exigência quanto ao envio mensal à ANP de dados de movimentação de produtos (OLUC e básico rerrefinado).

Nos Estados Unidos, a EPA define óleo usado como qualquer óleo que tenha sido refinado do petróleo, ou sintético, que tenha sido usado e que, como resultado deste uso, tenha sido contaminado por impurezas físicas ou químicas. ${ }^{39} \mathrm{Em}$ seu site, a EPA apresenta as formas possíveis de recuperação do OLUC, enfatizando o rerrefino como a ideal, mas sem se restringir a ela. Claxton $^{22}$ mostra que dos cerca de 2,75 bilhões de galões de OLUC produzidos, aproximadamente 1,5 bilhão são recuperáveis e, desses, menos de 0,25 bilhão são rerrefinados, havendo uma perspectiva de que este número suba até quase 0,5 bilhão de galão.

A Diretiva Europeia de Resíduos EC/98/2008 estabelece que todos os países membros da União Europeia devem garantir que o óleo usado seja coletado, segregado e tratado de forma a proteger o meio ambiente e a saúde humana. ${ }^{40}$ Monier e Labouze ${ }^{41}$ afirmam que, na União Europeia, em 2000, uma média de $50 \%$ do OLUC coletável foi rerrefinado. Segundo Audibert ${ }^{33}$, neste mesmo ano, $83 \%$ do OLUC coletado na Itália e $61 \%$ do coletado na Alemanha foram destinados ao rerrefino, enquanto em outros países da União Europeia, como 
Espanha e França, a maior parte do OLUC coletado foi destinada à reciclagem energética, 50 e $60 \%$ respectivamente.

Na Austrália, não existe uma regulamentação nacional para a disposição do óleo usado, mas alguns estados possuem uma regulamentação específica para ele, enquanto outros possuem apenas a regulamentação para resíduos perigosos de uma forma geral. Assim, o óleo usado deve ser disposto de forma adequada, o que inclui o rerrefino, reciclagem energética e outras técnicas. ${ }^{42}$

\subsection{Rerrefino}

O método clássico de rerrefino adotado mundialmente no passado foi o ácido$\operatorname{argila}^{43}$, o qual é tido hoje como obsoleto. Desenvolvido por Bernd Meinken, o processo se iniciava por uma decantação do OLUC para retirada de materiais grosseiros e aquecimento em pressão atmosférica até temperatura igual a 160 ${ }^{\circ} \mathrm{C}$ para separação da água e materiais voláteis. Em seguida, o óleo era resfriado e acidulado com ácido sulfúrico concentrado (92-96\%). A borra ácida era retirada e o óleo neutralizado e percolado em argila. $O$ produto resultante era, então, destilado a vácuo para que fossem retiradas as diferentes frações de óleo básico.

Recentemente, foi realizado estudo visando o rerrefino com a utilização de ácido acético glacial em lugar do ácido sulfúrico, com a finalidade de diminuir a decomposição do óleo básico presente no OLUC e diminuir a toxicidade. ${ }^{44}$ Amostras de óleo usado coletado em trocas de óleo foram submetidos a tratamento com ácido acético em diferentes concentrações e temperaturas até que fossem encontradas as condições ideais. Após essa etapa, o básico foi submetido à caulinita a $250{ }^{\circ} \mathrm{C}$ e, algumas amostras, à destilação a vácuo. Os básicos obtidos foram comparados ao OLUC, a básicos rerrefinados obtidos por outros métodos (ácido-argila e destilação a vácuo), a lubrificantes acabados e a básicos convencionais. Os autores concluíram que os básicos obtidos pelo tratamento proposto são compatíveis com os dos métodos tradicionais. 
Ogbeide $^{45}$ estudou a substituição da argila do método ácido-argila por carvão ativado, mas não apresentou os resultados das análises físico-químicas dos óleos obtidos e nada concluiu sobre o método proposto.

Atualmente, existem diversas técnicas de rerrefino, várias passam pelas etapas de sedimentação e filtração do material grosseiro e, de evaporação de água e voláteis (desidratação ou destilação atmosférica). Assim, essas etapas serão chamadas, daqui por diante, de pré-tratamento. A etapa seguinte envolve a remoção dos produtos de oxidação e contaminantes químicos e pode ser uma ou a combinação de várias técnicas, alguns exemplos são: extração a propano (desasfaltação a propano), termocraqueamento (pré-tratamento térmico), hidrotratamento, wiped film (evaporação por película ou evaporação total), destilação/argila e safety Kleen. As técnicas citadas serão abordadas em detalhes a seguir, mas deve ser ressaltado que não são as únicas e sim algumas das mais comuns.

O princípio da extração a propano utilizada em uma rerrefinadora é exatamente o mesmo da desasfaltação a propano das refinarias de petróleo destinadas à produção de óleos básicos. As diferenças consistem no material de entrada e nas etapas seguintes. Desenvolvido pelo Institut Français de Pétrole, IFP, inicialmente, a extração a propano era utilizada em conjunto com o tratamento ácido e, posteriormente, com o hidroacabamento. ${ }^{11}$ No primeiro caso, após o pré-tratamento, o OLUC é submetido à extração a propano, em uma ou em duas etapas, e, posteriormente, ao tratamento com ácido sulfúrico a $2 \%$, seguido de neutralização com argila aditivada e destilação fracionada para separação dos diferentes cortes de básico. No segundo caso, o tratamento ácido é substituído pelo hidroacabamento, eliminando-se o resíduo ácido. A Figura 17 apresenta um esquema desse processo. 


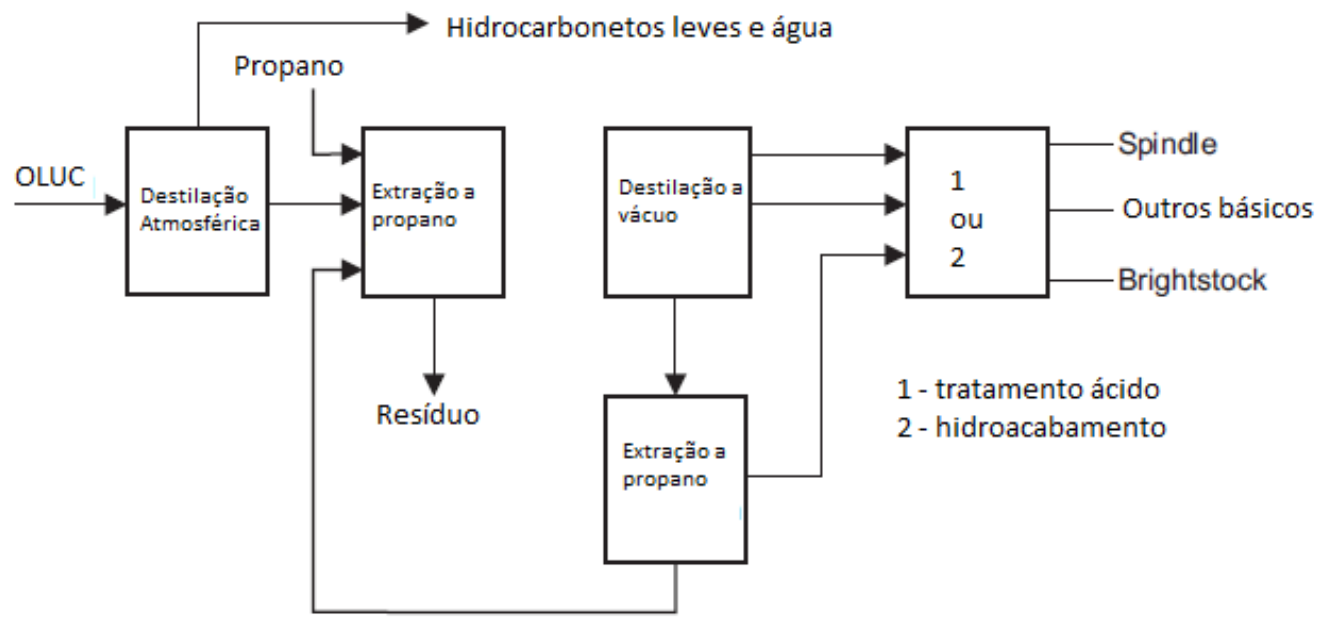

Figura 17. Esquema da extração a propano. ${ }^{11}$

Foram realizadas pesquisas no sentido de encontrar outros solventes que pudessem substituir o propano. Rincón et $a f^{46}$ estudaram o uso de diferentes cetonas e álcoois para extrair o óleo básico do OLUC,concluindo que o rendimento aumenta com o aumento da razão solvente/óleo até se estabilizar, que solventes com cadeia de mesmo tamanho estabilizam em razões próximas e que o rendimento de solventes do mesmo grupo tende a aumentar com o aumento do peso molecular. Assim, a eficiência na remoção de impurezas é igual entre cetonas e álcoois com mesmo tamanho de cadeia, mas os álcoois são mais eficientes na remoção de polímeros. Em outro estudo ${ }^{47}$, os autores verificaram que metais e compostos de oxidação continuam presentes no óleo extraído. Para resolver a questão, testaram a adição de pequenas quantidades de $\mathrm{KOH}$ ao solvente, removendo os compostos de oxidação devido à neutralização dos compostos ácidos e à sua saponificação com precipitação e os metais pela precipitação como hidróxidos metálicos.

No termocraqueamento ou pré-tratamento térmico, o OLUC é submetido a altas temperaturas $\left(280\right.$ a $360{ }^{\circ} \mathrm{C}$ ) com a finalidade de degradar os aditivos existentes e facilitar a eliminação de metais. Tanto a temperatura, quanto 0 tempo de permanência nesse processo são fixos. ${ }^{7}$ Após o pré-tratamento térmico, o OLUC passa pelo processo ácido-argila ou extração a propano. Como vantagens, apresenta a economia em ácido e argila, o aumento do rendimento e a diminuição na geração de resíduos. 
O hidrotratamento, assim como ocorre no refino do petróleo cru, se baseia na conversão das moléculas indesejáveis pela adição de hidrogênio na presença de um catalisador. Normalmente, é utilizada em combinação com outras técnicas citadas neste texto.

No processo denominado wiped film ou evaporação por película, o OLUC, após pré-tratamento, é aquecido a altas temperaturas (acima de $375^{\circ} \mathrm{C}$ ) e injetado em uma espécie de centrifuga a alto vácuo. As frações mais pesadas são separadas pela força centrífuga e mais leves por condensação dos vapores. A Figura 18 ilustra o funcionamento de evaporador por película.

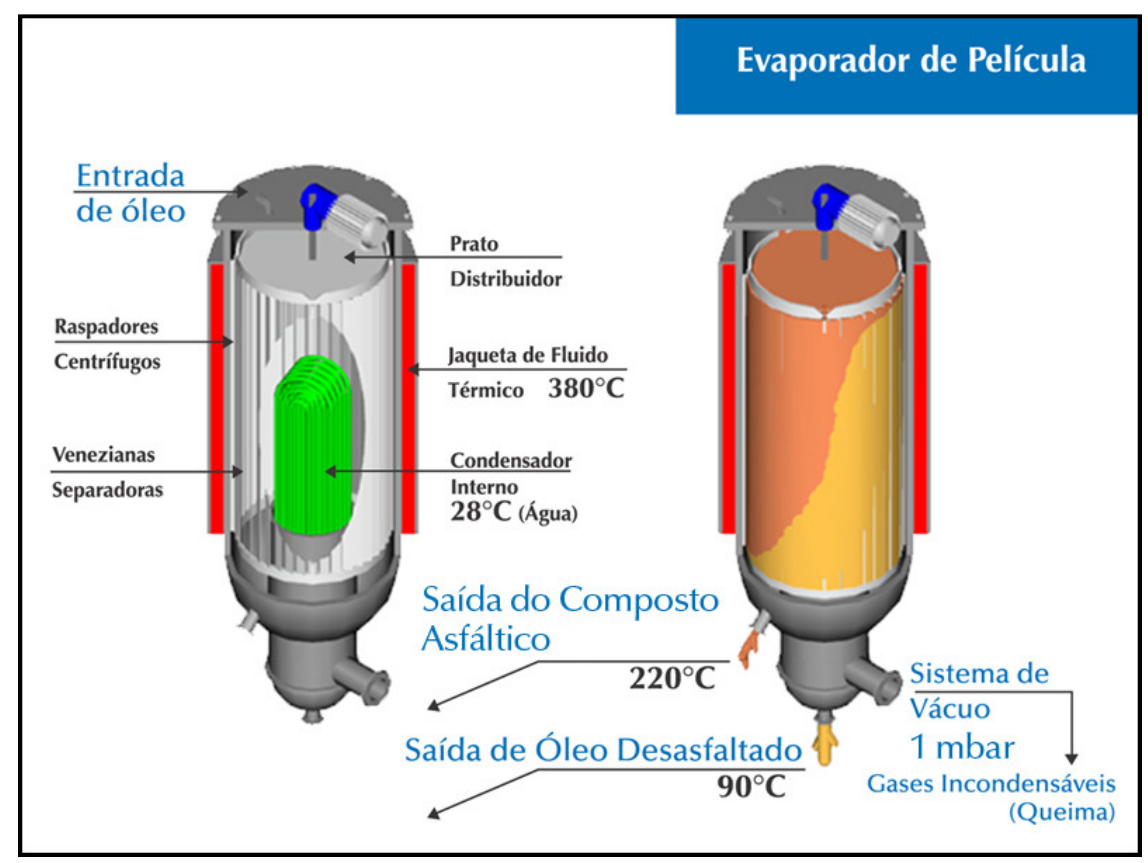

Figura 18. Evaporador por película. Fonte Lwart Lubrificantes.

O processo safety kleen é uma combinação de destilação a vácuo por película e hidrogenação através de leito catalítico. Após o pré-tratamento e a evaporação por película, o OLUC passa por uma hidrogenação catalítica em leito de Ni/Mo. Esse processo gera como subprodutos o querosene, combustíveis utilizados na própria instalação e manta asfáltica. A Figura 19 apresenta um esquema desse processo. 


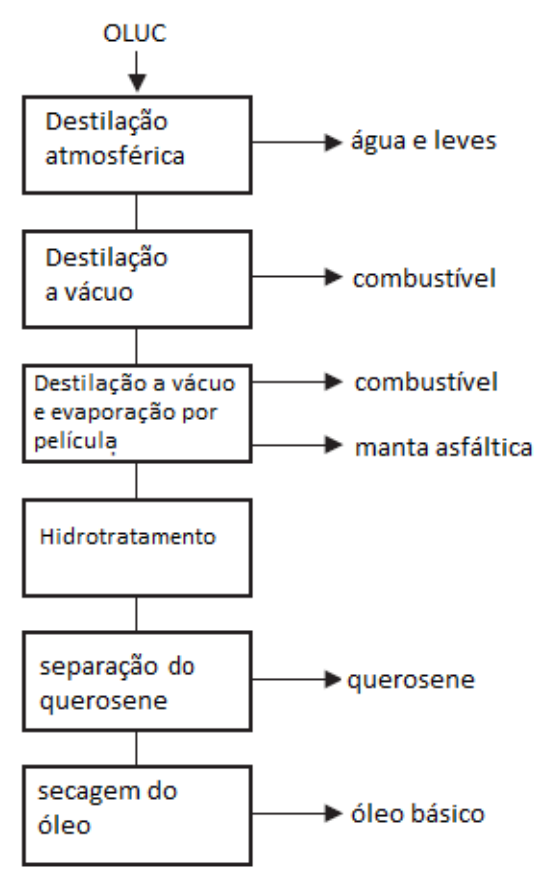

Figura 19. Processo safety kleen. ${ }^{11}$

No processo de destilação/argila, são adicionados ao OLUC, após prétratamento, hidróxidos de cálcio ou sódio e nafta. Os materiais precipitados são removidos por uma centrífuga. O óleo é destilado a vácuo, sendo o corte intermediário percolado e filtrado. Os produtos desse processo podem passar por outros processos como o hidroacabamento, dependendo do tipo de óleo básico almejado. ${ }^{7}$

Os processos baseados nas técnicas extração a propano (desasfaltação a propano), termocraqueamento (pré-tratamento térmico), wiped film (evaporação por película ou evaporação total) e destilação/argila geram básicos do grupo I ou I+, enquanto aqueles baseados no hidrotratamento, como o safety Kleen, produzem básicos grupos II e III.

A qualidade do básico produzido no rerrefino é avaliada através dos mesmos parâmetros físico-químicos utilizados na avaliação dos básicos minerais obtidos do petróleo e dos básicos sintéticos. No Brasil, a Portaria ANP $\mathrm{n}^{\circ}$ 130/99 especifica valores para os seguintes parâmetros: aspecto visual, cor ASTM, viscosidade cinemática a 40 e $100{ }^{\circ} \mathrm{C}$, índice de viscosidade, ponto de fulgor, ponto de fluidez, resíduo de carbono ramsbottom, cinzas, corrosividade ao cobre e número de acidez total. Essa portaria não especifica parâmetros 
relacionados à verificação da descontaminação do OLUC, ou seja, podem existir óleos básicos no mercado brasileiro que, embora atendam à especificação nacional, ainda estão contaminados com metais pesados ou resíduos da aditivação.

Nesta pesquisa, está sendo realizada uma avaliação dos óleos básicos rerrefinados disponível no mercado nacional através da análise físico-química de parâmetros especificados pela legislação brasileira e dos teores dos elementos provenientes da aditivação ou do desgaste de peças.

\subsection{A Fluorescência de Raios $X$ e a Determinação de Metais em Óleos Lubrificantes}

$\mathrm{Na}$ avaliação da qualidade de óleos lubrificantes acabados, dois parâmetros são considerados fundamentais: a viscosidade e a aditivação. Este último é avaliado de forma indireta pelos teores dos elementos cálcio, magnésio, zinco e fósforo presentes nos aditivos antidesgaste, detergentes e dispersantes. Atualmente, foram encontrados na literatura três métodos internacionais e dois brasileiros que podem ser utilizados para estas determinações. ${ }^{48-52}$ Os métodos ASTM D $4628^{48}$ e ABNT NBR $14066^{49}$ adotam a espectrometria de absorção atômica para determinação de bário, cálcio, magnésio e zinco; enquanto os métodos ASTM D $4951^{50}$ e o ABNT NBR $14786^{51}$, a espectrometria de emissão atômica de plasma indutivamente acoplado, incluindo, além dos elementos já citados, o fósforo. O método ASTM D $6481^{52}$ é próprio para a determinação dos elementos fósforo, enxofre, cálcio e zinco em óleos lubrificantes acabados usando a espectrometria de fluorescência de raios $X$ por energia dispersiva, FRX/EDX.

A determinação de elementos não é fundamental para a avaliação da qualidade dos óleos básicos obtidos pelo refino do petróleo, mas o é para a avaliação daqueles obtidos pelo rerrefino. Os teores dos elementos oriundos da aditivação e também do desgaste de peças metálicas podem indicar se 0 processo de rerrefino foi eficiente ou não. Apenas uma norma com essa finalidade foi encontrada na literatura, a ASTM D 5185 $5^{5}$. Ela abrange a determinação de elementos de aditivação e de desgaste por espectrometria de 
emissão atômica em plasma indutivamente acoplado em óleos usados e em óleos básicos virgens e rerrefinados. Essa técnica é bastante dispendiosa com relação aos seus consumíveis e pode aumentar os custos para o rerrefinador, caso seja estabelecida a obrigatoriedade do controle dos elementos por meio dela. Dessa forma, é necessário se encontrar alternativas para a determinação de elementos nos óleos básicos rerrefinados e a FRX/EDX pode ser uma boa opção.

Os raios $\mathrm{X}$ constituem uma radiação eletromagnética de pequeno comprimento de onda produzida pela aceleração ou desaceleração de elétrons de alta energia ou pelas transições de elétrons dos orbitais internos dos átomos. ${ }^{53} \mathrm{Na}$ espectroscopia de fluorescência de raios $X$, um átomo é irradiado com fótons primários de raios $X$ de alta energia, sendo ejetados elétrons orbitais internos na forma de fotoelétrons, convertendo-o a um íon instável. Ocorre, então, a transição de elétrons de níveis de energia mais alta, havendo a emissão de radiação $X$. As diferentes radiações características emitidas nessa redistribuição dependem do átomo incidido e dos níveis de energia final e inicial do elétron.

Existem três tipos básicos de instrumentos de fluorescência de raios $\mathrm{X}$ : dispersivos por comprimento de onda, dispersivos por energia e não dispersivos. Neste texto, serão discutidos apenas os equipamentos de fluorescência de raios $X$ por energia dispersiva.

Os espectrômetros de fluorescência de raios $X$ por energia dispersiva, FRX/EDX, são compostos basicamente de uma fonte de radiação policromática, um porta amostras, um detector e componentes eletrônicos para seleção de energia. Fontes de radiação possíveis são materiais radioativos e tubos de raios $X$ de baixa potência, os quais são compostos basicamente por um filamento, ou cátodo, nos quais são produzidos elétrons que são acelerados na direção do ânodo pela diferença de potencial entre eles. Os raios $X$ são gerados no ânodo pelo impacto da colisão e, através de uma janela de berílio, dirigem-se ao exterior. A Figura 20 apresenta ilustrações de FRX/EDX com os dois tipos de fonte. 


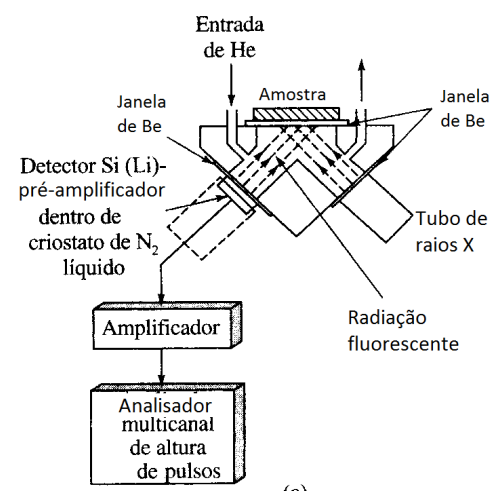

(a)

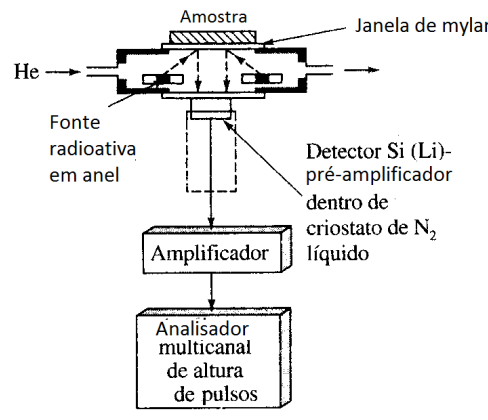

(b)

Figura 20. FRX/EDX, raios $X$ proveniente de (a) tubo de raios $X$ (b) substância radioativa. ${ }^{53}$

O detector é um transdutor de semicondutor, também chamado detector de silício com lítio difundido $\mathrm{Si}(\mathrm{Li})$ ou detector de germânio com lítio difundido $\mathrm{Ge}(\mathrm{Li})$. O semicondutor de silício ou germânio é feito por um cristal contendo três camadas: $p$, intrínseca e $n$. A camada $p$, que recebe os raios $X$ da fonte, é coberta por uma película de ouro que faz o contato elétrico. A camada $n$, que toma o sinal de saída, é recoberta por alumínio; essa saída é levada a um préamplificador com um fator de amplificação de cerca de 10. A camada $p$ recebe um depósito de vapor de lítio que se difunde no cristal, sendo aplicado um potencial cc através dele para provocar a saída dos elétrons da camada de lítio e das lacunas da camada p. A corrente através da junção pn requer a migração, ou difusão, dos íons lítio na camada $p$ e a formação da camada intrínseca na qual os íons lítio substituem as lacunas perdidas por condução. ${ }^{53}$ A camada intrínseca funciona da seguinte forma: inicialmente, a absorção de um fóton resulta na formação de fotoelétron altamente energético, que então perde sua energia cinética pela elevação de muitos milhares de elétrons do silício para a banda de condução, o resultado é um acréscimo acentuado na condutividade. Quando um potencial é aplicado através do cristal, um pulso de corrente acompanha a absorção de cada fóton. O tamanho do pulso é 
diretamente proporcional à energia dos fótons absorvidos. ${ }^{53}$ Com a intenção de diminuir o ruído térmico, o cristal de germânio deve ser mantido em baixa temperatura durante todo o tempo, enquanto os detectores de silício modernos, apenas durante o uso.

A espectrometria de fluorescência de raios $X$ pode ser utilizada para análise de um grande número de materiais, fornecendo resultados com precisão igual ou superior ao de outras técnicas analíticas, com a vantagem de ser uma técnica não destrutiva e de, quase sempre, não requerer pré-tratamento das amostras. A seguir, serão relatados de forma resumida alguns estudos em que 0 FRX/EDX foi utilizado para determinação de metais em diferentes tipos de amostras.

Odumo e colaboradores ${ }^{54}$ analisaram 11 amostras de água, coletadas em diferentes minas de ouro no Kênia, para determinar a contaminação pelos metais cromo, manganês, ferro, cobalto, cobre, zinco, arsênio e chumbo. Os autores optaram pela fluorescência de raios $X$ por energia dispersiva pelo fato da técnica não requerer grande quantidade de amostra, nem um preparo complexo. Eles constataram que os níveis dos metais arsênio, cobre, zinco e chumbo em algumas minas é preocupante e que os mineradores deveram ser melhor qualificados.

Natarajan e colaboradores ${ }^{55}$ desenvolveram um método por FRX/EDX para determinação de cobalto, cromo, cobre, ferro, magnésio, manganês, níquel, vanádio, molibdênio e zinco em $\mathrm{ThO}_{2}$. O método não envolvia nenhuma dissolução ou separação de matriz e foi utilizado como alternativa ao tradicional por espectrometria de emissão atômica. A precisão e exatidão observadas foram melhores que $20 \%$, mas os limites de detecção ainda podem ser melhorados.

Moraes ${ }^{56}$ utilizou a fluorescência de raios $\mathrm{X}$ para quantificar os elementos $\mathrm{Al}$, As, $\mathrm{Cr}, \mathrm{Cu}, \mathrm{Fe}, \mathrm{Mn}, \mathrm{Ni}, \mathrm{Pb}, \mathrm{S}$, Se, Si e V em lodo de esgoto, comparando os resultados com os obtidos pelo método convencional, o qual envolvia uma digestão ácida oxidativa anterior à determinação dos elementos por espectrometria de absorção atômica. $O$ autor afirma que a avaliação foi 
favorável e que o novo método apresenta como vantagem a rapidez analítica e o fato de não ser necessário o uso de reagentes químicos agressivos.

Schimidt e colaboradores ${ }^{57}$ analisaram os metais $\mathrm{Rb}, \mathrm{Sr}, \mathrm{Y}$ e $\mathrm{Zr}$ em amostras de solo. Para corrigir efeitos matriz foram utilizadas modelagens matemática em rede neural e análise multivariada (PLS e PCR). Os melhores resultados são obtidos pelo tratamento com rede neural.

Ponce e colaboradores $^{58}$ analisaram chumbo em amostras aquosas provenientes das roupas de trabalhadores de uma fábrica de baterias, comparando a fluorescência de raios $X$ por energia dispersiva com a espectrometria de absorção atômica. Os resultados encontrados foram concordantes.

Foram realizados muitos estudos envolvendo o uso de fluorescência de raios $\mathrm{X}$ na determinação de metais, mas não foram encontrados registros do uso dessa metodologia para determinação de metais em óleos básicos, apenas em óleos usados e lubrificantes acabados.

Simolon ${ }^{59}$ utilizou FRX/EDX para determinar $\mathrm{Cr}$, Fe e $\mathrm{Pb}$ em óleos usados, mas, devido ao efeito matriz, os resultados não foram satisfatórios. Para que pudesse quantificar esses elementos, ele usou curva de adição, metodologia trabalhosa e demorada, uma vez que é feita uma curva analítica para cada amostra. O efeito matriz, nesse caso, se deve ao fato de que o óleo lubrificante usado é formado por uma mistura de óleos básicos, aditivos (compostos organometálicos e polímeros), produtos de degradação e contaminantes típicos do uso do óleo lubrificante.

Schramm ${ }^{60}$ informou que a Texaco fez uma comparação entre resultados obtidos por ICP e FRX/EDX na determinação de Ca em óleos usados e que as duas técnicas mostraram uma boa correlação. As amostras utilizadas no teste eram de rotina e o autor afirmou ainda ser necessário avaliar amostras de resíduos, óleos usados com material particulado e lodo proveniente de fundo de tanque de armazenamento, pois esses materiais costumam ser heterogêneos e possuir mais de uma fase e suas matrizes não são bem conhecidas. 
O método ASTM D $6481^{52}$ utiliza uma correção matemática para minimizar a absorção dos raios $\mathrm{X}$ dos elementos de interesse por outros elementos presentes, devido a aditivação do óleo básico. No caso da análise de enxofre em produtos de petróleo pelo método ASTM D $4294^{61}$, o efeito de matriz pode ser causado pela diferença entre as razões carbono/hidrogênio $(\mathrm{C} / \mathrm{H})$ dos padrões e das amostras ou pela presença de outro heteroátomo. ${ }^{62}$

Quando comparados aos demais materiais citados, os óleos básicos rerrefinados apresentam uma matriz muito mais simples, pois não devem possuir aditivos ou produtos de degradação e são homogêneos. No Brasil, esses básicos são classificados pela Portaria ANP n ${ }^{\circ 130 / 99}$, de acordo com a sua viscosidade cinemática, em um dos seguintes tipos: parafínico spindle (PSP), parafínico neutro leve (PNL), parafínico neutro médio (PNM) e parafínico neutro pesado (PNP). ${ }^{4} \mathrm{~A}$ viscosidade cinemática está relacionada, entre outros fatores, à densidade e tamanho da cadeia carbônica do óleo básico. Portanto, as razões $\mathrm{C} / \mathrm{H}$ observadas para estes básicos são distintas entre si, o que pode causar efeito de matriz na determinação de metais por FRX/EDX, caso se queira utilizar um método único para todos os tipos de básicos rerrefinados.

Nesta pesquisa, será proposto e validado um método para determinação dos elementos $\mathrm{Ca}, \mathrm{Mg}, \mathrm{Zn}, \mathrm{Ba}, \mathrm{Fe}, \mathrm{Mo}, \mathrm{Cd}, \mathrm{Cr}, \mathrm{Pb}, \mathrm{Si}$ e $\mathrm{Ni}$ em óleos básicos rerrefinados utilizando a espectrometria de fluorescência de raios $\mathrm{X}$ por energia dispersiva. 


\section{Objetivos}

\subsection{Objetivo Geral}

Avaliar a qualidade dos óleos básicos rerrefinados produzidos nas instalações de rerrefino brasileiras quanto aos parâmetros estabelecidos pela legislação vigente e quanto à presença de elementos químicos típicos do OLUC, utilizando, neste último caso, espectrometria de fluorescência de raios $\mathrm{x}$ por energia dispersiva, FRX/EDX.

\subsection{Objetivos Específicos}

Os objetivos específicos são:

(1) Documentar informações sobre todas as instalações de rerrefino autorizadas pela Agência Nacional de Petróleo, identificando todos os processos utilizados no Brasil e a adequação destes frente à tendência mundial.

(2) Avaliar a qualidade dos óleos básicos rerrefinados brasileiros quanto aos parâmetros estabelecidos pela Portaria ANP n¹30/99.

(3) Propor e/ou implementar métodos de detecção e quantificação dos elementos traço remanescentes da aditivação e uso dos óleos lubrificantes acabados (Ca, Mg, Zn, Mo, Fe, Cd, Cu, Cr, Pb e Ni) por FRX/EDX.

(4) Avaliar a qualidade dos óleos básicos rerrefinados brasileiros quanto aos teores de elementos contaminantes.

(5) Avaliar quais as perspectivas futuras do mercado brasileiro de óleos básicos rerrefinados frente à evolução mundial da tecnologia de óleos lubrificantes acabados. 


\section{Metodologia}

A pesquisa está dividida em quatro etapas, sendo que algumas ocorreram concomitantemente: (1) visitas técnicas, coleta de dados e amostras; (2) determinação de características físico-químicas por métodos consolidados; (3) proposição e validação de método para quantificação de metais traço em óleo básico rerrefinado por FRX/EDX; (4) determinação dos metais nos óleos básicos rerrefinados coletados. A seguir, cada etapa será detalhada.

\subsection{Visitas Técnicas, Coleta de dados e Amostras}

As visitas técnicas fazem parte de programa do Centro de Pesquisas e Análises Tecnológicas da Agência Nacional do Petróleo, CPT/ANP, que prevê visitas a todos os agentes econômicos envolvidos na produção e distribuição de produtos derivados de petróleo. Assim, almejando buscar informações sobre os processos utilizados pela indústria nacional, todos os rerrefinadores de OLUC autorizados pela ANP e que estavam exercendo o rerrefino foram visitados entre março de 2010 e dezembro de 2012. A Tabela 8 apresenta a lista de rerrefinadores autorizados pela ANP à época da realização deste estudo. No período avaliado, 19 empresas eram autorizadas pela ANP para exercer o rerrefino. Dessas, 12 estão localizadas na região Sudeste, sendo 9 no estado de São Paulo.

Tabela 8. Empresas rerrefinadoras de OLUC autorizadas pela ANP no período avaliado. ${ }^{63}$

\begin{tabular}{lll}
\hline & Empresa & Estado \\
\hline 1 & Brazão Lubrificantes Ltda & São Paulo \\
2 & Eternal Indústria, Comércio, Serviços e Tratamento de Resíduos & Amazonas \\
& da Amazônia Ltda & \\
3 & Fábrica Química Petróleo e Derivados Ltda & Mato Grosso \\
4 & Falub Indústria e Comércio de Lubrificantes Ltda & São Paulo \\
5 & Indústria Petroquímica do Sul Ltda & Rio Grande do Sul \\
6 & Lubrasil Lubrificantes Ltda & São Paulo \\
7 & Lubrificantes Fênix & São Paulo \\
8 & Lubrinor - Lubrificantes do Nordeste Ltda & Bahia \\
9 & Lwart Lubrificantes Ltda & São Paulo \\
10 & Lwart Lubrificantes do Nordeste Ltda & Bahia \\
11 & Multimineral Química Ltda & Rio Grande do Sul \\
12 & Nortoil Lubrificantes Ltda & Paraná \\
13 & Perfilub Indústria e Comércio de Produtos de Petróleo Ltda & São Paulo \\
14 & Petrolub Industrial de Lubrificantes Ltda & Minas Gerais \\
15 & Prolub Rerrefino de Lubrificantes Ltda & São Paulo \\
16 & Proluminas Lubrificantes Ltda & Minas Gerais \\
17 & Química Industrial Suply & São Paulo \\
18 & Rerrefinadora Brasileira de Óleos Lubrificantes Ltda & São Paulo \\
19 & Tasa Lubrificantes Ltda & Rio de Janeiro \\
\hline
\end{tabular}


As visitas foram documentadas por meio de fotos, relatórios técnicos, fluxogramas e outros materiais fornecidos pelas empresas. Foram utilizadas informações obtidas em conversas formais e informais com diversos agentes do setor, tais como sindicatos de empresas correlatas, produtores e importadores de óleo básico, produtores e importadores de óleo lubrificante acabado, coletores e rerrefinadores, para levantar informações sobre o mercado atual de óleos lubrificantes básicos e acabados, assim como para apontar as perspectivas desses agentes em relação ao futuro.

Foram coletadas amostras de óleo básico rerrefinado em todas as rerrefinadoras brasileiras. As coletas foram realizadas durante as visitas técnicas e em ações de fiscalização da ANP.

\subsection{Determinação de Características por Métodos Consolidados}

Para que seja possível avaliar a qualidade dos básicos rerrefinados nacionais e correlacionar as suas características com os métodos de rerrefino utilizados, eles foram analisados quanto aos parâmetros especificados pela ANP na Portaria 130/994: perda por evaporação noack, teor de enxofre e espectroscopia de reflectância total atenuada, ATR, no infravermelho. Todos os ensaios desta etapa foram realizados no Centro de Pesquisas e Análises Tecnológicas da ANP, CPT/ANP.

Os ensaios para avaliação da aparência e de espectroscopia de reflectância total atenuada no infravermelho, ATR, não são normalizados e foram realizados de acordo com os procedimentos adotados internamente pelo CPT/ANP.

No primeiro caso, foi realizada uma inspeção visual, na qual foi verificado se as amostras eram homogêneas, se continham materiais sólidos em suspensão, se apresentavam odores fortes e qual a cor de cada uma. Nesse procedimento, parte da amostra é vertida em uma proveta de $100 \mathrm{~mL}$ que é avaliada contra um fundo branco, sendo anotada qualquer ocorrência estranha, como turbidez, presença de mais de uma fase líquida ou de sólidos. Em seguida, ela é comparada a uma cartela de cores típicas de óleos lubrificantes, sendo 
apontada a mais próxima. Caso seja percebido algum odor durante 0 manuseio, é feita a sua descrição.

No segundo caso, foi realizada análise de espectroscopia de reflectância atenuada total no infravermelho, ATR, das amostras, utilizando o espectrofotômetro Thermo Nicolet iS10, com célula de ZnSe. Os espectros obtidos foram comparados a espectros de óleos básicos de primeiro refino presentes no banco de dados da ANP. A intenção é verificar a presença de contaminantes como água ou aditivos.

Os demais ensaios foram realizados conforme os métodos relacionados na Tabela 9. Os resultados foram confrontados com a especificação da ANP e com resultados de análises de óleos básicos de primeiro refino constantes em banco de dados do CPT/ANP.

Tabela 9. Normas Técnicas utilizadas para avaliação da qualidade dos óleos rerrefinados

\begin{tabular}{cc}
\hline Característica & Norma \\
\hline Cor ASTM & ASTM D1500 ${ }^{64}$, ABNT NBR $14483^{65}$ \\
Viscosidade cinemática a 40 e $100{ }^{\circ} \mathrm{C}(\mathrm{cSt})$ & ABNT NBR $10441^{66}$ \\
Índice de Viscosidade & ABNT NBR $14358^{10}$ \\
Ponto de fulgor $\left({ }^{\circ} \mathrm{C}\right)$ & ABNT NBR $11341^{67}$ \\
Ponto de fluidez $\left({ }^{\circ} \mathrm{C}\right)$ & ABNT NBR $11349^{68}$ \\
Índice de Acidez total $(\mathrm{mgKOH} / \mathrm{g})$ & ABNT NBR $14448^{69}$ \\
Cinzas $(\%$ em massa) & ABNT NBR $9842^{70}$ \\
Resíduo de carbono Ramsbottom $(\%$ em massa) & ABNT NBR $14318^{71}$ \\
Corrosividade ao cobre, $3 \mathrm{~h}$ a $100{ }^{\circ} \mathrm{C}$ & ABNT NBR $14359^{72}$ \\
Perda por evaporação noack $(\%$ em massa) & ABNT NBR $14157-2^{73}$ \\
Enxofre (\% em massa) & ASTM D4294
\end{tabular}

$\mathrm{Na}$ determinação da cor ASTM, as amostras foram colocadas nos recipientse de ensaio e comparadas, contra uma fonte de luz, com padrões coloridos, cujas cores são numeradas de 0,5 a 8,0. Quanto maior o número, mais escura é a cor. O equipamento utilizado foi o Fisher ASTM colorimeter.

No ensaio de viscosidade cinemática, determina-se o tempo, em segundos, necessário para que um volume fixo do líquido flua por gravidade através do capilar de um viscosímetro calibrado, a uma temperatura rigorosamente controlada. A viscosidade cinemática é o produto do tempo de escoamento 
medido pela constante de calibração do viscosímetro. ${ }^{66}$ Nesse ensaio, foi usado o equipamento Herzog HVU 490 que é totalmente automatizado, ou seja, a sucção da amostra, a detecção dos meniscos inicial e final, o tempo de escoamento e a temperatura do banho termostático são controlados por ele, sem interferência do analista.

O cálculo do índice de viscosidade foi realizado de acordo com a norma NBR $14358^{10}$, conforme já discutido. O equipamento Herzog HVU 490 efetua 0 cálculo com base nos valores de viscosidade cinemática a 40 e $100^{\circ} \mathrm{C}$ medidos.

A análise do ponto de fulgor consiste em adicionar cerca de $70 \mathrm{~mL}$ da amostra em uma cuba de latão e submetê-la a aquecimento. A temperatura da cuba e da amostra não deve exceder a $56^{\circ} \mathrm{C}$ abaixo do valor esperado. Inicialmente, a amostra deve ser aquecida a uma taxa de 14 a $17^{\circ} \mathrm{C} / \mathrm{min}$. Nos últimos $28^{\circ} \mathrm{C}$ antes do ponto de fulgor esperado, a taxa deve ser de 5 a $6^{\circ} \mathrm{C} / \mathrm{min}$. Nesse momento, se inicia a aplicação da chama, cuja diâmetro deve ser entre 3,2 e $4,8 \mathrm{~mm}$, o que deve se repetir a cada $2^{\circ} \mathrm{C}$ até que ocorra $\mathrm{O}$ fulgor. $\mathrm{O}$ equipamento utilizado foi o ISL FP 92 5G2, automatizado. Para evitar a perda de voláteis, esse ensaio foi o primeiro a ser realizado.

$\mathrm{Na}$ determinação do ponto de fluidez, as amostras são colocadas em recipientes cilíndricos de $45 \mathrm{~mL}$ e, após aquecimento preliminar, são resfriadas a uma taxa especificada e, quando atingem $9^{\circ} \mathrm{C}$ acima do ponto de fluidez esperado, que sempre é um múltiplo de 3 , são retiradas do banho e inclinadas para verificar se há escoamento, retornando ao banho num intervalo máximo de 3 segundos. As amostras são examinadas a intervalos de $3^{\circ} \mathrm{C}$ até que não ocorra o escoamento, sendo essa temperatura anotada como o ponto de fluidez. O equipamento utilizado foi o Herzog HCP 852 automatizado, possuindo sensor térmico capaz de registrar temperaturas entre -38 e $50^{\circ} \mathrm{C}$ e sensor óptico para detecção do ponto de fluidez.

O número de acidez é a quantidade de base, expressa em miligramas de hidróxido de potássio por grama de amostra, necessária para titular uma amostra em solvente de titulação (mistura de tolueno e 2-propanol), em que se 
adiciona pequena quantidade de água, da leitura inicial no medidor em milivolts até uma leitura em milivolts correspondente a uma solução-tampão aquosa ou a um ponto de inflexão bem definido, conforme especificado no método de ensaio, NBR $14448 .{ }^{69}$ Nesse ensaio, aproximadamente $20 \pm 2 \mathrm{~g}$ de cada amostra foram dissolvidas em uma mistura de tolueno e isopropanol e água (para cada litro, usa-se $500 \mathrm{ml}, 495 \mathrm{ml}$ e $5 \mathrm{ml}$, respectivamente) e titulada potenciometricamente com hidróxido de potássio alcoólico $0,1 \mathrm{~mol} / \mathrm{L}$, usando um eletrodo combinado. As leituras foram plotadas automaticamente em um gráfico, permitindo a verificação do ponto de inflexão. O titulador utilizado foi o Titrino 702 SM da Methrom com eletrodo de LiCl.

O resíduo de carbono é o resíduo formado durante a evaporação e degradação térmica de um produto de petróleo. ${ }^{71} \mathrm{Nele}$, um bulbo de vidro termorresistente vazio e limpo, com o formato e dimensões definidos pela norma NBR 14318, é posto no forno Ramsbottom a $550^{\circ} \mathrm{C}$ por 20 minutos e depois em dessecador com sílica gel até resfriar. Toma-se a massa do bulbo vazio e, em seguida, pesa-se aproximadamente $4,0 \pm 0,1 \mathrm{~g}$ da amostra. Repete-se o procedimento anterior com o bulbo contendo a amostra, ocorrendo a queima desta. Toma-se a massa final, calculando-se qual o percentual ela representa do total inicial. A marca do forno utilizado é Precision.

A corrosão ao cobre é determinada pela imersão de uma lâmina de cobre 99,9 $\%$ de pureza, com 12,5 mm de largura, 1,5 a 3,0 mm de espessura e $75 \mathrm{~mm}$ de comprimento, previamente polida com carbureto de silício $150 \mu \mathrm{m}$, em um tubo de ensaio contendo $30 \mathrm{~mL}$ da amostra. $O$ tubo é tampado com rolha de cortiça e imerso em banho de aquecimento a $100 \pm 1^{\circ} \mathrm{C}$ por $3 \mathrm{~h} \pm 5 \mathrm{~min}$. Após esse período, retira-se o tubo do banho e, com uma pinça, a lâmina de cobre, imergindo-a imediatamente em isoctano para retirar o excesso da amostra. Compara-se a lâmina com os padrões de corrosão presentes no método, reportando-se o resultado de acordo com a classificação indicada.

A perda por evaporação pelo método noack é o percentual de massa perdida por evaporação quando o óleo é aquecido numa cuba de ensaio com tiragem constante de fluxo de $\operatorname{ar}^{73} \mathrm{~A}$ cuba de ensaio sem a tampa foi pesada vazia e com aproximadamente $65 \pm 0,1 \mathrm{~g}$ de cada amostra. A tampa foi rosqueada e a 
cuba foi inserida no equipamento, sendo conectado o sensor de temperatura e ajustado o tubo de extração de vapor. As amostras foram submetidas a $250^{\circ} \mathrm{C}$ por 60 minutos. Após esse tempo, a cuba foi retirada e colocada em um recipiente com água por 30 minutos. Pesou-se a cuba sem a tampa. Calculouse o percentual de massa perdida. O equipamento utilizado foi o ISL NCK2 5G.

$O$ teor de enxofre foi determinado for fluorescência de raios $X$ por energia dispersiva utilizando a norma ASTM D4294 ${ }^{61}$. De acordo com esse procedimento, deve-se traçar uma curva analítica na faixa de concentração que compreenda o teor esperado de enxofre na amostra. Em seguida, faz-se a leitura da amostra nas mesmas condições, calculando-se o teor de enxofre a partir da curva analítica. O equipamento utilizado foi o Horiba SLFA $1100 \mathrm{H}$.

\subsection{Fluorescência de Raios $X$ por Energia Dispersiva (FRX/EDX)}

Neste capítulo, serão descritas as etapas seguidas para elaboração e validação do método de análise dos elementos $\mathrm{Ca}, \mathrm{Mg}, \mathrm{Zn}, \mathrm{Mo}, \mathrm{Fe}, \mathrm{Cd}, \mathrm{Cu}, \mathrm{Cr}$, $\mathrm{Pb}$ e Ni em óleo básico rerrefinado por EDX/FRX.

A validação de um método analítico é a comprovação, através do fornecimento de evidência objetiva, de que os requisitos para uma aplicação ou uso específicos pretendidos foram atendidos. ${ }^{74}$ Ela é indispensável quando um método analítico é criado ou modificado.

Os passos de validação de um método quantitativo incluem, dentre outros, o estudo dos seguintes parâmetros: faixa linear de trabalho, sensibilidade, seletividade, precisão, exatidão, limite de detecção, limite de quantificação e incerteza de medição. Todos esses parâmetros foram avaliados para o método desenvolvido para determinação de metais em óleo básico rerrefinado por FRX/EDX e cada um deles será detalhado a seguir. Os cálculos estatísticos foram realizados em planilhas de Excel, não sendo utilizado nenhum software específico. 


\subsubsection{Preparo dos Padrões e Soluções}

Todos os padrões foram preparados por diluição em massa, sendo utilizado óleo mineral parafínico neutro médio de primeiro refino como diluente do material de referência certificado, MRC, multielementar contendo $900 \mathrm{mg} / \mathrm{kg}$ dos elementos $\mathrm{Ca}, \mathrm{Fe}, \mathrm{Si}, \mathrm{Mg}, \mathrm{Zn}, \mathrm{Cd}, \mathrm{Ba}, \mathrm{Cu}, \mathrm{Mo}, \mathrm{Cr}, \mathrm{Pb}$ e $\mathrm{Ni}$ e outros 9 elementos tipicamente encontrados em óleo usado. Esses elementos estavam presentes na forma de organometálicos e a matriz do MRC era óleo mineral. Após pesagem do MRC e do básico, a mistura foi aquecida em estufa a $45{ }^{\circ} \mathrm{C}$ por 15 min e, depois, agitada em agitador magnético, também a $45{ }^{\circ} \mathrm{C}$, por 5 $\min$.

\subsubsection{Condições de Análise por FRX/EDX}

O espectrômetro de fluorescência de raios $X$ por energia dispersiva utilizado foi o FRX/EDX 720 da Shimadzu da Central Analítica do Instituto de Química da UnB. Esse espectrômetro possui tubo de ródio e possibilidade de realizar o ensaio a vácuo ou ar atmosférico, mas apenas a segunda opção foi testada, visto que a primeira é recomendada apenas para amostras sólidas. O porta amostras utilizado possui volume de $10 \mathrm{~mL}$ e janela de polipropileno.

Um método inicial, denominado PNM1, foi elaborado de acordo com as sugestões tidas como padrão pelo equipamento, com algumas alterações nas voltagens e intensidade de corrente do tubo. As condições do método são apresentadas na Tabela 10. 
Tabela 10. Condições de análise dos métodos PNM1 e PNM3 para cada elemento

\begin{tabular}{c|cccc|cccc}
\hline Método & \multicolumn{4}{|c|}{ PNM1 } & \multicolumn{4}{c}{ PNM3 } \\
\hline Elemento & Linha & $\mathrm{kV}$ & $\mathrm{uA}$ & Filtro & Linha & $\mathrm{kV}$ & $\mathrm{uA}$ & Filtro \\
\hline $\mathrm{Mg}$ & $\mathrm{K} \alpha$ & 15 & 100 & não & $\mathrm{K} \alpha$ & - & - & - \\
$\mathrm{Si}$ & $\mathrm{K} \alpha$ & 15 & 100 & não & $\mathrm{K} \alpha$ & 10 & 400 & não \\
$\mathrm{Ca}$ & $\mathrm{K} \alpha$ & 15 & 100 & não & $\mathrm{K} \alpha$ & 15 & 357 & $\mathrm{Al}$ \\
$\mathrm{Cr}$ & $\mathrm{K} \alpha$ & 35 & 134 & $\mathrm{Al}$ & $\mathrm{K} \alpha$ & 20 & 168 & não \\
$\mathrm{Fe}$ & $\mathrm{K} \alpha$ & 50 & 100 & não & $\mathrm{K} \alpha$ & 50 & 100 & $\mathrm{Al}$ \\
$\mathrm{Ni}$ & $\mathrm{K} \alpha$ & 50 & 100 & não & $\mathrm{K} \alpha$ & 50 & 104 & $\mathrm{Ag}$ \\
$\mathrm{Cu}$ & $\mathrm{K} \alpha$ & 50 & 100 & não & $\mathrm{K} \alpha$ & 50 & 104 & $\mathrm{Ag}$ \\
$\mathrm{Zn}$ & $\mathrm{K} \alpha$ & 50 & 100 & não & $\mathrm{K} \alpha$ & 50 & 100 & $\mathrm{Ag}$ \\
$\mathrm{Mo}$ & $\mathrm{K} \alpha$ & 50 & 100 & não & $\mathrm{K} \alpha$ & 50 & 104 & $\mathrm{Ag}$ \\
$\mathrm{Cd}$ & $\mathrm{K} \alpha$ & 50 & 100 & não & $\mathrm{K} \alpha$ & 25 & 400 & não \\
$\mathrm{Ba}$ & $\mathrm{L} \alpha$ & 50 & 100 & não & $\mathrm{L} \alpha$ & 50 & 200 & $\mathrm{Al}$ \\
$\mathrm{Pb}$ & $\mathrm{L} \beta$ & 50 & 100 & não & $\mathrm{L} \beta$ & 50 & 104 & $\mathrm{Ag}$ \\
\hline
\end{tabular}

A medida que os testes de validação foram realizados, algumas modificações foram feitas para otimização do método e este recebeu o nome de PNM3.

\subsubsection{Faixa Linear de Trabalho e Sensibilidade}

O primeiro passo foi a definição da faixa de trabalho e a verificação da linearidade desta. A linearidade dos métodos analíticos quantitativos é a capacidade do método demonstrar que os resultados obtidos são diretamente proporcionais à concentração do analito na amostra, dentro de um intervalo especificado. ${ }^{75} \mathrm{~A}$ inclinação da reta de regressão expressa a sensibilidade do método, ou seja, a variação da resposta em função da concentração do analito.

A faixa de trabalho escolhida foi de 5 a $105 \mathrm{mg} / \mathrm{kg}$, pois não é esperado que, em óleos rerrefinados, sejam encontrados os elementos aqui estudados em teores superiores a $100 \mathrm{mg} / \mathrm{kg}$, pois teores a partir deste valor já são típicos de alguns óleos lubrificantes acabados, como aqueles para motores 2 tempos. Deve ser ressaltado que não existe um histórico de análises desses elementos em óleos rerrefinados no Brasil e, portanto, não existem informações sobre um valor típico esperado.

Foi realizada curva analítica em onze níveis na faixa de trabalho escolhida ( 5 , $15,25,35,45,55,65,75,85,95$ e $105 \mathrm{mg} / \mathrm{kg}$ ), com três padrões em cada nível. 
As curvas foram analisadas, sendo medidas aleatoriamente as intensidades de cada padrão. Com o objetivo de fazer uma análise exploratória inicial, os gráficos $X-Y$ das intensidades versus concentrações foram construídos para todos os elementos e os parâmetros da regressão linear foram determinados pelo Método dos Mínimos Quadrados Ordinários, MMQO. Sendo a Equação da regressão linear simples descrita pela Equação 4, as inclinações, b, interseções, $a$, e coeficientes de determinação $R^{2}$ foram determinadas para cada curva, de acordo com as equações (5 a 11).

$$
\begin{aligned}
& \text { (4) } \widehat{y}_{l}=a+b x_{i} \\
& \text { (5) } a=\bar{y}-b \bar{x} \\
& \text { (6) } \bar{y}=\frac{\sum_{i=1}^{n} y_{i}}{n} \\
& \text { (7) } \bar{x}=\frac{\sum_{i=1}^{n} x_{i}}{n} \\
& \text { (8) } b=\frac{s_{x y}}{S_{x x}} \\
& \text { (9) } S_{x y}=\sum_{i=1}^{n}\left(x_{i}-\bar{x}\right)\left(y_{i}-\bar{y}\right)=\sum_{i=1}^{n} x_{i} y_{i}-\sum_{i=1}^{n} x_{i} \sum_{i=1}^{n} y_{i} / n \\
& \text { (10) } \quad S_{x x}=\sum_{i=1}^{n}\left(x_{i}-\bar{x}\right)^{2}=\sum_{i=1}^{n} x_{i}{ }^{2}-\left(\sum_{i=1}^{n} x_{i}\right)^{2} / n \\
& \text { (11) } \quad R^{2}=\frac{\sum_{i=1}^{n}\left(\hat{y}_{l}-\bar{y}\right)^{2}}{\sum_{i=1}^{n}\left(y_{i}-\bar{y}\right)^{2}}
\end{aligned}
$$

Sendo:

$x_{i}$ a concentração conhecida do analito;

$y_{i}$ resposta medida;

$\widehat{y}_{l}$ a resposta estimada pela Equação da regressão;

$n$ o número de pontos da curva analítica.

A partir desses resultados, as condições estabelecidas para o método PNM1 foram modificadas para alguns elementos e um novo método, PNM3, foi testado da mesma forma, porém a curva foi realizada em 6 níveis $(5,25,45$, 65, 85 e 105), com três padrões em cada nível. A Tabela 10 apresenta também as condições desse método. Para cada elemento em que os dois métodos foram utilizados, um deles foi escolhido para prosseguir os estudos. 
Os resultados dos ensaios das curvas analíticas foram submetidos a tratamento de outliers, utilizando o teste de resíduos padronizados jacknife. Esse teste emprega uma estimativa da variância dos resíduos da regressão independente do ponto suspeito. ${ }^{76} \mathrm{O}$ resíduo da regressão é a diferença entre a resposta obtida em análise e a resposta estimada, conforme Equação 12.

$$
e_{i}=y_{i}-\widehat{y}_{\imath}
$$

A estatística utilizada no teste é o resíduo padronizado Jacknife, jei, calculado para cada ponto da curva analítica, conforme Equação 13. Os resíduos seguem a distribuição de $t_{(1-\alpha / 2 ; n-p-1)}$ e são considerados dispersos quando superiores ao $t$ crítico. $^{76}$ À medida que um outlier é retirado, os cálculos são refeitos, até que não restem mais resultados deste tipo ou até alcançar a $22 \%$ dos dados avaliados.

$$
J_{e_{i}}=r_{i} \sqrt{\frac{n-p-1}{n-p-r_{i}^{2}}}
$$

Sendo:

p o número de parâmetros do modelo;

$r_{i}$ o resíduo padronizado, $r_{i}=\frac{e_{i}}{S_{e_{i}}}$

$S_{e_{i}}$ o erro padrão do resíduo, $S_{e_{i}}=S_{r e s} \sqrt{1-h_{i}}$;

$h_{i}$ o ponto de alavanca, $h_{i}=\frac{1}{n}+\frac{\left(x_{i}-\bar{x}\right)^{2}}{S_{x x}}$

Para que se possa afirmar que o MMQO é o modelo que melhor descreve a relação entre as concentrações do analito e as respostas obtidas é necessário provar que o ajuste da Equação da curva analítica atende às premissas assumidas para os resíduos da regressão e para o próprio modelo. ${ }^{76}$ Assim, as curvas obtidas foram testadas quanto à: normalidade e independência dos resíduos, quanto a homocedasticidade, ou seja, variação constante dos resíduos em cada nível da faixa de trabalho, e inexistência de desvio da linearidade. 
Os testes estatísticos adotados nesta pesquisa partem do princípio de que os resíduos da regressão linear seguem a distribuição normal. Assim, é fundamental que isso seja comprovado antes de qualquer outro teste. A normalidade dos resíduos foi testada pelo método Ryan-Joiner, cuja hipótese nula é de que os resíduos seguem a normal e, a alternativa é de que eles seguem outra distribuição. A estatística adotada é o coeficiente de correlação do gráfico de probabilidade normal ou coeficiente de correlação de Ryan-

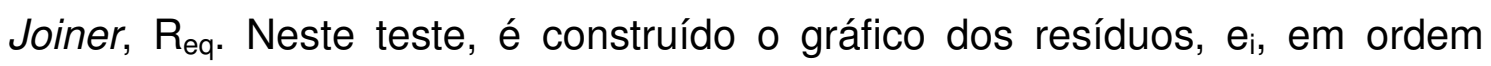
crescente versus os pontos percentis de uma distribuição normal reduzida, $\mathrm{q}_{\mathrm{i}}$, calculada conforme a Equação 14. Esse gráfico é comumente chamado quantil-quantil, QQ. O coeficiente de correlação entre $e_{i}$ e $q_{i}$ é calculado conforme a Equação 15 . O coeficiente de correlação crítico, $R_{\text {crítico, com nível }}$ de significância a igual a 0,10 é calculado por interpolação polinomial pela Equação 16.

$$
q_{i}=\emptyset^{-1} p_{i}, \text { na qual } p_{i}=\frac{(i-3 / 8)}{(n-1 / 4)}, \mathrm{i}=1, \ldots ., \mathrm{n}
$$

$$
R_{e q}=\frac{S_{e q}}{\sqrt{S_{e e} x S_{q q}}}
$$

Sendo:

$$
\begin{gathered}
S_{e q}=\sum_{i=1}^{n}\left(e_{i}-\bar{e}\right)\left(q_{i}-\bar{q}\right)=\sum_{i=1}^{n} e_{i} q_{i}-\sum_{i=1}^{n} e_{i} \sum_{i=1}^{n} q_{i} / n \\
S_{e e}=\sum_{i=1}^{n}\left(e_{i}-\bar{e}\right)^{2}=\sum_{i=1}^{n} e_{i}{ }^{2}-\left(\sum_{i=1}^{n} e_{i}\right)^{2} / n \\
S_{q q}=\sum_{i=1}^{n}\left(q_{i}-\bar{q}\right)^{2}=\sum_{i=1}^{n} q_{i}{ }^{2}-\left(\sum_{i=1}^{n} q_{i}\right)^{2} / n \\
\bar{e}=\frac{\sum_{i=1}^{n} e_{i}}{n} \\
\bar{q}=\frac{\sum_{i=1}^{n} q_{i}}{n} \\
R_{\text {crítico }} \approx 1,007-\frac{0,1371}{\sqrt{n}}-\frac{0,3682}{n}-\frac{0,7780}{n^{2}} \text { para } \alpha=0,10
\end{gathered}
$$

A independência dos resíduos foi testada pelo método Durbin-Watson, cuja hipótese nula afirma que não há autocorrelação dos resíduos e, a alternativa, 
que os resíduos são autocorrelacionáveis. A estatística deste teste é d, definido pela Equação 17. Há dois limites críticos $d_{L}$, limite inferior, e $d_{U}$, limite superior, calculados de acordo com as equações 18 e 19, para um nível de significância $\alpha=0,05$. A independência dos resíduos é comprovada quando $d_{U}<d<4-d_{U}$. Se $4-d_{U}<d<4-d_{L}$, o teste é inconclusivo. Valores de $d<d_{L}$ e de $d>4-d_{L}$ indicam, respectivamente, autocorrelação positiva e negativa e rejeição da hipótese nula a um nível de significância de $2 \alpha$.

$$
\begin{gathered}
\text { (17) } d=\frac{\sum_{i=2}^{n}\left(e_{i}-e_{i-1}\right)^{2}}{\sum_{i=1}^{n} e_{i}^{2}} \\
\text { (18) } d_{L} \approx 1,9693-\frac{2,8607}{\sqrt{n}}-\frac{3,4148}{n}-\frac{16,6400}{n^{2}} \text { para } \alpha=0,05 \\
\text { (19) } d_{U} \approx 1,9832-\frac{3,0457}{\sqrt{n}}-\frac{1,3862}{n}-\frac{16,3662}{n^{2}} \text { para } \alpha=0,05
\end{gathered}
$$

Os dados obtidos foram testados quanto à homocedasticidade utilizando 0 teste de Brown \& Forsythe ou Levene modificado. Nesse teste, a hipótese nula de que as variâncias dos resíduos não diferem entre si é confrontada com a hipótese que elas são diferentes. A estatística do teste é o $t_{L}$ e a hipótese nula é rejeitada, com nível de confiança de $95 \%$, quando a distribuição t de student de $t_{L}, p$, for menor que 0,05 . Os resíduos são divididos em dois grupos n1 e n2, sem separar as replicatas de um mesmo nível. Para cada grupo, é calculada a mediana e as diferenças, em módulo, entre ela e os resíduos. $O t_{L}$ é dado pela Equação 20.

$$
\text { (20) } t_{L}=\left|\frac{\left(\overline{d_{1}}-\overline{d_{2}}\right)}{\sqrt{\left(\frac{1}{n 1}+\frac{1}{n 2}\right) s_{p}^{2}}}\right|
$$

Sendo:

$\overline{d_{k}}=\sum \frac{\left|\widetilde{e_{k}}-e_{k j}\right|}{n_{k}}$, média dos módulos das diferenças entre o j-ésimo resíduo e a mediana de cada grupo $k=1$ e $k=2$;

$n_{k}$, número de observações em cada grupo;

$\widetilde{e_{k}}$, mediana de cada grupo;

$s_{p}^{2}=\frac{\left(S Q D_{1}-S Q D_{2}\right)}{(n 1-n 2-2)}$, variância combinada; 
$S Q D_{k}=\sum_{j=1}^{n k}\left(d_{k j}-\overline{d_{k}}\right)^{2}$, soma dos quadrados dos desvios entre cada j-ésima diferença e a média de seu k-ésimo grupo para cada grupo.

A análise de variância é o método mais usado para se avaliar numericamente a qualidade do ajuste de um modelo. ${ }^{77}$ Neste trabalho, a significância da regressão e o desvio da linearidade foram testados utilizando a Tabela de Análise da Variância, ANOVA, cujas equações são apresentadas na Tabela 11. No primeiro caso, a hipótese nula é de que a regressão linear não é significativa contra a alternativa de que a regressão é significativa. A hipótese nula é rejeitada quando a estatística $F$ estimada for maior que o valor crítico $F_{(1-}$ a;n-2). No segundo caso, a hipótese nula é de que não há desvio da linearidade contra a alternativa de que há desvio. A hipótese nula é rejeitada quando a estatística estima $F$ é maior que o valor crítico $F_{(1-a ; u-2 ; n-u)}$.

Tabela 11. Teste ANOVA da significância da regressão e do desvio da linearidade ${ }^{76}$

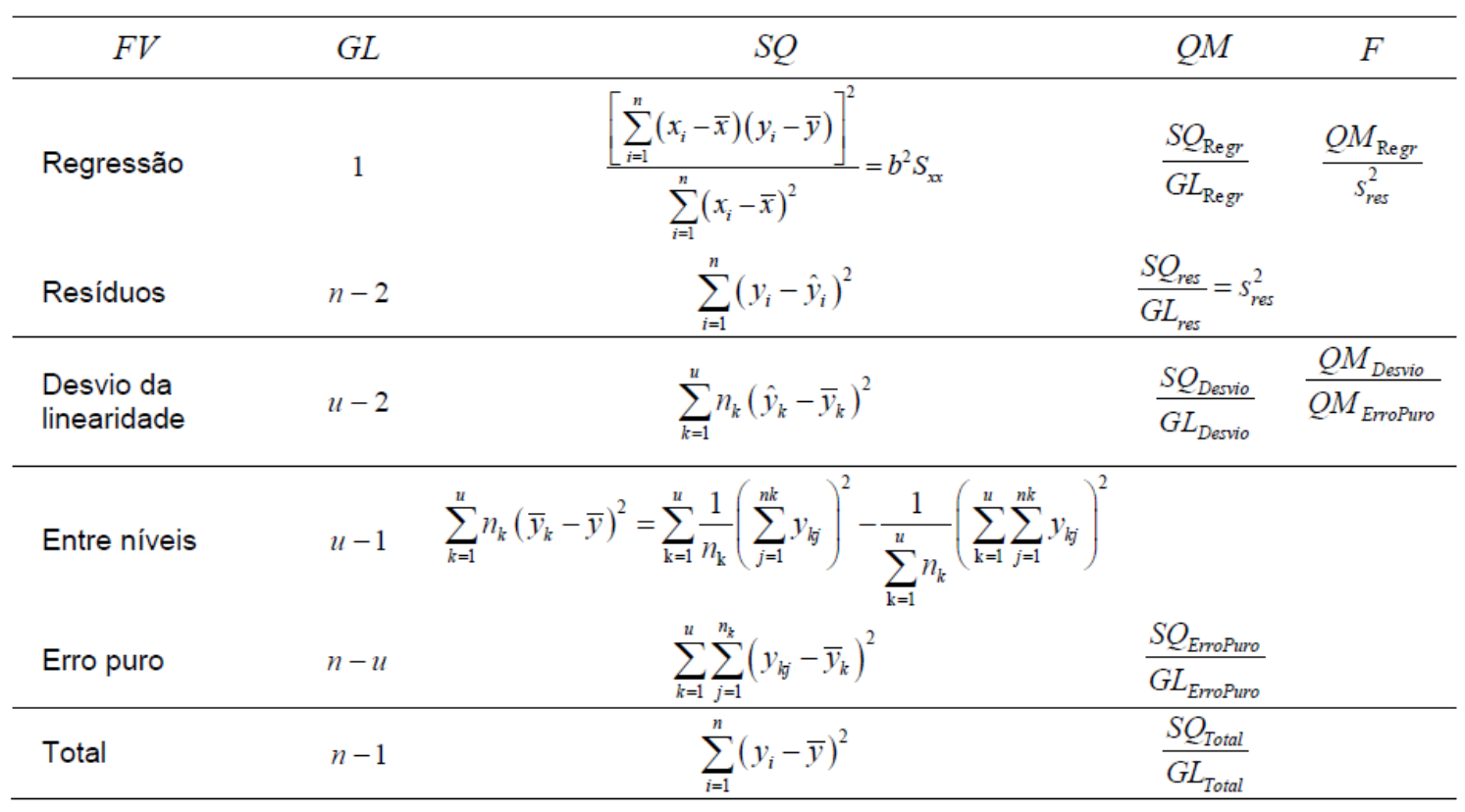

$\mathrm{FV}=$ fonte variação, $\mathrm{GL}=$ graus de liberdade, $\mathrm{SQ}=$ soma de quadrados, $\mathrm{QM}=$ quadrado médio, $\mathrm{F}=$ razão entre variâncias, $\mathrm{n}=$ número de i pontos da curva, $\mathrm{u}=$ número de níveis de concentração, $\mathrm{n}_{\mathrm{k}}=$ número de pontos j em cada nível de concentração $\mathrm{k}, \mathrm{y}_{\mathrm{kj}}=\mathrm{j}$-ésima resposta medida do k-ésimo nível de concentração, $\overline{y_{k}}=$ média das respostas medidas do k-ésimo nível de concentração, $\widehat{y_{k}}=$ variável dependente estimada pela Equação de regressão para o k-ésimo nível de concentração. 


\subsubsection{Seletividade e Efeito de Matriz}

A avaliação da seletividade do método foi feita por meio de um estudo do efeito de matriz. Para isso, foram realizadas curvas analíticas em 6 níveis $(5,25,45$, 65, 85 e $105 \mathrm{mg} / \mathrm{kg}$ ), com três padrões em cada um, utilizando os básicos parafínicos spindle, neutro leve e neutro pesado com o intuito de verificar a existência de interferência da razão $\mathrm{C} / \mathrm{H}$. Elas foram analisadas pelo método PNM1 e/ou PNM3, sendo verificada a linearidade. Nos casos em que esse parâmetro não foi comprovado, o método foi modificado, constando as novas condições na Tabela 10 como PNM3, e a curva usual (parafínico neutro médio) foi testada quanto à linearidade neste novo método.

Antes da avaliação do efeito de matriz, a homogeneidade das variâncias dos resíduos foi testada utilizando o teste $\mathrm{F}$ bilateral, cuja hipótese nula é de que há homocedasticidade e a alternativa é de que há heterocedasticidade. A estatística do teste é a razão entre as variâncias $F$, sendo a maior variância 0 numerador e a menor o denominador, conforme Equação 21. A hipótese nula é rejeitada quando o $\mathrm{F}$ calculado for maior que o $\mathrm{F}$ crítico, $\mathrm{F}_{(1-\alpha / 2 ; n 1-2 ; n 2-2) \text {, dado }}$ pela distribuição $F$.

$$
\text { (21) } F=\frac{s_{\text {res } 1}^{2}}{s_{\text {res } 2}^{2}}
$$

Em caso de homocedasticidade, as inclinações e interseções das curvas foram comparadas pelo teste t com variâncias combinadas. Neste, a hipótese nula é de que as inclinações e interseções não diferem entre si e, a alternativa é de que diferem. As estatísticas do teste, $t_{b}$ e $t_{a}$, são calculadas de acordo com as equações 22 e 23 e a hipótese nula é rejeitada quando elas forem maiores que o valor crítico $t_{(1-\alpha / 2 ; n 1+n 2-4)}$, o qual é dado pela distribuição t de student.

$$
\begin{aligned}
& \text { (22) } t_{b}=\frac{\left|b_{1}-b_{2}\right|}{\sqrt{\frac{s_{p}^{2}}{s x x_{1}}+\frac{s_{p}^{2}}{S x x_{2}}}} \\
& \text { (23) } t_{a}=\frac{\left|a_{1}-a_{2}\right|}{\sqrt{\frac{s_{p}^{2} \sum x_{1}^{2}}{n_{1} S x x_{1}}+\frac{s_{p}^{2} \sum x_{2}^{2}}{n_{2} S x x_{2}}}}
\end{aligned}
$$


Em caso de heterodasticidade, o teste t é empregado utilizando as variâncias amostrais de cada curva. As estatísticas do teste são t $t_{b}$, contraste entre inclinações, e ta', contraste entre interseções, calculadas pelas equações $24 \mathrm{e}$ 25 , respectivamente. A hipótese nula, de que as inclinações e interseções não diferem entre si, é rejeitada quando $t_{b}$ ' e $t_{a}$ ' são maiores que o valor crítico $t_{11-}$ a/2;0), sendo $u$ definido pela Equação 26.

$$
\begin{gathered}
\text { (24) } t_{b}{ }^{\prime}=\frac{\left|b_{1}-b_{2}\right|}{\sqrt{\frac{s_{r e s 1}^{2}}{s x x_{1}}+\frac{s_{r e s 2}^{2}}{s x x_{2}}}} \\
\text { (25) } t_{a}{ }^{\prime}=\frac{\left|a_{1}-a_{2}\right|}{\sqrt{\frac{s_{r e s 1}^{2} \sum x_{1}^{2}}{n_{1} S x x_{1}}+\frac{s_{r e s 2}^{2} \Sigma x_{2}^{2}}{n_{2} S x x_{2}}}} \\
\text { (26) } \mathrm{v}=\frac{\left(\frac{s_{r e s 1}^{2}}{n_{1}}+\frac{s_{r e s 2}^{2}}{n_{2}}\right)^{2}}{\frac{\left(s_{r e s 1}^{2} / n_{1}\right)^{2}}{n_{1}-2}+\frac{\left(s_{r e s 2}^{2} / n_{2}\right)^{2}}{n_{2}-2}}
\end{gathered}
$$

\subsubsection{Limites de Detecção e Quantificação}

O limite de detecção do método, LD, é definido como a concentração mínima de uma substância medida e declarada com $95 \%$ ou $99 \%$ de confiança de que a concentração do analito é maior que zero. Para a validação de um método analítico, é normalmente suficiente fornecer uma indicação do nível em que a detecção do analito começa a ficar problemática, ou seja, "Branco + 3s" e "0 (branco com adição) $+3 \mathrm{~s}$ ", na qual s é o desvio-padrão e 3 é a abcissa t da distribuição de Student quando o número de replicatas é entre 7 e $10 .{ }^{78}$

O Limite de Quantificação, LQ, é a menor concentração do analito que pode ser determinada com um nível aceitável de exatidão e precisão. Pode ser considerado como sendo a concentração do analito correspondente ao valor da média do branco mais 10 desvios-padrão. ${ }^{78}$

Para o cálculo dos limites de detecção e de quantificação, foram analisados dez brancos preparados com o mesmo óleo básico utilizado no preparo da curva, sendo calculado o desvio da média dos resultados. O limite de detecção foi calculado como a média das leituras dos brancos mais três vezes o desvio 
da média e, o limite de quantificação como a média das leituras dos brancos mais 10 vezes o desvio da média.

\subsubsection{Precisão e Exatidão}

Precisão é um termo geral para avaliar a dispersão de resultados entre ensaios independentes, repetidos de uma mesma amostra, amostras semelhantes ou padrões, em condições definidas. ${ }^{78}$ Comumente, a precisão de um método é representada pelos parâmetros repetibilidade e precisão intermediária.

A repetibilidade é a precisão obtida em condições de repetibilidade, ou seja, condições nas quais resultados de testes independentes são obtidos com o mesmo método, mesmo laboratório e mesmo operador, usando o mesmo equipamento e em curtos intervalos de tempo. ${ }^{79} \mathrm{O}$ limite de repetibilidade, $\mathrm{r}$, é dado pela Equação 27, que para um nível de significância de $95 \%$ equivale a $2,8 \mathrm{~s}$, onde s é o desvio padrão de repetibilidade associado aos resultados obtidos nessas condições. ${ }^{78}$

(27) $r=t_{\infty} \sqrt{2} s$ para $95 \%$ de confiança $t_{\infty} \sqrt{2}=2,8$

A precisão intermediária é o grau de concordância entre os resultados das medições de um mesmo mensurando, efetuadas sob condições variadas de medição. ${ }^{78} \mathrm{O}$ limite de precisão intermediária, PI, para um nível de significância de $95 \%$ é dado por 2,8 s, onde s é o desvio padrão da precisão intermediária associado aos resultados obtidos nas condições de precisão intermediária. ${ }^{78}$

Um padrão de concentração de metais igual a $55 \mathrm{mg} / \mathrm{kg}$ (ponto médio da curva) foi preparado com cada um dos básicos avaliados da mesma forma que os padrões da curva. Cada um foi analisado em dez replicatas, no mesmo dia, sob as mesmas condições de análise e o limite de repetibilidade, $r$, foi calculado conforme Equação 27.

O método em estudo sofre pouca influência do analista, por isso, para determinação da precisão intermediária, PI, a mesma amostra foi analisada em dez replicatas, em outro dia, sob as mesmas condições de análise. PI foi considerada igual a 2,8 vezes a média de todas as análises. 
A exatidão do método é definida como sendo a concordância entre o resultado de um ensaio e o valor de referência aceito como convencionalmente verdadeiro. ${ }^{78} \mathrm{~A}$ utilização de um material de referência certificado, MRC, e o cálculo da recuperação aparente são formas indicadas para verificação deste parâmetro.

Os MRCs adquiridos para esta pesquisa, embora em matriz de óleo mineral, não reproduzem fielmente os óleos básicos rerrefinados, pois a suas viscosidades cinemáticas não se encontram no mesmo intervalo que a desses óleos. Assim, a recuperação foi utilizada para avaliar este parâmetro. Para isso, amostras contendo concentrações conhecidas dos analitos de interesse são analisadas pelo método estudado e a recuperação aparente é calculada conforme a Equação 28. Essa técnica não permite afirmar que o método é exato no ponto avaliado, mas possibilita verificar se ele é inexato quando a recuperação obtida está fora dos limites previamente estabelecidos.

$$
\text { (28) } \mathrm{R}_{i}=\left(C_{i} / C_{e}\right) 100
$$

Sendo,

$\mathrm{R}_{i}$ recuperação aparente;

$\mathrm{C}_{i}$ concentração determinada pela curva analítica;

$\mathrm{C}_{e}$ concentração conhecida do MR ou MRC.

Nesta pesquisa, foi determinada a recuperação aparente de materiais de referência certificados, MRCs, nas concentrações 30,50 e $100 \mathrm{mg} / \mathrm{kg}$ e de amostras preparadas da mesma forma que os padrões das curvas em concentrações próximas aos limites de quantificação obtidos para cada elemento. De cada uma dessas amostras foram analisadas 12 replicatas. Os resultados foram submetidos ao teste de Grubbs para retirada dos outliers, sendo determinada a média. Foram considerados não inexatos no ponto avaliado os métodos cujas recuperações se encontraram entre 80 e 120. 


\subsubsection{Incerteza de Medição}

Pode-se definir incerteza como um parâmetro não negativo que caracteriza a dispersão dos valores atribuídos a um mensurando, com base nas informações utilizadas. $^{80}$

Foram adotados os seguintes passos para a determinação da incerteza de medição do método:

1 - Identificação das fontes de incerteza que poderiam influenciar nos resultados;

2 - Quantificação dessas fontes de incerteza e atribuição da distribuição de probabilidade;

3 - Determinação da incerteza padrão para cada fonte de incerteza;

4 - Cálculo da incerteza padrão combinada;

5 - Determinação do número de graus de liberdade efetivos e do fator de abrangência;

6 - Cálculo da incerteza expandida.

As fontes de incerteza identificadas foram: repetibilidade, precisão intermediária, incerteza do certificado de calibração da balança utilizada para preparo das amostras, incerteza do certificado do material de referência multielementar e o erro no ajuste da curva analítica.

Os cálculos das incertezas relacionadas à repetibilidade e à precisão intermediária foram realizados de acordo com as equações 29 e 30 .

$$
\begin{array}{ll}
\text { (29) } u_{r}=\frac{S_{r}}{\sqrt{m}}=\frac{\sqrt{\frac{\sum_{i=1}^{n}\left(X_{i}-\bar{X}\right)^{2}}{n-1}}}{\sqrt{m}} & \bar{X}=\frac{\sum_{i=1}^{n} X_{i}}{n} \\
\text { (30) } u_{P I}=\frac{s_{P I}}{\sqrt{m}}=\frac{\sqrt{\frac{\sum_{j=1}^{\prime \prime}\left(\bar{X}_{j}-\bar{X}\right)^{2}}{\left(n{ }^{\prime}-1\right)}}}{\sqrt{m}} & \bar{X}=\frac{\sum_{j=1}^{n^{\prime}} \bar{X}_{j}}{n^{\prime}}
\end{array}
$$

Sendo: 
$u_{r}$ a incerteza de medição devido à repetibilidade;

$u_{P I}$ a incerteza de medição devido à precisão intermediária;

$S_{r}$ desvio-padrão de uma série de análises em condições de repetibilidade;

$S_{P I}$ desvio-padrão de uma série de análises em condições de precisão intermediária;

$\bar{X}$ é a média dos valores encontrados nas análises em condições de repetibilidade;

$\overline{\bar{X}}$ é a média de todas as médias de repetibilidade, em um experimento de precisão intermediária ou reprodutibilidade;

n é o número total de medidas em um experimento de repetibilidade;

n' é o número de experimentos de repetibilidade que irão compor a precisão intermediária ou a reprodutibilidade;

m é o número de medidas realizadas em rotina no laboratório.

O cálculo da incerteza relacionada à curva analítica foi realizado de acordo com as equações 31 e 32 .

$$
\begin{aligned}
& \text { (31) } u(c)=\frac{s}{a} \sqrt{\frac{1}{N}+\frac{1}{n}+\frac{\left(\bar{y}_{o}-\bar{y}\right)^{2}}{a^{2} \sum_{i=1}^{n}\left(x_{i}-\bar{x}\right)^{2}}} \\
& \text { (32) } S=\sqrt{\frac{\sum_{i=1}^{n}\left(y_{i}-\hat{y}_{i}\right)^{2}}{n-2}}
\end{aligned}
$$

Sendo:

$y$ a resposta fornecida pelo equipamento para cada padrão de referência;

$x$ a concentração do padrão de referência;

$a$ o coeficiente angular da reta (inclinação);

$b$ o coeficiente linear da reta (intercepto);

$c$ a concentração de analito na amostra; 
$u(c)$ a incerteza padrão da curva analítica;

$S$ o desvio padrão residual;

$N$ o número de medições para determinação da concentração do analito;

n o número de medições para elaboração da curva analítica;

$\bar{y}_{o}$ a média da resposta instrumental para as medições da amostra;

$\bar{y}$ a média dos valores da resposta instrumental para as soluções da curva;

$\bar{x}$ a média das concentrações dos padrões usados na elaboração da curva analítica;

$y_{i}$ a resposta instrumental para um dado valor de concentração $x_{i}$;

$\hat{y}$ o valor de $y$ predito pela Equação de regressão;

i o índice para o número de padrões usados na preparação da curva analítica;

j o índice para o número de medições para obtenção da curva analítica.

A incerteza combinada, $u_{c}$, foi obtida pela raiz quadrada positiva da soma quadrática das várias incertezas padrão avaliada anteriormente.

Após determinar o fator de abrangência, a incerteza expandida, $U$, foi calculada como o produto da incerteza combinada, $u_{c}$, pelo fator de abrangência, $k$.

\subsubsection{Testes em Equipamento com Tubo de Raios X de Prata}

Um espectrofotômetro de fluorescência de raios $\mathrm{X}$ modelo Epsilon $3 \mathrm{XL}$ da Panalytical permaneceu por um mês no CPT/ANP para testes. Neste período, foi possível estabelecer um método de análises, denominado PNM2, cujas condições constam na Tabela 12 e testá-lo para a curva em PNM. Essa curva foi avaliada quanto à linearidade, conforme procedimento já discutido. Também foram determinados os limites de detecção e quantificação e a repetibilidade para alguns elementos. Infelizmente, não houve tempo para estudar o efeito de 
matriz, determinar a repetibilidade para todos os elementos e a precisão intermediária e estimar a incerteza.

Tabela 12. Condições de análise do método PNM2 para cada elemento

\begin{tabular}{ccccccc}
\hline Elemento & Linha & kV & uA & Filtro & Meio & Tempo \\
\hline $\mathrm{Ba}$ & LA & 12 & 357 & Al-50 & Hélio & 120 \\
$\mathrm{Ca}$ & $\mathrm{ROI}$ & 12 & 357 & $\mathrm{Al}-50$ & Hélio & 120 \\
$\mathrm{Cd}$ & $\mathrm{KA}$ & 50 & 300 & Cu-500 & ar & 60 \\
$\mathrm{Cr}$ & $\mathrm{KA}$ & 20 & 168 & $\mathrm{Al}-200$ & ar & 60 \\
$\mathrm{Cu}$ & KA & 50 & 104 & $\mathrm{Ag}$ & Hélio & 100 \\
$\mathrm{Fe}$ & KA & 20 & 168 & $\mathrm{Al}-200$ & ar & 60 \\
$\mathrm{Mg}$ & KA & 10 & 501 & $\mathrm{Ti}$ & Hélio & 240 \\
$\mathrm{Mo}$ & KA & 50 & 104 & $\mathrm{Ag}$ & Hélio & 100 \\
$\mathrm{Ni}$ & KA & 50 & 104 & $\mathrm{Ag}$ & Hélio & 100 \\
$\mathrm{~Pb}$ & LA & 50 & 104 & $\mathrm{Ag}$ & Hélio & 100 \\
$\mathrm{Si}$ & KA & 10 & 501 & $\mathrm{Ti}$ & Hélio & 240 \\
$\mathrm{Zn}$ & KA & 50 & 104 & $\mathrm{Ag}$ & Hélio & 100 \\
\hline
\end{tabular}

\subsection{Determinação dos metais}

As amostras coletadas nas rerrefinadoras foram analisadas quanto aos teores dos elementos $\mathrm{Ca}, \mathrm{Mg}, \mathrm{Zn}, \mathrm{Ba}, \mathrm{Fe}, \mathrm{Mo}, \mathrm{Cd}, \mathrm{Cr}, \mathrm{Pb}$, Si e Ni utilizando o método ASTM D $5185^{5}$ e utilizando a nova metodologia por FRX/EDX. Os resultados foram comparados entre si e confrontados com os das demais análises.

O preparo dos padrões e das amostras pelo método ASTM D 5185 é realizado da seguinte forma: o óleo básico (ou padrão multielementar) é pesado e diluído em uma solução de querosene contendo berílio em concentração conhecida. Este elemento é utlizado como padrão interno. As intensidades lidas para os padrões são utilizadas para realização de uma curva analítica, cuja equação é utilizada para o cálculo das concentrações das amostras. Para o preparo da curva, foi utilizado o mesmo MRC multielementar utilizado para a validação dos métodos em FRX/EDX. O espectrômetro utilizado foi o Optima 7300V da Perkin Elmer. 


\section{Resultados e Discussão}

\subsection{Visitas técnicas, Coleta de Dados e Amostras}

\subsubsection{Aspectos Gerais das Empresas Visitadas}

Entre março de 2010 e dezembro de 2012, foram visitados 18 (dezoito) rerrefinadores dos 19 (dezenove) autorizados pela ANP à época. Todas as visitas foram realizadas sem o conhecimento prévio dos responsáveis pelas empresas, exceto no caso de uma, cuja situação geográfica não permitia que assim fosse. Neste caso, a distância em relação a Brasília dificultaria o retorno se a fábrica não estivesse completamente em operação e por isso a visita foi previamente agendada. Algumas das visitas ocorreram em parceria com a Superintendência de Fiscalização do Abastecimento da ANP, durante ações de fiscalização. A Resolução ANP ${ }^{\circ} 19^{26}$, de junho de 2009 , alterou os requisitos necessários à autorização de empresas para o rerrefino, estabelecendo um prazo de 180 dias a contar de sua data de publicação, para que aquelas já autorizadas se adequassem à nova legislação. Dessa forma, no período em que as visitas foram realizadas, as empresas ainda se encontravam em fase de adequação, com exceção de uma que teve sua autorização renovada em setembro de 2010. Este rerrefinador não foi visitado, pois, em fevereiro de 2012 , sofreu um incêndio e teve $80 \%$ de sua planta consumida pelas chamas e até a conclusão deste trabalho as instalações não haviam sido reparadas, sendo a sua autorização cancelada. Até abril de 2015, sete autorizações de rerrefino foram revalidadas e uma nova foi concedida, enquanto seis foram revogadas e seis possuem processos de atualização em análise.

Quatro dos rerrefinadores visitados não estavam em operação, sendo este fato confirmado por meio de inspeção das instalações, que se encontravam em completo abandono. Nenhuma delas solicitou o cancelamento da autorização para o exercício da atividade de rerrefino de OLUC, mas, devido ao não envio de documentação para cumprimento do estabelecido na Resolução 19/2009, tiveram suas autorizações revogadas.

Uma das empresas visitadas, apesar de estar autorizada pela ANP para exercício do rerrefino, possui como atividade prioritária o tratamento de água 
contaminada com óleo lubrificante, a qual representa $95 \%$ dos resíduos recebidos. Além disso, ela presta serviço a indústrias, regenerando o óleo utilizado por elas, retornando-lhes o mesmo produto, porém isento de impurezas e com aditivação complementar. O rerrefino de OLUC ocorre unicamente como forma de tratamento do resíduo retirado da água tratada pela empresa e o óleo básico produzido é consumido no processo de regeneração do óleo industrial para acertar a viscosidade do produto final. Em grande parte, a água descontaminada por ela é de origem industrial e o óleo lubrificante presente nesta não passou por condições muito severas. Por isso, o processo de rerrefino adotado por esta empresa é muito simples, consistindo unicamente em uma desidratação para retirada da água remanescente, seguida de sulfonação com ácido sulfúrico, clarificação com argila, neutralização com $\mathrm{Ca}(\mathrm{OH})_{2}$ e filtração em filtro prensa. Por não apresentar o rerrefino como atividade principal, os dados referentes ao processo adotado pela referida empresa não serão considerados em conjunto com os dos rerrefinadores avaliados neste trabalho.

As treze empresas restantes exercem o rerrefino como atividade principal ou como uma das atividades principais. Dessas, sete exercem apenas o rerrefino e cinco também produzem lubrificantes acabados. A empresa Brazão Lubrificantes Ltda. também trata água contaminada com óleo lubrificante e a Eternal Indústria, Comércio Serviços e Tratamento de Resíduos da Amazônia, além de rerrefino e produção de óleos lubrificantes, também coleta e pré-trata embalagens usadas de óleos lubrificantes. O pré-tratamento das embalagens plásticas consiste em escorrer todo o óleo residual, triturar e lavar os frascos.

A época das visitas, todos os rerrefinadores produziam apenas básicos do grupo I. Ao final de 2012, a empresa Lwart Lubrificantes Ltda. inaugurou uma nova planta que se destina à produção de grupo II. Essa unidade foi visitada em 2014 e um breve resumo do processo de produção de grupo II é apresentado ao final do item 5.1.2. Nessa visita, não foram coletadas amostras. O panorama apresentado a seguir, se refere às visitada realizadas no período de março de 2010 a dezembro de 2012. Com exceção do fechamento da empresa 13, da abertura de uma nova empresa em 2014 e da nova unidade da Lwart, não houve alterações nos processos citados. 
Vários rerrefinadores visitados relataram que estão buscando uma aproximação com os produtores de lubrificantes industriais para conhecer as suas necessidades e, então, poderem oferecer produtos mais direcionados.

\subsubsection{Processos de Rerrefino Utilizados}

A seguir, serão relatadas com mais detalhes as etapas de recebimento, prétratamento, tratamento e aperfeiçoamento do OLUC realizadas pelos treze rerrefinadores de OLUC autorizados pela ANP. Para garantir o segredo industrial com relação aos processos de rerrefino adotados, as empresas serão denominadas por números, de acordo com a ordem em que foram visitadas.

\subsubsection{Recebimento}

Dos treze rerrefinadores, dez também são coletores de OLUC autorizados pela ANP. Destes, sete recebem apenas o OLUC coletado pela sua própria frota de caminhões coletores e três recebem também de outros coletores autorizados. As empresas 5 e 13 afirmam receber apenas óleo de transformador obtido em leilões das concessionárias de energia elétrica e/ou óleos industriais encaminhados por indústrias parceiras. A empresa 9 não é autorizada para a coleta de OLUC e recebe apenas de coletores autorizados pela ANP.

Com exceção da empresa 13, antes de descarregar o OLUC em seus tanques, os rerrefinadores analisam o material contido nos caminhões para adequação dos seus processos. Os ensaios mais usuais são: índice de saponificação, teste de gota ou pingo, presença de PCB e teor de água por destilação. Algumas empresas fazem também uma simulação de sulfonação e teste de filtrabilidade.

O índice de saponificação está relacionado ao teor de óleo vegetal presente no OLUC. Embora não seja permitido, é comum a mistura de óleo de cozinha usado com OLUC o que ocorre principalmente devido ao desconhecimento da população sobre as diferenças entres os resíduos e as formas de tratamento adotadas para cada um deles. Além disso, alguns óleos lubrificantes industriais podem ter em sua composição óleos vegetais. A presença do óleo vegetal no 
OLUC pode levar a uma reação de saponificação durante o processo de rerrefino comprometendo o material e inviabilizando a produção de óleo básico.

O teste da gota ou do pingo assemelha-se a uma cromatografia em papel e consiste em pingar uma gota de OLUC em uma folha de papel de filtro e observar o padrão de absorção do líquido. Quando é gerado um círculo com cor uniforme, normalmente escura, é indício de que o OLUC está homogêneo; a formação de um anel claro ao redor do círculo escuro indica a presença de contaminantes como água, combustível ou outro solvente e, quanto maior este anel, maior a quantidade deste tipo de contaminante. Este método não é normalizado e cada rerrefinador desenvolve os seus padrões de comparação e define o que é aceitável para o seu processo. A Figura 21 mostra um exemplo de padrão de aceitação desenvolvido por um dos rerrefinadores visitados.

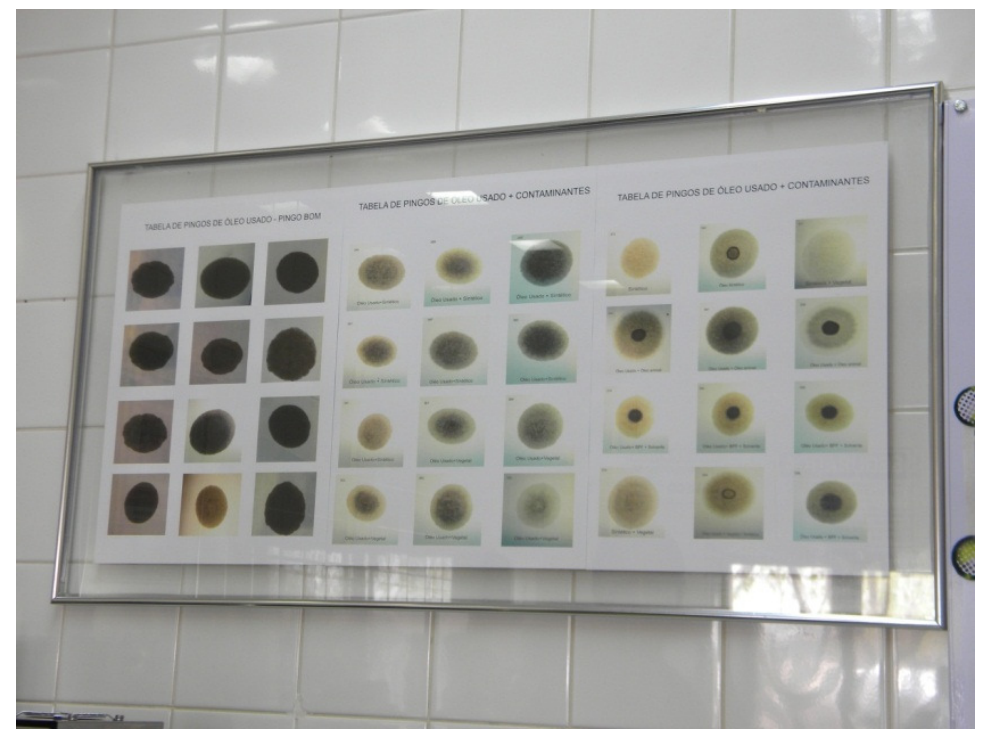

Figura 21. Padrões comparativos para o teste de pingo do OLUC.

A presença de policloreto de bifenilas, PCBs, no OLUC é determinado qualitativamente utilizando um kit denominado CLOR-N-OIL, que contem como reagentes principais o nitrato de mercúrio e um composto organo sulfurado patenteado. Os PCBs eram utilizados como componentes de óleos isolantes de transformadores de energia elétrica. Devido a sua toxicidade, foi proibido no Brasil por meio da Portaria Interministerial n ${ }^{\circ} 19$ de 29 de janeiro de $1981 .{ }^{81}$ Embora o seu uso tenha sido banido, existe a possibilidade de equipamentos antigos ainda conterem óleos isolantes contaminados com esses compostos. $O$ 
tratamento adequado para óleos contaminados com PCBs é a incineração, portanto, a presença destes no OLUC inviabiliza o processo de rerrefino.

O teor de água por destilação é um teste adotado para averiguação do percentual desta no OLUC, visa à valoração do resíduo e à otimização do processo.

O teste de sulfonação é uma simulação de uma das etapas do processo de rerrefino. O objetivo é definir o teor de ácido sulfúrico e o tempo de decantação a serem utilizados e inferir o rendimento do processo.

Tais ensaios, exceto a detecção de PCBs, não são realizados com o intuito de recusar o OLUC, mas para definição de preço e adequação da carga para processo. Caso o OLUC recebido não seja o ideal para o processo adotado pelo rerrefinador, é comum a sua segregação em um tanque para que ele possa ser adicionado em pequenas parcelas a outras cargas de OLUC mais próximas do ideal para o processo. Dessa forma, é possível o rerrefino de todo o OLUC recebido, além de se manter uma maior homogeneidade da carga inicial do processo.

$\mathrm{Na}$ Figura 22, são apresentadas algumas fotos de caminhões coletores de OLUC e do descarregamento deste para caixas receptoras a partir das quais são bombeados para os tanques de armazenamento. Em uma delas, é possível observar uma tela para retenção de material grosseiro. 


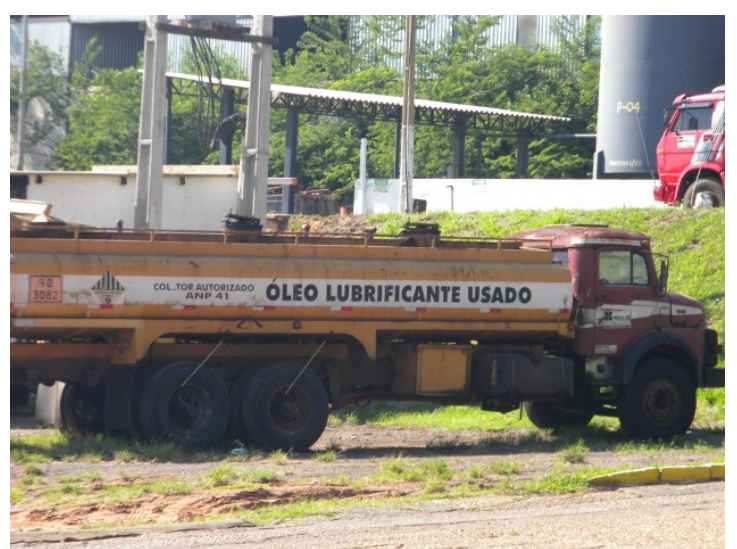

(a)

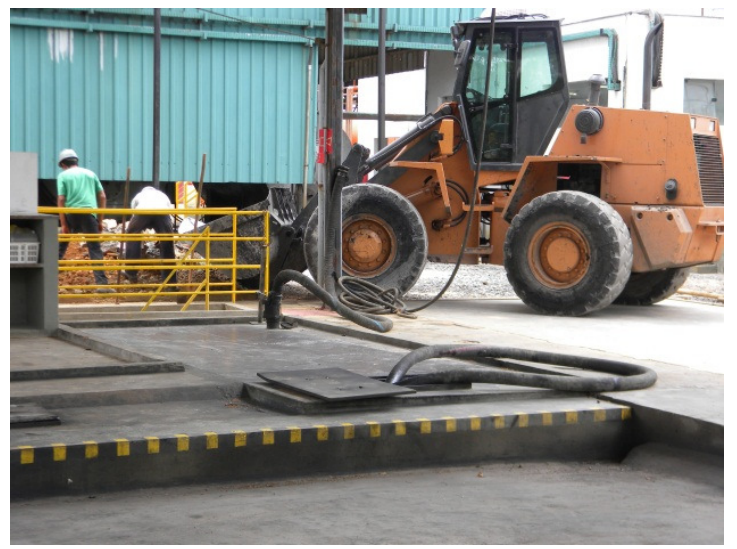

(c)

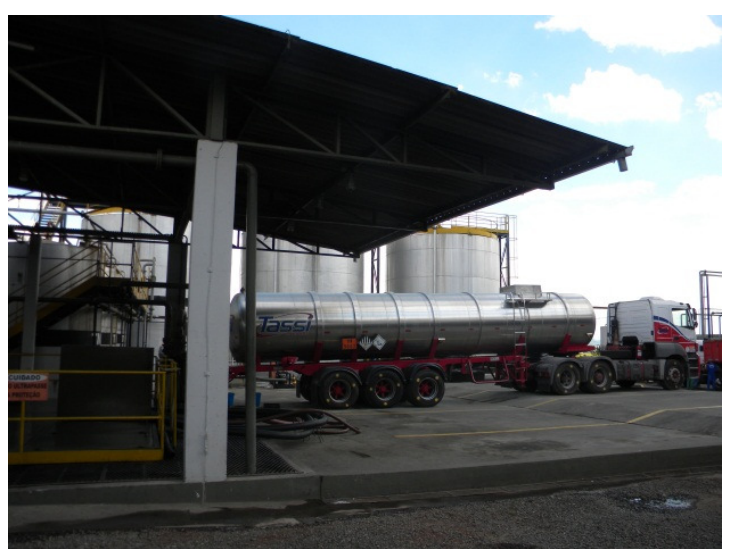

(b)

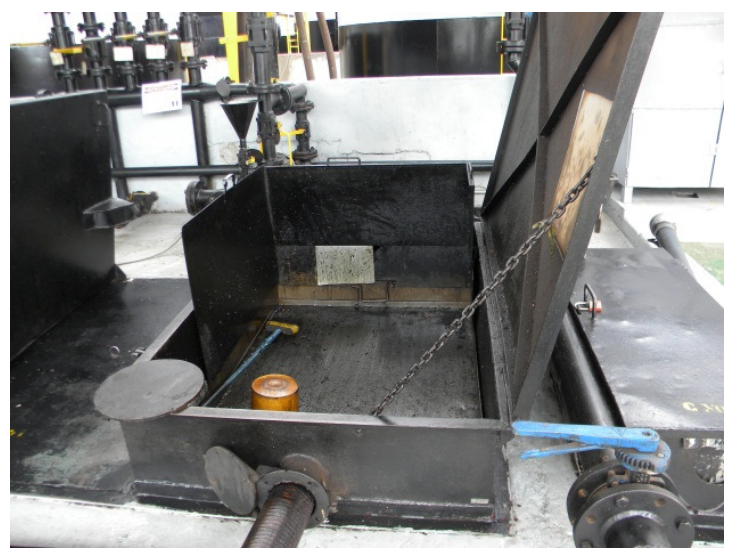

(d)

Figura 22. Recebimento do OLUC: (a) e (b) caminhões coletores (c) e (d) descarregamento nas caixas receptoras.

\subsubsection{Pré-tratamento}

Neste trabalho, foram considerados como pré-tratamento os processos físicos e químicos utilizados com o objetivo de facilitar o rerrefino e aumentar o seu rendimento.

Nas empresas visitadas, foram identificadas as seguintes etapas de prétratamento: filtração grosseira, decantação, decantação seguida de choque térmico, desidratação e termocraqueamento ou pré-tratamento térmico.

A filtração grosseira é realizada em praticamente todas as empresas visitadas, com exceção daquelas que recebem apenas óleo industrial. Ela é executada no ato do descarregamento do OLUC na caixa receptora, como pode ser observado na Figura 22d, e seu objetivo é a retirada de materiais grosseiros 
tais como estopas e filtros de óleo, os quais são comumente descartados nas caixas coletoras dos estabelecimentos que efetuam a troca de óleo de motor.

O intuito da decantação antes do rerrefino é a remoção de água. Apenas duas empresas utilizam este método como pré-tratamento. Este método só é justificável para teor de água elevado, cujo excesso é removido, sendo necessário destilar para retirar a água remanescente. A empresa 5 decanta 0 OLUC após choque térmico, aquecendo-o e resfriando-o em seguida, não adotando nenhum outro processo especificamente para desidratar o OLUC.

A retirada de água do OLUC é comumente efetuada por meio de destilação atmosférica ou a vácuo, recebendo o nome de desidratação. A temperatura em que o OLUC pode chegar varia entre 120-160 $\mathrm{O}$, sendo retirados também alguns hidrocarbonetos leves. Onze dos treze rerrefinadores adotam esta etapa como a etapa inicial de todo o processo.

O termocraqueamento, craqueamento térmico ou pré-tratamento térmico é adotado por oito dos rerrefinadores visitados. Nesta etapa, as substâncias presentes no OLUC são quebradas em moléculas menores facilitando as reações que ocorrerão nas etapas seguintes. Uma das vantagens da sua utilização é a diminuição do resíduo gerado com o processo adotado, seja ele o ácido/argila, a desasfaltação a propano ou a evaporação total (wiped film), além do aumento do rendimento total. Quando o processo de rerrefino utilizado é o ácido/argila, ocorre também a diminuição da quantidade de ácido sulfúrico necessária na etapa de sulfonação. A Figura 23 mostra alguns exemplos de tanques para termocraqueamento. 


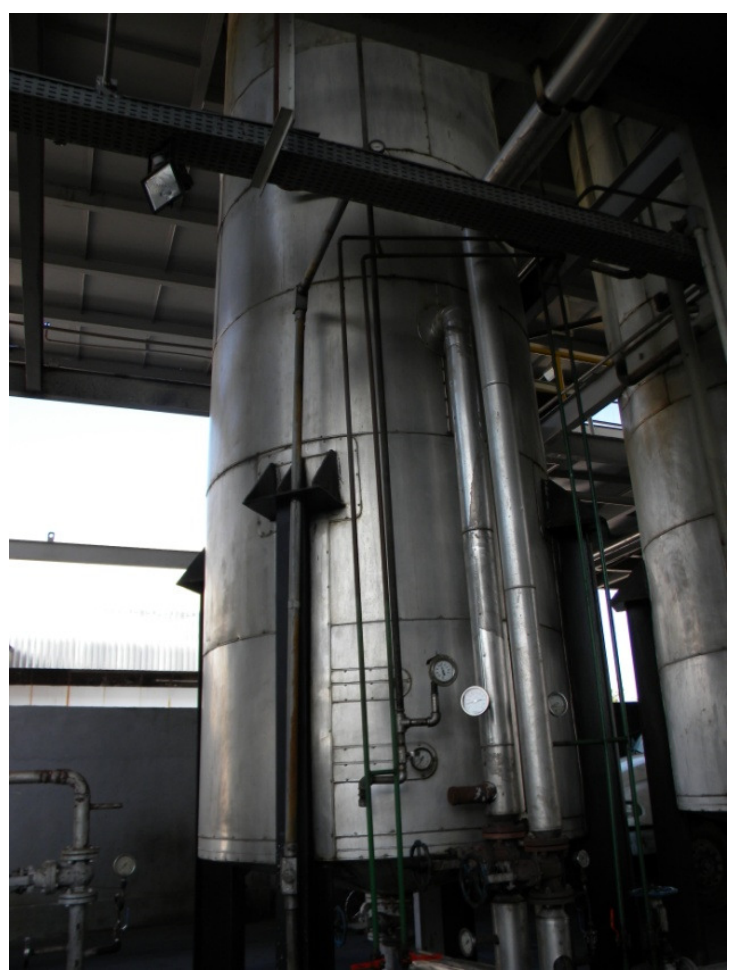

(a)

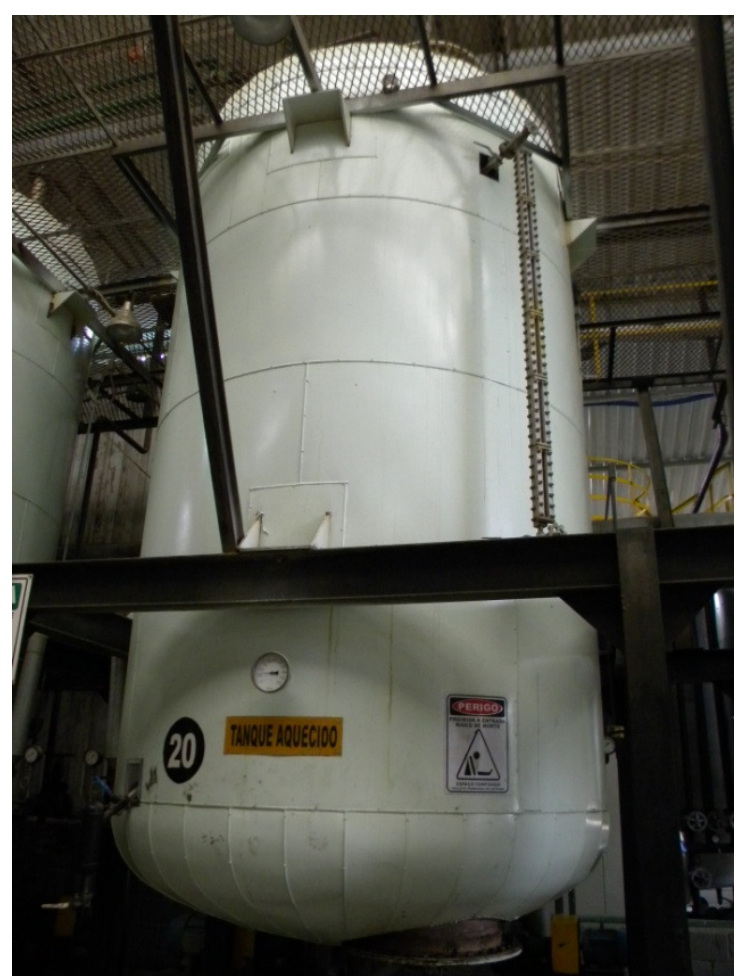

(b)

Figura 23. Exemplos de tanques para termocraqueamento.

\subsubsection{Rerrefino}

Os processos de rerrefino adotados pelas empresas brasileiras são combinações de tipos diferentes de técnicas conhecidas mundialmente. Para uma análise mais aprofundada, inicialmente, a incidência de cada técnica será abordada separadamente e, em seguida, serão abordadas as combinações mais frequentes.

O processo ácido/argila original não é mais utilizado no Brasil, mas onze dos treze rerrefinadores adotam a acidificação com ácido sulfúrico (sulfonação) em alguma etapa de seu processo, utilizando concentrações diferentes de ácido de acordo com as demais etapas adotadas e todos utilizam argila (terra diatomácea ou terra fuller) na etapa de clarificação, a qual será abordada mais adiante. Em seis dessas empresas, o termocraqueamento antecede a sulfonação, podendo-se afirmar que 0 processo utilizado é 0 termocraqueamento/ácido/argila. Em uma delas, a destilação a vácuo antecede a sulfonação. Nas demais, a sulfonação é apenas uma etapa de um processo mais complexo. A Figura 24 mostra imagens de tanques de sulfonação. 


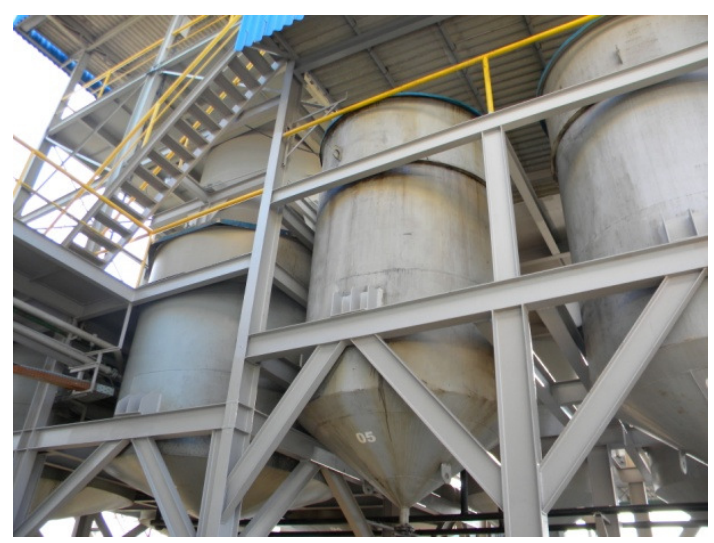

(a)

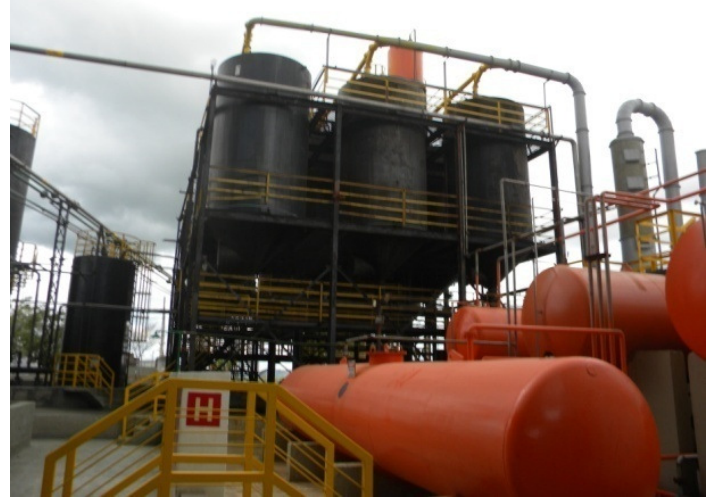

(b)

Figura 24. Processo de sulfonação (a) tanques de sulfonação, (b) tanques de sulfonação e tanques de ácido sulfúrico na horizontal.

A empresa 5 é uma das que não utiliza a acidificação no seu processo e também é a única que usa apenas a destilação a vácuo para rerrefinar o OLUC, num processo de rerrefino muito simplificado, Figura 25.

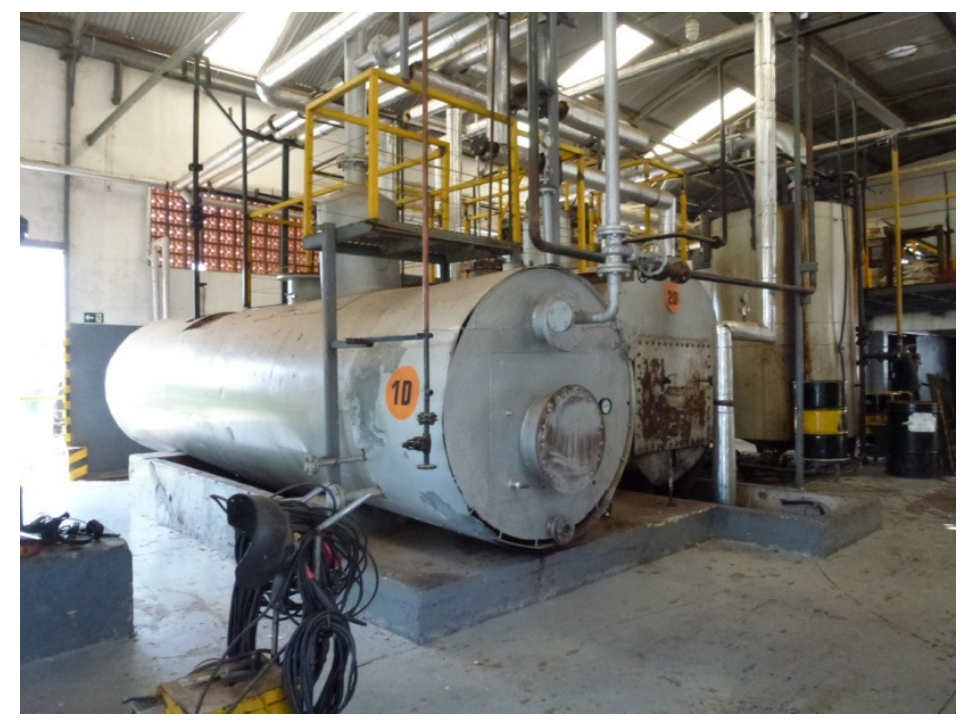

Figura 25. Processo da empresa 5: a esquerda, na horizontal, destilador e a direita, na vertical, tanque de clarificação.

A desasfaltação a propano é utilizada por apenas duas empresas, 3 e 6, e em associação com outras técnicas. No primeiro caso, a desasfaltação é associada à evaporação total. No segundo caso, ela é a técnica principal, sendo seguida da sulfonação.

A evaporação total é utilizada por outras duas empresas, sendo antecedida pelo termocraqueamento. A empresa 10 utiliza também a sulfonação após essa técnica. 
A clarificação com argila está presente em todos os processos adotados no Brasil como uma etapa final do rerrefino. O objetivo é a absorção de materiais particulados e outros contaminantes ainda presentes. O mais comum é a adição de argila ao óleo em tratamento, em um tanque específico, sob aquecimento. A temperatura de trabalho varia entre 150 e $350^{\circ} \mathrm{C}$. Em alguns casos, o óleo é destilado na presença de argila, sendo retiradas as diferentes frações de básico. A clarificação também possui o papel de neutralizar o óleo que passou pela sulfonação, sendo efetuada em conjunto com uma destilação por arraste de vapor d'água. Nas situações em que altas concentrações de ácido sulfúrico são utilizadas, é necessária a adição de cal $\left(\mathrm{Ca}(\mathrm{OH})_{2}\right)$. $\mathrm{Na}$ Tabela 13, é possível visualizar de forma resumida o procedimento adotado por cada empresa.

Tabela 13. Processo de rerrefino adotado por cada empresa

\begin{tabular}{|c|c|c|}
\hline Rerrefinador & Pré-tratamento* & Tratamento \\
\hline 1 & desidratação/termocraqueamento & ácido/argila \\
\hline 2 & desidratação/termocraqueamento & ácido/argila (arraste a vapor e $\mathrm{Ca}(\mathrm{OH})_{2}$ ) \\
\hline 3 & desidratação & $\begin{array}{c}\text { desasfaltação a propano/evaporação } \\
\text { total/ácido/argila e } \mathrm{Ca}(\mathrm{OH})_{2}\end{array}$ \\
\hline 4 & desidratação/termocraqueamento & ácido/argila (arraste a vapor) \\
\hline 5 & choque térmico/decantação & destilação a vácuo/argila \\
\hline 6 & Nenhum & $\begin{array}{c}\text { destilação a } \\
\text { vácuo/desasfaltação/ácido/argila } \\
\text { evaporação total/argila (arraste a vapor) - }\end{array}$ \\
\hline 7 & desidratação/termocraqueamento & $\begin{array}{l}\text { leves são sulfonados e neutralizados } \\
\text { com cal }\end{array}$ \\
\hline 8 & desidratação/termocraqueamento & ácido/argila \\
\hline 9 & desidratação & $\begin{array}{c}\text { destilação a vácuo/ácido/argila (vácuo e } \\
\text { cal) }\end{array}$ \\
\hline 10 & desidratação/termocraqueamento & evaporação total/ácido/argila (vácuo) \\
\hline 11 & desidratação/termocraqueamento & $\begin{array}{c}\text { ácido/argila (destilação a vácuo) - leves } \\
\text { neutralizados com NaOH }\end{array}$ \\
\hline 12 & $\begin{array}{l}\text { decantação/desidratação/ } \\
\text { termocraqueamento }\end{array}$ & ácido/argila (arraste a vapor) \\
\hline 13 & Nenhum & argila \\
\hline
\end{tabular}

A empresa 13 adotava um processo de rerrefino extremamente simplificado, o qual consistia unicamente na etapa de clarificação com argila. Embora esta empresa trabalhasse apenas com óleo industrial, não se pode afirmar que por 
isso a clarificação com argila fosse suficiente para a remoção de metais e aditivos remanescentes. Essa empresa teve sua autorização de exercício do rerrefino revogada pela ANP.

\subsubsection{Purificação}

Neste trabalho, chama-se purificação o(s) processo(s) físico(s) utilizado(s) para separação final dos óleos básicos obtidos e/ou melhoria destes. Em todos os rerrefinadores, após a clarificação com argila, o óleo é filtrado em filtro prensa. Apenas quatro dos treze rerrefinadores adotam outros tipos de purificação. Desses, três efetuam ultrafiltração e/ou filtração em filtro manga. $\mathrm{Na}$ ultrafiltração, o óleo final é filtrado, em sequência, em filtros de 3, 10 e 25 mesh (aproximadamente 5,$66 ; 2,00$ e $0,707 \mathrm{~mm}$ ) e por último em filtro manga. A empresa 4, antes da ultrafiltração, submete o óleo à desaeração e secagem a vácuo, objetivando a retirada de baixos teores de umidade. A empresa 12 , após a filtração em filtros prensa, centrifuga o óleo obtido. A Figura 26 apresenta fotos desses filtros.

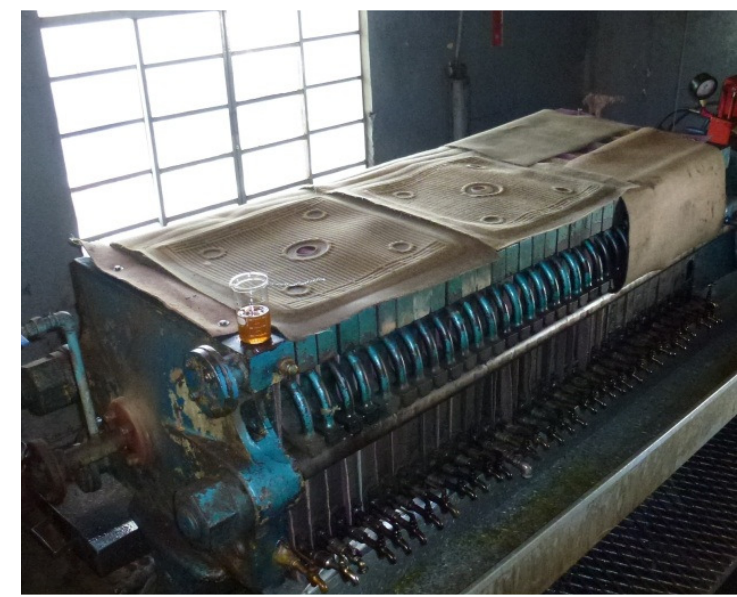

(a)

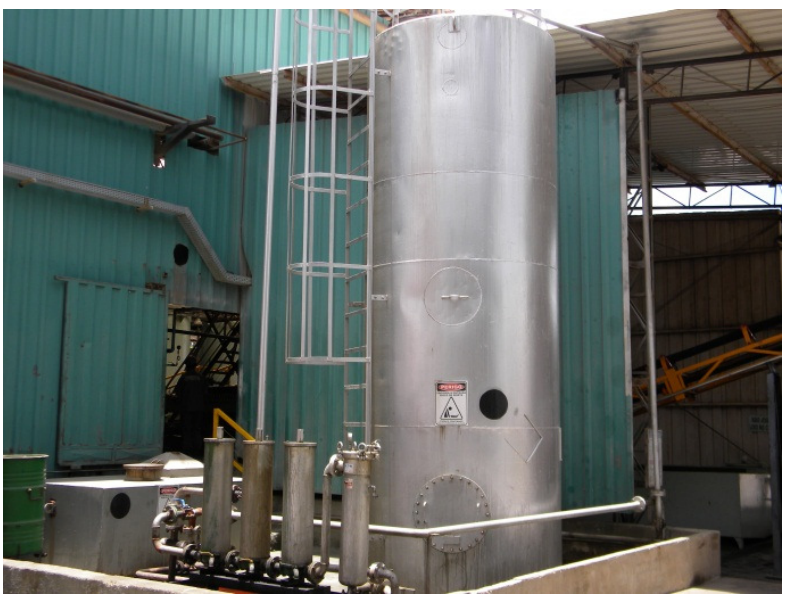

(b)

Figura 26. Purificação (a) filtro prensa e (b) filtros de 3, 10 e 25 mesh e filtro manga, da esquerda para a direita, respectivamente

$\mathrm{Na}$ empresa 13, o óleo filtrado no filtro prensa era armazenado em tanques dentro da fábrica, os quais também eram utilizados para a armazenagem de OLUC. O volume total desses tanques é de $23000 \mathrm{~L}$. A linha de transferência usada era a mesma, havendo um sistema de fechamento e abertura de válvulas manual muito simples, que permitia ao operador escolher de qual tanque seria retirado o óleo para produção de graxa e de qual tanque sairia o 
OLUC para a filtração. A possibilidade de contaminação por OLUC do óleo utilizado para produção de graxa era muito alta.

\subsubsection{Resíduos Gerados e sua Disposição Final}

O processo de rerrefino também gera resíduos que precisam ser destinados de forma adequada, a qual depende de características específicas de cada um. A seguir, serão relatados os resíduos gerados por todos os processos e os tratamentos adotados com maior frequência.

Na desidratação e na destilação a vácuo, são extraídos água contaminada com óleo e os hidrocarbonetos leves. Na maior parte das indústrias visitadas, a água contaminada é tratada em estações de tratamento de efluentes, ETE, onde é separada do óleo e utilizada nos processos de resfriamento dentro da própria planta. Os hidrocarbonetos leves são utilizados como combustível nas caldeiras dos rerrefinadores.

A acidificação com ácido sulfúrico, sulfonação, gera borra ácida que é neutralizada e encaminhada à incineração ou coprocessamento. O resíduo dos filtros prensa, chamados tortas de argila, são encaminhados ao coprocessamento.

A evaporação total e a desasfaltação a propano gera borra neutra que é utilizada na fabricação de manta asfáltica, pois se trata principalmente de hidrocarbonetos pesados.

\subsubsection{Controle de Qualidade}

Seis dos treze rerrefinadores visitados coletam amostras em determinados pontos do processo para avaliação de uma etapa específica. De acordo com os resultados, a etapa avaliada pode ser interrompida, passando-se à próxima, ou intensificada. A coleta mais comum se dá durante a clarificação, sendo realizados testes para verificar a filtrabilidade, cor, viscosidade cinemática e o índice de acidez do óleo básico.

O controle de qualidade do produto final é realizado por doze dos treze rerrefinadores, sendo realizados os ensaios especificados na Portaria ANP 
130/99. Onze destes também avaliam outros parâmetros não contemplados pela referida portaria, o principal desses é a densidade. O rerrefinador 13 não realizava nenhum ensaio físico-químico para controle da qualidade dos básicos que produz. A empresa 11 possui o laboratório mais completo e controle de qualidade em cada etapa do processo.

\subsubsection{Unidade Produtora de Grupo II}

O processo adotado na nova unidade da Lwart em Lençóis Paulista começa com a retirada dos leves por aquecimento a vácuo, em seguida, os aditivos presentes são precipitados por reação com hidróxido de sódio sob aquecimento. $\mathrm{O}$ óleo resultante é submetido à evaporação por película e ao hidrotratamento. Essa última etapa ocorre em quatro tanques com leito catalítico de Co-Mo sob pressão de $\mathrm{H}_{2}$ de $105 \mathrm{kgf} / \mathrm{cm}^{2}$. Nos dois primeiros é finalizada a retirada dos aditivos presentes e nos dois últimos a eliminação de enxofre e a elevação do teor de saturados. A etapa final do processo é uma destilação a vácuo para separação das diferentes frações.

Em 2014, apenas a unidade nova estava funcionando e produzindo básicos dos grupos I e II. Em 2015, Lwart passará a produzir apenas grupo II.

\subsubsection{Coleta de Amostras}

As amostras analisadas nesta pesquisa foram coletadas durante as visitas às empresas ou em ações de fiscalização efetuadas pela ANP.

O número de amostras coletado em cada empresa não está relacionado ao volume de vendas delas, mas ao número de bateladas disponível no rerrefinador no momento da visita ou fiscalização. Não se pode dizer que elas representam a situação do mercado de básicos rerrefinados no país, pois não foi realizado um estudo estatístico para determinar como deveria ser realizada a amostragem de forma a contemplar tal hipótese. Elas são, na verdade, um retrato de cada empresa no momento da visita ou ação de fiscalização. Tal fato não invalida as conclusões que se possa tirar dos resultados das análises, pois a informação extraída pode apontar problemas comuns a várias empresas e/ou que podem vir a se repetir. 
No total, foram coletadas 39 amostras, sendo 8 parafínicos spindle, 4 neutros leves, 19 neutros médios, 6 neutros pesados e 2 não classificados em nenhum desses tipos. A classificação desses básicos é realizada de acordo com 0 resultado da viscosidade cinemática a $40{ }^{\circ} \mathrm{C}$ ou a $100^{\circ} \mathrm{C}$. Assim, o rerrefinador 13 não tinha condições de classificar os óleos que produzia. A Tabela 14 apresenta a nomenclatura das amostras associadas ao código da empresa que as produziram. Aquelas coletadas pela fiscalização tiveram sua numeração modificada neste trabalho para não serem diferenciadas das demais. A numeração foi dada de acordo com a ordem de coleta.

Tabela 14. Nomenclatura das amostras coletadas por rerrefinador

\begin{tabular}{ccc}
\hline Rerrefinador & Amostras & $\mathrm{N}^{\circ}$ de Amostras \\
\hline 1 & RR1, RR2, RR29 & 3 \\
2 & RR3, RR33, RR34 & 3 \\
3 & RR4, RR5 & 2 \\
4 & RR6, RR27, RR28 & 3 \\
5 & RR7, RR8, RR35, RR36, RR38 & 5 \\
6 & RR9, RR10, RR11, RR12, RR15, RR16, RR30, RR31 & 8 \\
7 & RR13, RR14 & 2 \\
8 & RR19 & 1 \\
9 & RR18 & 1 \\
10 & RR20, RR21, RR22, RR23 & 4 \\
11 & RR24, RR25, RR26 & 3 \\
13 & $R R 32$ & 1 \\
\hline
\end{tabular}

\subsection{Determinação de Características por Métodos Consolidados}

Todas as amostras foram ensaiadas quanto à espectroscopia de reflectância no infravermelho, teor de enxofre por espectrometria de fluorescência de raios $X$ por energia dispersiva, $F R X / E D X$, e quanto aos parâmetros especificados na Portaria ANP 130/99 ${ }^{4}$, exceto teor de cinzas. Algumas foram analisadas quanto à perda por evaporação noack, pois nem todas tinham a quantidade suficiente para realização deste ensaio. Além disso, esse parâmetro não se aplica aos parafínicos spindle, que são mais voláteis. 
Os resultados dos ensaios especificados pela Portaria ANP $n^{\circ} 130 / 99^{4}$, assim como os valores limites fixados por esta portaria são mostrados nas Tabelas 15 e 16. Na avaliação dos resultados de cada ensaio, foi dada uma tolerância em relação ao especificado igual a mais ou menos o valor da reprodutibilidade da norma adotada. Os itens em vermelho foram considerados não conforme. As duas amostras não classificadas, RR37 e RR 39, foram comparadas a todos os óleos parafínicos. A viscosidade cinemática a $40{ }^{\circ} \mathrm{C}$ da amostra RR37 se encontra entre o limite superior especificado para os parafínicos neutros leves e o inferior estabelecido para os neutros médios. De forma análoga, a viscosidade cinemática a $40{ }^{\circ} \mathrm{C}$ da amostra RR39 se encontra entre o limite superior especificado para os parafínicos spindle e o inferior estabelecido para os neutros leves. Assim, essas amostras permanecem como não classificadas em nenhum dos tipos de básicos rerrefinados regulamentados pela ANP.

Tabela 15. Resultados para os ensaios aparência, cor ASTM, viscosidade cinemática a 40 e $100{ }^{\circ} \mathrm{C}$, índice de viscosidade e ponto de fulgor

\begin{tabular}{|c|c|c|c|c|c|c|}
\hline Amostra & Aparência & Cor ASTM & $\begin{array}{l}\text { Viscosidade } \\
40^{\circ} \mathrm{C} \text { (cSt) }\end{array}$ & $\begin{array}{l}\text { Viscosidade } \\
100^{\circ} \mathrm{C} \text { (cSt) }\end{array}$ & IV & $\begin{array}{l}\text { fulgor } \\
\left({ }^{\circ} \mathrm{C}\right)\end{array}$ \\
\hline \multicolumn{7}{|c|}{ Parafínico Spindle (PSP) } \\
\hline Especificação & Límpida & máx 2,0 & 8 a 18 & - & - & $\begin{array}{l}\text { mín } \\
155\end{array}$ \\
\hline Limite & - & 3,0 & 7,948 a 18,12 & - & - & 137 \\
\hline RR1 & límpida & 2,5 & 12,59 & 3,081 & 102 & 165 \\
\hline RR5 & límpida & 2,5 & 16,26 & 3,574 & 99 & 171 \\
\hline RR8 & $\begin{array}{l}\text { límpida/cheiro } \\
\text { de queimado }\end{array}$ & 3,0 & 12,43 & 2,954 & 82 & 157,9 \\
\hline RR12 & límpida & 1,5 & 12,8 & 3,062 & 93 & 162,8 \\
\hline RR15 & límpida & 2,0 & 15,48 & 3,512 & 104 & 162,7 \\
\hline RR26 & límpida & $\mathrm{L} 2,5$ & 18,77 & 3,905 & 100 & 179,9 \\
\hline RR30 & límpida & 3,0 & 37,88 & 6,094 & 106 & 220,6 \\
\hline RR35 & $\begin{array}{l}\text { límpida/cheiro } \\
\text { de queimado }\end{array}$ & 2,0 & 12,75 & 2,555 & -35 & 149,9 \\
\hline \multicolumn{7}{|c|}{ Parafínico Neutro Leve (PNL) } \\
\hline Especificação & Límpida & 3,0 & 26 a 32 & - & 95 & 200 \\
\hline Limite & - & 4,0 & 25,83 a 32,21 & - & 90 & 182 \\
\hline RR20 & límpida & 2,5 & 35,66 & 5,911 & 108 & 195,8 \\
\hline RR22 & límpida & 1,0 & 34,59 & 6,095 & 123 & 189,7 \\
\hline RR23 & límpida & 3,0 & 35,8 & 5,925 & 108 & 200,8 \\
\hline RR34 & límpida & 3,5 & 57,64 & 8,623 & 124 & 215,4 \\
\hline
\end{tabular}


Tabela 15 (continuação). Resultados para os ensaios aparência, cor ASTM, viscosidade cinemática a 40 e $100{ }^{\circ} \mathrm{C}$, índice de viscosidade e ponto de fulgor.

\begin{tabular}{|c|c|c|c|c|c|c|}
\hline Amostra & Aparência & Cor ASTM & $\begin{array}{l}\text { Viscosidade } \\
40^{\circ} \mathrm{C} \text { (cSt) }\end{array}$ & $\begin{array}{l}\text { Viscosidade } \\
100^{\circ} \mathrm{C} \text { (cSt) }\end{array}$ & IV & $\begin{array}{l}\text { fulgor } \\
\left({ }^{\circ} \mathrm{C}\right)\end{array}$ \\
\hline \multicolumn{7}{|c|}{ Parafínico Neutro Médio (PNM) } \\
\hline Especificação & Límpida & máx 4,0 & 50 a 70 & - & mín 95 & $\begin{array}{l}\text { mín } \\
215\end{array}$ \\
\hline Limite & diferente & 5,0 & 49,68 a 70,46 & - & 90 & 187 \\
\hline RR3 & $\begin{array}{c}\text { límpida/odor } \\
\text { forte }\end{array}$ & $\mathrm{R} 7,5$ & 66,76 & 9,758 & 128 & 221 \\
\hline RR4 & límpida & $\mathrm{R} 4$ & 53,61 & 7,548 & 103 & 245 \\
\hline RR6 & límpida & 4,5 & 67,67 & 9,735 & 125 & 228,8 \\
\hline RR7 & límpida & 4,5 & 105 & 14,56 & 143 & 172,8 \\
\hline RR9 & límpida & R3 & 63,97 & 9,046 & 90 & 230,9 \\
\hline RR10 & $\begin{array}{c}\text { límpida/odor } \\
\text { forte }\end{array}$ & 3,0 & 56,22 & 8,06 & 111 & 228,9 \\
\hline RR13 & $\begin{array}{c}\text { límpida/odor } \\
\text { forte }\end{array}$ & 4,5 & 59,42 & 8,59 & 118 & 234,8 \\
\hline RR14 & límpida & 4,5 & 47,37 & 7,073 & 107 & 234,8 \\
\hline RR16 & límpida & 2,5 & 70,27 & 9,064 & 104 & 246,7 \\
\hline RR17 & límpida & 1,5 & 41,28 & 6,571 & 111 & 185,9 \\
\hline RR18 & $\begin{array}{l}\text { límpida/odor } \\
\text { forte }\end{array}$ & 4,5 & 58,22 & 8,735 & 125 & 208,8 \\
\hline RR19 & $\begin{array}{c}\text { límpida/odor } \\
\text { forte }\end{array}$ & 4,0 & 62,39 & 9,103 & 93 & 213,9 \\
\hline RR21 & límpida & 3,0 & 57,08 & 8,93 & 134 & 195,3 \\
\hline RR24 & límpida & 3,5 & 65 & 9,32 & 121 & 225,8 \\
\hline RR28 & límpida & 3,5 & 60,29 & 9,028 & 127 & 212,8 \\
\hline RR31 & límpida & $3,0 \mathrm{~L}$ & 38,12 & 6,093 & 104 & 224,7 \\
\hline RR32 & límpida & 2,0 & 52,12 & 8,184 & 128 & 223,8 \\
\hline RR33 & límpida & 3,5 & 65,35 & 9,317 & 121 & 228,8 \\
\hline RR38 & límpida & 4,0 & 70,48 & 9,607 & 116 & 171,8 \\
\hline \multicolumn{7}{|c|}{ Parafínico Neutro Pesado (PNP) } \\
\hline Especificação & Límpida & 4,5 & - & 9,6 a 12,9 & 95 & 226 \\
\hline Limite & - & 5,5 & - & $\begin{array}{c}9,538 \mathrm{a} \\
12,98 \\
\end{array}$ & 90 & 208 \\
\hline RR2 & Límpida & 4,5 & 87,73 & 11,37 & 118 & 241 \\
\hline RR11 & $\begin{array}{c}\text { límpida/odor } \\
\text { forte }\end{array}$ & 3,0 & 70,79 & 10,08 & 126 & 228,8 \\
\hline RR25 & Límpida & 4,0 & 71,02 & 9,832 & 118 & 231,9 \\
\hline RR27 & Límpida & 3,5 & 73,04 & 10,51 & 122 & 214,6 \\
\hline RR29 & Límpida & 3,0 & 83,06 & 11,11 & 121 & 224,9 \\
\hline RR36 & Límpida & 4,0 & 92,34 & 11,86 & 119 & 216,9 \\
\hline
\end{tabular}


Tabela 15 (continuação). Resultados para os ensaios aparência, cor ASTM, viscosidade cinemática a 40 e $100{ }^{\circ} \mathrm{C}$, índice de viscosidade e ponto de fulgor.

\begin{tabular}{|c|c|c|c|c|c|c|}
\hline Amostra & Aparência & Cor ASTM & $\begin{array}{c}\text { Viscosidade } \\
40^{\circ} \mathrm{C}(\mathrm{cSt})\end{array}$ & $\begin{array}{c}\text { Viscosidade } \\
100{ }^{\circ} \mathrm{C}(\mathrm{cSt})\end{array}$ & IV & $\begin{array}{c}\text { fulgor } \\
\left({ }^{\circ} \mathrm{C}\right)\end{array}$ \\
\hline \multicolumn{7}{|c|}{ Não classificadas } \\
\hline Especificação & Límpida & - & - & - & - & - \\
\hline Limite & - & - & - & - & - & - \\
\hline RR37 & $\begin{array}{c}\text { turva (emulsão) } \\
\text { com material } \\
\text { em suspensão }\end{array}$ & $2,5 \mathrm{R}$ & 40,8 & 6,226 & 98 & 205,8 \\
\hline RR39 & límpida/amarela & 1,5 & 23,17 & 4,412 & 98 & 164 \\
\hline
\end{tabular}

Tabela 16. Resultados dos ensaios ponto de fluidez, índice de acidez total, resíduo de carbono ramsbottom, corrosividade ao cobre.

\begin{tabular}{|c|c|c|c|c|}
\hline Amostra & Fluidez $\left({ }^{\circ} \mathrm{C}\right)$ & IAT (mgKOH/g) & $\begin{array}{c}\text { Ramsbottom } \\
(\%)\end{array}$ & Corrosividade \\
\hline \multicolumn{5}{|c|}{ Parafínico Spindle (PSP) } \\
\hline Especificação & máx-3 & máx 0,05 & máx 0,2 & máx 1 \\
\hline Limite & 3 & 0,1 & 0,27 & - \\
\hline RR1 & -6 & 0,06 & 0,062 & $1 \mathrm{a}$ \\
\hline RR5 & -9 & 0,03 & 0,0555 & $1 a$ \\
\hline RR8 & $<-24$ & 0,07 & 0,0794 & $1 b$ \\
\hline RR12 & -12 & 0,065 & 0,0127 & $1 b$ \\
\hline RR15 & -9 & 0,02 & 0,054 & $1 a$ \\
\hline RR26 & -9 & 0,05 & 0,0439 & $1 a$ \\
\hline RR30 & -3 & 0,03 & 0,0447 & $1 \mathrm{a}$ \\
\hline RR35 & $<-18$ & 0,01 & 0,055 & $1 a$ \\
\hline \multicolumn{5}{|c|}{ Parafínico Neutro Leve (PNL) } \\
\hline Especificação & -3 & 0,05 & 0,3 & 1 \\
\hline Limite & 3 & 0,1 & 0,37 & - \\
\hline RR20 & -3 & 0,07 & 0,0732 & $1 a$ \\
\hline RR22 & -6 & 0,08 & 0,0783 & $1 a$ \\
\hline RR23 & -3 & 0,07 & 0,0789 & $1 a$ \\
\hline RR34 & -9 & 0,03 & 0,1074 & $1 a$ \\
\hline \multicolumn{5}{|c|}{ Parafínico Neutro Médio (PNM) } \\
\hline Especificação & -3 & 0,05 & 0,3 & 1 \\
\hline Limite & 3 & 0,1 & 0,37 & - \\
\hline RR3 & -6 & 0,055 & 0,1698 & $1 a$ \\
\hline RR4 & -3 & 0,05 & 0,0656 & $1 a$ \\
\hline RR6 & -12 & 0,03 & 0,1242 & $1 a$ \\
\hline RR7 & $<-25$ & 0,4 & 0,3382 & $3 a$ \\
\hline
\end{tabular}


Tabela 16 (continuação) Resultados dos ensaios ponto de fluidez, índice de acidez total, resíduo de carbono ramsbottom, corrosividade ao cobre.

\begin{tabular}{|c|c|c|c|c|}
\hline Amostra & Fluidez $\left({ }^{\circ} \mathrm{C}\right)$ & IAT (mgKOH/g) & $\begin{array}{c}\text { Ramsbottom } \\
\text { (\%) }\end{array}$ & Corrosividade \\
\hline \multicolumn{5}{|c|}{ Parafínico Neutro Médio (PNM) } \\
\hline Especificação & -3 & 0,05 & 0,3 & 1 \\
\hline Limite & 3 & 0,1 & 0,37 & - \\
\hline RR9 & -6 & 0,13 & 0,1222 & $1 \mathrm{a}$ \\
\hline RR10 & -6 & 0,09 & 0,1125 & $1 a$ \\
\hline RR13 & -6 & 0,06 & 0,08 & $1 a$ \\
\hline RR14 & -6 & 0,05 & 0,098 & $1 \mathrm{a}$ \\
\hline RR16 & -3 & 0,03 & 0,0811 & $1 a$ \\
\hline \multicolumn{5}{|c|}{ Parafínico Neutro Médio (PNM) } \\
\hline Especificação & máx -3 & máx 0,05 & máx 0,3 & máx 1 \\
\hline Limite & 3 & 0,1 & 0,37 & - \\
\hline RR17 & -9 & 0,03 & 0,0834 & $1 a$ \\
\hline RR18 & -6 & 0,1 & 0,1391 & $1 a$ \\
\hline RR19 & -9 & 0,21 & 0,1471 & $1 a$ \\
\hline RR21 & -9 & 0,05 & 0,0735 & $1 \mathrm{a}$ \\
\hline RR24 & -12 & 0,10 & 0,1354 & $1 \mathrm{~b}$ \\
\hline RR28 & -9 & 0,10 & 0,1249 & $1 a$ \\
\hline RR31 & -3 & 0,03 & 0,05071 & $1 a$ \\
\hline RR32 & -6 & 0,04 & 0,09959 & $1 a$ \\
\hline RR33 & -12 & 0,06 & 0,1228 & $1 a$ \\
\hline RR38 & $<-18$ & 2,71 & 0,2108 & $3 a$ \\
\hline \multicolumn{5}{|c|}{ Parafínico Neutro Pesado (PNP) } \\
\hline Especificação & máx -3 & máx 0,05 & máx 0,3 & máx 1 \\
\hline Limite & 3 & 0,1 & 0,37 & - \\
\hline RR2 & -9 & 0,08 & 0,142 & $1 \mathrm{a}$ \\
\hline RR11 & -6 & 0,08 & 0,0417 & $1 a$ \\
\hline RR25 & -12 & 0,06 & 0,1492 & $1 a$ \\
\hline RR27 & -15 & 0 & 0,1272 & $1 a$ \\
\hline RR29 & -9 & 0,06 & 0,1444 & $1 a$ \\
\hline RR36 & $<-18$ & 1,2 & 0,7869 & $1 a$ \\
\hline \multicolumn{5}{|c|}{ Não classificadas } \\
\hline Especificação & máx -3 & máx 0,05 & máx 0,3 & Máx 1 \\
\hline Limite & 3 & 0,1 & 0,37 & - \\
\hline RR37 & $<-18$ & 0,1 & 0,0762 & $1 a$ \\
\hline RR39 & $<-18$ & 0,09 & 0,0671 & $1 \mathrm{~A}$ \\
\hline
\end{tabular}


Pela avaliação das Tabelas 15 e 16, observa-se que 17 das 39 amostras coletadas apresentam algum tipo de não conformidade relacionada aos parâmetros especificados pela Portaria ANP n 130/99, representando 43,6\% do total. $O$ gráfico da Figura 27 mostra a distribuição das não conformidades por parâmetros analisados.

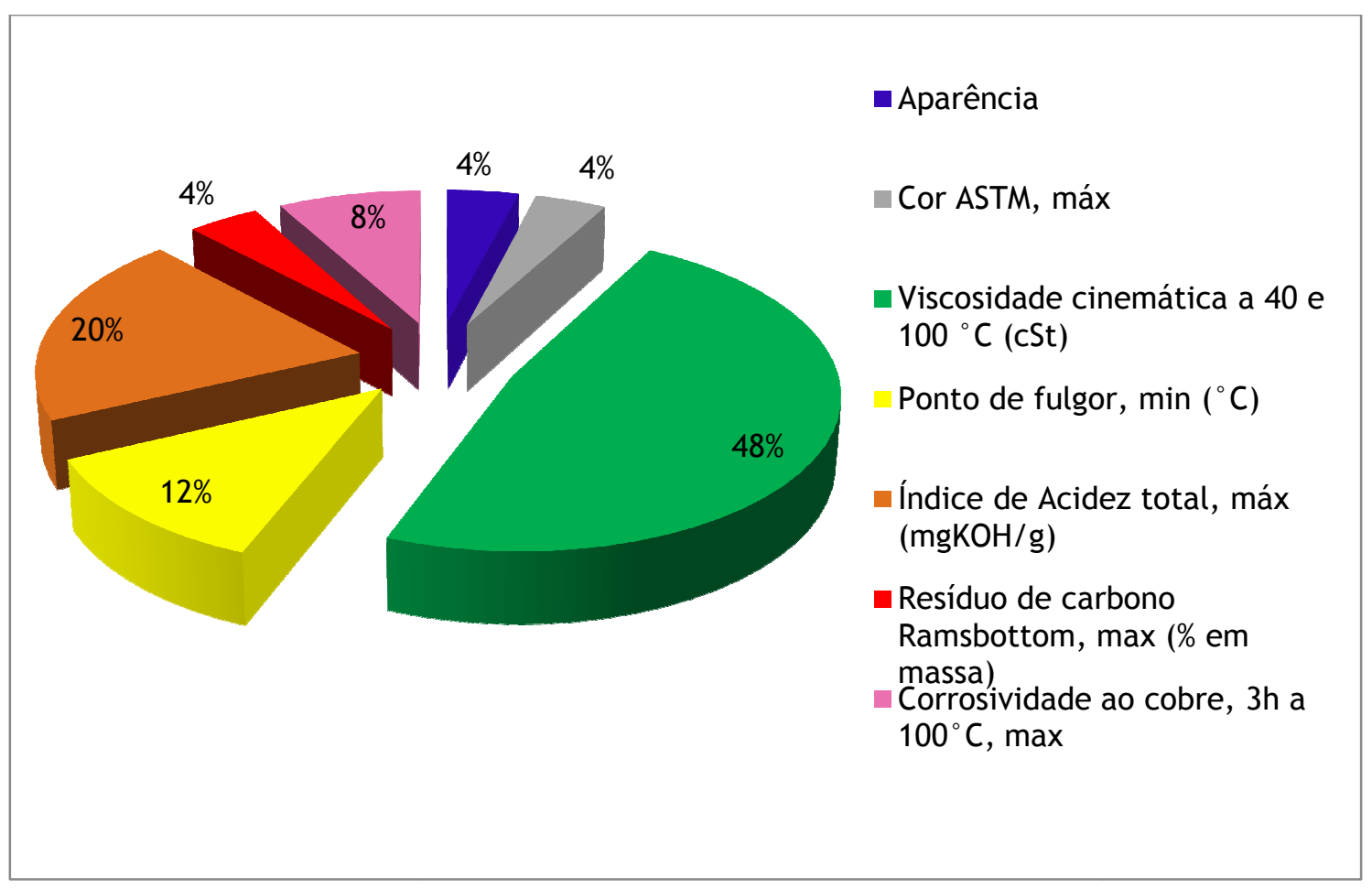

Figura 27. Distribuição das não conformidades por parâmetros da Portaria ANP n 130/99.

Problemas relacionados à viscosidade representam $48 \%$ das não conformidades constatadas, correspondendo a 12 amostras das 39 analisadas, incluindo as duas não classificadas em nenhum tipo. Essas amostras foram fabricadas por diferentes processos, não sendo possível associar o fato a nenhum deles em específico. O óleo RR34, levando-se em conta o resultado da viscosidade, deveria ser classificado como parafínico neutro médio e estaria conforme também com relação aos demais parâmetros. As demais amostras não conformes, não poderiam ser enquadradas em nenhum dos tipos de básico rerrefinado estabelecidos pela Portaria ANP n॰130/99, mostrando que os rerrefinadores possuem dificuldades no controle de qualidade de seus processos ou que negligenciam os resultados obtidos em seus ensaios. Para o consumidor do óleo básico, ou seja, para o produtor de óleo lubrificante acabado, a classificação dada pela Portaria ANP n 130/99 não é fundamental, 
mas sim o conhecimento do valor da viscosidade cinemática do básico que adquiriu. Logo, o problema real é o consumidor comprar um básico acreditando que este está de acordo com o estabelecido pela ANP e, por isso, crer conhecer a sua faixa de viscosidade, enquanto, na verdade, o valor de viscosidade cinemática do produto é completamente diferente. Isso pode gerar transtornos na fabricação de óleo lubrificante acabado, bem como gastos desnecessários com aditivos melhoradores do índice de viscosidade ou com outros básicos para ajustar o processo. Por esta razão, não conformidades relacionadas ao valor de viscosidade cinemática devem ser consideradas não conformidades de qualidade, pois o consumidor é diretamente lesado. No entanto, uma alteração na especificação dos básicos rerrefinados poderia auxiliar a ambos, rerrefinador e produtor de óleo acabado. Possíveis soluções são a criação de faixas intermediárias de viscosidade e a possibilidade de se comercializar produtos que não se enquadrem em nenhuma das faixas da legislação desde que o cliente estivesse ciente do valor da viscosidade cinemática do produto e de acordo com a compra mesmo nesta situação. Esse tipo de acordo é permitido pela Portaria ANP 129/99 no caso da comercialização de óleos básicos de primeiro refino. Se a legislação atual permitisse tal acordo, o número de amostras não conforme cairia para 9 , o que representaria $23,1 \%$ das amostras analisadas.

O segundo parâmetro com maior número de não conformidades é o índice de acidez total, com 5 amostras não conforme. Esse parâmetro reflete a presença de compostos ácidos que tanto podem ser oriundos do OLUC quanto do processo ácido-argila. No primeiro caso, esses ácidos estão presentes no OLUC em decorrência das reações de oxidação sofridas pelo óleo lubrificante durante o uso. No segundo, a acidez seria fruto da baixa eficiência na etapa de neutralização. Portanto, um índice de acidez total, IAT, acima do especificado significa que há ineficiência do processo de rerrefino adotado. Pela visualização da Tabela 14, constata-se que 3 das 5 amostras foram fabricadas pelo rerrefinador número 5 , cujo processo consiste em uma simples destilação a vácuo. Outra observação importante, é que 2 dessas amostras, a RR7 e a RR38, também apresentaram corrosão ao cobre superior ao especificado e ponto de fulgor inferior. O primeiro parâmetro, assim como o IAT, é reflexo da 
presença de compostos ácidos que podem ser os originados na degradação do óleo lubrificante. $O$ baixo ponto de fulgor indica a presença de compostos voláteis, como combustíveis e solventes. O resultado do ensaio de resíduo de carbono ramsbottom da amostra RR36 corrobora a hipótese de que o processo da empresa 5 não é eficiente. Nesse ensaio, é medido o resíduo formado durante a evaporação e degradação térmica de um produto de petróleo e valores altos podem significar a presença de compostos de difícil degradação, como, por exemplo, polímeros como os utilizados em aditivos melhoradores de índice de viscosidade ou borra presente óleo de motor usado. Assim, é mais provável que, no caso das amostras RR7, RR36 e RR38, a não conformidade observada no IAT seja consequência de um processo de rerrefino inadequado. Por outro lado, no caso das amostras RR9 e RR19, obtidas pelos processos de destilação a vácuo/desasfaltação/ácido-argila e termocraqueamento/ácidoargila, é possível que o problema seja na etapa onde ocorre a neutralização do óleo básico obtido, pois nenhuma outra não conformidade foi verificada para estas amostras ou para outras obtidas por seus produtores quando se desconsidera a viscosidade cinemática. No caso do rerrefinador 6 , onde foi coletada a amostra 9, outros 7 óleos rerrefinados foram analisados e não apresentaram não conformidades, o que implica que o problema pode ter sido pontual e não um erro sistemático do processo.

O resultado da cor ASTM obtido para a amostra RR3, produzida pelo rerrefinador 2, foi muito superior ao especificado. Esse fato é um indício da presença de compostos oriundos da degradação do óleo lubrificante, mas os outros testes não confirmaram essa hipótese.

A amostra RR37, rerrefinada pela empresa 13, apresentou turbidez e material em suspensão, fato inaceitável para um óleo básico. O espectro de infravermelho, como será discutido adiante, confirma a presença de água.

Os resultados dos ensaios de espectroscopia de infravermelho, teor de enxofre e perda por evaporação noack são apresentados na Tabela 17. Os teores de enxofre são superiores a $0,03 \%$, confirmando que todos os óleos são do grupo I. A perda por evaporação noack é especificada pela Portaria ANP n ${ }^{129} / 99$ apenas para o óleo básico parafínico neutro leve de primeiro refino. Dessa 
forma, os valores obtidos para as amostras de óleo rerrefinado foram avaliados de acordo com o especificado para o neutro leve, pois, a tendência das frações mais pesadas, ou seja, dos óleos neutro médio e neutro pesado, é sofrer uma perda menor que o neutro leve. Assim, o valor utilizado com referência limite é o menos restritivo possível. Através da leitura da Tabela 17, constata-se que as amostras RR7, RR38, RR37 e RR39 sofreram uma perda por evaporação muito superior à esperada para óleos parafínicos neutros leves. Esse fato indica presença de materiais voláteis não esperados para parafínicos neutros médios, como é o caso das amostras RR7 e RR38, endossando as conclusões tomadas a partir dos seus resultados de ponto de fulgor. As amostras RR37 e RR39 não foram classificadas como nenhum dos tipos de básico especificados, mas, como é possível observar na Tabela 15, os valores de viscosidade cinemática são superiores ao especificado para o parafínico spindle, ou seja, a perda por evaporação esperada também é inferior a 16\%.

Tabela 17. Resultados para os ensaios espectroscopia no infravermelho, teor de enxofre e perda por evaporação noack.

\begin{tabular}{|c|c|c|c|}
\hline \multirow{4}{*}{ Amostra } & Noack (\%) & Enxofre (\%) & Infravermelho \\
\hline \multicolumn{4}{|c|}{ Parafínico Spindle (PSP) } \\
\hline Recomendável & Não aplicável & Não aplicável & Ausência de contaminantes \\
\hline Limite & - & - & - \\
\hline RR1 & - & 0,2254 & PSP \\
\hline RR5 & - & 0,3321 & PSP \\
\hline RR8 & - & 0,1963 & naftênico \\
\hline RR12 & - & 0,1965 & PSP \\
\hline RR15 & - & 0,3079 & PSP \\
\hline RR26 & - & 0,2316 & PSP \\
\hline RR30 & - & 0,3284 & PSP \\
\hline RR35 & - & 0,1346 & naftênico \\
\hline \multicolumn{5}{|c|}{ Parafínico Neutro Leve (PNL) } \\
\hline Recomendável & Máx 16\% & Não aplicável & Ausência de contaminantes \\
\hline Limite & - & - & PNL \\
\hline RR20 & 15,7 & 0,3608 & PNL \\
\hline RR22 & 16 & 0,2755 & PNL \\
\hline RR23 & 15,6 & 0,3854 & PNL \\
\hline RR34 & 13,9 & 0,3469 & \\
\hline
\end{tabular}


Tabela 17 (continuação). Resultados para os ensaios espectroscopia no infravermelho, teor de enxofre e perda por evaporação noack.

\begin{tabular}{|c|c|c|c|}
\hline Amostra & Noack (\%) & Enxofre (\%) & Infravermelho \\
\hline \multicolumn{4}{|c|}{ Parafínico Neutro Médio (PNM) } \\
\hline Recomendável & Máx 16\% & $\begin{array}{c}\text { Não } \\
\text { aplicável }\end{array}$ & Ausência de contaminantes \\
\hline Limite & - & - & - \\
\hline RR3 & - & 0,3694 & PNM \\
\hline RR4 & - & 0,4838 & PNM \\
\hline RR6 & - & 0,3246 & PNM \\
\hline RR7 & 29,6 & 0,8437 & éster (óleo vegetal) e naftênico \\
\hline RR9 & - & 0,454 & PNM \\
\hline RR10 & 12,6 & 0,4537 & PNM \\
\hline RR13 & - & 0,3779 & PNM \\
\hline RR14 & - & 0,3795 & PNM \\
\hline \multicolumn{4}{|c|}{ Parafínico Neutro Médio (PNM) } \\
\hline Recomendável & Máx 16\% & $\begin{array}{c}\text { Não } \\
\text { aplicável }\end{array}$ & Ausência de contaminantes \\
\hline Limite & - & - & - \\
\hline RR16 & 6 & 0,5104 & PNM \\
\hline RR17 & 13,7 & 0,6525 & $\begin{array}{c}\text { éster (óleo vegetal) e } \\
\text { contaminante desconhecido }\end{array}$ \\
\hline RR18 & - & 0,0379 & PNM \\
\hline RR19 & 14,7 & 0,3746 & PNM \\
\hline RR21 & - & 0,3979 & éster (óleo vegetal) \\
\hline RR24 & - & 0,3379 & PNM \\
\hline RR28 & - & 0,318 & PNM \\
\hline RR31 & 10,2 & 0,3246 & PNM \\
\hline RR32 & 13,4 & 0,2781 & PNM \\
\hline RR33 & 11,6 & 0,3497 & PNM \\
\hline RR38 & 24,9 & 0,8923 & $\begin{array}{c}\text { éster (óleo vegetal) e } \\
\text { contaminante não identificado }\end{array}$ \\
\hline \multicolumn{4}{|c|}{ Parafínico Neutro Pesado (PNP) } \\
\hline Recomendável & Máx 16\% & $\begin{array}{c}\text { Não } \\
\text { aplicável }\end{array}$ & Ausência de contaminantes \\
\hline Limite & - & - & - \\
\hline RR2 & - & 0,382 & PNP \\
\hline RR11 & - & 0,4309 & PNP \\
\hline RR25 & - & 0,3474 & PNP \\
\hline RR27 & - & 0,3006 & PNP \\
\hline
\end{tabular}


Tabela 17 (continuação). Resultados para os ensaios espectroscopia no infravermelho, teor de enxofre e perda por evaporação noack.

\begin{tabular}{|c|c|c|c|}
\hline Amostra & Noack (\%) & Enxofre (\%) & Infravermelho \\
\hline \multicolumn{4}{|c|}{ Parafínico Neutro Pesado (PNP) } \\
\hline Recomendável & Máx 16\% & $\begin{array}{c}\text { Não } \\
\text { aplicável }\end{array}$ & Ausência de contaminantes \\
\hline Limite & - & - & - \\
\hline RR29 & 10,1 & 0,3487 & PNP \\
\hline RR36 & - & 0,3909 & PPD \\
\hline \multicolumn{4}{|c|}{ Não classificadas } \\
\hline Recomendável & Máx 16\% & $\begin{array}{c}\text { Não } \\
\text { aplicável }\end{array}$ & Ausência de contaminantes \\
\hline Limite & - & - & água \\
\hline RR37 & 19,7 & 0,02804 & naftênico \\
\hline RR39 & 35,8 & 0,3032 &
\end{tabular}

Os espectros de infravermelho das amostras foram comparados aos de óleos básicos minerais de primeiro refino correspondente, ou seja, óleos básicos parafínicos spindle rerrefinados foram comparados com óleo básico parafínico splindle de primeiro refino e assim por diante. As duas amostras não classificadas, RR37 e RR 39, foram comparadas a todos os óleos parafínicos. Dessa forma, foram consideradas não conformes aquelas amostras cujo espectro apresentavam bandas não presentes nos espectros dos óleos básicos minerais usados como referência. Quando possível, estas bandas foram identificadas e o contaminante encontrado é citado na Tabela 17 em vermelho. Todos os espectros obtidos são apresentados no Anexo 1 e partes de alguns desses serão discutidos a seguir.

Dentre as amostras de parafínicos spindle, observa-se, por avaliação das Figuras 28 e 29, que a RR8 e a RR35 apresentaram presença de óleos naftênicos. A principal diferença verificada entre espectros de óleos parafínicos e os de óleos naftênicos é a intensidade e o formato da banda em $720 \mathrm{~cm}^{-1}$, a qual se deve à vibração de deformação angular assimétrica no plano dos grupos metileno $\left(\rho \mathrm{CH}_{2}\right)$. Ela se destaca de forma acentuada em espectros de alcanos de cadeia linear, perdendo a intensidade quando se trata de cicloalcanos. Nas Figuras 28 e 29, é possível observar que as intensidades da banda em $720 \mathrm{~cm}^{-1}$ nos espectros das amostras se encontram entre aquelas 
verificadas para os óleos parafínico e naftênico utilizados como referência. Os óleos naftênicos são básicos que possuem aplicações diferentes dos óleos parafínicos, sendo muito úteis na produção de óleos de transformador e em alguns tipos de óleo industrial e de graxas. No entanto, são prejudiciais quando utilizados para produção de óleos lubrificantes para motor, pois oxidam mais facilmente, levando à formação de borra. O problema resultante da presença de naftênicos nos óleos rerrefinados analisados é a possibilidade do óleo ser utilizado como se fosse um parafínico spindle puro, quando, na verdade, é uma mistura deste óleo com um naftênico. Outro ponto a ser destacado é que essas amostras foram coletadas no rerrefinador número 5 , que recebe apenas óleo de transformador, formulados principalmente com básicos naftênicos. 0 processo adotado pelo citado rerrefinador consiste numa simples destilação a vácuo e percolação em argila, não sendo eficiente na quebra dos cicloalcanos e, por isso, os óleos básicos permanecem contendo em sua composição uma maior parcela desses hidrocarbonetos.

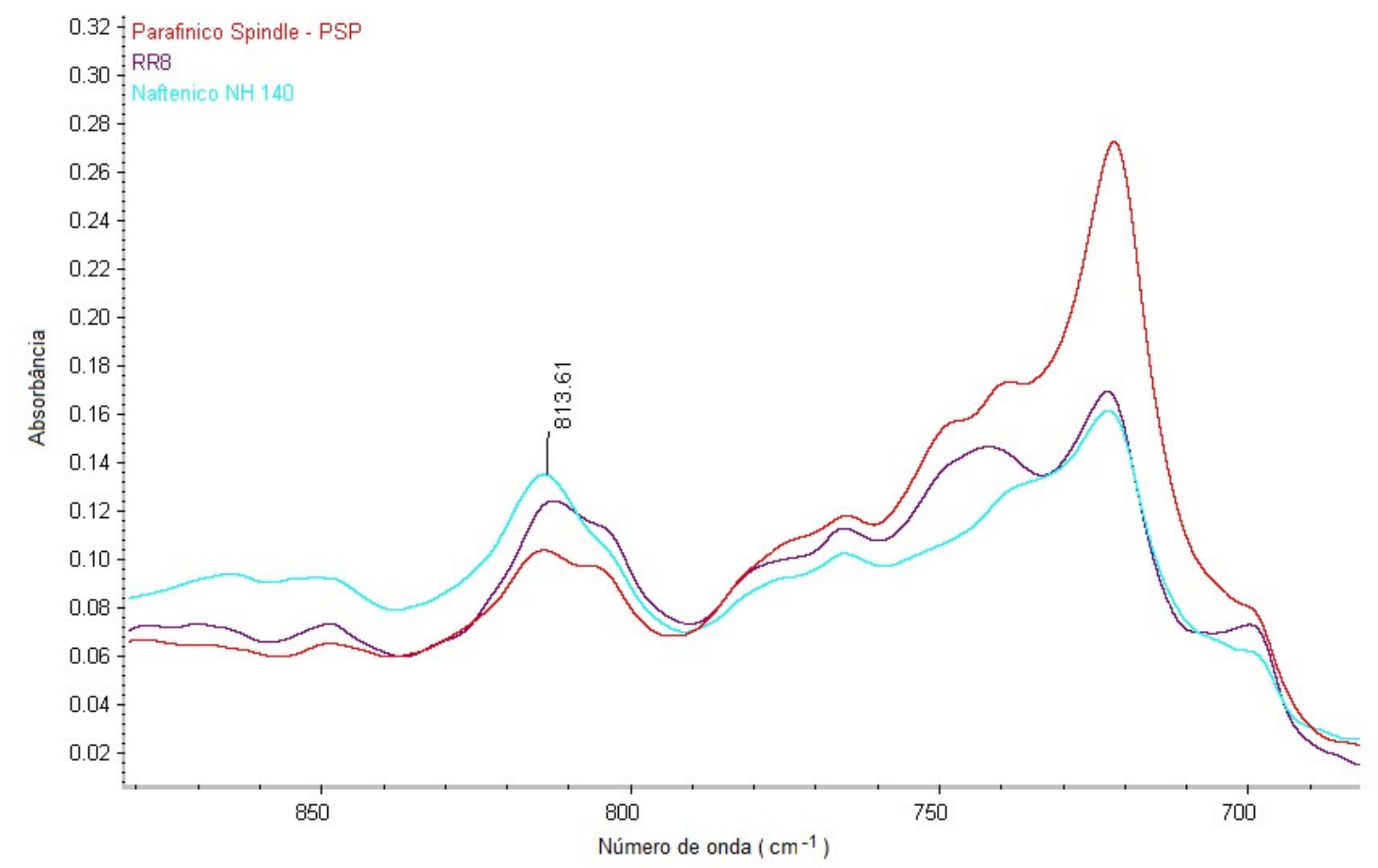

Figura 28. Espectro da amostra RR8 em comparação com espectros de parafínico spindle e naftênico $\mathrm{NH} 140$, ambos de primeiro refino. 


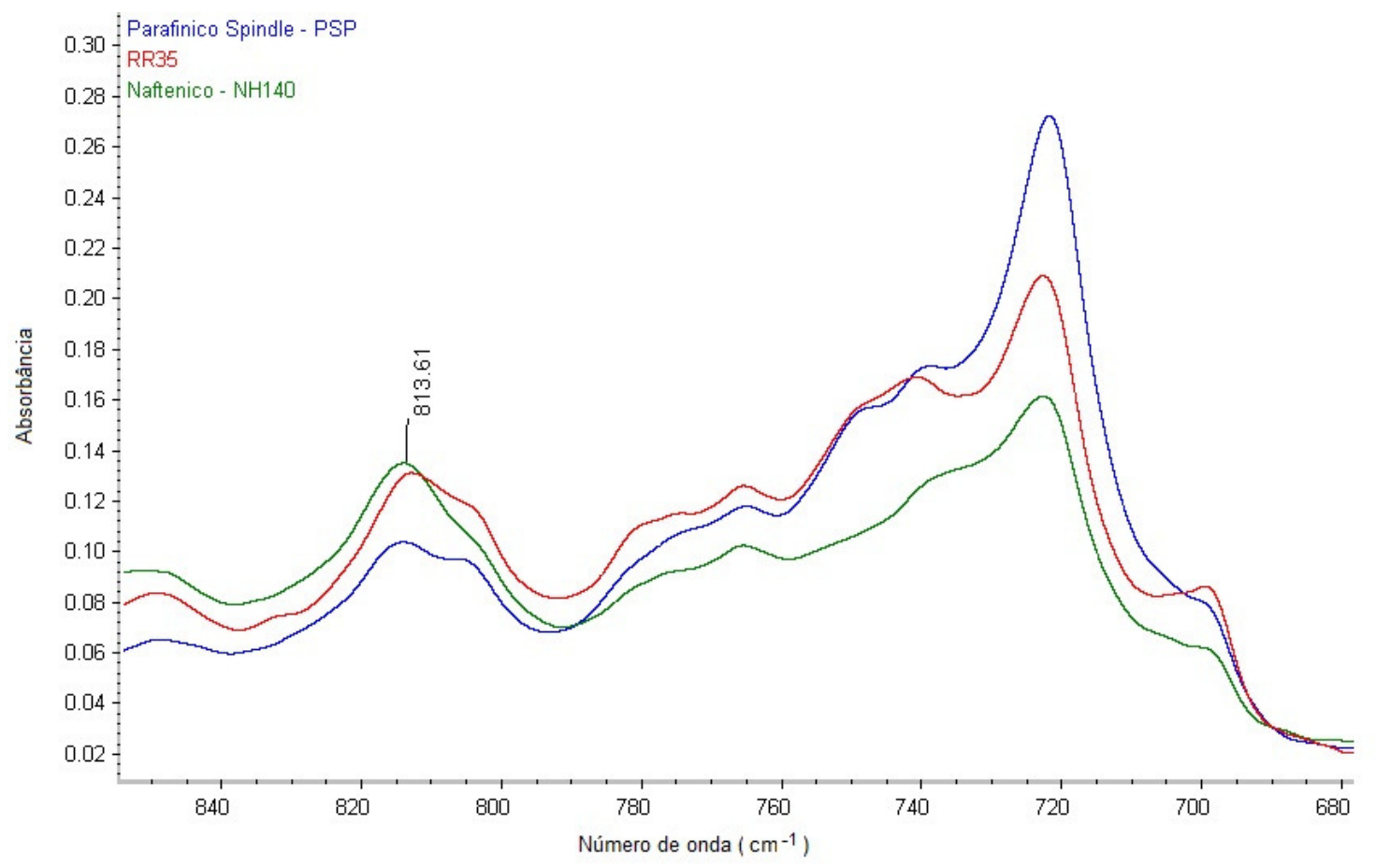

Figura 29. Espectro da amostra RR35 em comparação com espectros de parafínico spindle e naftênico NH140, ambos de primeiro refino.

As análises de infravermelho das amostras dos parafínicos neutros leves não mostraram indícios de contaminação.

Dentre as amostras de parafínico neutro médio, os espectros das amostras RR7, RR17 e RR21, mostrados nas Figuras 30 a 32, apresentam bandas pouco intensas entre 1740 e $1750 \mathrm{~cm}^{-1}$, as quais foram atribuídas à deformação axial de carbonila de ésteres. Esse fato indica possível presença, em baixos teores, de óleos vegetais, aditivos abaixadores do ponto de fluidez, PPDs, ou óleos sintéticos. A presença de ésteres no óleo rerrefinado é um indício de que o processo não está adequado, pois tais substâncias tendem a serem removidas da mesma forma que os compostos de oxidação gerados no uso do lubrificante. A capacidade de oxidação dos ésteres graxos é mais acentuada que a dos óleos básicos minerais puros, assim, um básico contaminado com óleo vegetal tende a ser mais suscetível a oxidar, se tornando inviável para algumas aplicações. Os abaixadores do ponto de fluidez são utilizados em pequena quantidade, em torno de $0,1 \%$ em peso, na formulação de óleos lubrificantes acabados. A sua presença no óleo básico altera não só o ponto de fluidez, mas pode alterar outras características físicoquímicas, gerando problemas ao produtor de lubrificantes. No caso da amostra 
RR7, a suspeita sobre a presença desse aditivo é intensificada pelo baixo ponto de fluidez verificado.

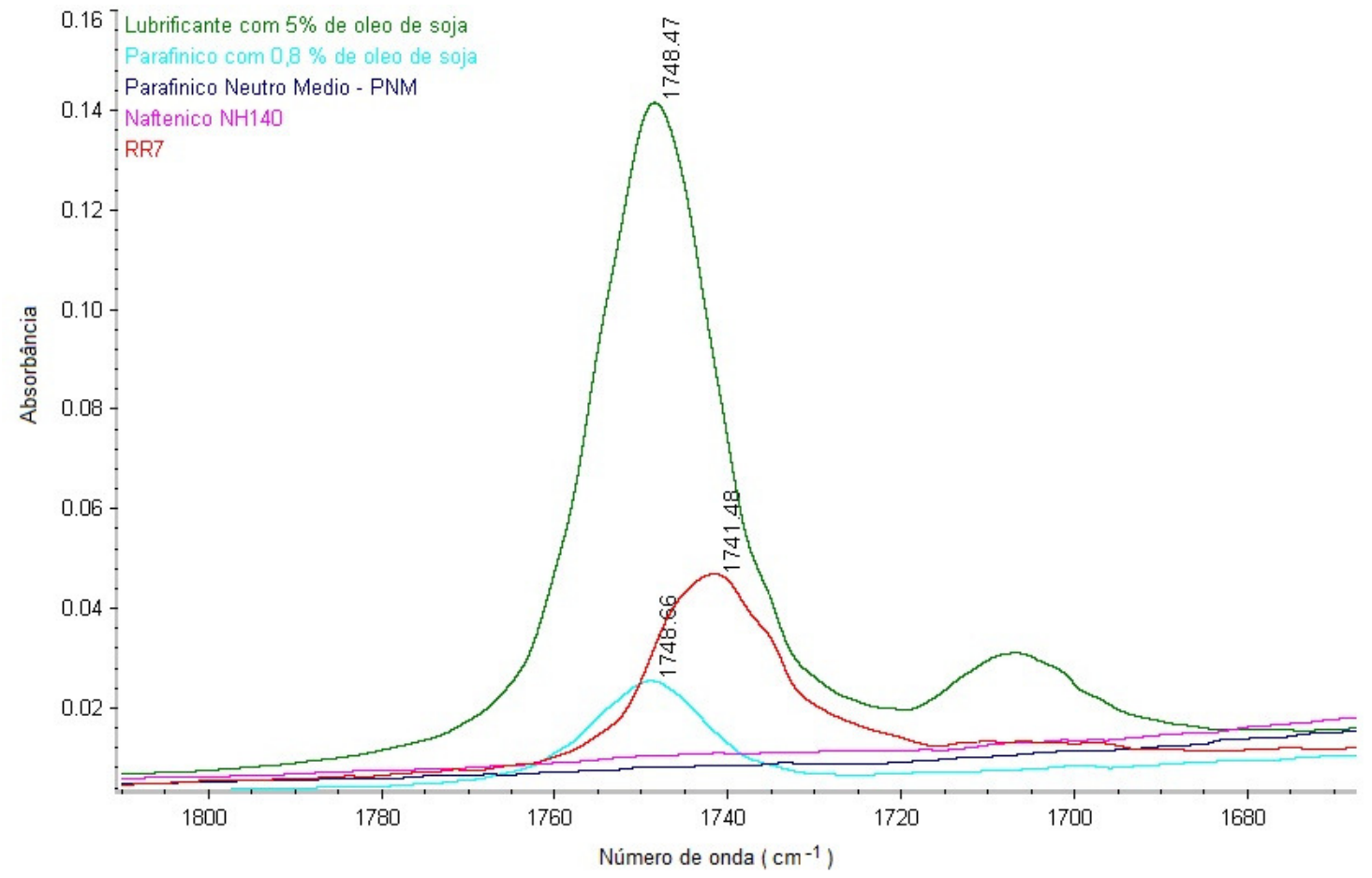

Figura 30. Espectro da amostra RR7 em comparação com espectros de parafínico neutro médio, naftênico NH140 e de básicos contendo óleo vegetal.

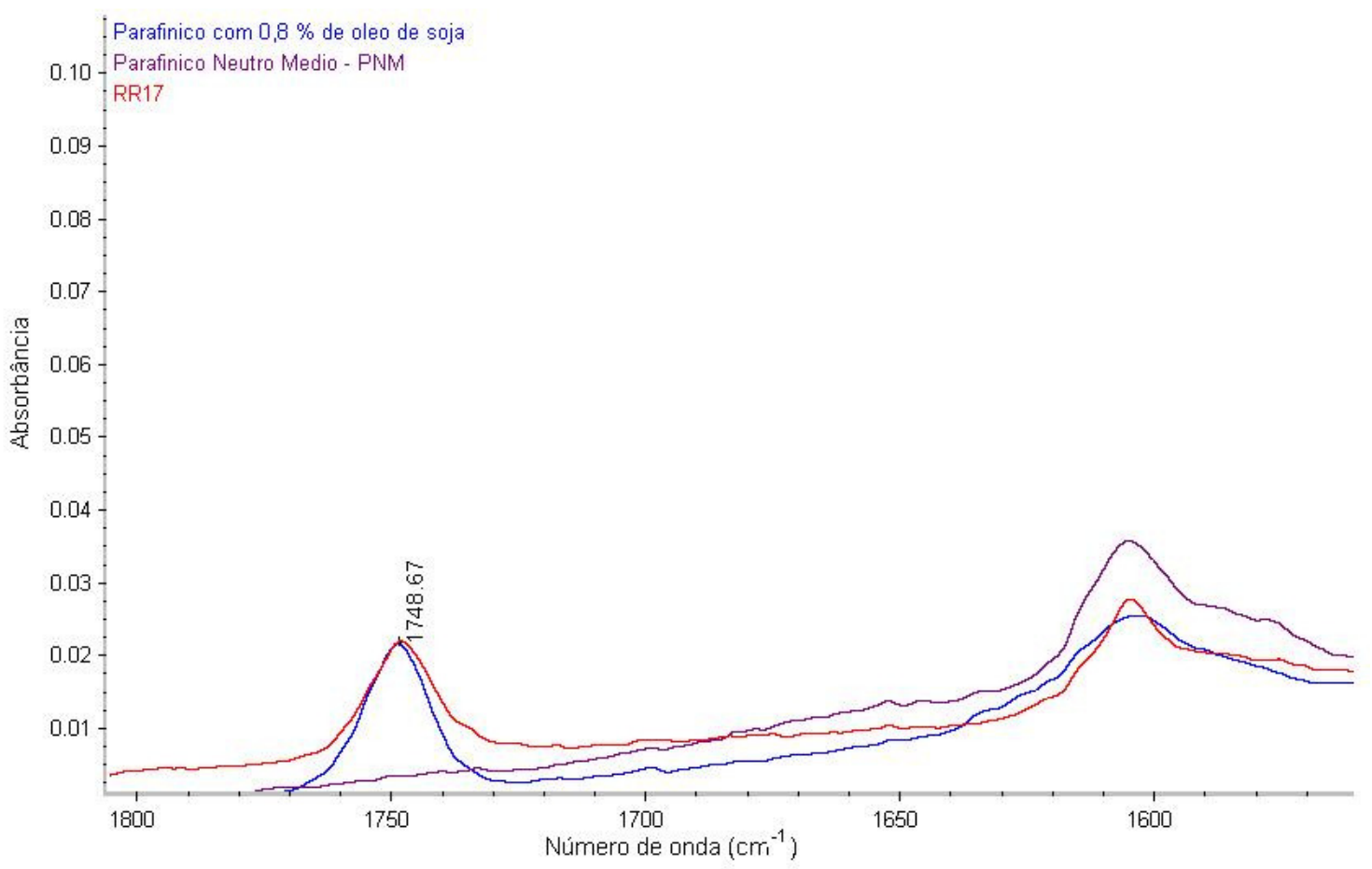

Figura 31. Espectro da amostra RR17 em comparação com espectros de parafínico neutro médio e de parafínico contendo óleo vegetal. 


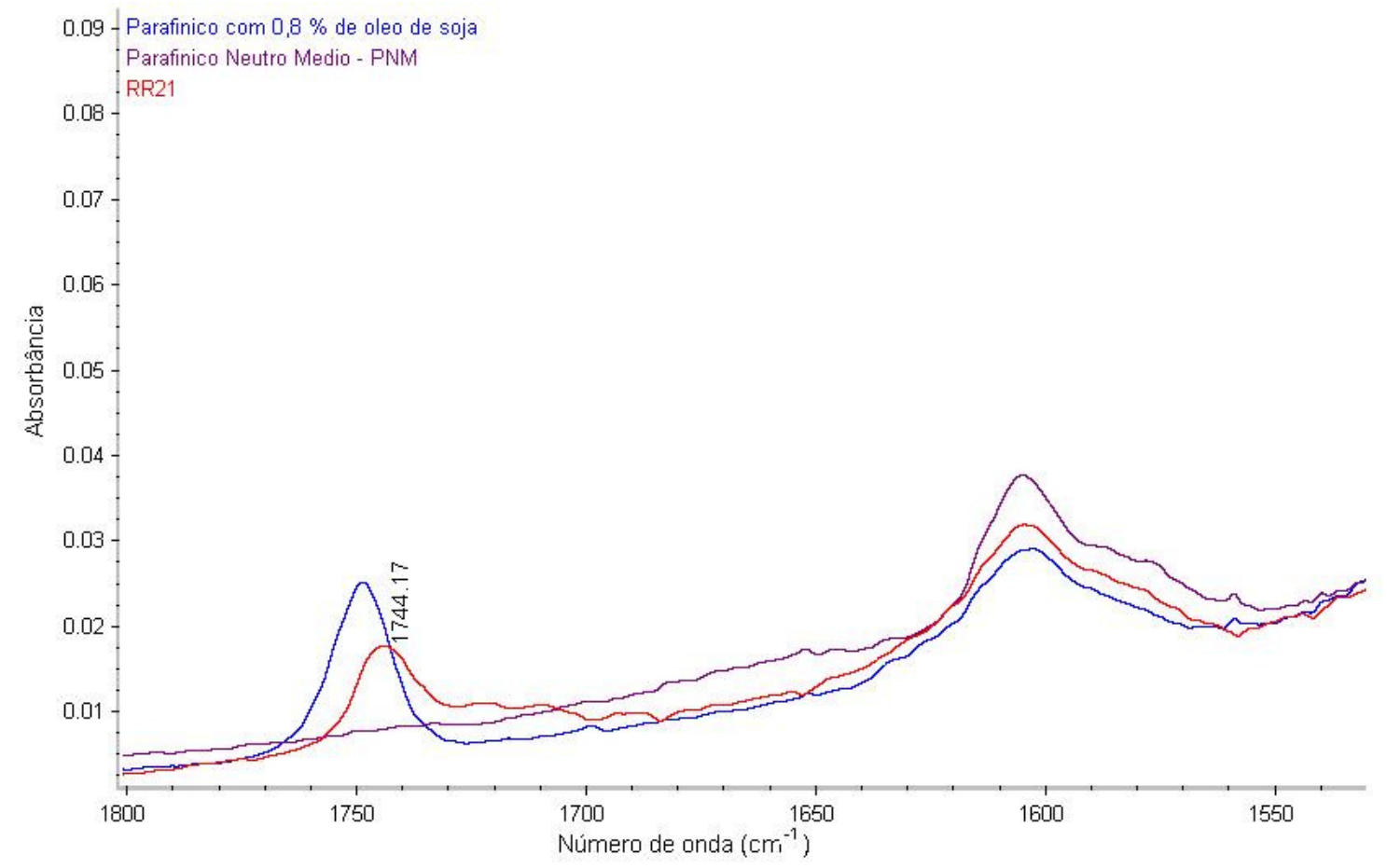

Figura 32. Espectro da amostra RR21 em comparação com espectros de parafínico neutro médio e de parafínico contendo óleo vegetal.

O espectro da amostra RR7, Figura 33, também indica a presença de naftênico e, assim como as amostras RR8 e RR35, ela é proveniente do rerrefinador número 5. A presença de éster e compostos naftênicos na amostra RR7 ressalta a baixa eficiência do processo de rerrefino adotado. 


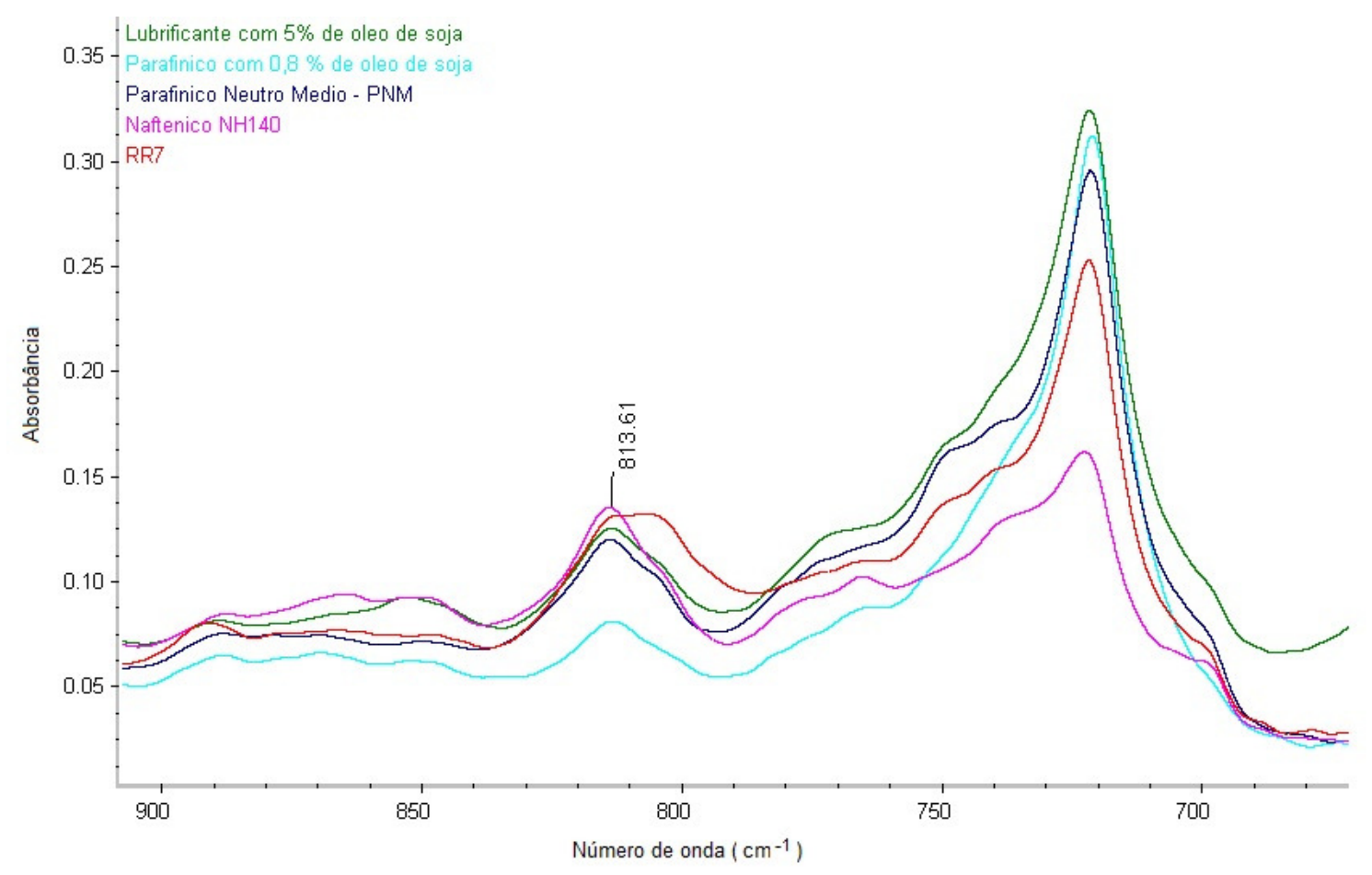

Figura 33. Espectro da amostra RR7 em comparação com espectros de parafínico neutro médio, naftênico NH140 e de básicos contendo óleo vegetal.

A amostra RR17, como pode ser visualizado por meio da Figura 34, apresenta um pico em $695 \mathrm{~cm}^{-1}$, o qual não foi identificado. Uma possibilidade é que este se trate de deformação angular fora do plano das ligações entre carbonos de anel aromático substituído. Infelizmente, não há como confirmar a presença deste contaminante, pois as demais bandas dos compostos aromáticos ocorrem nas mesmas frequências que as bandas dos hidrocarbonetos presentes nos óleos minerais. A amostra RR17 foi produzida pela empresa número 13, cujo processo é ainda mais simples que o do rerrefinador $5 \mathrm{e}$ também se mostra incapaz de remover todos os contaminantes do OLUC recebido. 


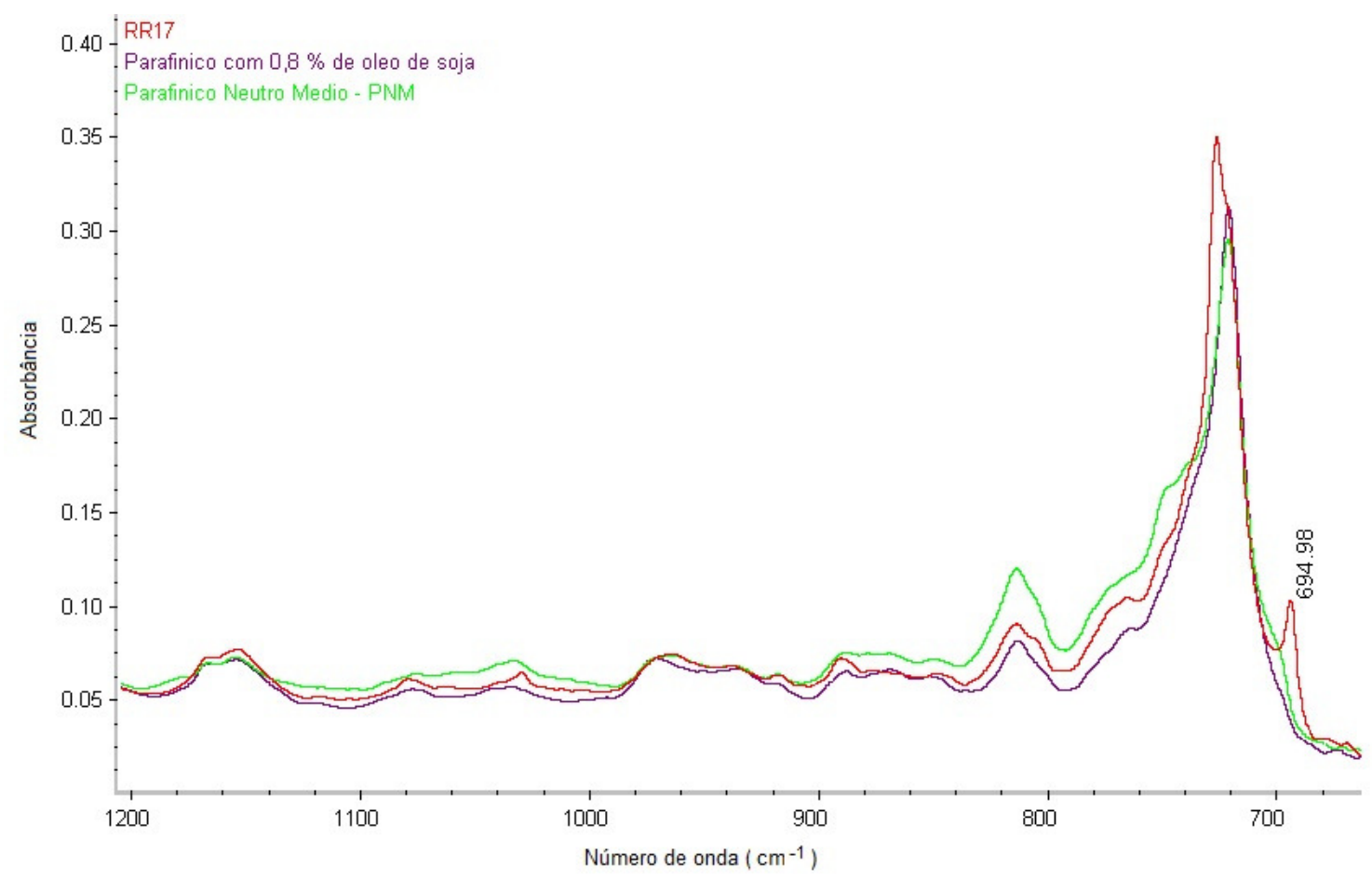

Figura 34. Espectro da amostra RR17 em comparação com espectros de parafínico neutro médio e de parafínico contendo óleo vegetal.

As Figuras 35 e 36 mostram partes do espectro obtido para a amostra RR38 também coletada no rerrefinador 5. Na Figura 35, é possível observar bandas em 1710, 1748 e $1782 \mathrm{~cm}^{-1}$. A banda em $1748 \mathrm{~cm}^{-1}$ assim como no caso das amostras RR7, RR17 e RR21, foi atribuída à deformação axial de carbonila de ésteres. As bandas em 1710, 1782 (figura 35) e $1227 \mathrm{~cm}^{-1}$ (Figura 36) não foram identificadas. Uma possibilidade é que a banda em $1710 \mathrm{~cm}^{-1}$ seja devido a deformação axial do grupo carbonila de ácidos carboxílicos alifáticos $\mathrm{cm}^{-1}$, mas não foi constatada banda que pudesse ser atribuída à absorção de deformação axial do grupo hidroxila, o qual ocorre normalmente entre $3300 \mathrm{e}$ $2500 \mathrm{~cm}^{-1}$ ou a deformação angular deste grupo químico. A detecção de contaminantes, ainda que estes não sejam identificáveis, complementa os resultados dos ensaios de ponto de fulgor, IAT e corrosão ao cobre e indica que o processo de rerrefino não é eficiente. 


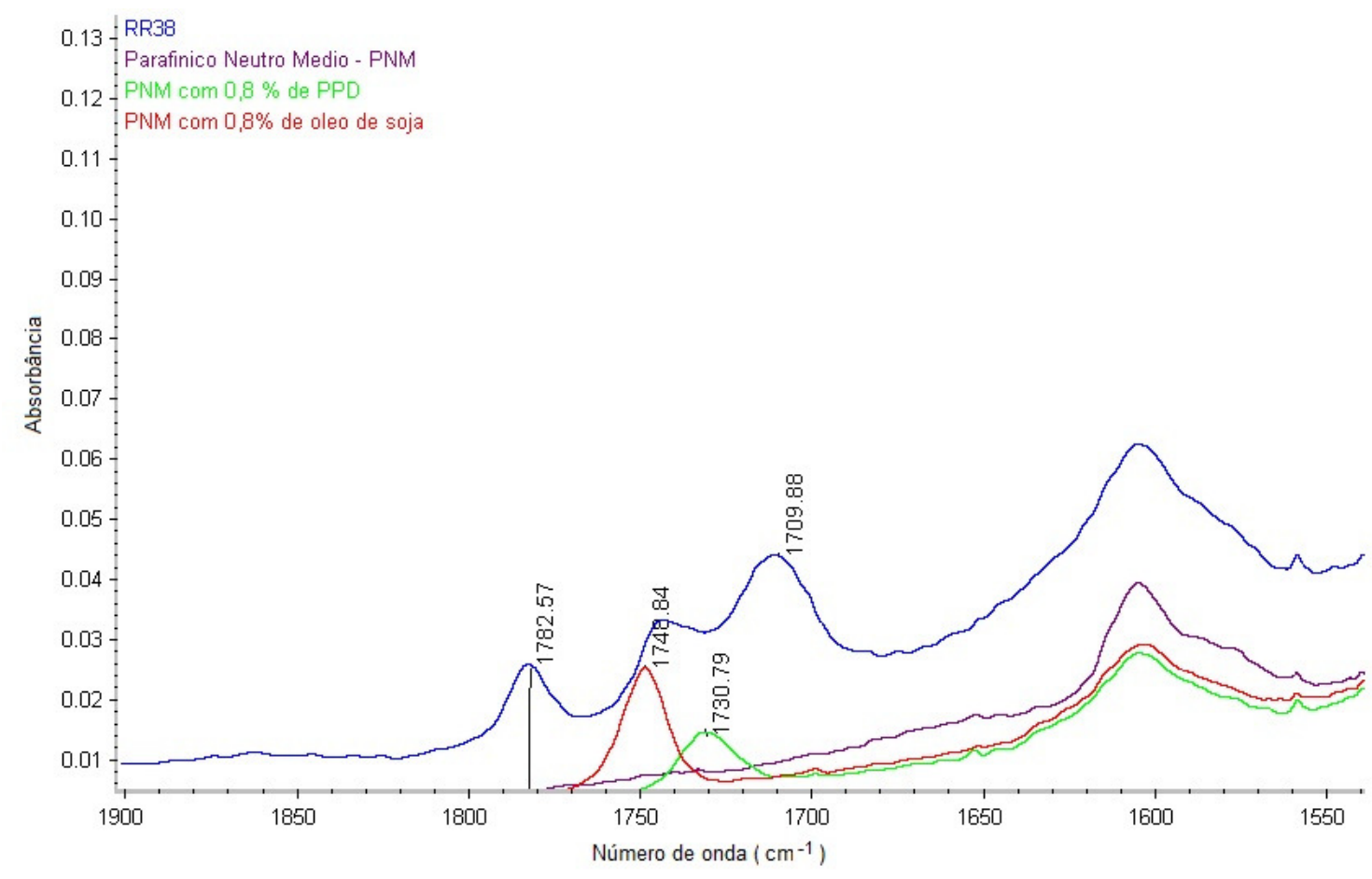

Figura 35. Espectro da amostra RR38 em comparação com espectros de parafínico neutro médio e de parafínico contendo óleo vegetal e aditivo abaixador do ponto de fluidez, PPD.

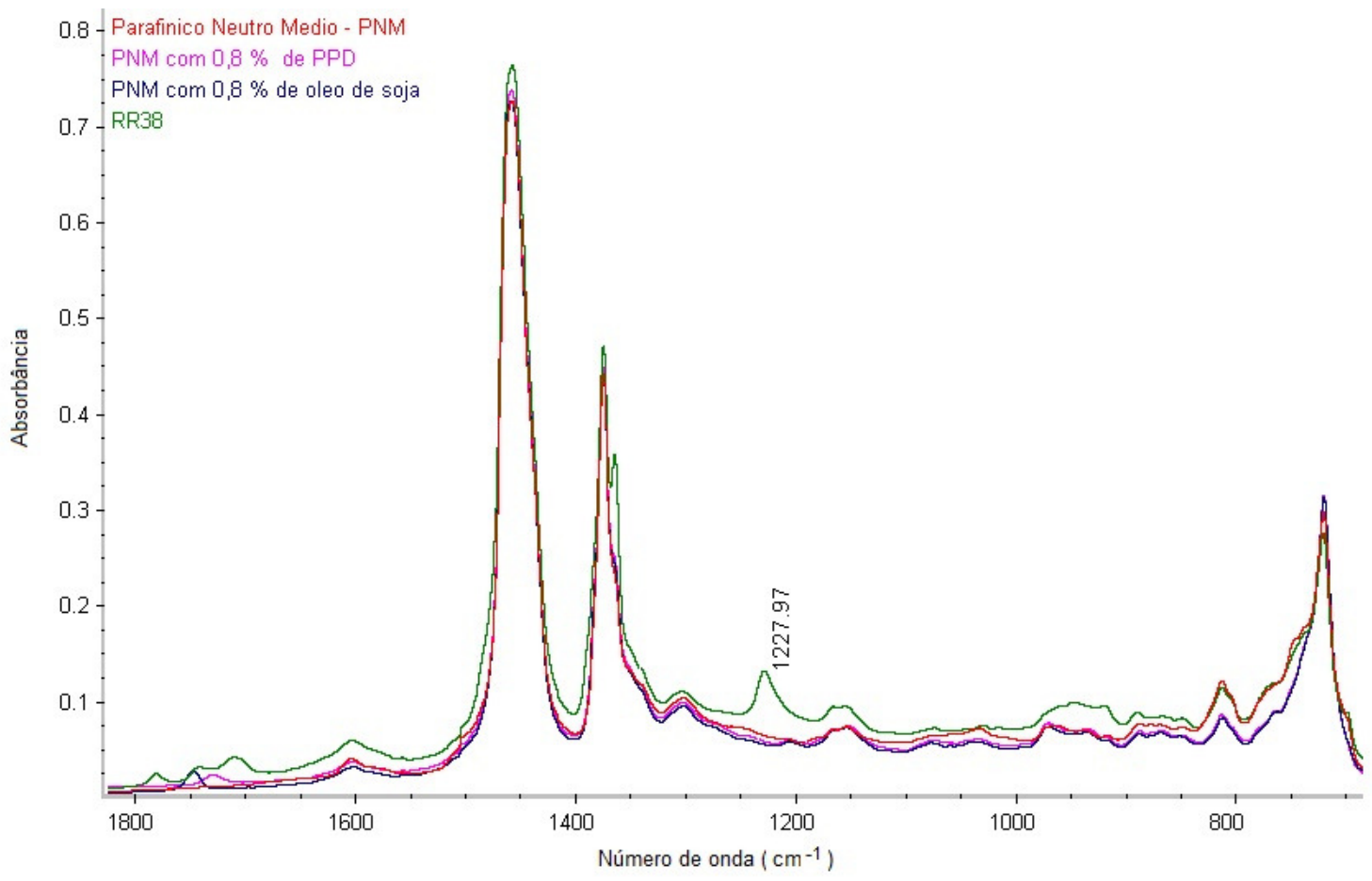

Figura 36. Espectro da amostra RR38 em comparação com espectros de parafínico neutro médio e de parafínico contendo óleo vegetal e aditivo abaixador do ponto de fluidez, PPD. 
Dentre os parafínicos neutros pesados, apenas a amostra RR36 apresentou irregularidades no espectro de infravermelho. Na Figura 37, é possível verificar banda pouco intensa em $1730 \mathrm{~cm}^{-1}$, atribuída, como mencionado anteriormente, à deformação axial de carbonila de ésteres. Neste caso, em particular, a banda coincide com a obtida para um óleo neutro pesado contendo $0,8 \%$ de PPD. Por observação da Tabela 16 , nota-se que o ponto de fluidez obtido para essa amostra é muito inferior ao esperado. Além disso, a presença desse aditivo, que é um polímero, justifica o valor encontrado para resíduo de carbono ramsbottom. As amostras RR36 e RR38 também foram produzidas pelo rerrefinador 5 , acentuando que esta indústria não está utilizando a técnica adequada à reciclagem dos resíduos que recebe.

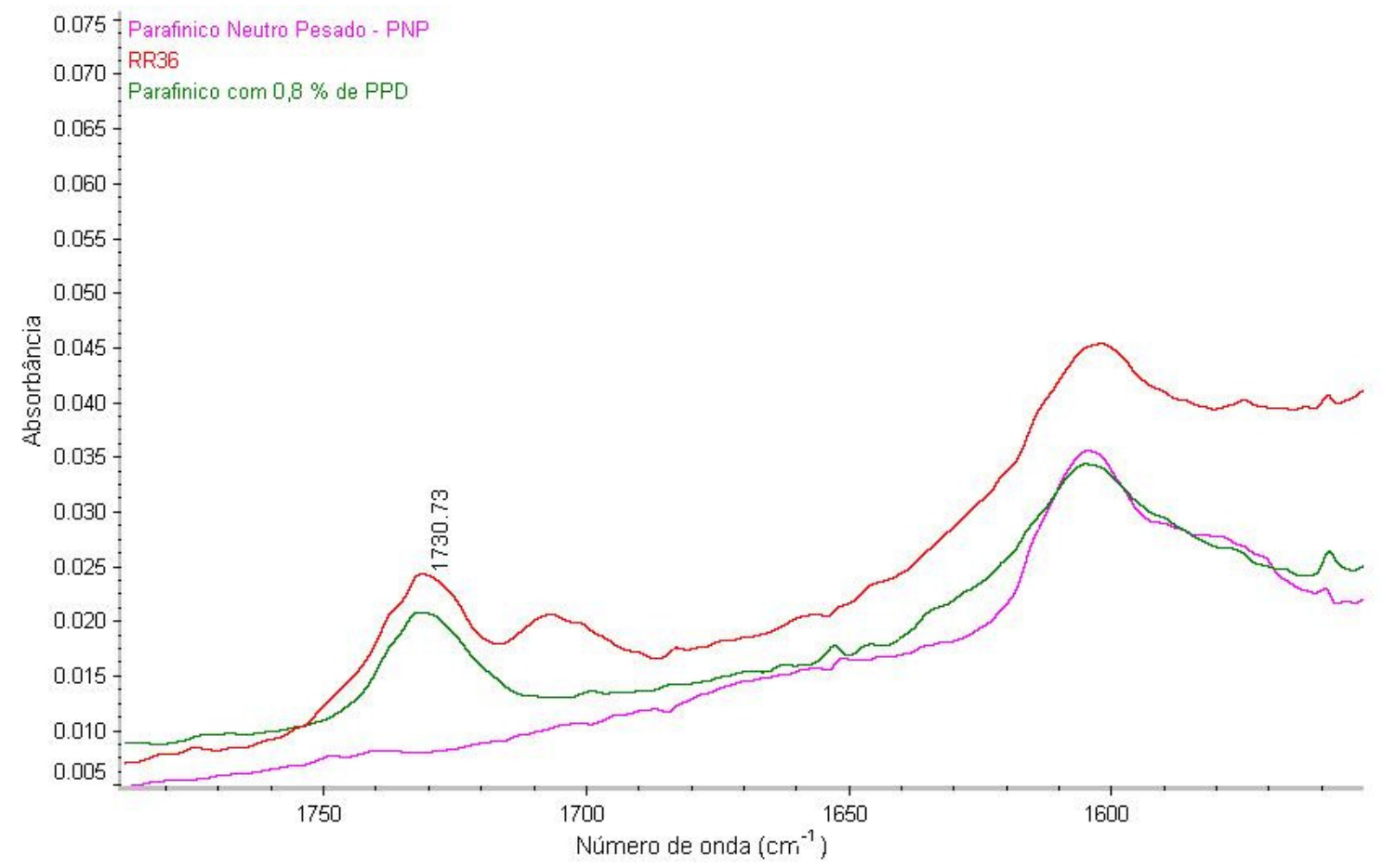

Figura 37. Espectro da amostra RR36 em comparação com espectros de parafínico neutro médio e de parafínico contendo óleo vegetal e aditivo abaixador do ponto de fluidez, PPD.

A Figura 38 mostra o espectro da amostra RR37, que apresentou uma banda larga entre $3600-3100 \mathrm{~cm}^{-1}$ característica de deformação axial de ligação $\mathrm{O}-\mathrm{H}$, atribuída à presença de água. $\mathrm{O}$ espectro não apresentou banda típica de deformação axial de C-O, na região de 1260-1000 cm presença de álcool. Essa amostra, visualmente, parecia se tratar de uma emulsão de água em óleo, além de apresentar materiais em suspensão, como é destacado na Tabela 16. Parte do espectro da amostra RR39 é mostrada na 
Figura 39, destacando o óleo naftênico neste básico rerrefinado. Essa amostra e a RR37 foram produzidas pelo rerrefinador 13 , ressaltando as deficiências do processo adotado por ele. Todas as amostras coletadas nas empresas 5 e 13 continham contaminantes.

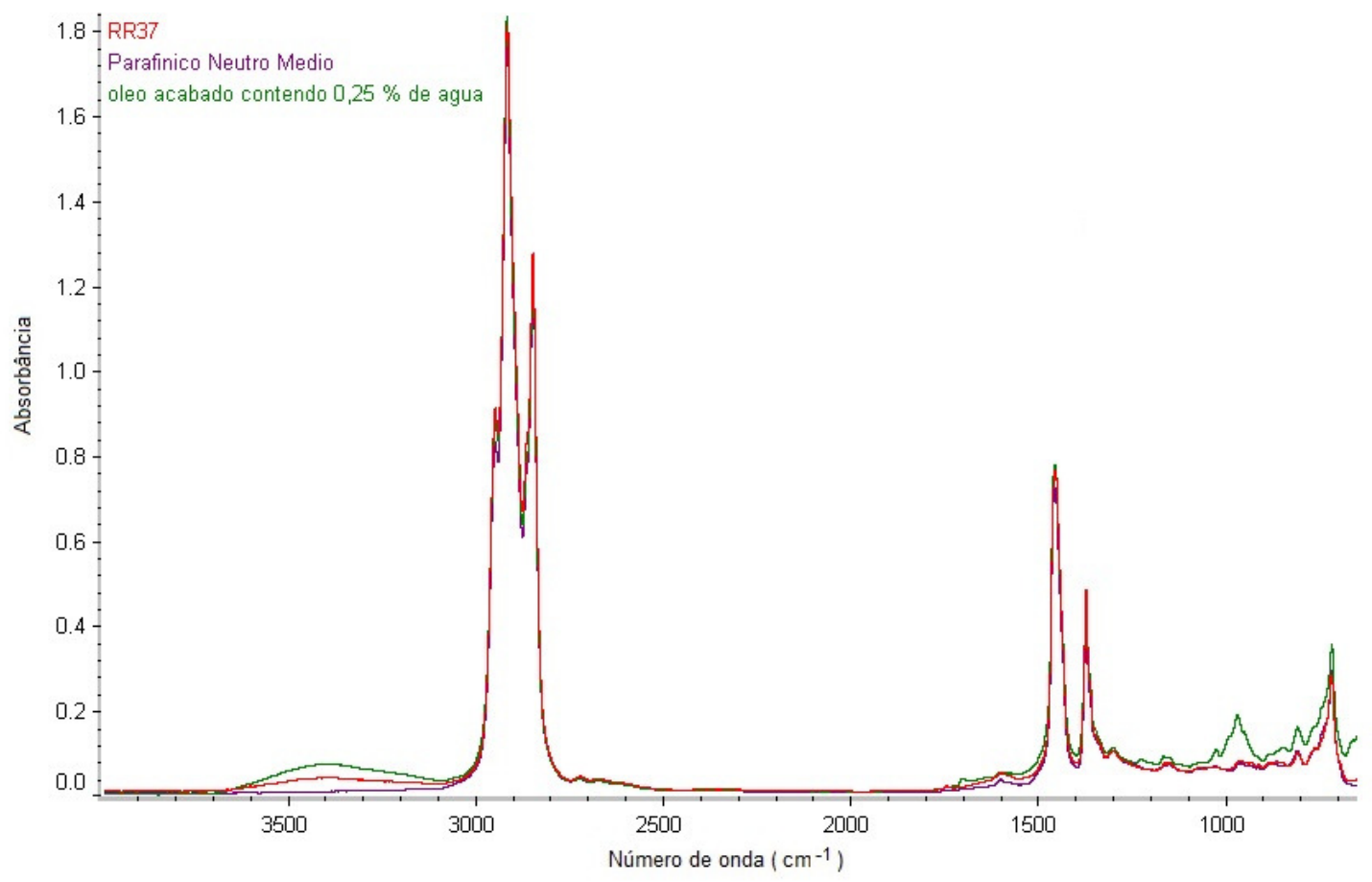

Figura 38. Espectro da amostra RR37 em comparação com espectros de parafínico neutro médio e de parafínico contendo $0,25 \%$ em peso de água. 


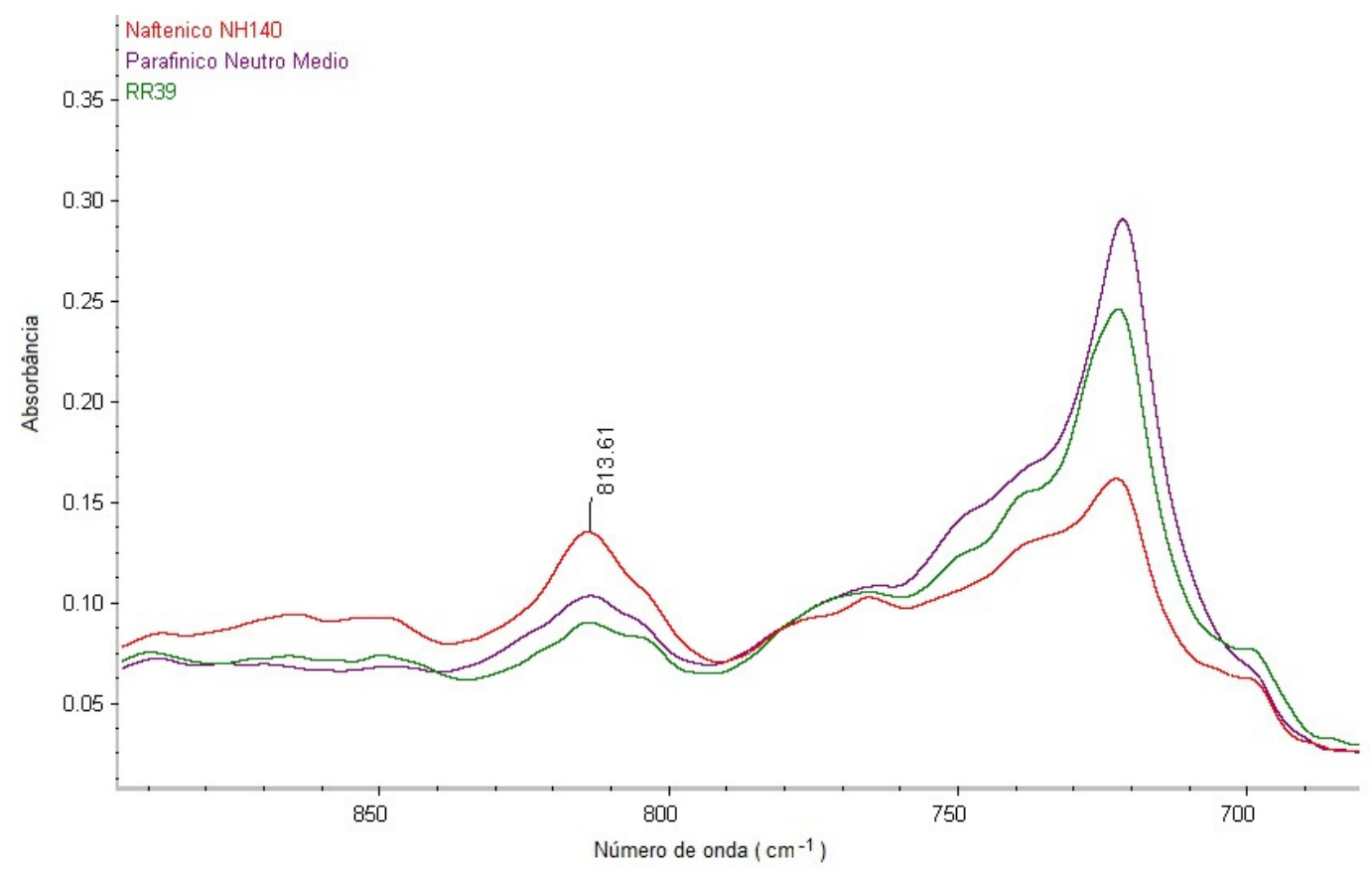

Figura 39. Espectro da amostra RR39 em comparação com espectros de parafínico neutro médio e naftênico $\mathrm{NH} 140$.

A espectroscopia no infravermelho não consta na Portaria ANP $n^{\circ}$ 130/99, mas, por ser uma técnica capaz de apontar a presença de contaminantes, ela deveria ser inserida como um dos métodos de avaliação dos básicos rerrefinados. Abaixo, a Figura 40 mostra como ficaria a distribuição das não conformidades por parâmetro caso a viscosidade cinemática fosse revista e a espectroscopia no infravermelho inserida. Nesta situação, 12 amostras seriam consideradas não conforme, o que equivale a $30,8 \%$ das analisadas. Dessas, 8 são dos rerrefinadores 5 e 13 . 


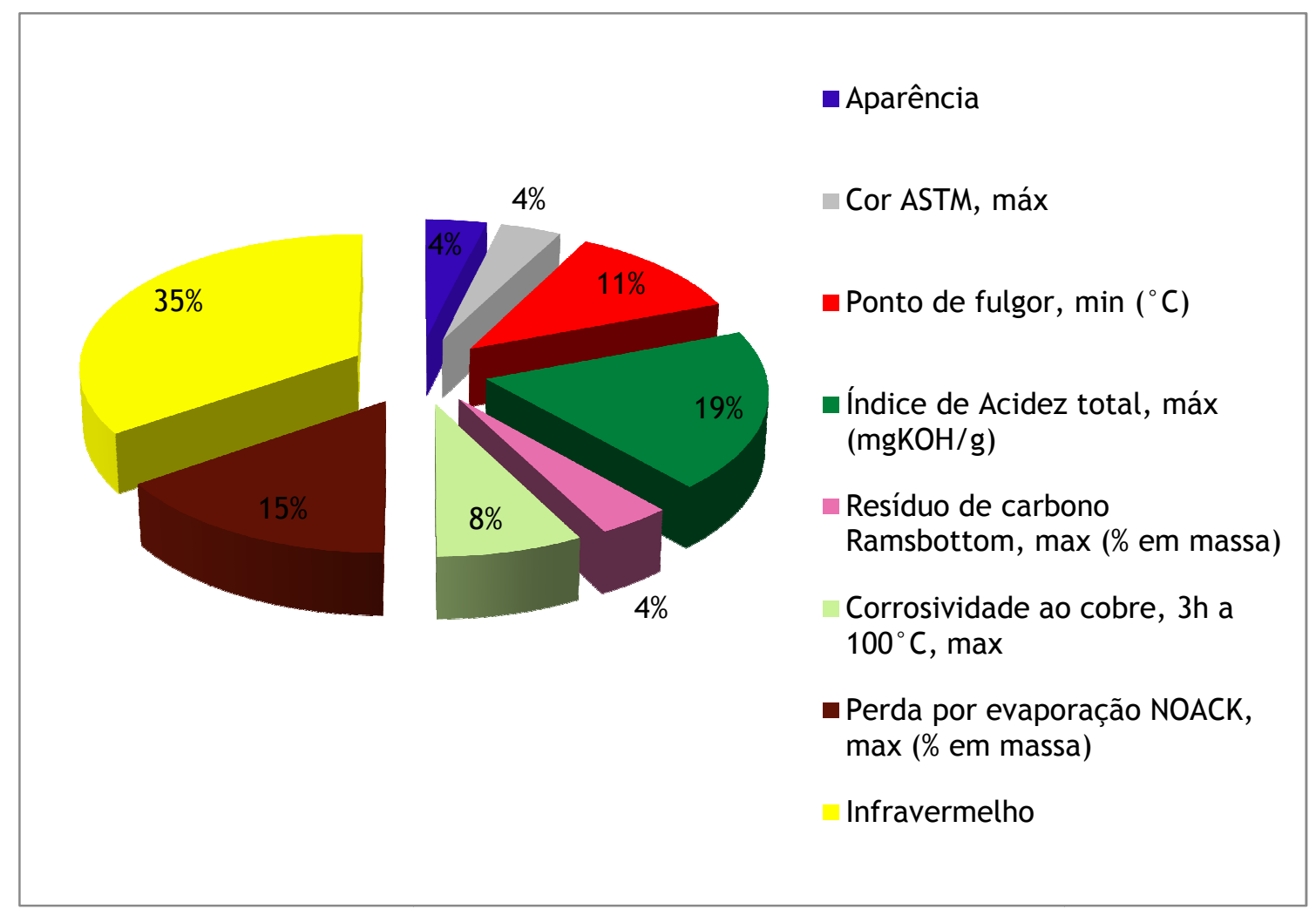

Figura 40. Distribuição das não conformidades por parâmetros da Portaria ANP n 130/99, excluindo a viscosidade cinemática e inserindo ATR.

As informações obtidas nas visitas aos rerrefinadores e os resultados das análises dos parâmetros regulamentados pela Portaria ANP n¹30/99 foram relatados à Superintendência do Abastecimento da ANP, responsável pela concessão de autorização para exercício do rerrefino, e serviram de subsídio à análise dos processos de revalidação de acordo com a Resolução da ANP $n^{\circ} 18 / 2009$.

\subsection{Fluorescência de Raios X por Energia Dispersiva}

\subsubsection{Faixa Linear de Trabalho e Sensibilidade}

Os gráficos exploratórios iniciais $\mathrm{X}-\mathrm{Y}$ das Intensidades versus concentrações construídos para os elementos magnésio e silício utilizando o equipamento FRX/EDX 720 são apresentados nas Figuras 41 e 42. Percebe-se, por análise visual, que a dispersão dos dados é elevada, principalmente no caso do silício, e que a sensibilidade do método na faixa de trabalho é baixíssima, sendo as intensidades próximas a zero. Além disso, os coeficientes angulares obtidos com a regressão linear e os coeficientes de determinação das três curvas são 
muito baixos. Assim, no caso desses elementos, os testes estatísticos relativos à linearidade não foram concluídos e os demais ensaios para validação dos métodos não foram realizados. Esse resultado não é totalmente inesperado visto que, no caso dos elementos leves (com número atômico menor que 23), a intensidade de fluorescência sofre influencia do processo de emissão Auger. ${ }^{53}$

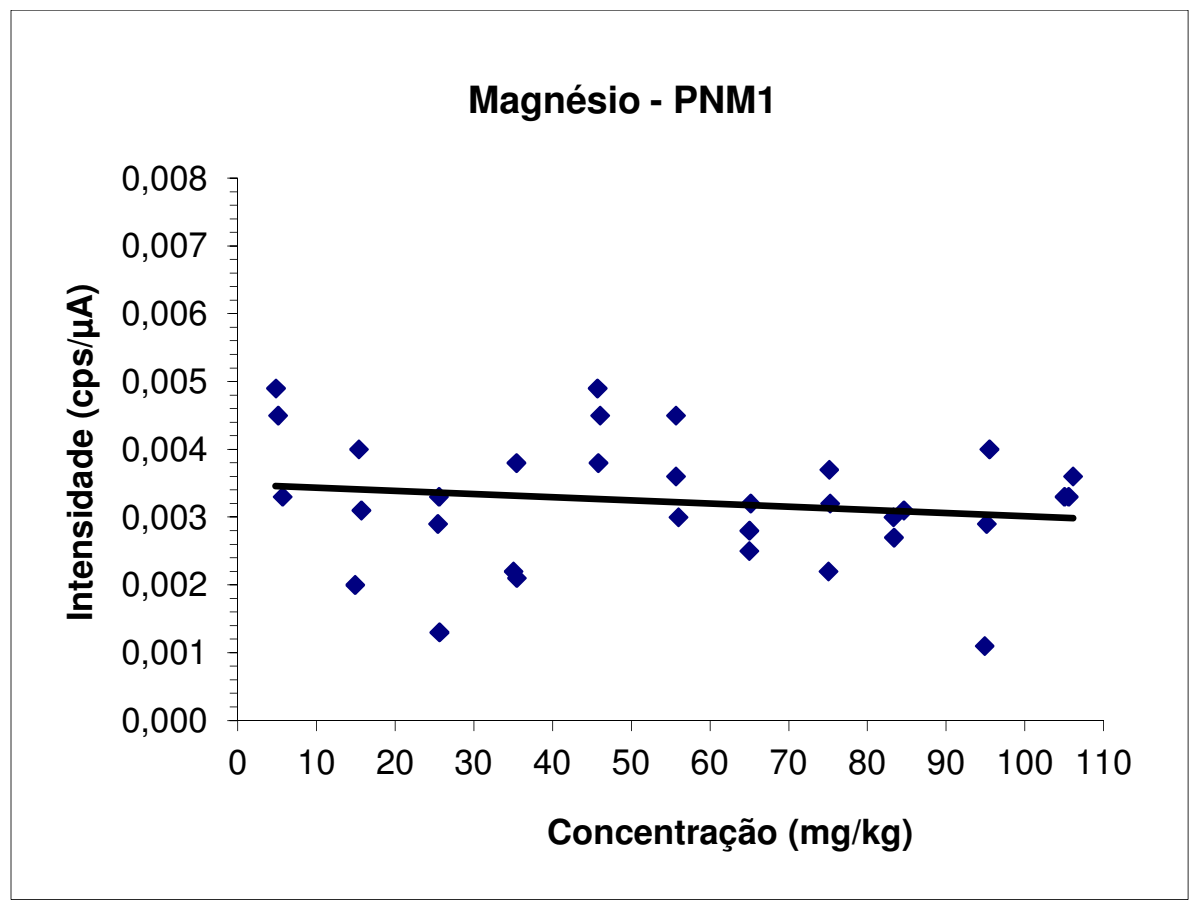

Figura 41. Gráfico exploratório inicial obtido para o magnésio pelo método PNM1.

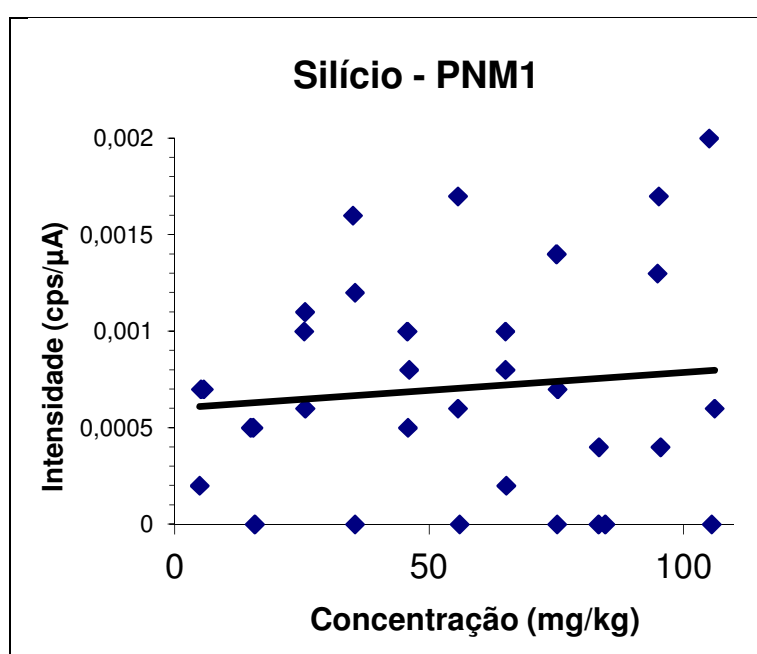

(a)

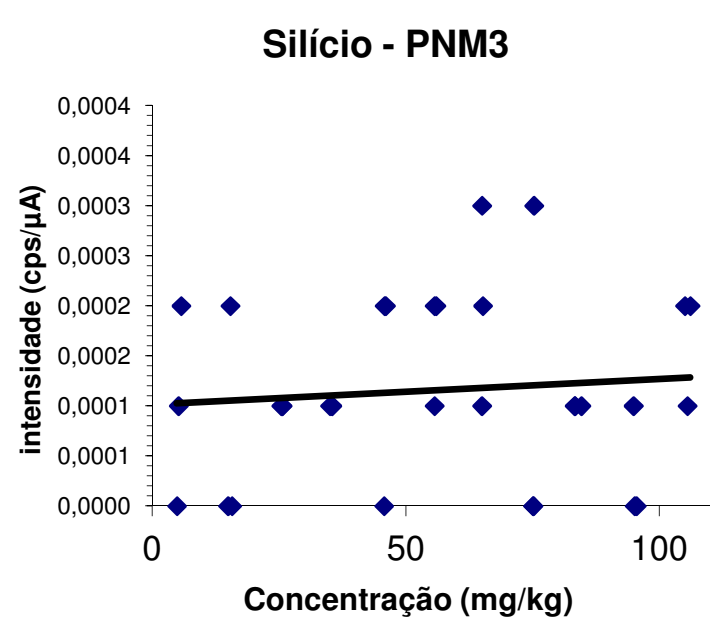

(b)

Figura 42. Gráficos exploratórios obtidos para o silício pelos métodos (a) PNM1 e (b) PNM3. 
Os resultados obtidos para o magnésio utilizando o Epsilon 3 XL também são muito dispersos e os demais testes não foram realizados. Com relação ao silício, pode se observar na Figura 43 que a sensibilidade alcançada foi muito maior, embora ainda seja possível perceber uma dispersão dos dados e 0 coeficiente de determinação está muito próximo do desejado $(0,99)$. Assim, ele foi avaliado quanto à linearidade em conjunto com os dados dos outros elementos.

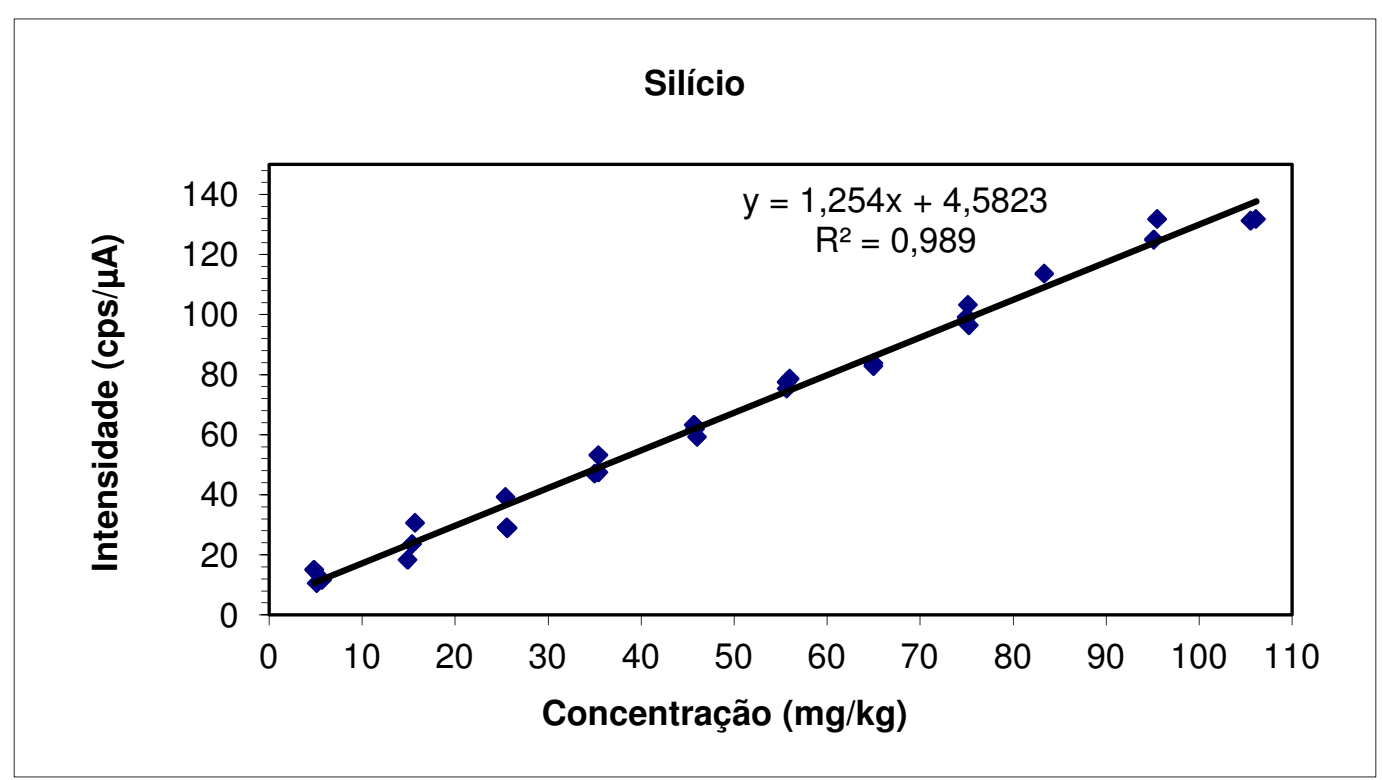

Figura 43. Gráfico exploratório inicial obtido para o silício utilizando o Epsilon 3 XL (método PNM2).

Os dados dos demais elementos foram tratados para retirada de outliers, utilizando o teste de resíduos padronizados jacknife. Em todos os casos, o número de outliers encontrados e descartados foi inferior a $22 \%$ dos dados, ou seja, menor que 7. Inicialmente, serão discutidos os dados obtidos com 0 equipamento FRX/EDX 720 da shimadzu e, posteriormente, os provenientes do Epsilon da Panalytical.

Os gráficos de regressão linear são apresentados nas Figuras 44 a 53. Por análise visual, percebe-se que os elementos cádmio e chumbo, Figura 44, apresentaram a maior dispersão dos dados. Os coeficientes de determinação $R^{2}$ das curvas desses elementos são inferiores ao desejado $(0,99)$ e as intensidades medidas também são baixas, inferiores a um no caso do cádmio, cujo coeficiente angular está na ordem de milionésimos. 


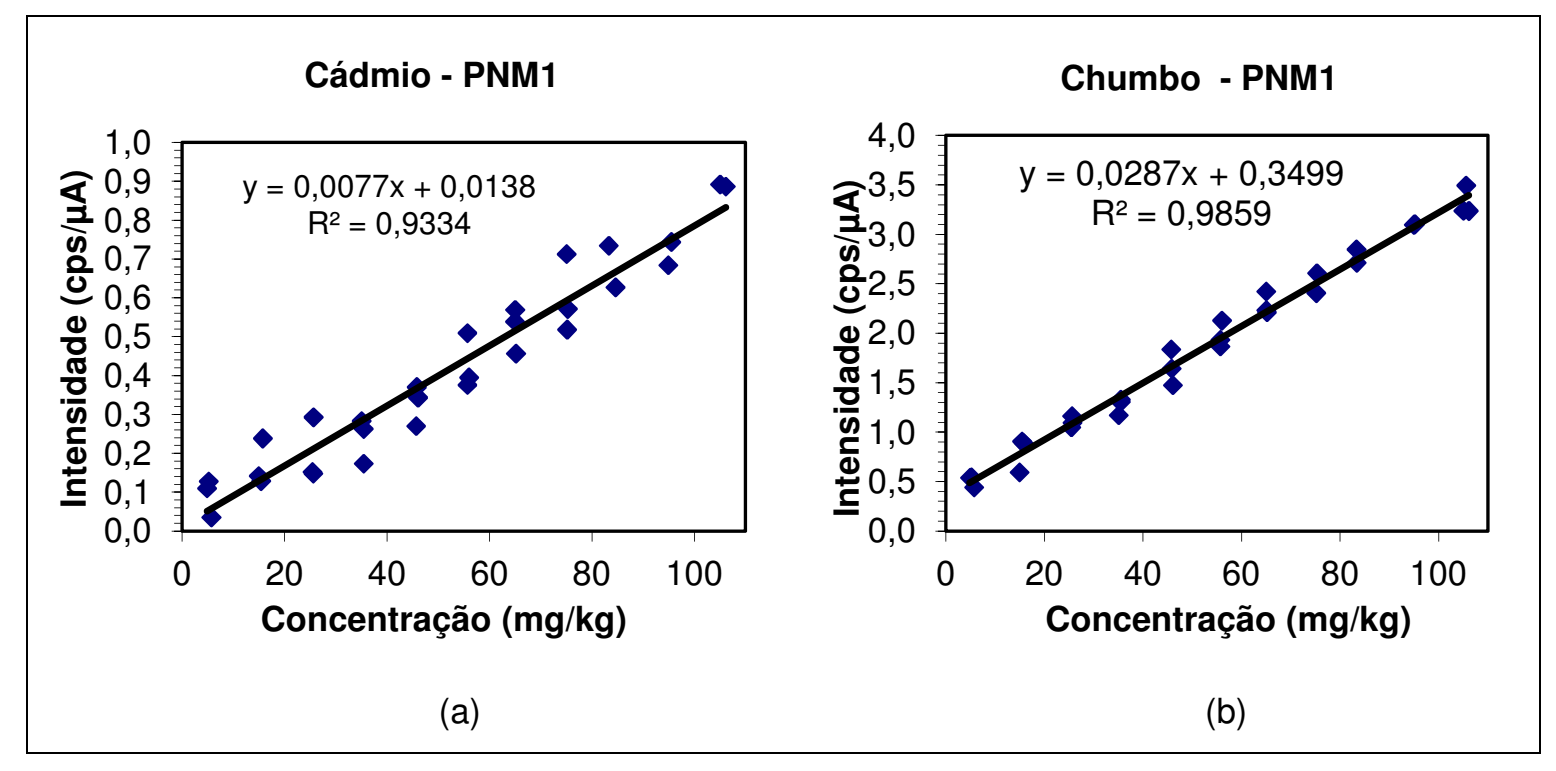

Figura 44. Gráfico da regressão linear obtida para o cádmio (a) e chumbo (b) pelo método PNM1.

Os gráficos de regressão linear para o cromo, cálcio e o bário são mostrados nas Figuras 45 e 46 . Os coeficientes de determinação $R^{2}$ dessas curvas são superiores a 0,99 , sendo observada para o bário uma dispersão maior dos dados. Os coeficiente angulares das curvas de cálcio e bário também na ordem de milionésimos, e as intensidades observada são menores que 1.

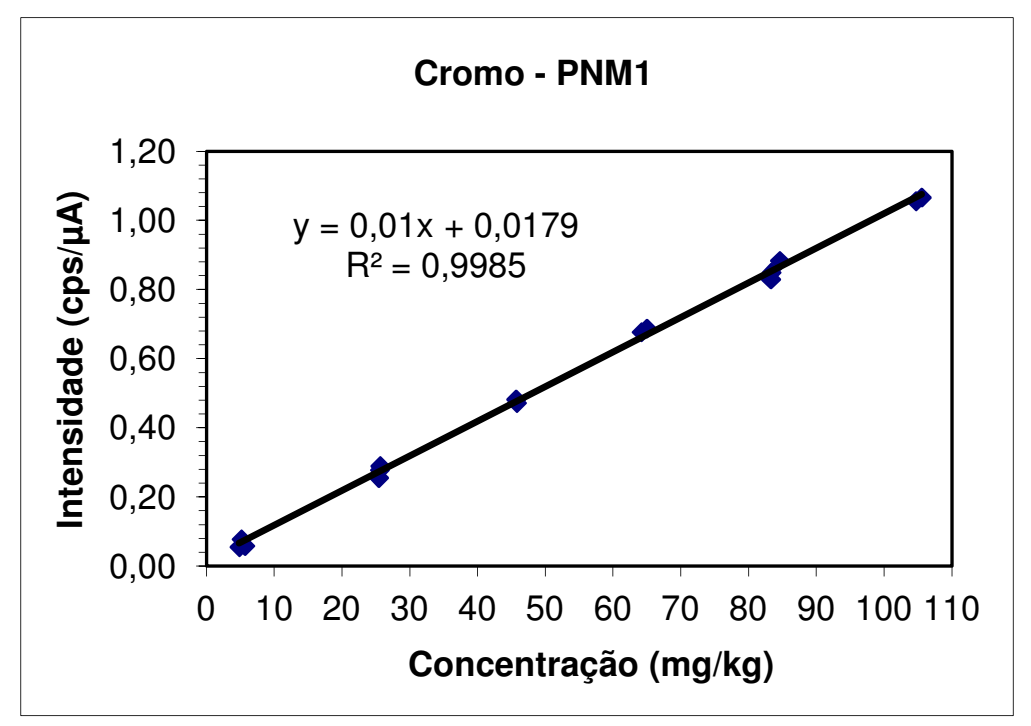

Figura 45. Gráfico da regressão linear obtida para o cromo pelo método PNM1. 


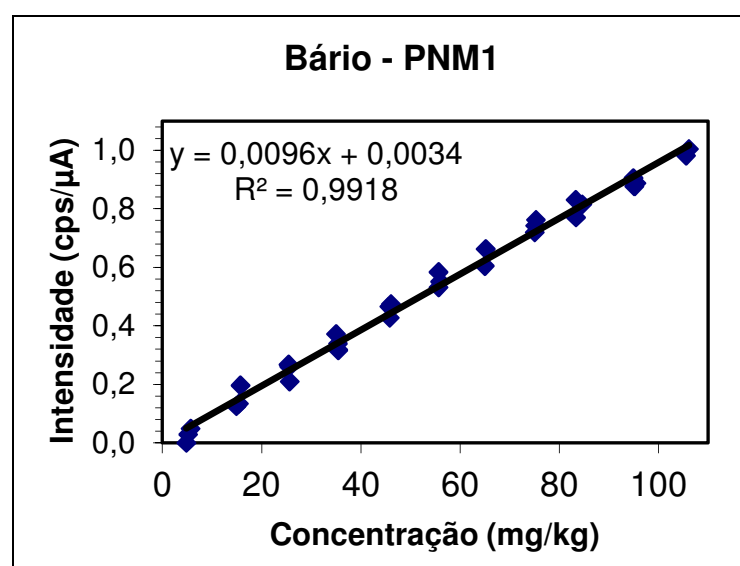

(a)

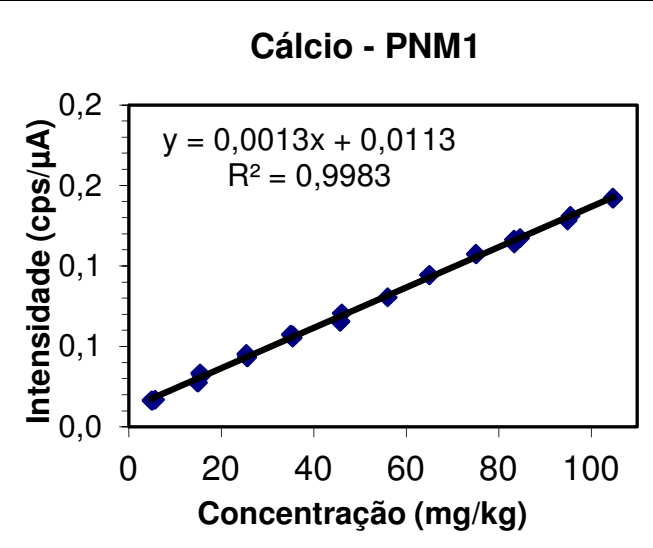

(b)

Figura 46. Gráfico da regressão linear obtida para o bário (a) e cálcio (b) pelo método PNM1.

A Figura 47 mostra os gráficos de regressão linear dos elementos ferro, zinco, níquel, cobre e molibdênio. As intensidades medidas para esses elementos são maiores que as observadas para os já discutidos. Os coeficientes de determinação são superiores a 0,99 e os coeficientes angulares são da ordem de centésimos, mostrando uma sensibilidade maior que a observada para os outros elementos. 


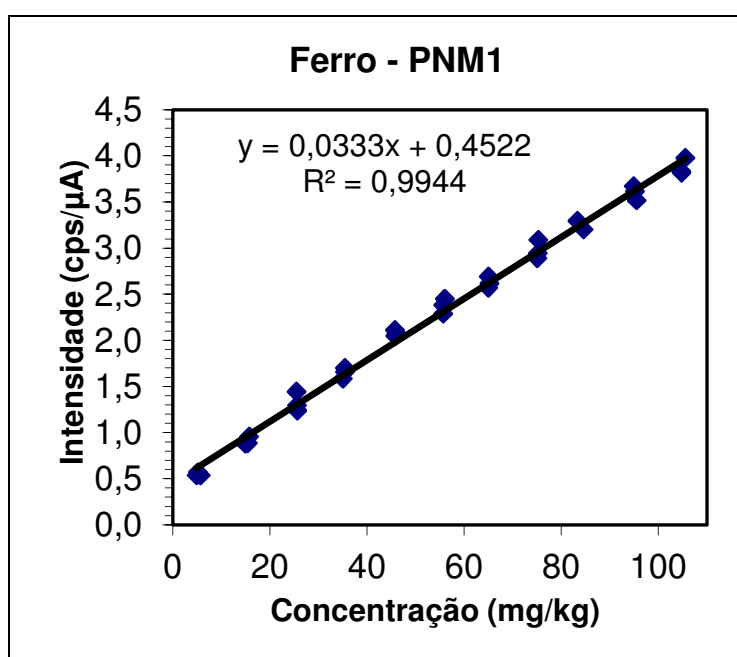

(a)

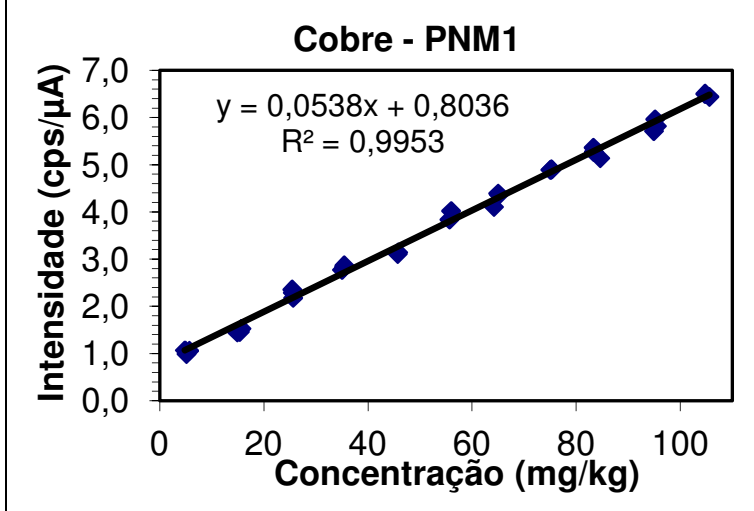

(c)

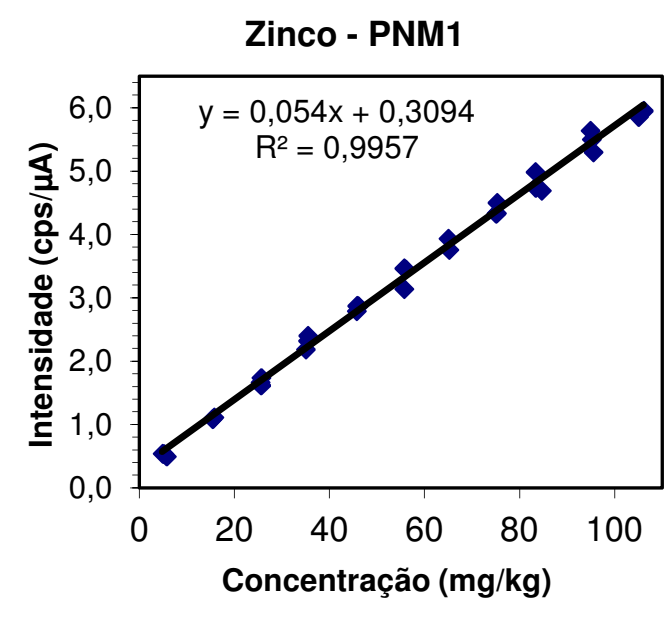

(b)

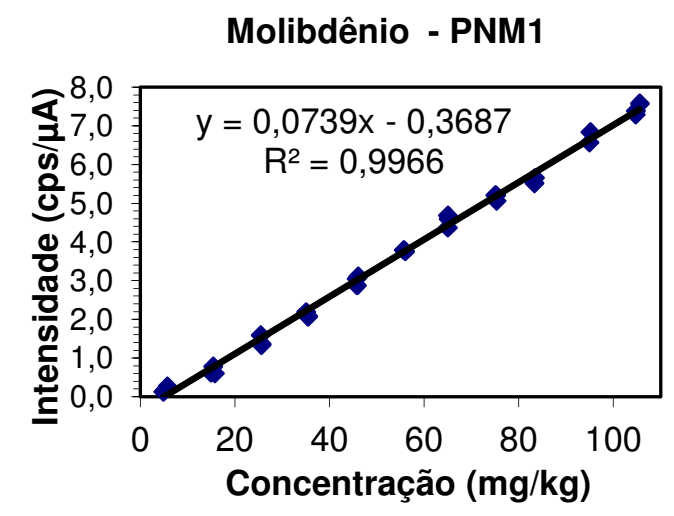

(d)

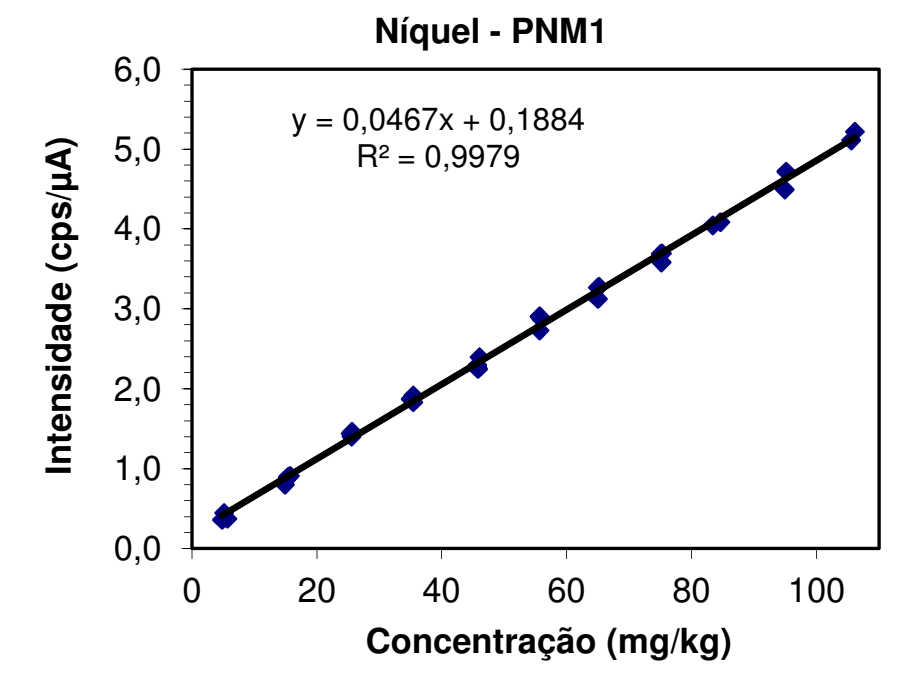

(e)

Figura 47. Gráficos de regressão linear para ferro (a), zinco (b), cobre(c), molibdênio (d) e níquel (e) obtidos pelo método PNM1. 
Os resultados dos testes de Ryan-Joiner e de Durbin-Watson para o ferro constam no Anexo 2, como um exemplo. As premissas de que os resíduos seguem a distribuição normal e são independentes foram confirmadas para as curvas de todos os elementos.

O resultado do teste de homocedasticidade dos resíduos obtido para curva do cálcio é apresentado na Tabela 18, sendo comprovada a hetorodasticidade dos dados. Duas possibilidades foram pensadas: transformar os dados e refazer os testes ou modificar o método e reavaliar. A segunda opção foi escolhida, pois os modelos lineares são mais simples e fáceis de serem adotados cotidianamente. Novo método para o cálcio foi testado, recebendo o nome de PNM3, sendo as condições do método apresentadas na Tabela 10. A homocedasticidade dos resíduos das curvas dos demais elementos foi comprovada e os resultados alcançados para o ferro são apresentados como exemplo no Anexo 2.

Tabela 18. Resultados do teste de Brown \& Forsythe obtidos para o cálcio - método PNM1

\begin{tabular}{|c|c|c|c|c|c|c|}
\hline$k=1$ & $k=2$ & & & & & \\
\hline $\mathbf{e}_{1 \mathbf{j}}$ & $\mathbf{e}_{2 j}$ & $\left|d_{1}\right|$ & $\left|d_{2}\right|$ & Estatística & $k=1$ & $k=2$ \\
\hline$-0,001$ & 0,001646855 & 0,0007 & 0,0016 & nk & 16 & $1,00 \mathrm{E}+01$ \\
\hline$-0,001$ & 0,0016 & 0,0013 & 0,0000 & $e_{k}$ (mediana) & $-0,00016$ & 1,74E-05 \\
\hline$-0,001$ & & 0,0013 & & $\mathrm{~d}_{\mathrm{k}}$ (média) & 0,001538 & 5,77E-04 \\
\hline 0,001 & 0,0020 & 0,0011 & 0,0000 & $S Q D_{k}$ & $1,55 \mathrm{E}-05$ & 6,88E-06 \\
\hline$-0,002$ & & 0,0022 & & $s_{p}^{2}$ & $9,33 \mathrm{E}-07$ & \\
\hline 0,003 & 0,0017 & 0,0029 & 0,0006 & $t_{L}$ & 2,466679 & \\
\hline 0,002 & 0,0006 & 0,0023 & 0,0019 & p & 0,021163 & \\
\hline 0,000 & $-0,0019$ & 0,0002 & 0,0000 & & & \\
\hline 0,000 & 0,0000 & 0,0001 & 0,0000 & & & \\
\hline 0,000 & & 0,0001 & & & & \\
\hline 0,001 & 0,0000 & 0,0014 & 0,0020 & & & \\
\hline 0,002 & $-0,001962286$ & 0,0024 & 0,0000 & & & \\
\hline$-0,003$ & & 0,0031 & & & & \\
\hline$-0,003$ & $-0,0008$ & 0,0029 & 0,0002 & & & \\
\hline 0,002 & $-0,0001$ & 0,0018 & 0,0000 & & & \\
\hline$-0,001$ & & 0,0008 & & & & \\
\hline
\end{tabular}

O gráfico de regressão linear obtido para o cálcio utilizando o método PNM3 é apresentado na Figura 48. Os coeficientes de determinação e angular são menores que os obtidos para este elemento pelo método PNM1. No entanto, foi 
comprovado que o novo método atende às premissas normalidade, independência e homocedasticidade dos resíduos.

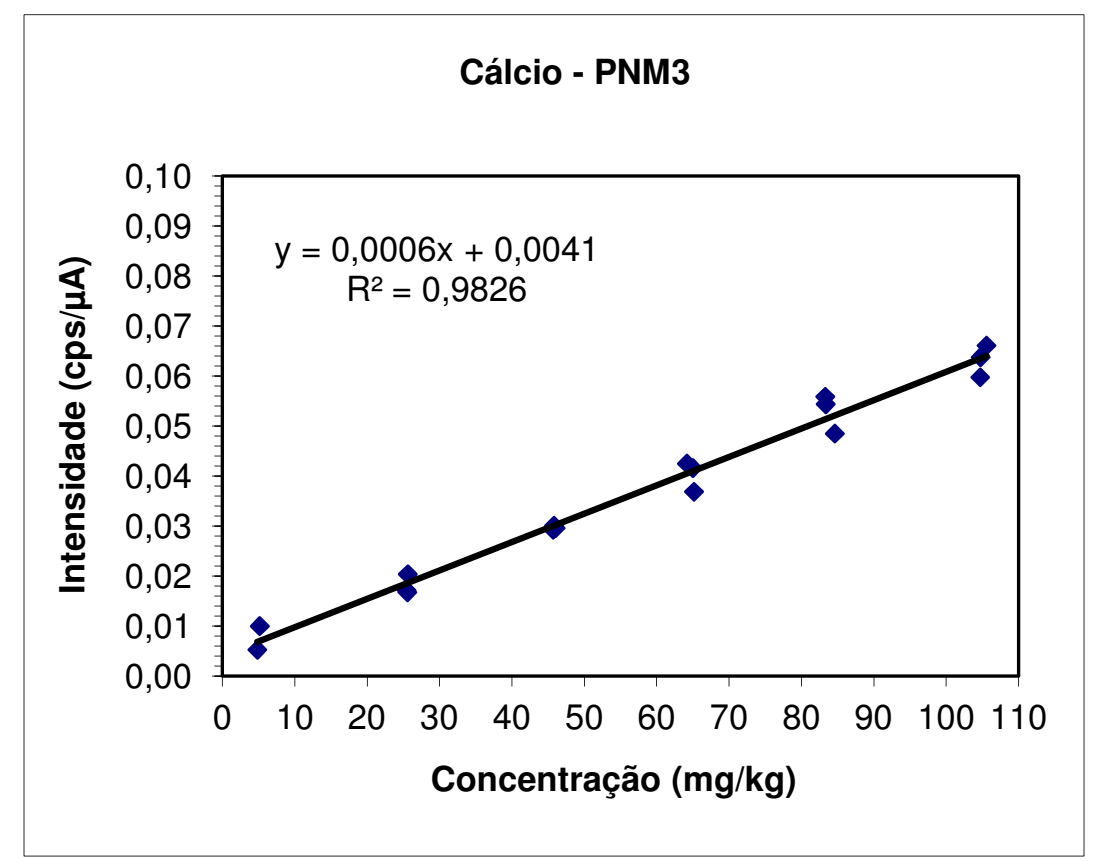

Figura 48. Gráfico da regressão linear obtida para o cálcio pelo método PNM3.

A Tabela 19 apresenta os resultados do teste ANOVA obtidos para a curva analítica do cobre. Foi constatado que a regressão é significativa, mas há desvio da linearidade. Novamente, optou-se por modificar as condições do método, construindo um novo, também denominado PNM3. Conforme os testes realizados para os demais elementos, inclusive para o cálcio pelo método PNM3, a regressão é significativa e não há desvios da linearidade nas curvas analíticas avaliadas.

Tabela 19. Resultados do teste ANOVA para o cobre - método PNM1

\begin{tabular}{|c|c|c|c|c|c|}
\hline$F V$ & $G L$ & $S Q$ & $Q M$ & $\boldsymbol{F}$ & $\boldsymbol{F}_{\text {critico }}$ \\
\hline Regressão & 1 & $8,65 E+01$ & $8,65 \mathrm{E}+01$ & 5978,01 & 4,195972 \\
\hline Resíduo & 28 & $4,05 E-01$ & $1,45 \mathrm{E}-02$ & & \\
\hline Desvio da linearidade & 9 & 2,81E-01 & $3,12 \mathrm{E}-02$ & 4,756 & 2,422699 \\
\hline Entre níveis & 10 & $8,68 \mathrm{E}+01$ & & & \\
\hline Erro puro & 19 & $1,25 E-01$ & 6,56E-03 & & \\
\hline Total & 29 & $8,69 \mathrm{E}+01$ & & & \\
\hline
\end{tabular}

A Figura 49 apresenta o gráfico da regressão obtido pelo novo método. Os coeficientes de determinação dos dois métodos são muito próximos, porém o coeficiente angular é aproximadamente 10 vezes menor que o do método 
PNM1, indicando que o novo método é muito menos sensível. No entanto, foi comprovado que o método PNM3 atende às premissas normalidade, independência e homocedasticidade dos resíduos, que a regressão é significativa e que não há desvio da linearidade. Os resultados do teste ANOVA realizado para o ferro consta no Anexo 2.

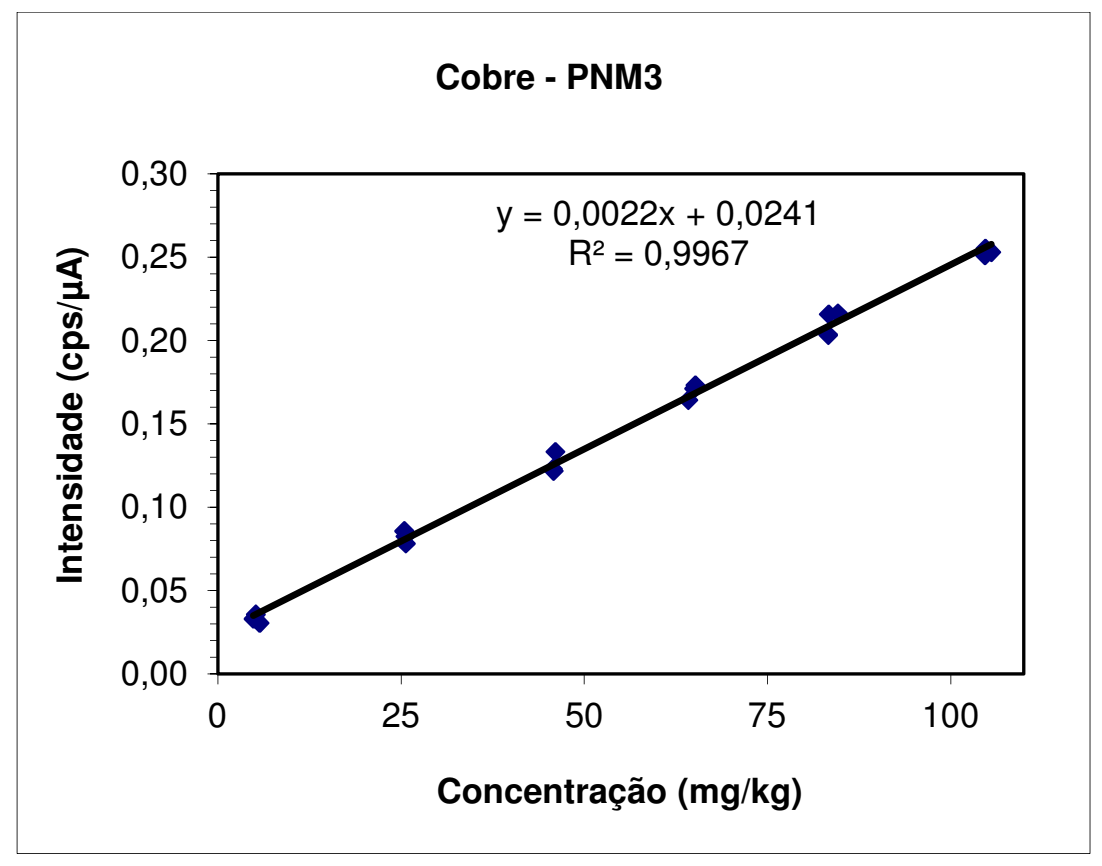

Figura 49. Gráfico da regressão linear obtida para o cobre pelo método PNM3.

Os gráficos de regressão linear obtidos para os metais $\mathrm{Cd}, \mathrm{Pb}, \mathrm{Cr}, \mathrm{Ca}, \mathrm{Ba}, \mathrm{Fe}$, Zn, Cu e Ni com a utilização do equipamento Epsilon $3 \mathrm{XL}$ são apresentados nas Figuras 50 e 51 . Os dados referentes ao molibdênio estavam muito dispersos, com número de outliers superior a $22 \%$, por isso a validação do método para esse metal não foi continuada. Em todos os outros casos, o coeficiente angular é maior que o verificado com o uso do equipamento FRX/EDX 720, o que é um indício de que os metais estudados apresentam uma sensibilidade maior aos raios $\mathrm{X}$ emitidos pelo tubo de $\mathrm{Ag}$. $\mathrm{O}$ aumento da sensibilidade foi ainda maior no caso de $\mathrm{Pb}$ e $\mathrm{Ba}$. Observa-se que os elementos $\mathrm{Cd}$, $\mathrm{Ca}$ e $\mathrm{Ba}$, Figura 50, apresentam uma dispersão dos dados maior que a dos demais e os coeficientes de determinação de $\mathrm{Ca}$ e $\mathrm{Ba}$ são inferiores a 0,99 . As premissas da linearidade foram confirmadas para todos os metais com exceção do bário que apresentou heterocedasticidade. Comparando-se as curvas referentes ao Epsilon $3 \mathrm{XL}$ com as do FRX/EDX 
720, nota-se que o uso do primeiro equipamento é mais promissor que o do segundo.

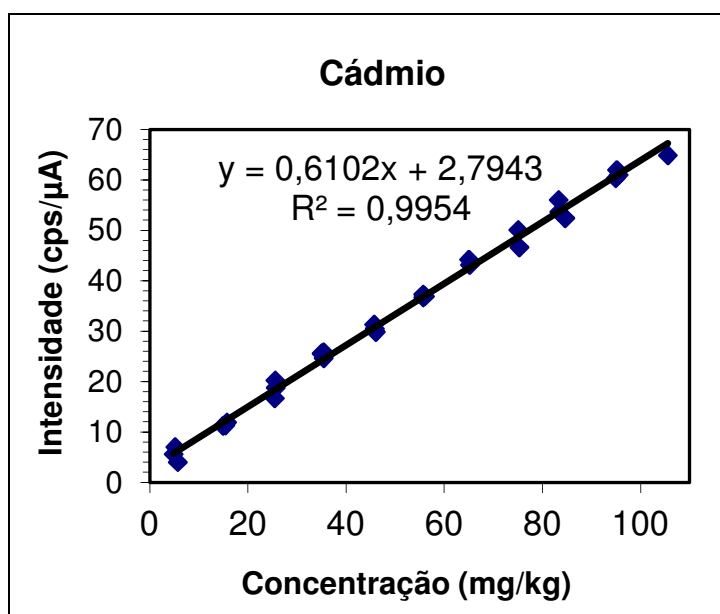

(a)

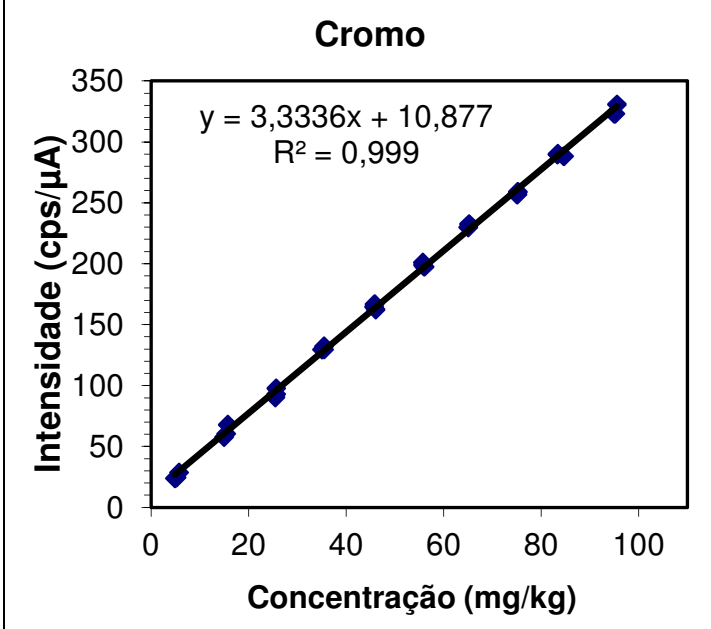

(c)

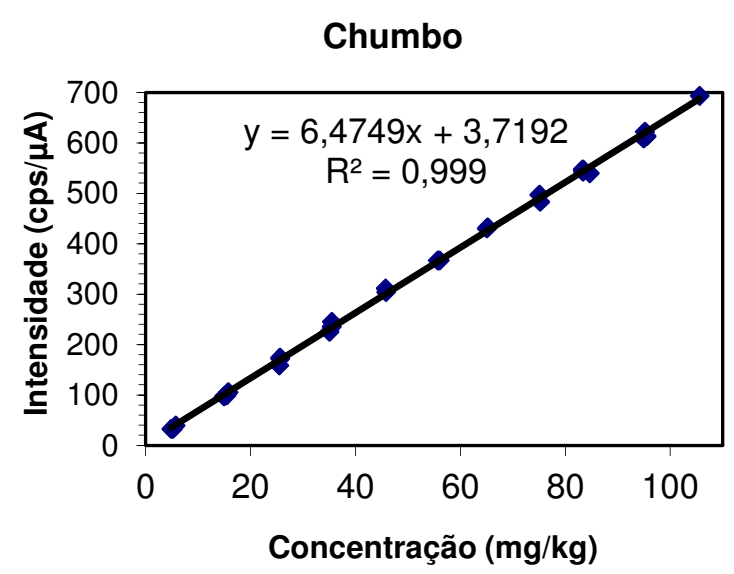

(b)

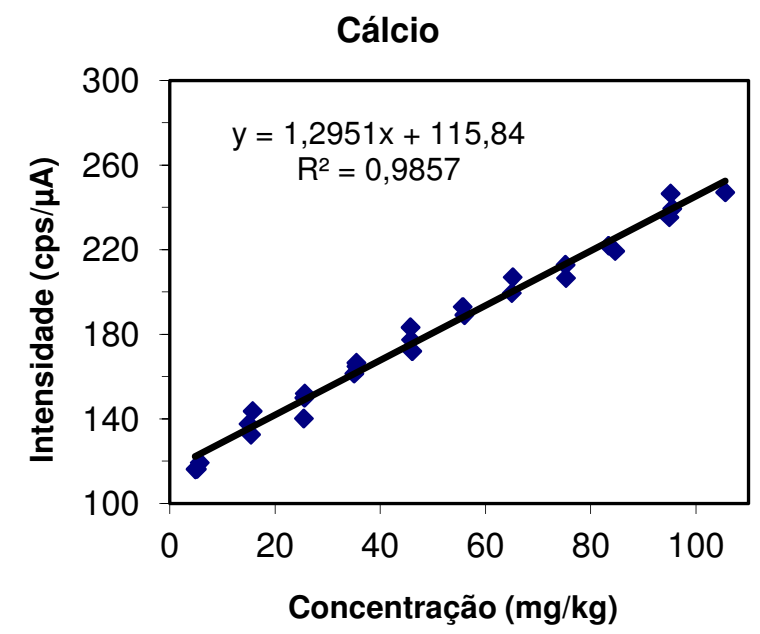

(d)

\section{Bário}

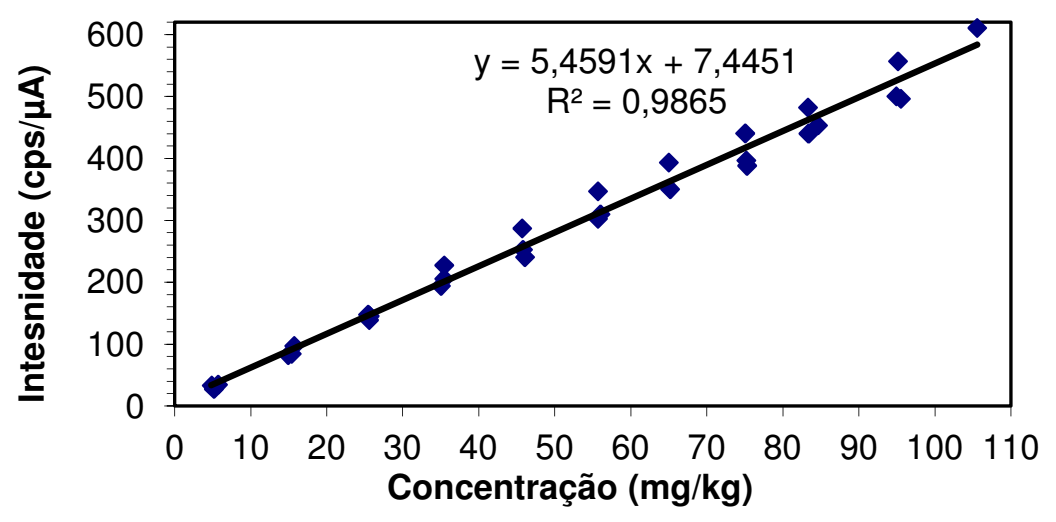

(e)

Figura 50. Gráficos de regressão linear obtidos para cádmio, chumbo, cromo, cálcio e bário usando o equipamento Epsilon $3 \mathrm{XL}$ (método PNM2). 


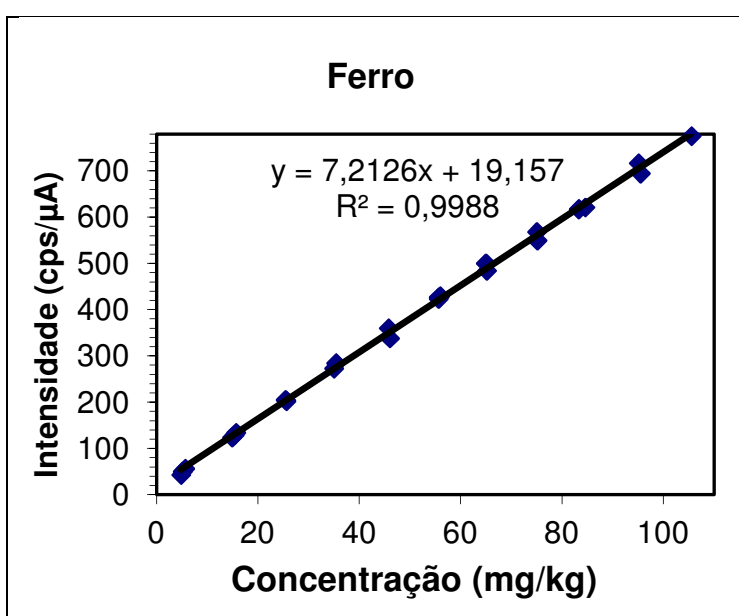

(a)

\section{Cobre}

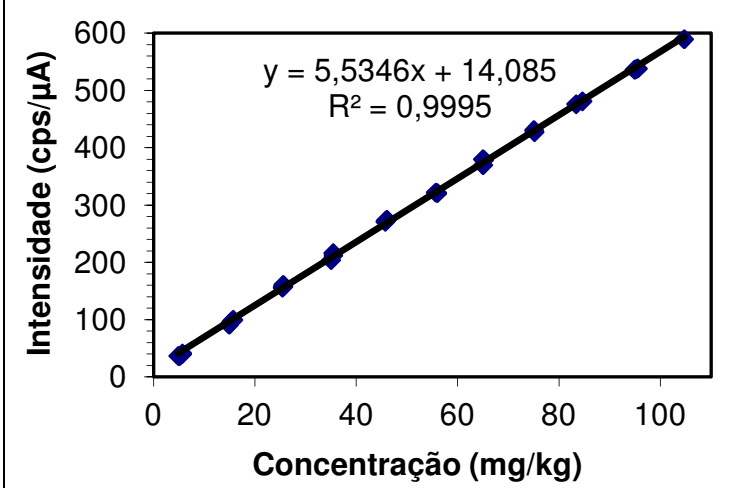

(c)

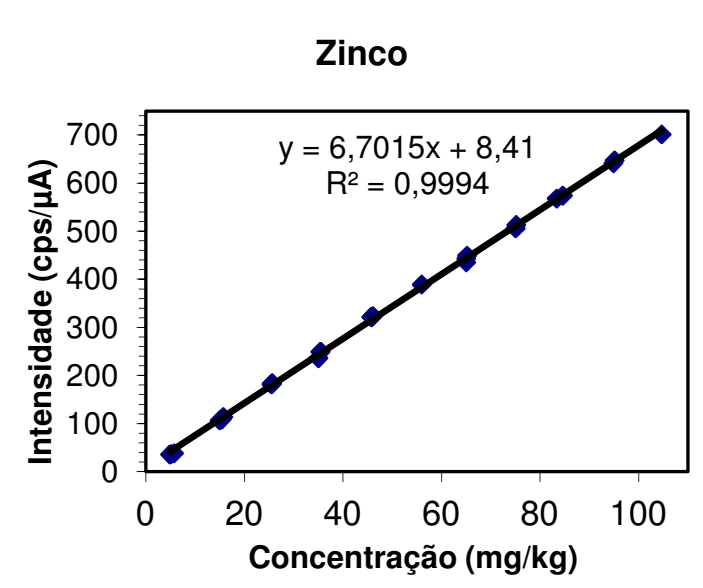

(b)

Níquel

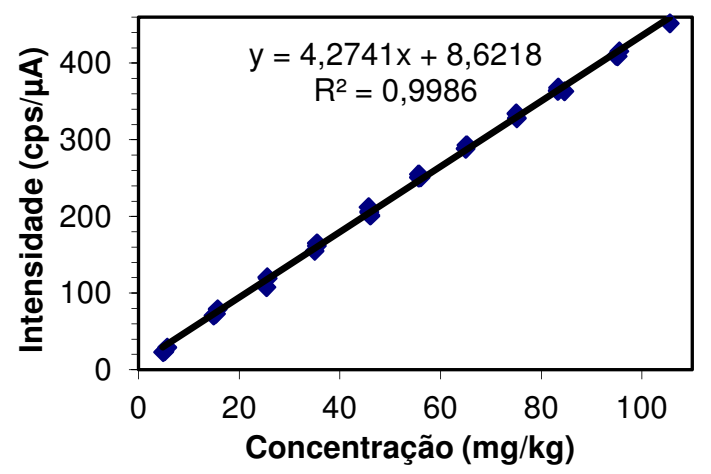

(d)

Figura 51. Gráficos de regressão linear obtidos para ferro, zinco, cobre e níquel usando 0 equipamento Epsilon $3 \mathrm{XL}$.

\subsubsection{Efeitos de Matriz}

Não foi possível a realização de teste de efeito de matriz nos métodos para determinação de metais usando o Epsilon $3 \mathrm{XL}$, portanto, apenas os métodos do FRX/EDX 720 foram testados. Os resultados dos estudos são resumidos na Tabela 20 que informa, para cada elemento, quais curvas apresentaram esse efeito quando comparadas à curva em PNM. Foi comprovado que algumas delas não seguem o modelo linear, sendo elaborado e testado um novo método que, em muitas situações, também não se mostrou linear. A seguir, serão discutidos de forma mais detalhada esses resultados. 
Tabela 20. Resumo dos resultados dos testes de efeito de matriz

\begin{tabular}{cccc}
\cline { 2 - 4 } Elemento & \multicolumn{3}{c}{ Básico } \\
\hline $\mathrm{Fe}$ & sim & PNL & PNP \\
$\mathrm{Zn}$ & sim & não & nim \\
$\mathrm{Mo}$ & não linear \\
$\mathrm{Cd}$ & não & não linear & não linear \\
$\mathrm{Ba}$ & não & sim & não \\
$\mathrm{Pb}$ & não & não linear & sim \\
$\mathrm{Ni}$ & sim & sim & não linear \\
$\mathrm{Ca}$ & não & sim & sim \\
$\mathrm{Cr}$ & sim & sim & não linear \\
$\mathrm{Cu}$ & não linear & sim & não linear \\
\hline
\end{tabular}

PSP - parafínico splindle; PNL - parafínico neutro leve; PNP - parafínico neutro pesado; sim apresenta efeito de matriz; não - não apresenta efeito de matriz; não linear - os métodos testados para a curva não são lineares.

\subsubsection{Cálcio e Cádmio}

A linearidade das curvas analíticas de cálcio e cádmio formuladas com os básicos PSP, PNL e PNP também foi comprovada. As curvas de cádmio em PSP, PNL e PNP são muito similares às obtidas para o básico PNM, ou seja, os coeficientes angulares e de determinação são muito baixos e a dispersão é alta.

A Figura 52 apresenta o gráfico da regressão obtido para as quatro curvas de cálcio pelo método PNM3. Observa-se que para os pontos de menor concentração, as curvas estão muito próximas, mas à medida que a concentração aumenta, elas se distanciam um pouco. A análise visual não é suficiente para que possa concluir sobre o real efeito da matriz. A Tabela 21 apresenta os resultados dos testes realizados para cada tipo de básico. Foi comprovado o efeito de matriz quando se compara as inclinações das curvas em PNM com as curvas em PNL e PNP. 
Tabela 21. Resultados dos testes das três comparações das curvas de cálcio - método PNM3

\begin{tabular}{|c|c|c|}
\hline PSP & PNL & PNP \\
\hline $\begin{array}{c}\text { F } 2,845 \\
F_{\text {crítico }} 2,533 \\
\text { Há Heterocedasticidade }\end{array}$ & $\begin{array}{c}\mathrm{F} 2,131 \\
\mathrm{~F}_{\text {crítico }} 2,533 \\
\text { Há Homocedasticidade }\end{array}$ & 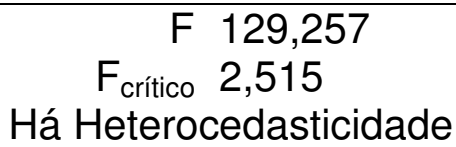 \\
\hline \multicolumn{3}{|c|}{ Inclinação } \\
\hline $\begin{array}{cc}t_{\mathrm{b}}{ }^{\prime} & 1,198 \\
\mathrm{t}_{\text {crítico }} & 2,064 \\
\text { Não há efeito de matriz }\end{array}$ & 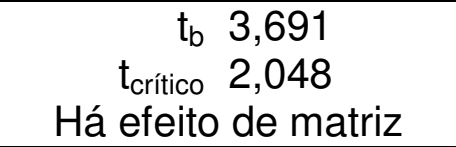 & 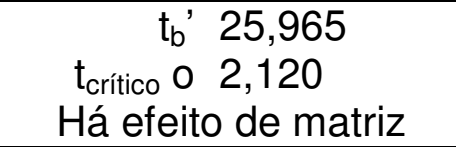 \\
\hline \multicolumn{3}{|c|}{ Interseção } \\
\hline $\begin{array}{c}\mathrm{t}_{\mathrm{a}}{ }^{\prime} \quad 0,325 \\
\text { Não há efeito de matriz }\end{array}$ & $\begin{array}{c}t_{a} 1,417 \\
\text { Não há efeito de matriz }\end{array}$ & $\begin{array}{c}\mathrm{t}_{\mathrm{a}}{ }^{\prime} \quad 0,714 \\
\text { Não há efeito de matriz }\end{array}$ \\
\hline
\end{tabular}

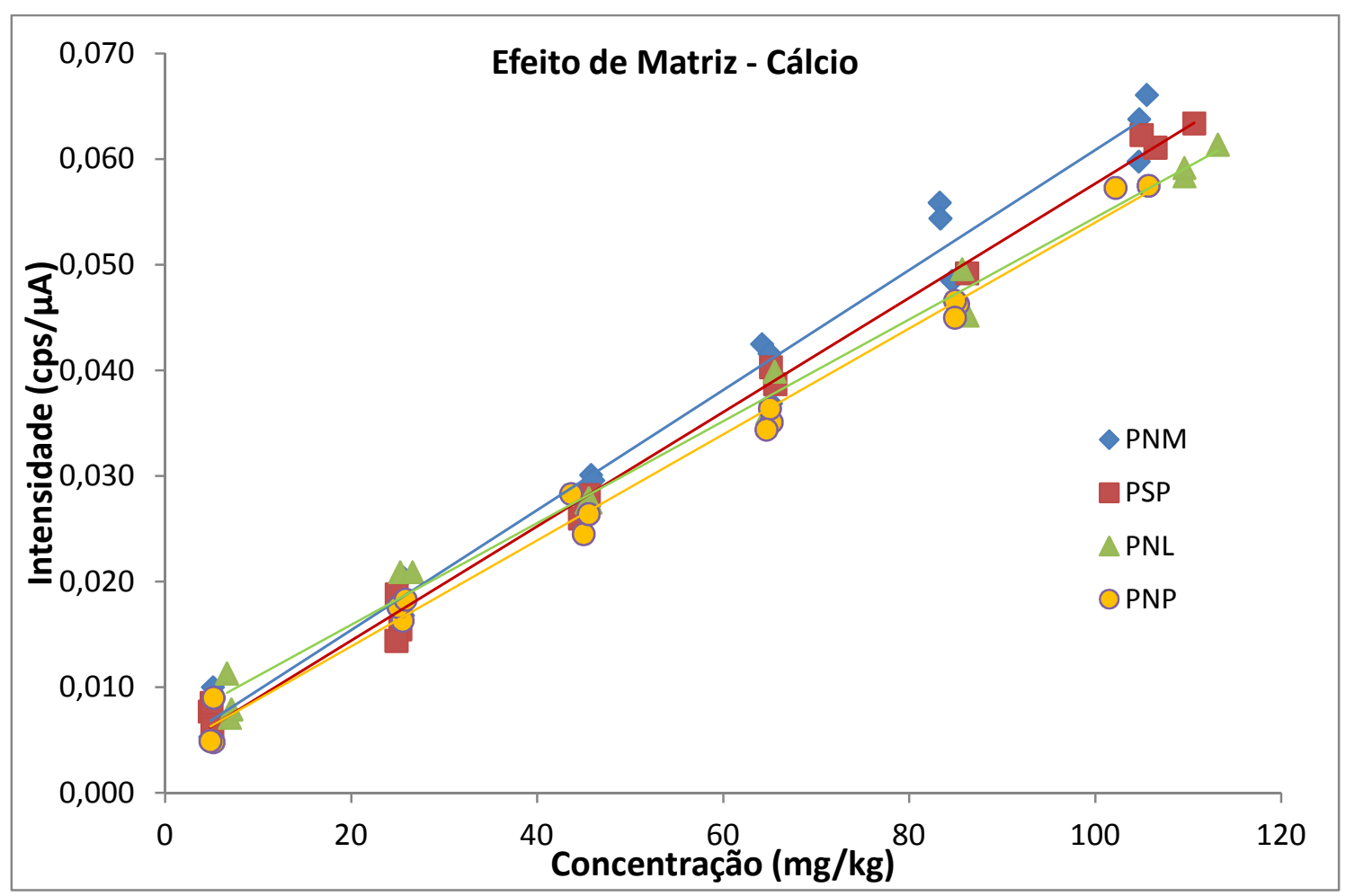

Figura 52. Gráfico de regressão linear das curvas de cálcio com os quatro tipos de básicos método PNM3.

A Figura 53 apresenta o gráfico da regressão obtido para as quatro curvas de cádmio pelo método PNM1. A curva em PNL se mostra distinta das demais, que quase se sobrepõem. Os testes de variância confirmaram não haver efeito de matriz no caso de PSP e PNP e a existência do efeito para a curva em PNL na inclinação e interseção. 


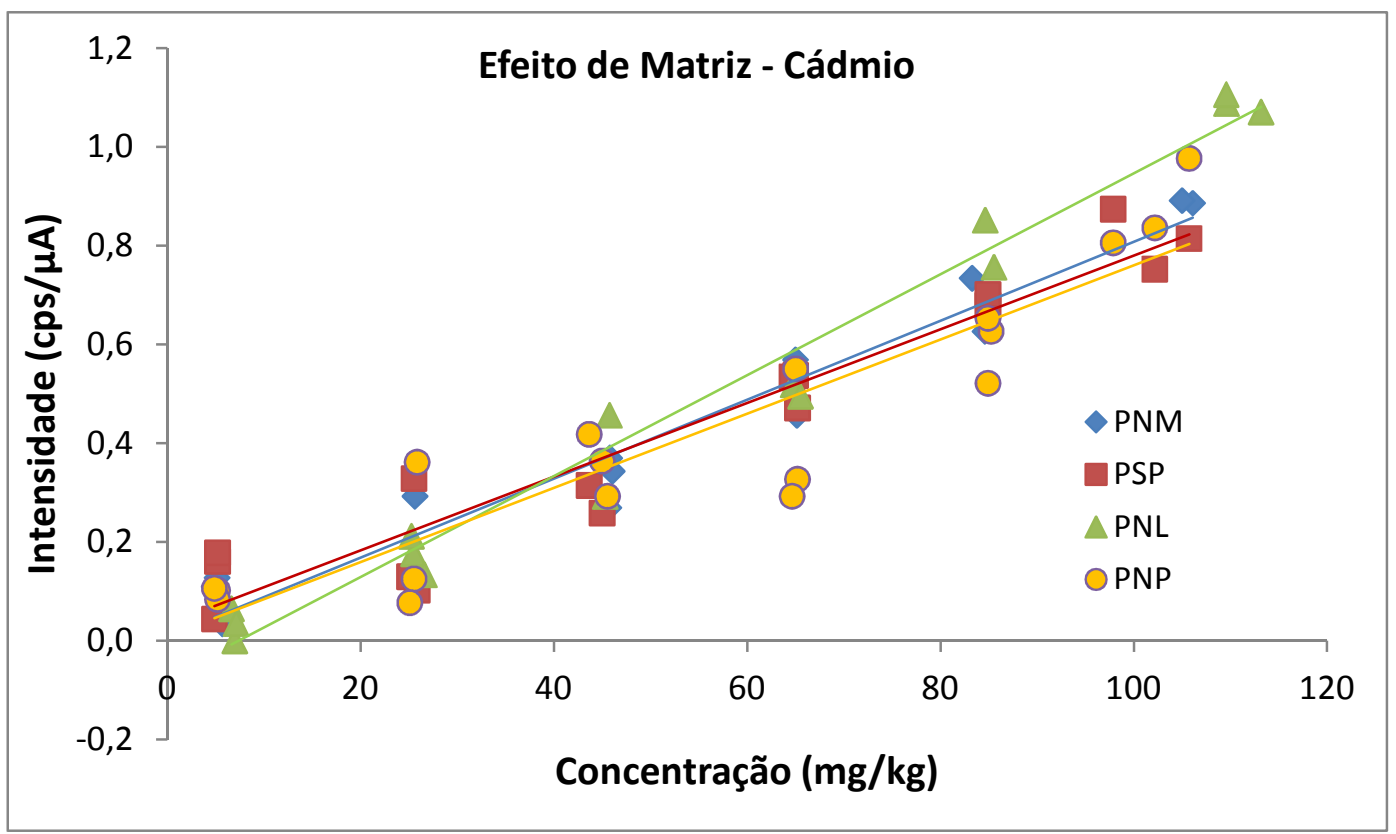

Figura 53. Gráfico de regressão linear das curvas de cádmio com os quatro tipos de básicos método PNM1.

\subsubsection{Zinco, Cromo e Níquel}

A linearidade das curvas analíticas de zinco, níquel e cromo formuladas com os básicos PSP e PNL foi comprovada. As curvas formuladas com PNP apresentaram desvio da linearidade para o zinco e cromo e teste de autocorrelação dos resíduos não conclusivo para níquel, mas, ainda sim, foram realizados os testes para verificação de efeito matriz com a finalidade de confirmar as avaliações visuais.

A Figura 54 apresenta o gráfico da regressão obtido para as quatro curvas pelo método PNM1 para o zinco. É possível notar que a curva PSP se distingue da curva PNM nas menores concentrações, mas se sobrepõe a ela nas maiores. As curvas PNL e PNP quase se sobrepõem e parecem distintas da curva de PNM, quase paralelas a ela, embora, no caso do PNP, nas menores concentrações, pareça haver uma convergência na direção de PNM. A análise visual indica a existência de efeito da matriz nos três casos. O teste $t$ de variância combinada realizado para as curvas em PSP e em PNP mostrou que há efeito de matriz na interseção e na inclinação, respectivamente, confirmando a impressão dada pela observação das curvas. O teste t de variância distinta realizado para a curva em PNL demonstrou não haver efeito matriz neste caso. 


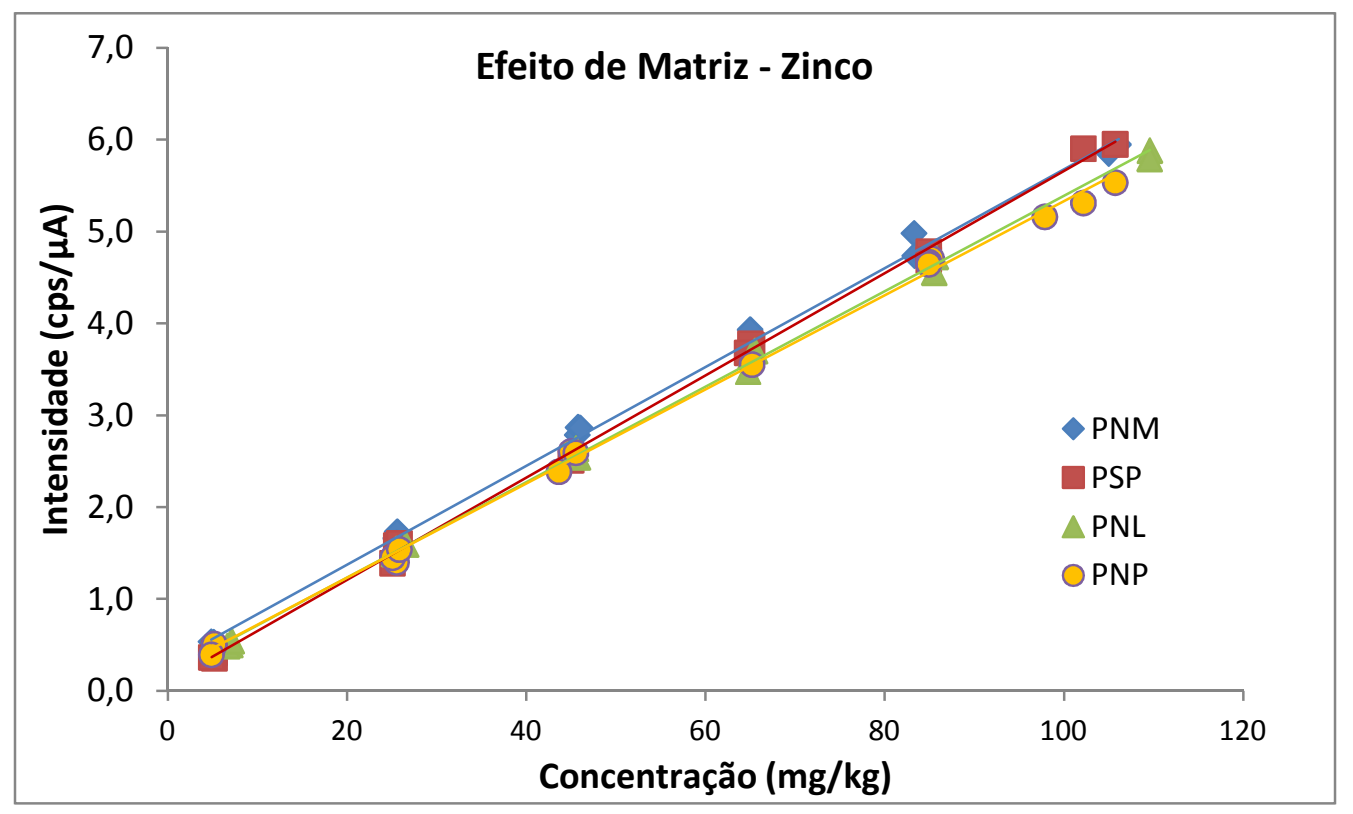

Figura 54. Gráfico de regressão linear das curvas de zinco com os quatro tipos de básicos método PNM1.

A Figura 55 apresenta o gráfico da regressão obtido para as quatro curvas pelo método PNM1 para o níquel. Assim como ocorreu no caso do zinco, as curvas PNL e PNP parecem se sobrepor e as quatro curvas convergem nas menores concentrações. A análise visual indica a existência de efeito da matriz nos três casos. O teste $\mathrm{t}$ de variância combinada realizado para as curvas mostrou que há efeito de matriz na inclinação nas três situações, confirmando a impressão dada pela observação das curvas.

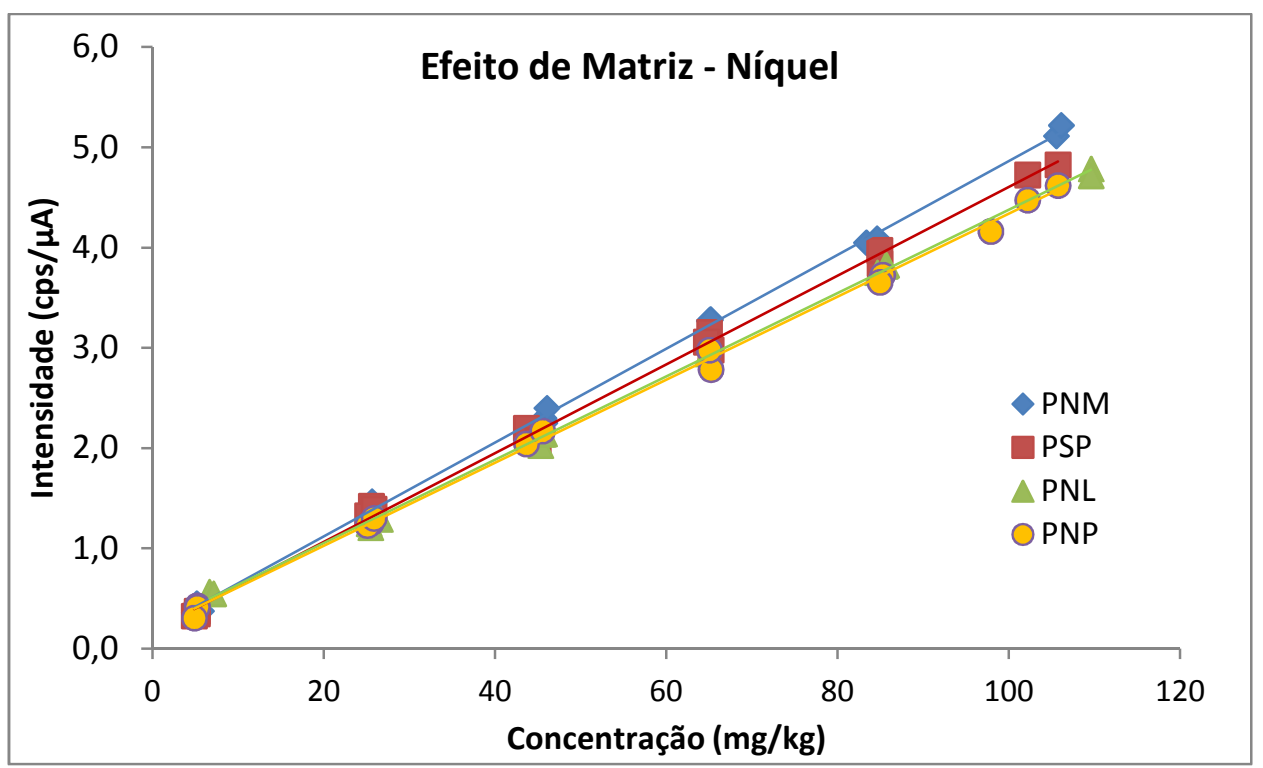

Figura 55. Gráfico de regressão linear das curvas de níquel com os quatro tipos de básicos método PNM1. 
A Figura 56 apresenta o gráfico da regressão obtido para as quatro curvas pelo método PNM1 para o cromo. Observa-se que a curva em PNL é completamente distinta das demais, que parecem convergir nas menores concentrações. A análise visual indica a existência de efeito da matriz nos três casos. O teste t de variância combinada realizado para as curvas em PSP e PNP mostrou que há efeito de matriz na inclinação nas duas situações, e o teste de variância distinta mostrou que há efeito de matriz na inclinação e na interseção, confirmando a impressão dada pela observação das curvas.

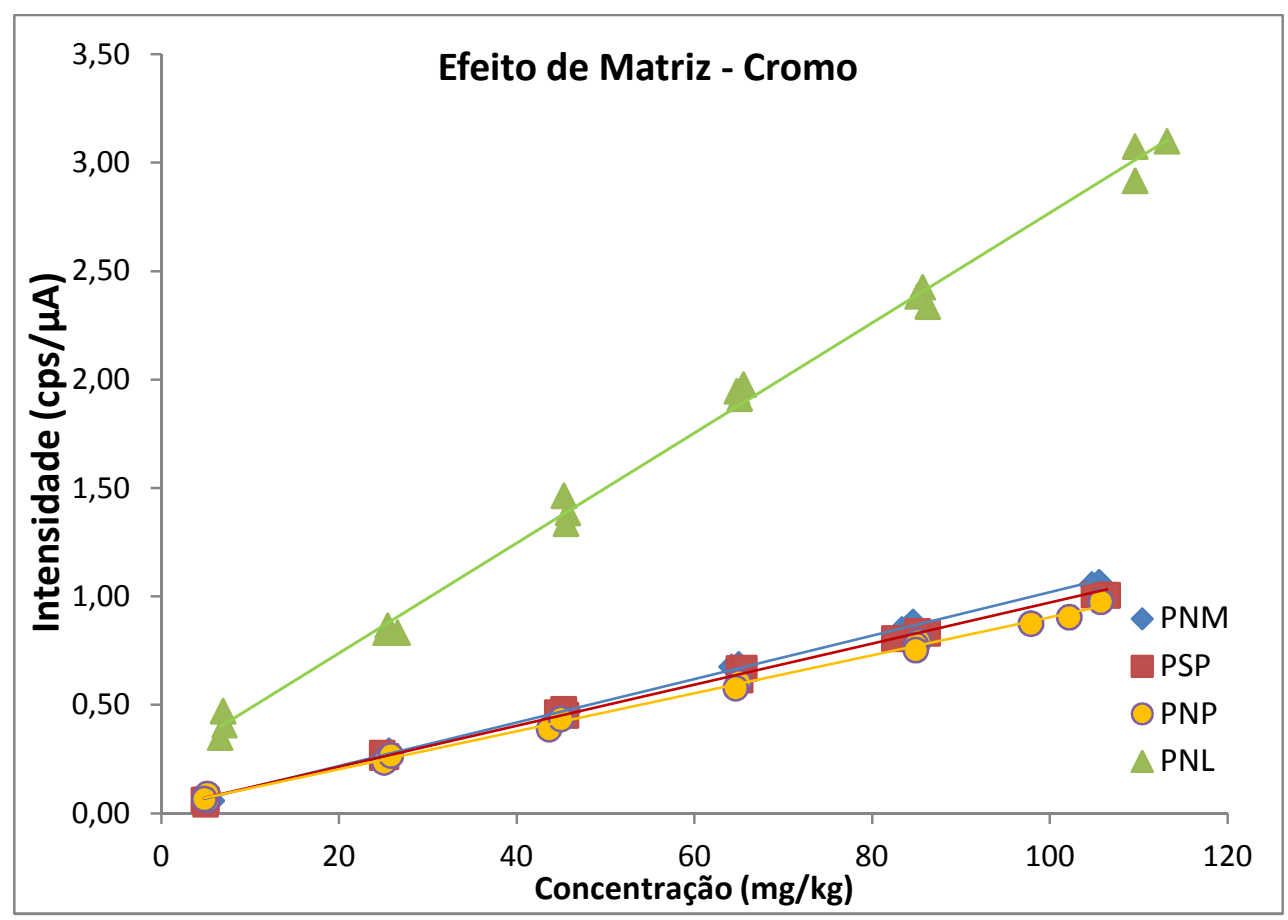

Figura 56. Gráfico de regressão linear das curvas de cromo com os quatro tipos de básicos método PNM1.

Foram feitas algumas modificações no método PNM1 para esses três elementos, recebendo o nome PNM3, as quais constam na Tabela 10. As curvas formuladas em PNP foram testadas quanto à linearidade, apresentando desvio no caso do zinco. Observando o gráfico da regressão linear obtido para a curva de zinco em PNP pelo método PNM3, Figura 57, nota-se que a sensibilidade do método é 10 vezes menor que a obtida pelo método PNM1. O coeficiente angular é da ordem de milésimos. Assim, devido à baixa sensibilidade e ao desvio da linearidade, não foram realizados outros testes nas condições estabelecidas pelo método PNM3 para zinco. Com relação ao cromo e ao níquel, o teste de autocorrelação dos resíduos foi não conclusivo. 
Além disso, o coeficiente angular da curva de níquel é cerca de 10 vezes menor que o obtido pelo método PNM1, mostrando baixa sensibilidade.

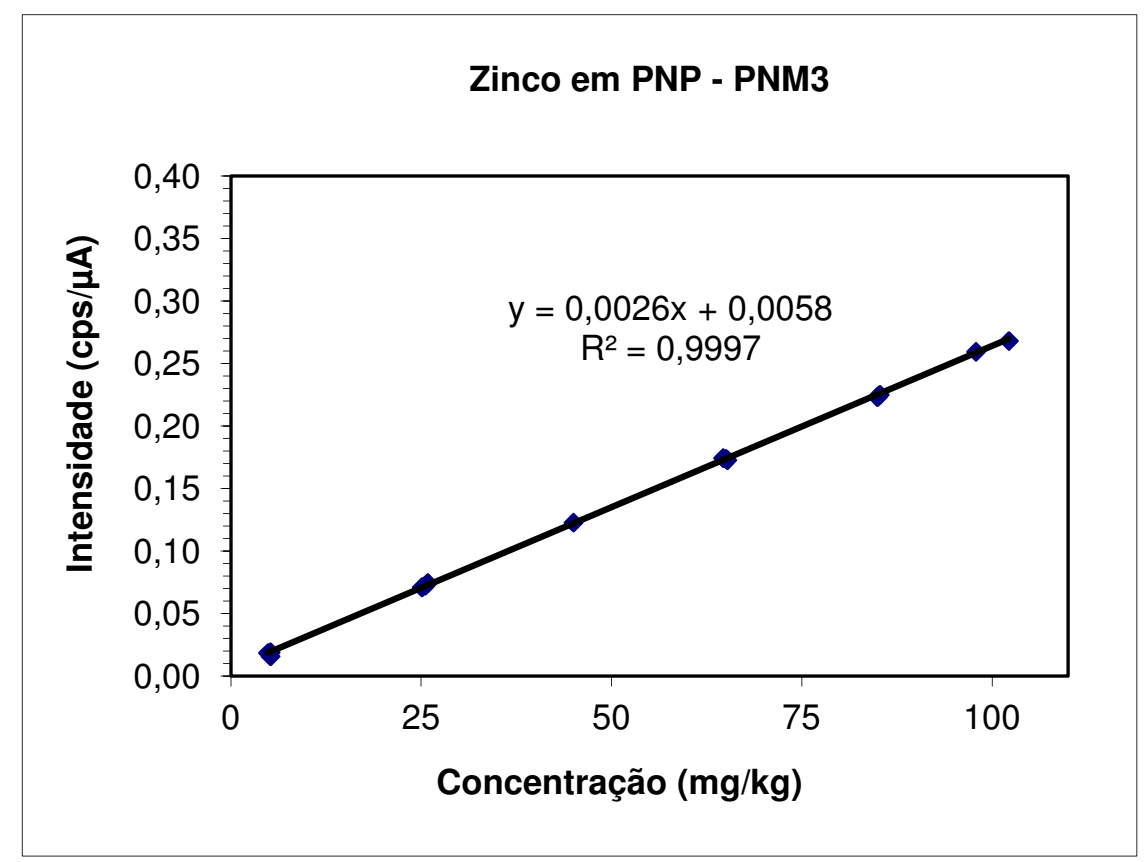

Figura 57. Gráfico da regressão linear obtida para o zinco pelo método PNM3.

\subsubsection{Ferro e bário}

A linearidade das curvas analíticas de ferro e bário formuladas com os básicos PSP e PNL foi comprovada. As curvas formuladas com PNP apresentaram desvio da linearidade, no caso do ferro, e autocorrelação negativa dos resíduos no caso do bário. Novo método, chamado PNM3, foi estabelecido para ambos e as suas condições de análise constam na Tabela 10. A linearidade das curvas formulada em PNP foi comprovada para os dois, por isso o método foi avaliado também para as curvas em PSP, PNL e PNM, sendo comprovada a linearidade em todos os casos. Como pode ser constatado por visualização dos gráficos de regressão linear das curvas em PNP apresentados na Figura 58, e pelo coeficiente angular, a sensibilidade do método é próxima à do PNM1, assim como os coeficientes de determinação. Assim, as curvas de ferro e bário obtidas com o método PNM3 foram testadas quanto ao efeito de matriz e os demais parâmetros de validação também foram determinados para este método apenas. 


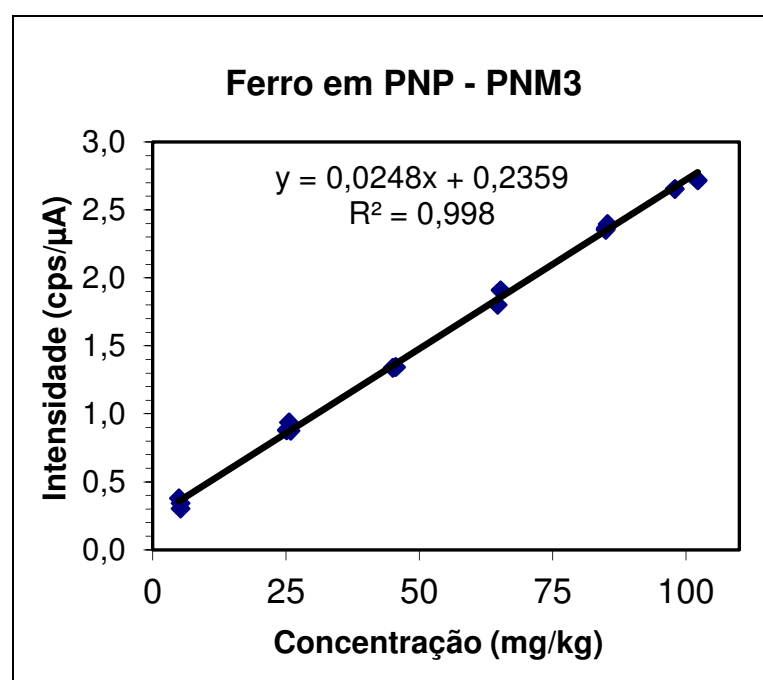

(a)

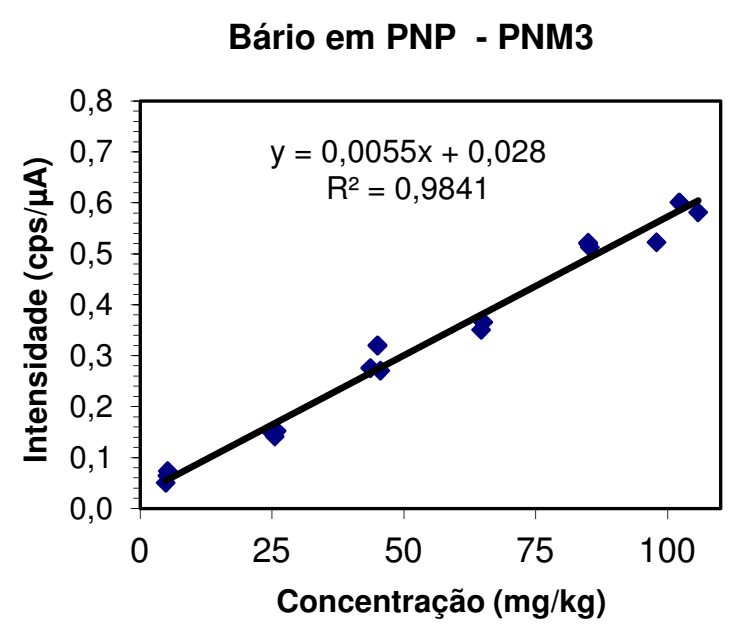

(b)

Figura 58. Gráfico da regressão linear das curvas em PNP para ferro (a) e bário (b) pelo método PNM3.

As Figuras 59 e 60 apresentam os gráficos da regressão obtidos para as quatro curvas de ferro e bário, respectivamente. No primeiro caso, as curvas PNL e PNP quase se sobrepõem e parecem distintas da curva de PNM, embora as três pareçam convergir nas menores concentrações. A curva em PSP é quase paralela à curva em PNM. A análise visual indica a existência de efeito da matriz nos três casos. $O$ teste $t$ de variância combinada realizado para as curvas mostrou que há efeito de matriz na inclinação nos casos de PNL e PNP e efeito na interseção, no caso de PSP, confirmando a impressão dada pela observação das curvas.

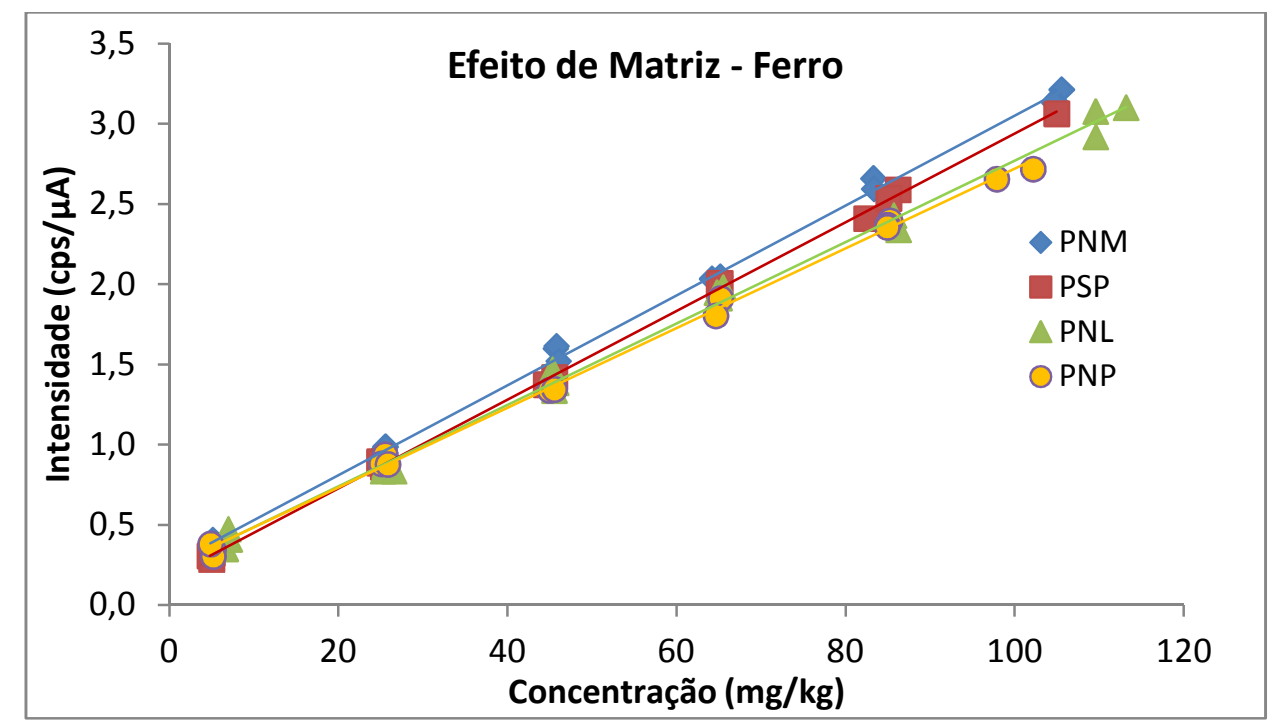

Figura 59. Gráfico de regressão linear das curvas de ferro com os quatro tipos de básicos método PNM1. 


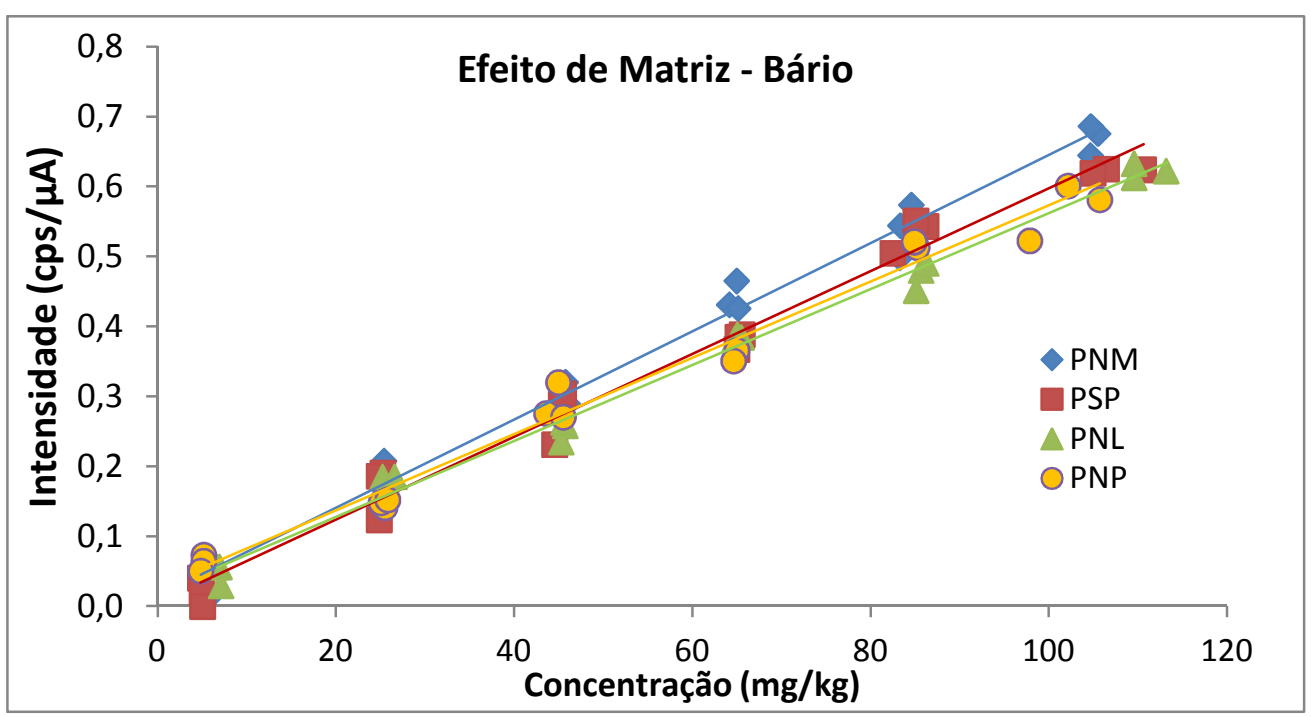

Figura 60. Gráfico de regressão linear das curvas de bário com os quatro tipos de básicos método PNM1.

No caso do bário, as curvas não são visualmente diferentes, apena PNM parece ter a inclinação um pouco maior que as demais. $O$ teste $t$ de variância combinada realizado para as curvas mostrou que há efeito de matriz na inclinação nos casos de PNL e PNP. PSP não apresentou efeito de matriz de nenhum tipo.

\subsubsection{Chumbo}

A linearidade das curvas de chumbo em PSP e PNP foi confirmada, mas a curva em PNL apresentou heterodasticidade dos resíduos. Por observação do gráfico da Figura 61, percebe-se que não existem diferenças significativas entre as quatro curvas, o que foi comprovada pelos testes de variância, não havendo efeitos de matriz. Um novo método, PNM3, foi testado para a curva em PNL, mas também foi constatado o desvio da linearidade. 


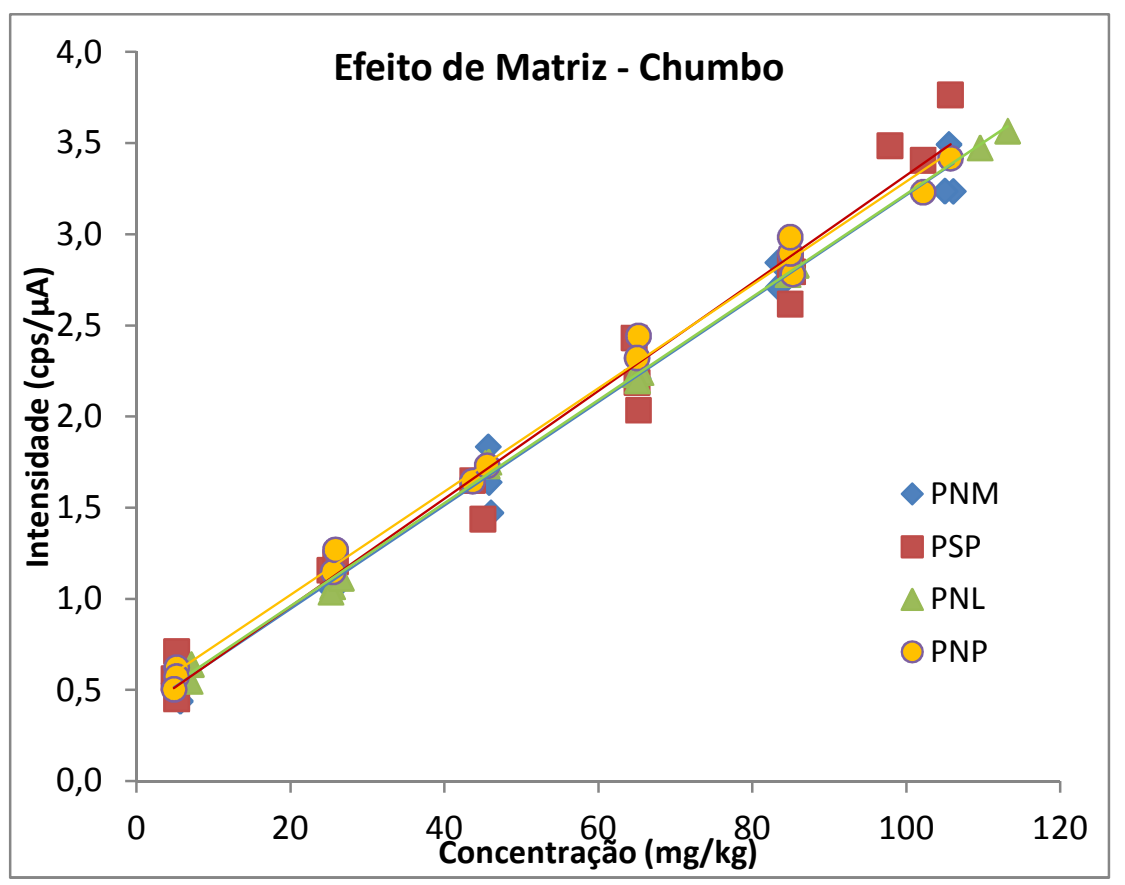

Figura 61. Gráfico de regressão linear das curvas de chumbo com os quatro tipos de básicos método PNM1.

\subsubsection{Molibdênio}

A linearidade da curva de molibdênio em PSP foi confirmada, mas a curvas em PNL e PNP apresentaram desvio. Por observação do gráfico da Figura 62, percebe-se que não existem diferenças significativas entre as quatro curvas, 0 que foi comprovada pelos testes de variância, não havendo efeitos de matriz. Um novo método, PNM3, foi testado para as curvas em PNL e PNP, mas também foi constatado o desvio da linearidade. 


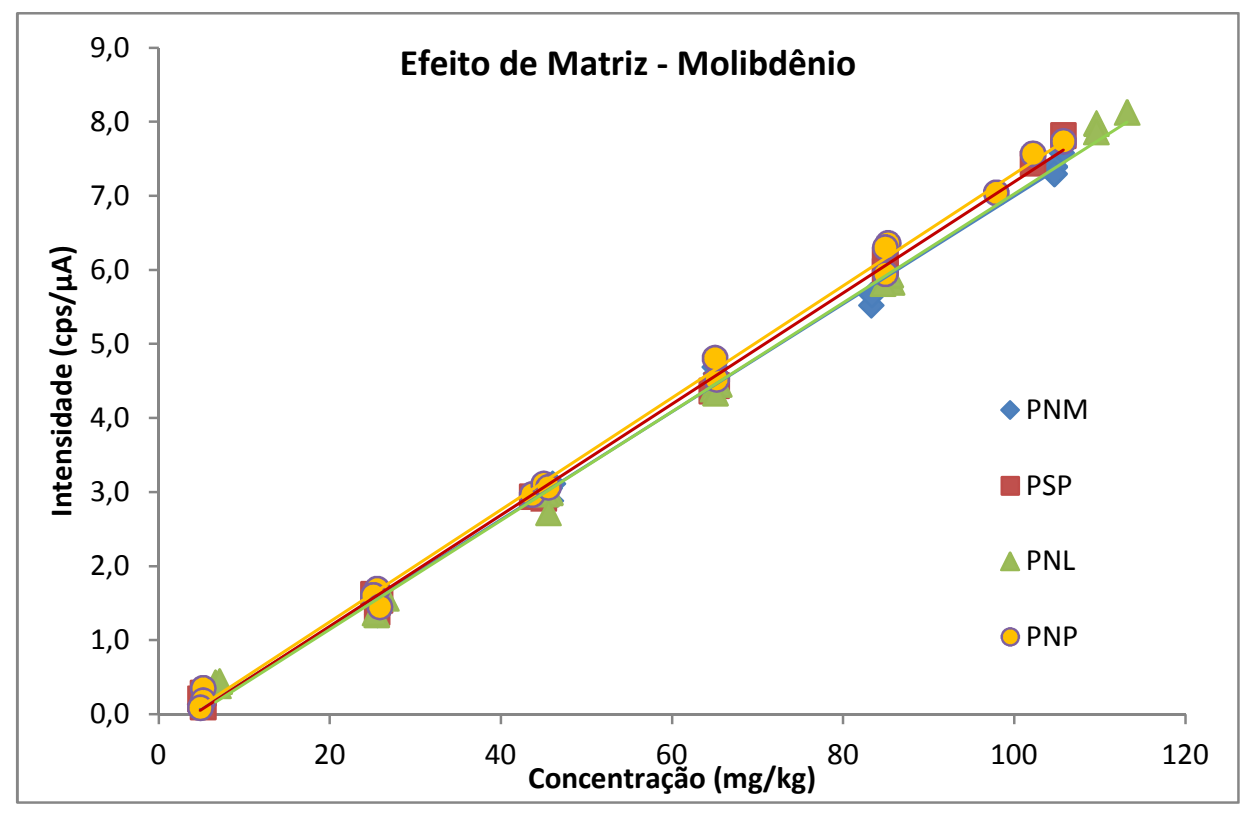

Figura 62. Gráfico de regressão linear das curvas de molibdênio com os quatro tipos de básicos - método PNM1.

\subsubsection{Cobre}

A linearidade da curva de cobre em PNL foi confirmada, mas a curvas em PSP e PNP apresentaram desvio. Por observação do gráfico da Figura 63, percebese que as curvas em PSP e PNP se sobrepõem e que, assim como a curva em PNL, são distintas das curvas em PNM. Os testes de variância apontam para efeito de matriz na inclinação nos três casos.

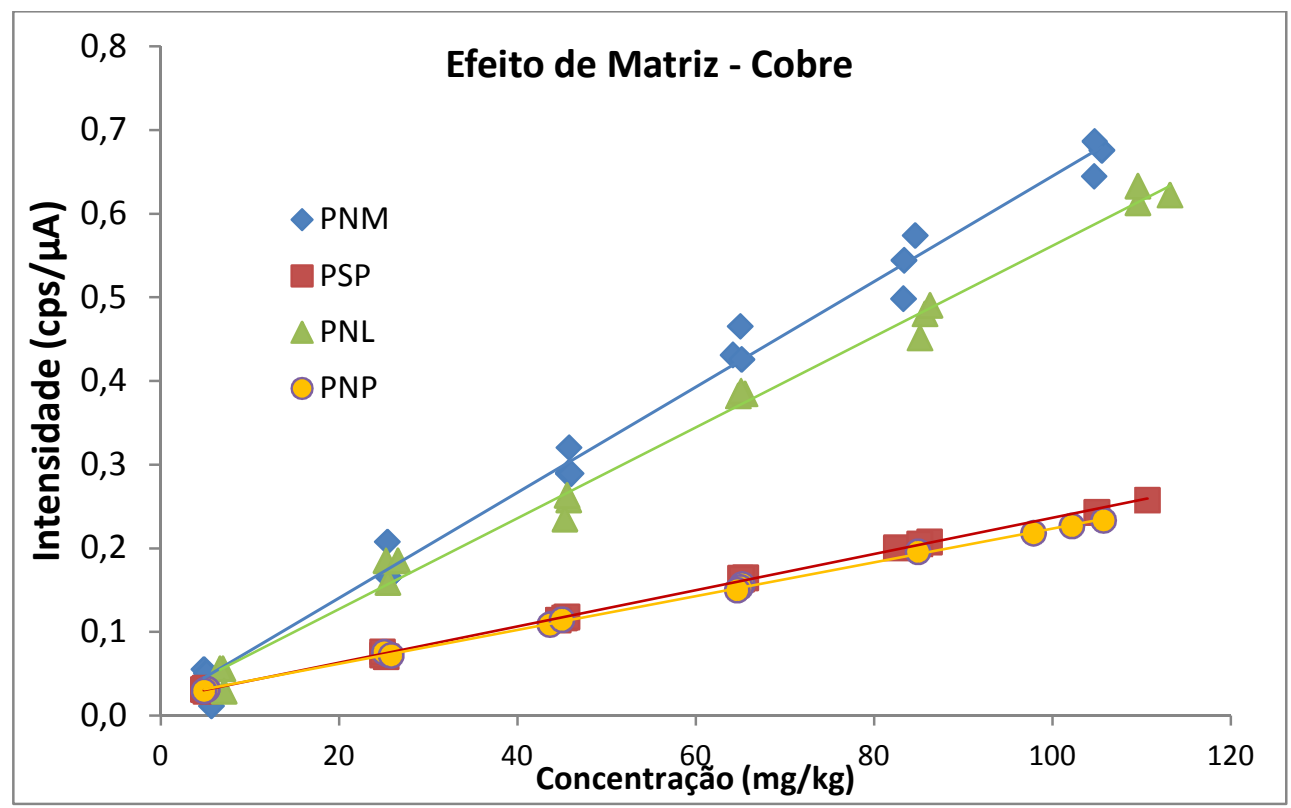

Figura 63. Gráfico de regressão linear das curvas de cobre com os quatro tipos de básicos método PNM3. 
O efeito de matriz foi confirmado na maior parte das situações avaliadas, além disso, em alguns casos, nenhum método linear pôde ser estabelecido. Portanto, optou-se por prosseguir a validação considerando que, para cada básico, deverá existir um método próprio e que um mesmo método não possibilita a determinação dos teores dos elementos em todos os tipos de básicos. A Tabela 22 resume os métodos adotados.

Tabela 22. Resumo dos métodos adotados para cada elemento

\begin{tabular}{ccccc}
\hline \multicolumn{4}{c}{ Básico } \\
\hline Elemento & PNM & PSP & PNL & PNP \\
\hline Fe & PNM3 & PNM3 & PNM3 & PNM3 \\
Mo & PNM1 & PNM1 & PNM1 & sem método \\
$\mathrm{Cd}$ & PNM1 & PNM1 & sem método & sem método \\
$\mathrm{Ba}$ & PNM1 & PNM1 & PNM1 & PNM1 \\
$\mathrm{Pb}$ & PNM3 & PNM3 & PNM3 & PNM3 \\
$\mathrm{Ni}$ & PNM1 & PNM1 & sem método & PNM1 \\
$\mathrm{Ca}$ & PNM1 & PNM1 & PNM1 & sem método \\
$\mathrm{Cr}$ & PNM3 & PNM3 & PNM3 & PNM3 \\
$\mathrm{Cu}$ & PNM3 & PNM3 & PNM3 & sem método \\
\hline
\end{tabular}

PSP - parafínico splindle; PNL - parafínico neutro leve; PNM - parafínico neutro médio; PNP _ parafínico neutro pesado

\subsubsection{Limites de Detecção e Quantificação}

Os cálculos dos limites de detecção, LD, e quantificação, $L Q$, da curva em PNM para determinação de Fe em PNM1 consta no Anexo 3, como um exemplo. Os limites de detecção e quantificação são informados na Tabela 23 em comparação com limites teóricos de equipamentos de FRX/EDX informados por Wolska. ${ }^{82}$ 
Tabela 23. Limites de detecção e quantificação dos elementos para cada básico (mg/kg)

\begin{tabular}{c|c|cccccc|cccccc}
\hline \multirow{2}{*}{$\mathrm{E}$} & \multirow{2}{*}{$\mathrm{LD}^{*}$} & \multicolumn{6}{|c|}{ Limites de Detecção } & \multicolumn{5}{c}{ Limites de Quantificação } \\
\cline { 3 - 14 } & & PNM & ICP & PNM & PSP & PNL & PNP & PNM & ICP & PNM & PSP & PNL & PNP \\
\hline $\mathrm{Fe}$ & 0,5 & $-0,38$ & 1,58 & 2,70 & 6,18 & 1,08 & 1,87 & 1,65 & 3,22 & 13,32 & 18,25 & 7,86 & 11,93 \\
$\mathrm{Zn}$ & 0,2 & $-0,81$ & 3,38 & 0,40 & 6,01 & 3,52 & - & $-0,31$ & 7,34 & 6,98 & 17,43 & 13,57 & - \\
$\mathrm{Mo}$ & - & - & 2,81 & 2,65 & 2,23 & - & - & - & 4,48 & 6,27 & 5,57 & - & - \\
$\mathrm{Cd}$ & 0,8 & 4,33 & 3,33 & 29,33 & 1,23 & 13,91 & 11,96 & 13,55 & 4,99 & 74,44 & 3,97 & 24,58 & 38,36 \\
$\mathrm{Ba}$ & 2,3 & - & 2,78 & 13,32 & 13,35 & 7,60 & 7,64 & - & 4,68 & 41,33 & 38,41 & 27,56 & 30,15 \\
$\mathrm{~Pb}$ & 0,4 & $-0,08$ & 2,33 & 21,66 & 10,32 & - & 6,39 & 0,44 & 3,23 & 42,17 & 32,81 & - & 25,10 \\
$\mathrm{Ni}$ & 0,2 & $-0,87$ & 2,63 & 1,36 & 0,28 & 0,55 & - & 0,62 & 4,07 & 8,56 & 5,32 & 6,02 & - \\
$\mathrm{Ca}$ & 1,1 & 12,79 & 3,19 & 4,26 & 35,58 & 7,41 & 11,45 & 51,18 & 4,62 & 22,37 & 104,9 & 37,25 & 39,74 \\
$\mathrm{Cr}$ & 0,8 & $-0,63$ & 2,82 & 4,19 & 2,87 & 1,54 & - & 3,07 & 4,16 & 12,35 & 11,68 & 5,55 & - \\
$\mathrm{Cu}$ & 0,2 & $-0,21$ & 2,93 & 0,52 & - & 0,45 & - & 1,86 & 4,49 & 4,34 & - & 5,05 & - \\
$\mathrm{Si}$ & 10 & 7,28 & 0,09 & - & - & - & - & 17,13 & 4,21 & - & - & - & - \\
\hline
\end{tabular}

$\mathrm{E}$ - elemento; $\mathrm{LD}^{*}$ - Limite de deteç̧ão teórico de um FRX/EDX ${ }^{82} ; \mathrm{PNM}_{\mathrm{E}}$ - parafínico médio usando o Epsilon; ICP - dados usando o ICP; PSP - parafínico splindle; PNL - parafínico neutro leve; PNM - parafínico neutro médio; PNP - parafínico neutro pesado

Os limites de detecção do método adotado usando o Epsilon 3 XL apresentam em sua maioria sinais negativos, ou seja, os ruídos são baixos, o que permite concluir que a forma como foram estabelecidos não é a ideal, mas sim a utilização de amostras dopadas em baixíssimas concentrações. Com exceção dos elementos cálcio e silício, os limites de quantificação deste método também são muito baixos e ambos, LD e LQ, são da mesma ordem de grandeza que os limites do método por ICP. Apesar de serem necessários outros estudos afim de melhor estimar esses parâmetros para este método, os resultados obtidos indicam que com o Epsilon 3 XL é possível obter limites próximos aos do ICP para vários elementos.

O mesmo não se pode afirmar sobre o FRX/EDX 720, pois os valores obtidos para esses parâmetros nos casos dos métodos que o utilizam na maioria das situações são altos. De uma forma geral, os maiores limites pertencem aos elementos cádmio, bário, chumbo e cálcio. Como discutido anteriormente, as curvas desses metais apresentaram menor sensibilidade e coeficientes de determinação, o que tem um peso maior quando se trata de valores de menor concentração e, por isso, já era esperado que os limites para esses métodos fossem altos. Em contrapartida, não se esperava o mesmo para o ferro que apresentou uma sensibilidade razoável e um coeficiente de determinação próximo de 1. No entanto, a sua curva em PSP obteve LD igual a $6,18 \mathrm{mg} / \mathrm{kg} \mathrm{e}$ LQ $18,25 \mathrm{mg} / \mathrm{kg}$. Os limites de detecção de ferro nas demais curvas e dos 
outros elementos ficou abaixo de 5 e os de quantificação abaixo de 13,5 com exceção do zinco em PSP, cujo LD foi $6,01 \mathrm{mg} / \mathrm{kg}$ e o LQ 17,43. Os menores valores de LD e LQ foram os do cobre. Esses resultados são um bom indício de que os métodos estudados podem ser utilizados para quantificar ferro, zinco, níquel e cobre. Quando comparados aos limites de detecção obtidos pelo método ASTM D5185, observa-se que, com exceção dos elementos Mo, $\mathrm{Ni}$ e $\mathrm{Cu}$, os valores obtidos para o FRX/EDX são sempre superiores.

\subsubsection{Precisão: Repetibilidade e Precisão Intermediária}

A Tabela 24 informa os valores de repetibilidade e precisão intermediária obtidos para cada elemento nas diferentes curvas analíticas e os de repetibilidade e reprodutibilidade estabelecidos pela ASTM D5185. O cádmio não é contemplado pela ASTM D5185, por isso não existe um valor para comparação e o zinco foi avaliado na faixa de 60 a $1600 \mathrm{mg} / \mathrm{kg}$. No Anexo 4, consta os dados referentes ao ferro. Apenas as retitividades de $\mathrm{Zn}, \mathrm{Cd}, \mathrm{Ca}$ e Si foram determinadas para o método usando o Epsilon $3 \mathrm{XL}$, sendo os valores encontrados para $\mathrm{Zn}$ e Si inferiores aos estabelecidos pela ASTM D5185. Os valores de repetibilidade encontrados para o FRX/EDX 720 são maiores que os estabelecidos pelo método ASTM D5185, exceto para o zinco e molibdênio em PNM e PSP e para o cobre em PNM. Isso implica que a dispersão dos resultados pelo método ASTM é menor que pelos métodos avaliados neste estudo e que estes são menos precisos. A precisão intermediária determinada para o método em FRX/EDX foi comparada à reprodutibilidade estabelecida pela ASTM, embora não se trate do mesmo parâmetro, o esperado é que a precisão intermediária não seja superior à reprodutibilidade, o que é comprovado. 
Tabela 24. Repetibilidade e precisão intermediária dos métodos avaliados (mg/kg)

\begin{tabular}{c|cccccc|ccccc}
\hline \multirow{2}{*}{ Elemento } & \multicolumn{7}{|c|}{ Repetitibilidade } & \multicolumn{5}{c}{ Precisão intermediária } \\
\cline { 2 - 12 } & PNM $_{\mathrm{E}}$ & ICP & PNM & PSP & PNL & PNP & ICP & PNM & PSP & PNL & PNP \\
\hline $\mathrm{Fe}$ & - & 3,21 & 6,40 & 3,30 & 5,11 & 2,85 & 12,83 & 3,67 & 0,31 & 0,72 & 1,67 \\
$\mathrm{Zn}$ & 1,40 & 5,10 & 5,20 & 3,59 & 5,52 & - & 6,82 & 2,96 & 1,15 & 1,62 & - \\
$\mathrm{Mo}$ & - & 4,79 & 3,36 & 3,37 & - & - & 11,01 & 0,76 & 2,97 & - & - \\
$\mathrm{Cd}$ & 2,05 & - & 24,71 & 33,01 & 30,63 & 23,86 & - & 9,06 & 1,05 & 4,10 & 3,39 \\
$\mathrm{Ba}$ & - & 3,38 & 7,0 & 6,1 & 12,18 & 15,39 & 23,55 & 1,16 & 0,82 & 2,75 & 2,68 \\
$\mathrm{~Pb}$ & - & 5,77 & 12,46 & 10,00 & - & 11,57 & 12,70 & 26,86 & 3,60 & - & 8,11 \\
$\mathrm{Ni}$ & - & 3,70 & 4,19 & 5,24 & 5,13 & - & 11,12 & 1,44 & 4,41 & 0,40 & - \\
$\mathrm{Ca}$ & 12,00 & 0,55 & 5,76 & 12,36 & 4,42 & 18,72 & 2,75 & 1,39 & 5,74 & 1,08 & 3,72 \\
$\mathrm{Cr}$ & - & 3,43 & 5,03 & 3,73 & 7,08 & - & 9,33 & 0,56 & 2,95 & 2,46 & - \\
$\mathrm{Cu}$ & - & 4,60 & 4,35 & - & 5,25 & - & 13,20 & 3,55 & - & 1,17 & - \\
$\mathrm{Si}$ & 3,10 & 3,68 & - & - & - & - & 13,84 & - & - & - & - \\
\hline
\end{tabular}

$\mathrm{PNM}_{\mathrm{E}}$ - parafínico médio usando o Epsilon; ICP - dados usando o ICP; PSP - parafínico splindle; PNL - parafínico neutro leve; PNM - parafínico neutro médio; PNP - parafínico neutro pesado

\subsubsection{Exatidão}

No caso do Epsilon $3 \mathrm{XL}$, os testes de recuperação foram realizados no ponto médio da curva, ou seja, $55 \mathrm{mg} / \mathrm{kg}$. Nesse ponto, o método não é inexato para nenhum dos elementos estudados.

Com relação aos métodos de análise adotados para o FRX/EDX 720, foi comprovado que as curvas dos metais $\mathrm{Fe}, \mathrm{Zn}$ e Mo em PSP são inexatas em 6 $\mathrm{mg} / \mathrm{kg}$ e a curva de Mo é inexata também a $12 \mathrm{mg} / \mathrm{kg}$. Nenhuma curva em PSP apresentou inexatidão nos pontos 30,50 e $100 \mathrm{mg} / \mathrm{kg}$. Esse resultado não era esperado para o $\mathrm{Ca}$, pois o seu LQ é igual a $104,9 \mathrm{mg} / \mathrm{kg}$ e, portanto, pensavase que seria constatada a inexatidão do método para este metal. As curvas de $\mathrm{Fe}, \mathrm{Cd}, \mathrm{Ca}$ e $\mathrm{Cu}$ em PNL são inexatas em $10 \mathrm{mg} / \mathrm{kg}$ e a de $\mathrm{Fe}$ é inexata também em $30 \mathrm{mg} / \mathrm{kg}$. As curvas de $\mathrm{Pb}$, Mo e Cd em PNM são inexatas em 10 $\mathrm{mg} / \mathrm{kg}$ e a de $\mathrm{Pb}$ é inexata também em 30 e $50 \mathrm{mg} / \mathrm{kg}$. Mais uma vez, esperava-se comprovar a inexatidão de $\mathrm{Cd}$ em $30 \mathrm{mg} / \mathrm{kg}$ e de Ba em 10 e 30 $\mathrm{mg} / \mathrm{kg}$, pois os limites de quantificação desses metais são superiores a 40 $\mathrm{mg} / \mathrm{kg}$. As curvas de Fe em PNP são inexatas nos pontos 10, 30 e $50 \mathrm{mg} / \mathrm{kg}$ e a curva de Ca nesse mesmo básico é inexata em $10 \mathrm{mg} / \mathrm{kg}$. Acreditava-se que seria constatada a inexatidão da curva de $\mathrm{Cd}$ em $30 \mathrm{mg} / \mathrm{kg}$, o que não foi concretizado. 
Os resultados citados confirmam que $\mathrm{Fe}$ não pode ser quantificado com exatidão em PNL quando em concentrações inferiores a $30 \mathrm{mg} / \mathrm{Kg}$ e em PNP em concentrações inferiores a $50 \mathrm{mg} / \mathrm{kg}$, embora os limites de quantificação dessas curvas sejam abaixo de $12 \mathrm{mg} / \mathrm{kg}$. O chumbo não pode ser quantificado com exatidão em concentrações inferiores a $50 \mathrm{mg} / \mathrm{kg}$.

Ficou comprovado que os elementos não podem ser quantificados com exatidão em pontos inferiores aos limites de quantificação estimados. Como exceção, a determinação de $\mathrm{Ca}$ em PSP e Cd e Ba em PNM não tiveram sua inexatidão comprovada, o que indica que deve ser buscada uma forma diferente de determinar os limites de detecção e quantificação dos métodos estudados.

\subsubsection{Incerteza}

A Figura 64 mostra o diagrama de Ishikawa construído para avaliar as possíveis fontes de incerteza dos métodos de determinação de metais utilizando o equipamento FRX/EDX 720. Um exemplo dos cálculos de incerteza combinada de cada fonte e da incerteza final consta no Anexo. Em todos os casos, a maior contribuição foi da repetibilidade e, na maioria, a segunda maior foi da precisão intermediária. Isso confirma a baixa precisão dos métodos avaliados.

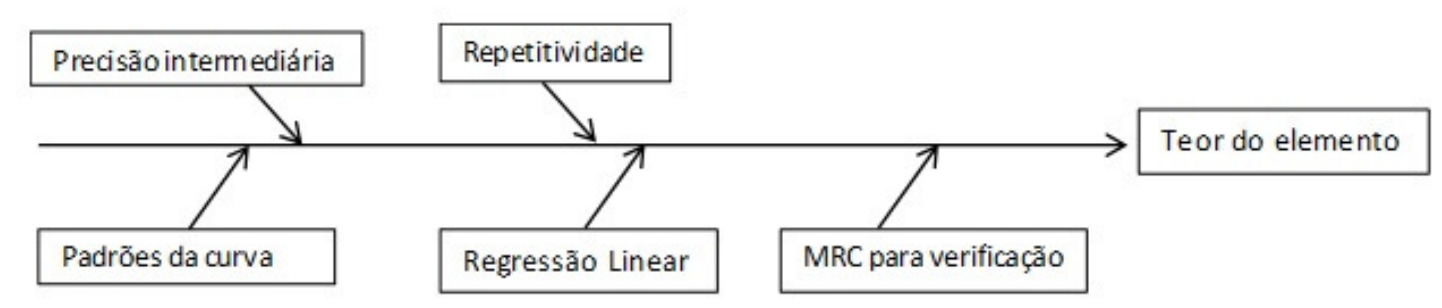

Figura 64. Diagrama de Ishikawa com as fontes de incerteza avaliadas para os métodos.

Os valores de incerteza expandida são apresentados na Tabela 25. O ponto de referência para o cálculo foi o meio da curva, ou seja, $55 \mathrm{mg} / \mathrm{kg}$. Os cálculos realizados para o ferro constam no Anexo 5. A menor incerteza alcançada foi a da determinação de ferro em PSP, a qual corresponde a cerca de $14 \%$ de 55 $\mathrm{mg} / \mathrm{kg}$. Os piores resultados foram para o $\mathrm{Cd}, \mathrm{Pb}$ e $\mathrm{Ca}$, justamente os que apresentaram os maiores valores de repetibilidade. Infelizmente, as incertezas 
estimadas inviabilizam a utilização desses métodos para controle da qualidade de óleos básicos rerrefinados.

Tabela 25. Incerteza expandida de medição dos métodos do equipamento FRX/EDX 720 $(\mathrm{mg} / \mathrm{kg})$

\begin{tabular}{ccccc}
\hline Elemento & PNM & PSP & PNL & PNP \\
\hline $\mathrm{Fe}$ & 17,46 & 7,84 & 12,14 & 7,98 \\
$\mathrm{Zn}$ & 14,47 & 8,68 & 13,16 & - \\
$\mathrm{Mo}$ & 8,24 & 13,10 & - & - \\
$\mathrm{Cd}$ & 61,03 & 77,20 & 71,90 & 56,34 \\
$\mathrm{Ba}$ & 16,45 & 14,55 & 29,11 & 36,47 \\
$\mathrm{~Pb}$ & 68,94 & 24,72 & - & 35,71 \\
$\mathrm{Ni}$ & 10,28 & 19,74 & 11,99 & - \\
$\mathrm{Ca}$ & 13,91 & 31,72 & 10,74 & 44,38 \\
$\mathrm{Cr}$ & 11,80 & 12,77 & 17,18 & - \\
$\mathrm{Cu}$ & 15,34 & - & 12,40 & - \\
\hline
\end{tabular}

\subsection{Determinação de Metais das Amostras Coletadas}

Os teores de $\mathrm{Ba}, \mathrm{Ca}, \mathrm{Cr}, \mathrm{Cd}, \mathrm{Cu}, \mathrm{Fe}, \mathrm{Pb}, \mathrm{Mo}, \mathrm{Ni}, \mathrm{Zn}$ e Si nos óleos rerrefinados coletados determinados por ICP constam na Tabela 26. Apenas 12 das 39 amostras não continham nenhum dos elementos investigados e em outras 8 foram detectados elementos em teores abaixo do limite de quantificação do método. Os metais cromo e cádmio não apareceram em nenhuma das amostras. A portaria ANP $n^{\circ} 130 / 99$ não estabelece um teor de elementos máximo permitido, mas o Sindicato Nacional da Indústria do Rerrefino de Óleos Minerais, Sindirrefino, sugere que esse limite seja igual a $20 \mathrm{mg} / \mathrm{kg}$. O cálcio foi detectado em 26 amostras, das quais 12 possuem teores superiores a 20 $\mathrm{mg} / \mathrm{kg}$, destacando-se a RR7, RR11 e RR36, cujas concentrações são superiores a $100 \mathrm{mg} / \mathrm{kg}$. As amostras RR7, RR8, RR36 e RR38 também apresentaram concentrações altas de $\mathrm{Zn}$, que é o terceiro elemento mais presente nas amostras, estando em 7 , sendo que em 4 a concentração é superior a $20 \mathrm{mg} / \mathrm{kg}$. O segundo é o $\mathrm{Si}$, que aparece em 9 amostras, mas apenas em $2 \mathrm{com}$ teores superiores a $20 \mathrm{mg} / \mathrm{kg}$. Os demais elementos não aparecem em teores elevados, com exceção do Fe na amostra RR38. As amostras RR7, RR36 e RR38 se destacam por apresentarem vários elementos em teores elevados. Esses óleos foram produzidos pelos rerrefinadores 5 e 13, 
que possuem os processos mais simples e, como discutido anteriormente, essas amostras estão não conforme com relação a vários parâmetros.

As amostras RR10, RR11, RR12, RR13 e RR14 não apresentaram nenhuma outra não conformidade, mas as concentrações de elementos que elas possuem as tornam inadequadas para uso. A necessidade da inserção de limites para teores de elementos na especificação dos óleos básicos rerrefinados se torna evidente diante desses resultados. $O$ índice de não conformidade das amostras avaliadas sobe para 46,15\%, com a adição daquelas com teores de elementos superiores a $20 \mathrm{mg} / \mathrm{kg}$ e considerando a espectroscopia no infravermelho e a revisão do parâmetro viscosidade cinemática. A Figura 65 mostra como ficaria a distribuição das não conformidades por parâmetros. O teor de elementos tem o maior índice, 33,3 $\%$, seguido da espectroscopia no infravermelho, 23,1\%.

Tabela 26. Teor de elementos nos óleos rerrefinados determinados por ICP (mg/kg)

\begin{tabular}{|c|c|c|c|c|c|c|c|c|c|c|c|}
\hline Elemento & $\mathrm{Ba}$ & $\mathrm{Ca}$ & $\mathrm{Cr}$ & $\mathrm{Cd}$ & $\mathrm{Cu}$ & $\mathrm{Fe}$ & $\mathrm{Pb}$ & Mo & $\mathrm{Ni}$ & $\mathrm{Zn}$ & $\mathrm{Si}$ \\
\hline RR1 & ND & ND & ND & ND & ND & ND & ND & ND & ND & ND & ND \\
\hline RR2 & ND & ND & ND & ND & ND & ND & ND & ND & ND & ND & ND \\
\hline RR3 & ND & $<4,62$ & ND & ND & ND & ND & ND & ND & ND & ND & ND \\
\hline RR4 & ND & ND & ND & ND & ND & ND & ND & ND & ND & ND & ND \\
\hline RR5 & ND & 6,05 & ND & ND & ND & ND & ND & ND & ND & ND & 3,59 \\
\hline RR6 & ND & $<4,62$ & ND & ND & ND & ND & $<3,23$ & ND & ND & ND & ND \\
\hline RR7 & 17,18 & 302,6 & ND & ND & $<4,49$ & 3,34 & $<3,23$ & ND & ND & 97,55 & ND \\
\hline RR8 & ND & 49,81 & ND & ND & ND & ND & ND & ND & ND & 18,75 & ND \\
\hline RR9 & ND & 60,76 & ND & ND & ND & $<3,22$ & ND & ND & ND & ND & ND \\
\hline RR10 & ND & 48,96 & ND & ND & ND & ND & ND & ND & ND & ND & ND \\
\hline RR11 & ND & 110,7 & ND & ND & ND & $<3,22$ & $<3,23$ & ND & ND & ND & 10,59 \\
\hline RR12 & ND & 33,34 & ND & ND & ND & ND & ND & ND & ND & ND & 4,99 \\
\hline RR13 & ND & 39,93 & ND & ND & ND & ND & ND & ND & ND & $<7,34$ & ND \\
\hline RR14 & ND & 36,86 & ND & ND & ND & ND & ND & ND & ND & ND & ND \\
\hline RR15 & ND & $<4,62$ & ND & ND & ND & ND & ND & ND & ND & ND & ND \\
\hline RR16 & ND & ND & ND & ND & ND & ND & $<3,23$ & ND & ND & ND & ND \\
\hline RR17 & ND & $<4,62$ & ND & ND & $<4,49$ & ND & ND & ND & ND & ND & 11,25 \\
\hline RR18 & ND & ND & ND & ND & ND & ND & ND & ND & ND & ND & ND \\
\hline RR19 & ND & ND & ND & ND & ND & ND & ND & ND & ND & ND & ND \\
\hline RR20 & ND & 7,50 & ND & ND & ND & ND & ND & ND & ND & ND & ND \\
\hline RR21 & ND & 9,29 & ND & ND & ND & ND & $<3,2$ & ND & ND & ND & ND \\
\hline RR22 & ND & 29,83 & ND & ND & ND & ND & ND & ND & ND & ND & ND \\
\hline RR23 & ND & 12,45 & ND & ND & ND & ND & ND & ND & ND & ND & ND \\
\hline RR24 & ND & ND & ND & ND & ND & ND & ND & ND & ND & ND & ND \\
\hline
\end{tabular}


Tabela 26 (continuação). Teor de elementos nos óleos rerrefinados determinados por ICP $(\mathrm{mg} / \mathrm{kg})$

\begin{tabular}{cccccccccccc}
\hline Elemento & $\mathrm{Ba}$ & $\mathrm{Ca}$ & $\mathrm{Cr}$ & $\mathrm{Cd}$ & $\mathrm{Cu}$ & $\mathrm{Fe}$ & $\mathrm{Pb}$ & $\mathrm{Mo}$ & $\mathrm{Ni}$ & $\mathrm{Zn}$ & $\mathrm{Si}$ \\
\hline RR25 & ND & ND & ND & ND & ND & ND & ND & ND & ND & ND & ND \\
RR26 & ND & $<4,62$ & ND & ND & ND & ND & ND & ND & ND & ND & ND \\
RR27 & ND & ND & ND & ND & ND & ND & ND & ND & ND & ND & ND \\
RR28 & ND & ND & ND & ND & ND & ND & ND & ND & ND & ND & ND \\
RR29 & ND & ND & ND & ND & ND & ND & ND & ND & ND & ND & ND \\
RR30 & ND & ND & ND & ND & ND & ND & ND & ND & ND & ND & ND \\
RR31 & ND & $<4,62$ & ND & $<4,9$ & ND & $<3,22$ & $<3,2$ & $<4,48$ & $<4,0$ & ND & ND \\
RR32 & ND & $<4,62$ & ND & ND & ND & ND & $<3,2$ & ND & ND & ND & ND \\
RR33 & ND & ND & ND & ND & ND & ND & ND & ND & ND & ND & ND \\
RR34 & ND & $<4,62$ & ND & ND & ND & ND & $<3,2$ & ND & ND & ND & ND \\
RR35 & ND & 9,30 & ND & ND & ND & $<3,22$ & ND & ND & $<4,0$ & ND & 222,2 \\
RR36 & 6,11 & 1625 & ND & ND & ND & 4,88 & $<3,2$ & 14,9 & $<4,0$ & 485 & 0,64 \\
RR37 & ND & 31,76 & ND & ND & $<4,5$ & 4,54 & ND & ND & ND & 10,14 & 5,82 \\
RR38 & $<4,68$ & 73,90 & ND & ND & 5,31 & 29,80 & $<3,23$ & ND & ND & 23,42 & 32,96 \\
RR39 & ND & 9,23 & ND & ND & $<4,49$ & 3,98 & 3,46 & ND & ND & $<7,34$ & 11,30 \\
\hline ND - não detectado & & & & & & & & & &
\end{tabular}

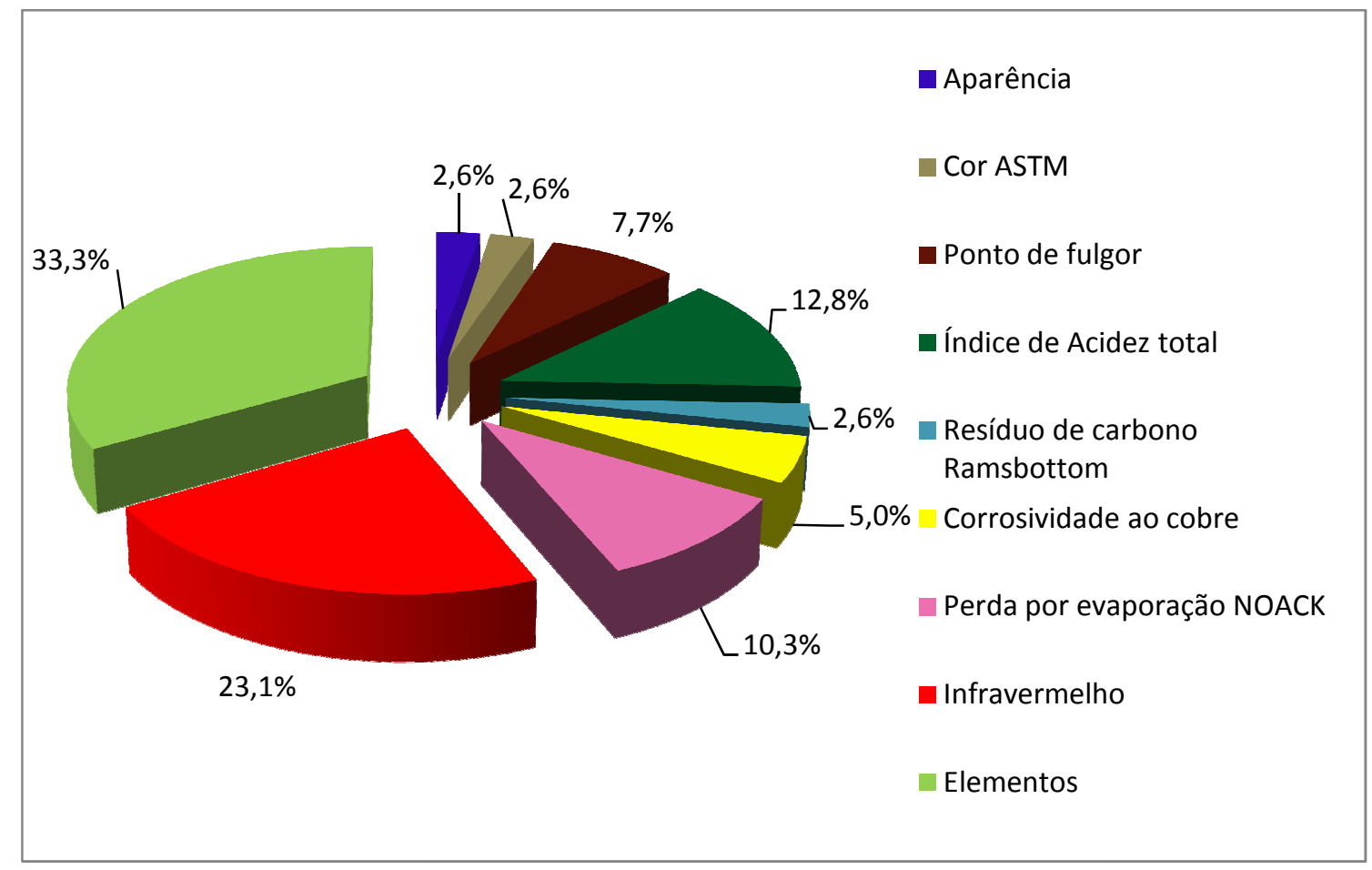

Figura 65. Distribuição das não conformidades por parâmetros da Portaria ANP $n^{\circ}$ 130/99, excluindo a viscosidade cinemática e inserindo ATR e teor de elementos.

Alguns dos resultados obtidos utilizando o FRX/EDX 720 da shimadzu constam na Tabela 25, apenas aqueles cujos teores determinados são superiores à incerteza estimada para o método. 
Tabela 27. Teor de elementos nos óleos rerrefinados determinados por FRX/EDX (mg/kg)

\begin{tabular}{ccccccccccc}
\hline Amostra & $\mathrm{Ba}$ & $\mathrm{Ca}$ & $\mathrm{Cr}$ & $\mathrm{Cd}$ & $\mathrm{Cu}$ & $\mathrm{Fe}$ & $\mathrm{Pb}$ & $\mathrm{Mo}$ & $\mathrm{Ni}$ & $\mathrm{Zn}$ \\
\hline RR7 & ND & $298 \pm 14$ & ND & ND & ND & ND & ND & ND & ND & $114 \pm 14$ \\
RR8 & ND & $<104,9$ & ND & ND & - & ND & ND & ND & ND & $21 \pm 9$ \\
RR9 & ND & $61 \pm 14$ & ND & ND & $<4,34$ & ND & ND & ND & ND & ND \\
RR10 & ND & $63 \pm 14$ & ND & ND & ND & ND & ND & ND & ND & ND \\
RR11 & ND & $141 \pm 44$ & - & $<38,36$ & - & ND & ND & - & - & - \\
RR13 & ND & $31 \pm 14$ & ND & ND & ND & ND & ND & ND & ND & $<6,98$ \\
RR14 & ND & $47 \pm 14$ & ND & ND & ND & ND & ND & ND & ND & ND \\
RR18 & ND & $28 \pm 14$ & ND & ND & ND & ND & ND & ND & ND & ND \\
RR36 & ND & $1619 \pm 44$ & - & ND & - & ND & ND & - & - & - \\
RR38 & ND & $61 \pm 14$ & ND & ND & $<4,34$ & $23 \pm$ & ND & ND & ND & $20 \pm 14$ \\
\hline
\end{tabular}

$\mathrm{ND}$ - não detectado

De acordo com esses resultados, 10 amostras seriam consideradas não conforme ao invés de 13. Isso deve ao fato de que os limites de quantificação observados para o FRX/EDX são muito superiores aos do ICP, como discutido anteriormente. Considerando o intervalo abrangido pelas incertezas, constatase que os teores determinados usando FRX/EDX são os mesmos valores encontrados por ICP, ou seja, utilizando o FRX/EDX corre-se o risco de não verificar todas as não conformidades existentes, mas não o de considerar uma amostra não conforme indevidamente. Ainda assim, o ICP é mais indicado para a avaliação do teor de elementos nos óleos básicos rerrefinados, pois os limites de detecção e quantificação obtidos no FRX/EDX são, na maioria dos casos, superiores ao que tende a ser o limite máximo especificado para esses óleos.

Os resultados das análises dos óleos parafínicos neutro médio realizadas com o uso do Epsilon $3 \mathrm{XL}$ da panalytical e que apresentaram teores superiores ao LQ do método constam na Tabela 28. Os valores também estão dentro do intervalo de incerteza do FRX/EDX 720.

Tabela 28. Teor de elementos nos óleos parafínicos neutro médio determinados com o Epsilon $3 \mathrm{XL}(\mathrm{mg} / \mathrm{kg})$

\begin{tabular}{ccccccccc}
\hline Amostra & $\mathrm{Ca}$ & $\mathrm{Cr}$ & $\mathrm{Cd}$ & $\mathrm{Cu}$ & $\mathrm{Fe}$ & $\mathrm{Pb}$ & $\mathrm{Ni}$ & $\mathrm{Zn}$ \\
\hline RR7 & 337,47 & $\mathrm{ND}$ & $\mathrm{ND}$ & $<1,86$ & $<1,65$ & 1,08 & $\mathrm{ND}$ & 109,2 \\
RR9 & 67,26 & ND & ND & ND & $<1,65$ & ND & ND & ND \\
RR38 & 65,6 & ND & ND & $<1,86$ & 25,33 & 0,81 & ND & 22,22 \\
\hline
\end{tabular}




\section{Conclusões}

Apesar de, no período em que este trabalho foi desenvolvido, existirem 19 empresas autorizadas pela ANP para o exercício do rerrefino de OLUC, apenas 13 estavam atuando efetivamente. Os resultados obtidos foram relatados à ANP e subsidiaram a avaliação dos processos de revalidação das autorizações para exercício do rerrefino de acordo com a RANP n¹8/2009. Assim, das 19 empresas, 6 tiveram suas autorizações para exercício do rerrefino revogadas. Dentre as 13 que exercem o rerrefino atualmente, apenas uma produz básicos do grupo II e há pouco mais de dois anos. Dois dos 13 rerrefinadores visitados produzem básico apenas para o seu próprio consumo na produção de lubrificantes acabados. Em sua grande maioria, os rerrefinadores efetuam análises físico-químicas do OLUC recebido com vistas a aperfeiçoar o seu processo e não em recusar o material. Apenas óleos contaminados com PCBs são recusados e encaminhados à incineração. O termocraqueamento é adotado por 8 dos 13 rerrefinadores visitados, visando aumentar o rendimento do processo e diminuir a quantidade de resíduos gerados, além de diminuir a quantidade de reagentes utilizados em alguns casos. O processo ácido-argila convencional não é mais utilizado no Brasil, mas a maioria dos rerrefinadores ainda utiliza a acidificação com ácido sulfúrico combinada com outras técnicas mais atuais. Pode se afirmar que o processo mais utilizado no Brasil atualmente é o termocraqueamento seguido por sulfonação e clareamento com argila (termocraqueamento/ácido-argila), o qual é utilizado por 6 dos rerrefinadores. Os outros processos adotados são a desasfaltação a propano e a evaporação total ou wiped film. Todos os rerrefinadores possuem sistema de gestão dos resíduos gerados pelos seus processos e apenas um não possui controle de qualidade dos óleos básicos produzidos. Uma boa parte dos rerrefinadores exerce controle de qualidade também em etapas intermediárias do processo, de forma que possibilita a intervenção para melhoria das características do produto antes de finalizar o rerrefino. $O$ mito de que 0 rerrefino no Brasil ainda se baseia no método convencional ácido-argila foi desfeito.

Apesar da evolução dos óleos para motores automotivos apontar uma tendência de aumento do consumo de básicos sintéticos e do grupo III, os 
óleos industriais ainda necessitam de básicos parafínicos. Assim, grande parte dos rerrefinadores está investindo na proximidade com os produtores de óleos industriais a fim de estabelecer um mercado e, dessa forma, não precisar migrar de tecnologia. Outros, no entanto, estão buscando conhecimento no exterior para modificar os seus processos e, então, produzir básicos do grupo II ou III, mas o investimento financeiro é bastante elevado e muitos não possuem capital para executar essa transição. A Lwart, por ser a maior empresa de rerrefino no Brasil foi a primeira a inaugurar uma instalação de rerrefino que gera básico grupo II. Mas, a perspectiva é que, em médio prazo, a maioria dos rerrefinadores nacionais continue produzindo básico mineral do grupo I.

Os resultados das análises físico-químicas especificadas na Portaria ANP 130/99 apontam para um índice de não conformidades de 43,6\%. Dentre os parâmetros avaliados a viscosidade cinemática é o mais relevante e tem sido discutida a possibilidade de rever as faixas especificadas na portaria criando-se faixas intermediárias ou flexibilizando-se a comercialização de produtos fora da faixa especificada desde que com o aceite do cliente.

A espectroscopia de reflectância atenuada no infravermelho foi uma ferramenta importante para identificação de contaminantes presentes nos básicos rerrefinados. O teor de elementos $\mathrm{Ca}$, Si e $\mathrm{Zn}$ encontrados em algumas amostras confirmaram haver problemas em alguns processos, como já havia sido verificado pelos demais ensaios, e revelaram falhas em outros que até então pareciam não ter problemas.

Em virtude dos fatos expostos anteriormente, conclui-se que a Portaria ANP $n^{\circ}$ 130/99 deve ser revista para ajuste da especificação no que diz respeito à faixa de viscosidade cinemática aceita e à inserção dos ensaios de espectroscopia no infravermelho e teor de elementos. Com essas alterações, o índice de não conformidades seria $46,15 \%$, ou seja, em números a diferença seria pequena, mas em termos de quais as empresas não funcionam bem, haveria diferenças significativas. A inclusão dos teores de elementos como parâmetro de qualidade afeta diretamente aos rerrefinadores, pois implica na necessidade de aquisição de equipamentos e reagentes até então pouco presentes neste tipo de indústria, o que justifica a busca por mais simples e barato. 
Embora a coleta realizada não seja representativa em relação à situação do mercado de rerrefinado no Brasil, a avaliação feita foi suficiente para revelar que as empresas 5 e 13 possuem problemas sérios nos seus processos, pois todas as amostras dessas rerrefinadoras possuíam contaminantes. Os processos adotados por elas são muito simplificados e não conseguem garantir a qualidade do básico que produzem. Além disso, a 13 não possuía laboratório capaz de avaliar a qualidade de seus produtos. A autorização para exercício do rerrefino da empresa 13 foi revogada. Outras empresas apresentaram falhas pontuais.

A baixa sensibilidade dos metódos desenvolvidos neste estudo para análise dos metais $\mathrm{Ca}, \mathrm{Cr}, \mathrm{Fe}, \mathrm{Ni}, \mathrm{Cu}, \mathrm{Zn}, \mathrm{Mo}, \mathrm{Cd}, \mathrm{Ba}$, e $\mathrm{Pb}$ utilizando o equipamento FRX/EDX 720 desmotivam a utilização dessa técnica no controle de qualidade de básicos rerrefinados, sobretudo para $\mathrm{Ca}, \mathrm{Cr}, \mathrm{Cu}, \mathrm{Cd}, \mathrm{Ba}$, e $\mathrm{Pb}$ que também apresentaram coeficientes de determinação inferiores a 0,99 em alguns casos. Neste aspecto, destaca-se o cádmio, pois $0 \mathrm{R}^{2}$ de todas as curvas foi muito inferior a 0,98. Os metais $\mathrm{Fe}, \mathrm{Ni}$ e $\mathrm{Zn}$ apresentaram coeficientes de determinação satisfatórios e sensibilidade maior em relação aos demais. Os coeficientes angulares e de determinação obtidos com o uso do equipamento Epsilon $3 \mathrm{XL}$ mostraram que ele possui uma sensibilidade maior que 0 FRX/EDX 720, o que pode ter relação com o material do tubo de raios $X$, pois no primeiro este é de prata e, no segundo, de ródio. Outros fatores que podem justificar a baixa sensibilidade e coeficiente de determinação podem envolver 0 uso de MRC multielementar e atmosfera a ar.

Apesar dos resultados desencorajarem o uso do FRX/EDX para quantificar $\mathrm{Ca}$, $\mathrm{Cr}, \mathrm{Fe}, \mathrm{Ni}, \mathrm{Cu}, \mathrm{Zn}, \mathrm{Mo}, \mathrm{Cd}$, Ba, e Pb em básicos rerrefinados, a confirmação da interferência da razão $\mathrm{C} / \mathrm{H}$ na quantificação desses elementos é um importante passo para estudos futuros, os quais terão como desafio superá-la. A alternativa mais simples para tanto é o uso de curvas analíticas individuais para cada tipo de básico, o que torna o método menos prático, mas não é um impeditivo. 
Com exceção para o cálcio, os métodos para determinação de metais em PNM usando Epsilon $3 \mathrm{XL}$ apresentaram limites de detecção e quantificação menores que os estabelecidos com o uso do FRX/EDX 720.

Os valores de repetibilidade e precisão intermediária mostraram que os métodos não são precisos e contribuíram muito na incerteza estimada. Além disso, foi confirmada a inexatidão da determinação de $\mathrm{Fe}$ e $\mathrm{Pb}$ em concentrações inferiores a $30 \mathrm{mg} / \mathrm{kg}$ no primeiro caso e $50 \mathrm{mg} / \mathrm{kg}$ no segundo.

Os limites de detecção e quantificação determinados e as incertezas estimadas para o FRX/EDX 720 são muito altos e conclui-se que os métodos estudados não atendem plenamente ao propósito de determinar os teores de metais em óleos básicos rerrefinados, pois quando se comparou os resultados obtidos por FRX/EDX com os do ICP, o número de amostras não conforme foi menor, pois, devido ao $L Q$ e incerteza altos, alguns resultados não puderam ser considerados.

Os teores de elementos verificados nas amostras de básicos rerrefinados confirmaram a necessidade de avaliar este parâmetro e, embora a validação dos métodos utilizando o FRX/EDX 720 tenha comprovado que estes não se adequam à necessidade, a espectrometria de fluorescência de raios $X$ continua sendo uma alternativa interessante. Os resultados obtidos com Epsilon $3 \mathrm{XL}$ são uma prova disso. Dessa forma, sugere-se para próximas pesquisas o uso de equipamento de FRX/EDX com tubo de prata e atmosfera a hélio e materiais de referência monoelementares. Além disso, agora existe um registro dos teores de elementos encontrados nos óleos rerrefinados brasileiros, o que permite escolher melhor a faixa de trabalho a ser avaliada. 


\section{Referências}

1. BRASIL. Ministério do Meio Ambiente. Conselho Nacional do Meio Ambiente. Resolução $\mathrm{N}^{\circ} \mathrm{g}$ de agosto de 1993. Disponível em: http://www.mma.gov.br/port/conama, acessado em 17 de abril de 2015.

2. BRASIL. Ministério do Meio Ambiente. Conselho Nacional do Meio Ambiente. Resolução N³62 de junho de 2005. Disponível em: http://www.mma.gov.br/port/conama, acessado em 17 de abril de 2015.

3. BRASIL. Ministério de Minas e Energia. Agência Nacional do Petróleo, Gás Natural e Biocombustível. Portaria No129 de julho de 1999. Disponível em: http://www.anp.gov.br/?id=478 acessado em em 17 de abril de 2015.

4. BRASIL. Ministério de Minas e Energia. Agência Nacional do Petróleo, Gás Natural e Biocombustível. Portaria N`130 de julho de 1999. Disponível em: http://www.anp.gov.br/?id=478 acessado em em 17 de abril de 2015.

5. AMERICAN SOCIETY FOR TESTING AND MATERIALS. D5185: Standard test method for determination of additive elements, wear metals, and contaminants in used lubricating oils and determination of selected elements in base oils by inductively coupled plasma atomic emission spectrometry (ICPAES). 2009.

6. AMERICAN SOCIETY FOR TESTING AND MATERIALS. D6074: Standard guide for characterizing hydrocarbon lubricant base oils. 2008.

7. Carreteiro, R. P.; Belmiro, P. N. A. Lubrificantes e Lubrificação Industrial. 1. Ed. Editora Interciência Ltda e Instituto Brasileiro de Petróleo: Rio de Janeiro, 2006.

8. Rizvi, S. Q. A. A Comprehensive Review et Lubricant Chemistry, Technology, Selection, and Design. ASTM: West Conshohocken, 2009.

9. AMERICAN SOCIETY FOR TESTING AND MATERIALS. D2270: Standard Practice for Calculating Viscosity Index from Kinematic Viscosity at 40 and $100^{\circ} \mathrm{C} .2010$.

10. ASSOCIAÇÃO BRASILEIRA DE NORMAS TÉCNICAS. NBR 14358: Cálculo do índice de viscosidade a partir da viscosidade cinemática. Rio de Janeiro, 2005.

11. Mang, T.; Dresel, W.; Lubrication and Lubricants. 2nd Ed.; Wiley-VCH Verlag GmbH\& Co. KGaA: Weinheim, 2007.

12. Quelhas, A. D. et al Processamento de Petróleo e Gás. Livros Técnicos e Científicos Editora: Rio de Janeiro, 2011.

13. Nelson,D.L.; Cox,M.M.; Lehninger Princípios de Bioquímica, $4^{\circ} \mathrm{ed}$; Sarvier: São Paulo, 2006.

14. Matos, P. R. R.; Utilização de Óleos Vegetais Como Bases Lubrificantes. Dissertação de Mestrado, Universidade de Brasília, Brasília, 2011.

15. BRASIL. Ministério de Minas e Energia. Agência Nacional do Petróleo, Gás Natural e Biocombustível. Resolução N ${ }^{\circ} 16$ de junho de 2009. Disponível http://www.anp.gov.br/?id=478 acessado em 17 de abril de 2015. 
16. Totten, E, G.; Fuel and Lubricants handbook: technology, properties, performance and testing. PO Box C7000. ASTM International: West Conshohocken, 2009.

17. ETHYL CORPORATION. Specification Handbook. Richmond, 2009.

18. BRASIL. Ministério de Minas e Energia. Agência Nacional do Petróleo, Gás Natural e Biocombustível. Resolução N²2 de abril de 2014. Disponível http://www.anp.gov.br/?id=478 acessado em 17 de abril de 2015.

19. Campos, E. B. Previsão da Demanda de Óleos Básicos Lubrificantes: Uma Análise Através de Regressão Múltipla. Dissertação de Mestrado, Faculdade de Economia e Finanças IBMEC, Rio de Janeiro, 2008.

20. Henderson, H. E. Impacto of Automotive Specification and Industry Changes on Base Oil and Lubricant Formulations. ICIS: New Jersey, 2011.

21. TOTAL LUBRIFIANTS. Memento Lub: Collection of Automotive Lubricants Standard an Specification, 2006.

22. Claxton, A.; Apostila do Curso Base Oils II - Product Qualities \& Blending Options. ICIS: New Jersey, 2011.

23. Belmiro, P. N.; Lubes em Foco. 2010, 19. Disponível em: http://www.lubes.com.br/revista/ed19n06.htmL

24. http://www.lubes.com.br/Newsletter/News/2015/150230/pdfs/150230-

01.pdf, acessado em 17 de abril de 2015.

25. Serra-Holm, V.; Lubes em Foco. 2010, 21, $22-27$.

26. BRASIL. Ministério de Minas e Energia. Agência Nacional do Petróleo, Gás Natural e Biocombustível. Resolução No19 de junho de 2009. Disponível http://www.anp.gov.br/?id=478 acessado em 17 de abril de 2015.

27. BRASIL. Ministério de Minas e Energia. Agência Nacional do Petróleo, Gás Natural e Biocombustível. Resolução N²0 de junho de 2009. Disponível http://www.anp.gov.br/?id=478 acessado em 17 de abril de 2015.

28. DUARTE, V. L. P. Atualidades Conselho Nacional do Petróleo.1981, 13, 78, 33-35.

29. http://www.epa.gov/wastes/conserve/materials/usedoil, acessado em 17 de abril de 2015.

30. Boughton, B.; Horvath, A.; Environ. Sci. Technol. 2004, 38, 353-358.

31. Brinkman, D. W.; Dickson, J. R.; Environ. Sci. Technol. 1995, 29, 81-86.

32. Cherednichenko, R. O.; Dorogochinskaya, V. A.; Stan'kovski, L. Chemistry and Technology of Fuels and Oils. 2011, 46, 6, 430-436.

33. Audibert, F., Waste Engine Oils Refining and Energy Recovery. 1 Ed. Elsevier Science and Technology Books: Amsterdam, The Netherlands, 2006.

34. Raldenes, E.; Assis, V. P.; Ornelas, R. B.; Atualidades Conselho Nacional do Petróleo. 1981, 13, 78, 16-27.

35. BRASIL. Ministério de Minas e Energia e Ministério do Meio Ambiente. Portaria Interministerial N59 de fevereiro de 2012. Disponível em: http://www.mme.gov.br acessado em 20 de março de 2015. 
36. BRASIL. Ministério de Minas e Energia. Agência Nacional do Petróleo, Gás Natural e Biocombustível. Resolução No17 de junho de 2009. Disponível http://www.anp.gov.br/?id=478 acessado em 17 de abril de 2015.

37. BRASIL. Ministério de Minas e Energia. Agência Nacional do Petróleo, Gás Natural e Biocombustível. Resolução Nº18 de junho de 2009. Disponível http://www.anp.gov.br/?id=478 acessado em 17 de abril de 2015.

38. http://www.anp.gov.br/?pg=74105\&m=\&t1=\&t2=\&t3=\&t4=\&ar=\&ps=\&cac hebust=1426971699406 Acessado em 21 de março de 2015.

39. http://www.epa.gov/wastes/conserve/materials/usedoil/usedoil.htm, acessado em 17 de abril de 2015.

40. http://ec.europa.eu/environment/waste/oil index.htm, acessado em 17 de abril de 2015.

41. Monier, V.; Labouze, E. Critical Review of Existing Studies and Life Cycle Analysis on the Regeneration and Incineration of Waste Oils (2001). Disponivel em: http://ec.europa.eu/environment/waste/studies/waste oil.htm, acessado em 17 de abril de 2015.

42. Guerin, T. F., Journal of Hazardous Materials. 2008, 160, 256-264.

43. Digilio, A. O Petróleo, A Sociedade e A Ecologia. 1 Ed.; Centrais Impressoras Brasileiras Ltda: São Paulo, 1986.

44. Hamawand, I.; Yusaf, T.; Rafat, S. Energies. 2013, 6, 1023-1049.

45. Ogbeide, S. O. Journal of Engineering Science and Technology Review. 2010, 3, 32-35.

46. Rincón, J.; Cañizares, P.; Garcías, M. T. Ind. Eng. Chem. Res. 2005, 44, 4373-4379.

47. Rincón, J.; Cañizares, P.; Garcías, M. T. Ind. Eng. Chem. Res. 2005, 44, 7854-7859.

48. AMERICAN SOCIETY FOR TESTING AND MATERIALS. D4628: Standard Test Method for Analysis of Barium, Calcium, Magnesium, and Zinc in Unused Lubricating Oils by Atomic Absorption Spectrometry. 2005.

49. ASSOCIAÇÃO BRASILEIRA DE NORMAS TÉCNICAS. NBR 14066: Óleos Lubrificantes - Determinação de bário, cálcio, magnésio e zinco por espectrometria de absorção atômica. Rio de Janeiro, 2008.

50. AMERICAN SOCIETY FOR TESTING AND MATERIALS. D4951: Standard Test Method for Determination of Additive Elements in Lubricating Oils by Inductively Coupled Plasma Atomic Emission Spectrometry. 2009.

51. ASSOCIAÇÃO BRASILEIRA DE NORMAS TÉCNICAS. NBR 14786: Óleos Lubrificantes - Determinação de elementos por espectrometria de emissão atômica de plasma indutivamente acoplado. Rio de Janeiro, 2010.

52. AMERICAN SOCIETY FOR TESTING AND MATERIALS. D6481: Standard Test Method for Determination of Phosphorus, Sulfur, Calcium, and Zinc in Lubrication Oils by Energy Dispersive X-ray Fluorescence Spectroscopy. 2010. 
53. Skoog, D. A.; Holler, F. J.; Nieman, T. A. Princípios de Análise Instrumental. 5 ed.; Bookman: Porto Alegre, 2002.

54. Odumo, O. B.; Mustapha, A. O.; Patel, J. P.; Angeyo, H. K.; Bull Environ Contam Toxicol. 2011, 87, 260-263.

55. Natarajan, V.; et al; J. Radioanal. Nucl. Chem. 2009, 280, 27-31.

56. Moraes, M. P. G. Determinação de Metais Pesados em Lodos de Esgotos por Espectrometria de Fluorescência de Raios X. Dissertação de Mestrado, Universidade Estadual de Campinas, 2003.

57. Schidmidt, F.; Bueno, M. I. M. S.; Einzweiler, J.; Determinação de Alguns Metais em solos por Espectroscopia de Fluorescência de Raios $X$ de Energia Dispersiva com modelagem por Redes Neurais. IV Congresso Brasileiro de Redes Neurais. ITA: São José dos Campos, 1999. P. 396-399.

58. PONCE, L. C.; ZMURA, P. P.; BUENO, M.I.M.S. Quím. Nova. 1996, 19, 30-32.

59. SIMBOLON, S.; Atom Indonesia. 1996, 22, 55.

60. Schramm, R. Industrial Lubrication and Tribology. 2005, 54, 234-237.

61. AMERICAN SOCIETY FOR TESTING AND MATERIALS. ASTM D4294: Standard Test Method for Sulfur in Petroleum and Petroleum Products by Energy Dispersive X-ray Fluorescence Spectrometry. 2008.

62. Nadkarni, R. A. K. Spectroscopy Analysis of Petroleum Products and Lubricants. 1 Ed. ASTM: Bridgeport, 2011.

63. http://www.anp.gov.br/?id=506, acessado em 22 de maio de 2012.

64. AMERICAN SOCIETY FOR TESTING AND MATERIALS. D1500: Standard Test Method for ASTM color of Petroleum Products (ASTM color scale). 2007.

65. ASSOCIAÇÃO BRASILEIRA DE NORMAS TÉCNICAS. NBR 14483: Produtos de Petróleo - Determinação da cor - método do colorímetro ASTM. Rio de Janeiro, 2008.

66. ASSOCIAÇÃO BRASILEIRA DE NORMAS TÉCNICAS. NBR 10441: Produtos de Petróleo - Líquidos transparentes e opacos - Determinação da viscosidade cinemática e cálculo da viscosidade dinâmica. Rio de Janeiro, 2007.

67. ASSOCIAÇÃO BRASILEIRA DE NORMAS TÉCNICAS. NBR 11341: Derivados de Petróleo - Determinação dos pontos de fulgor e de combustão em vaso aberto Cleveland. Rio de Janeiro, 2008.

68. ASSOCIAÇÃO BRASILEIRA DE NORMAS TÉCNICAS. NBR 11349: Produto de Petróleo - Determinação do ponto de fluidez. Rio de Janeiro, 2009.

69. ASSOCIAÇÃO BRASILEIRA DE NORMAS TÉCNICAS. NBR 14448: Óleos Lubrificantes e Fluidos Hidráulicos - Determinação do número de acidez pelo método de titulação potenciométrica. Rio de Janeiro, 2009.

70. ASSOCIAÇÃO BRASILEIRA DE NORMAS TÉCNICAS. NBR 9842: Produtos de Petróleo - Determinação do teor de cinzas. Rio de Janeiro, 2009. 
71. ASSOCIAÇÃO BRASILEIRA DE NORMAS TÉCNICAS. NBR 14318: Produto de Petróleo - Determinação do resíduo de carbono Ramsbottom. Rio de Janeiro, 2012.

72. ASSOCIAÇÃO BRASILEIRA DE NORMAS TÉCNICAS. NBR 14359: Produtos de Petróleo - Determinação da corrosividade - Método da lâmina de cobre. Rio de Janeiro, 2005.

73. ASSOCIAÇÃO BRASILEIRA DE NORMAS TÉCNICAS. NBR 14157-2: Óleos Lubrificantes - Determinação da perda por evaporação pelo método Noack - Parte 2: Não utilizando a liga de woods. Rio de Janeiro, 2007.

74. ASSOCIAÇÃO BRASILEIRA DE NORMAS TÉCNICAS. NBR ISO/IEC 9000: Sistemas de gestão da qualidade - Fundamentos e vocabulário. 2005.

75. Albano, F. M.; Raya-Rodriguez, M. T. Validação e Garantia da Qualidade de Ensaios Laboratoriais. Rede Metrológica do Rio Grande do Sul: Porto Alegre, 2009.

76. Souza, S. V. C. Procedimento para Validação Intralaboratorial de Métodos de Ensaio: Delineamento e Aplicabilidade em Análise de Alimentos. Tese de Doutorado da Faculdade de Farmácia da UFMG, Belo Horizonte, 2007.

77. Neto, B. B.; Scarmino, I. S.; Bruns, R. E. Como fazer Experimentos. $4^{\circ}$ Ed., Bookman: Porto Alegre, 2010.

78. INSTITUTO NACIONAL DE METROLOGIA. Orientação Sobre Validação de Métodos de Ensaios Químicos, DOQ-CGCREE-008. 2007.

79. EURACHEM - The Fitness for Purpose of Analytical Methods - A Laboratory Guide to Mehod Validation and Related Topics. 1998.

80. INSTITUTO NACIONAL DE METROLOGIA. Vocabulário Internacional de Metrologia - Conceitos Fundamentais e Gerais e Termos Associados - VIM 2008.

81. BRASIL. Ministério de Estado do Interior, Ministério da Indústria e do Comércio e Ministério de Minas e Energia. Portaria Interministerial N¹9 de janeiro de 1981.

82. Wolska, J.; Vrebos, B.; Brouwer, P. Journal of ASTM International. 2006, $3,1-10$. 


\section{Anexos}

\subsection{Anexo 1 - Espectros de infravermelho}

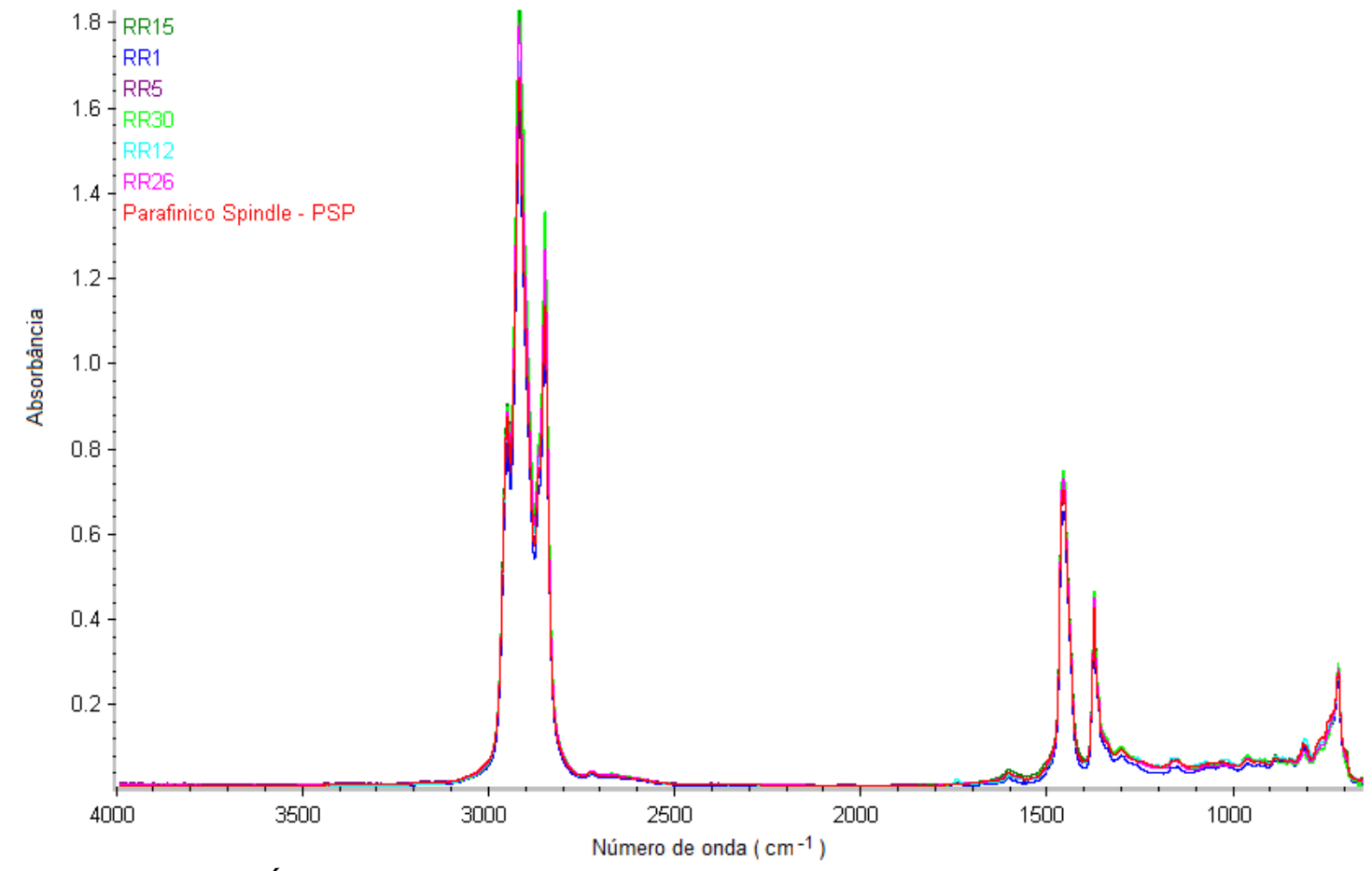

Espectros dos Óleos Rerrefinados Parafínico Spindle considerados conforme.

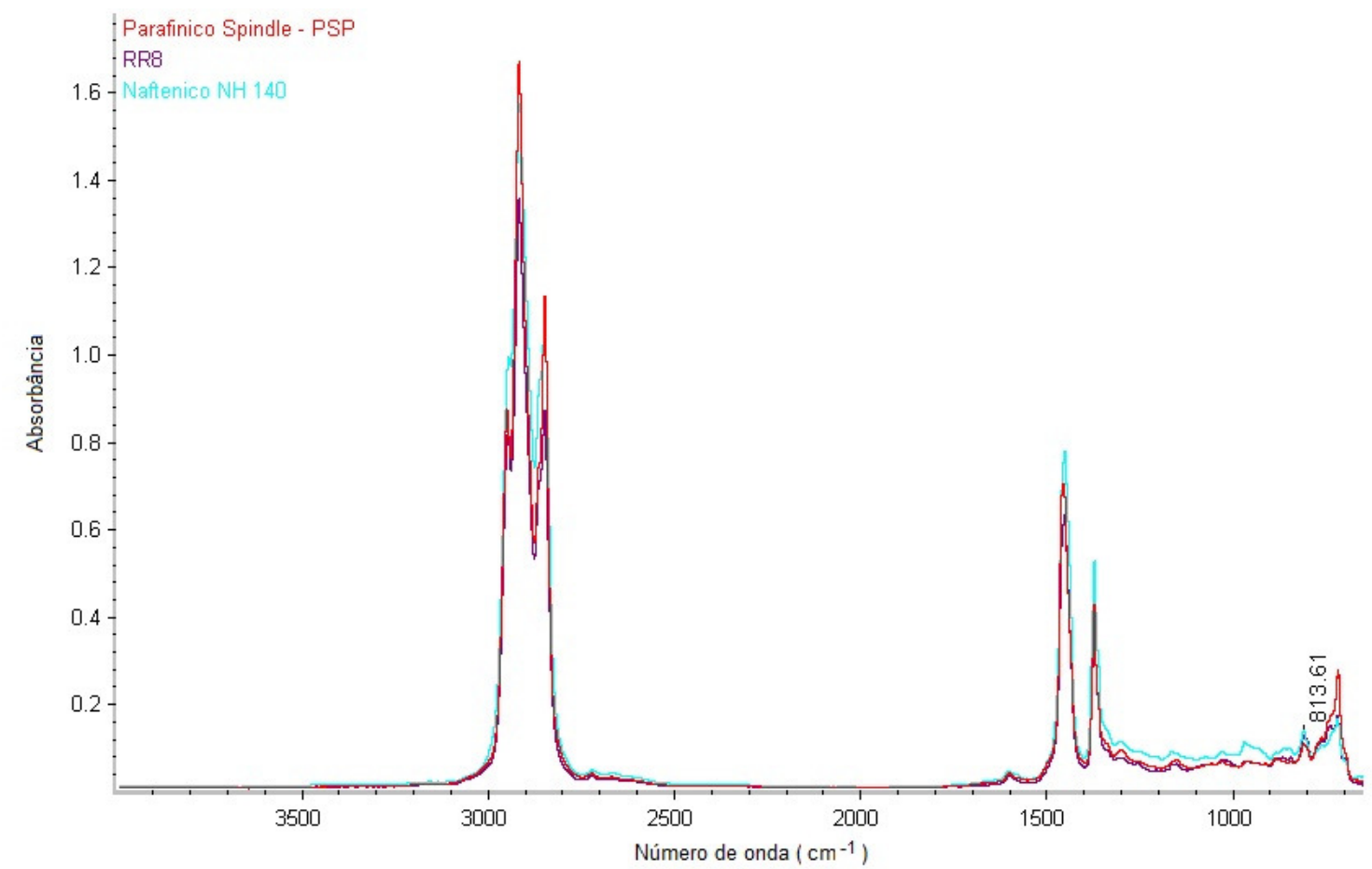

Espectro completo da Amostra RR8 


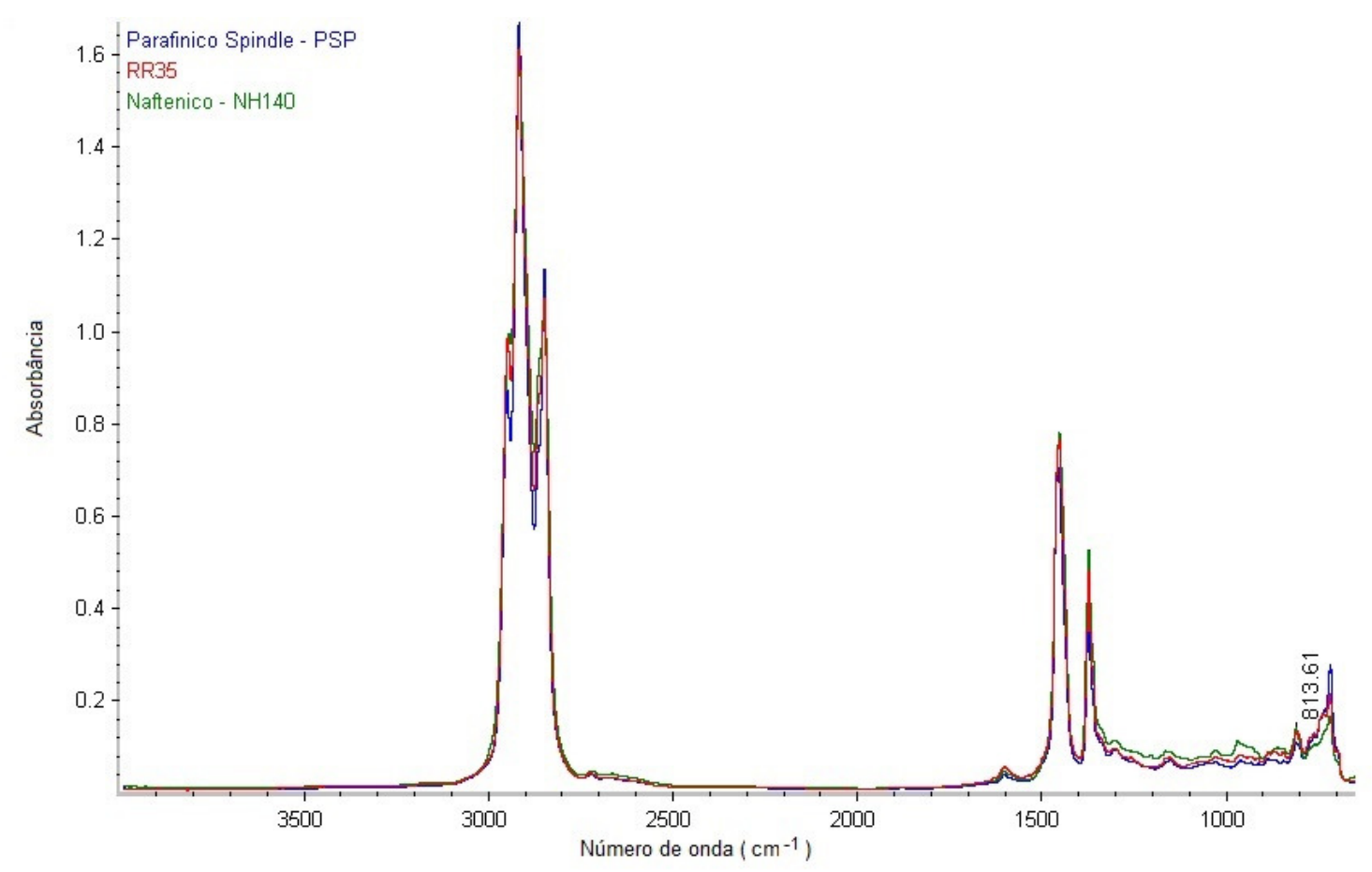

Espectro completo da Amostra RR35

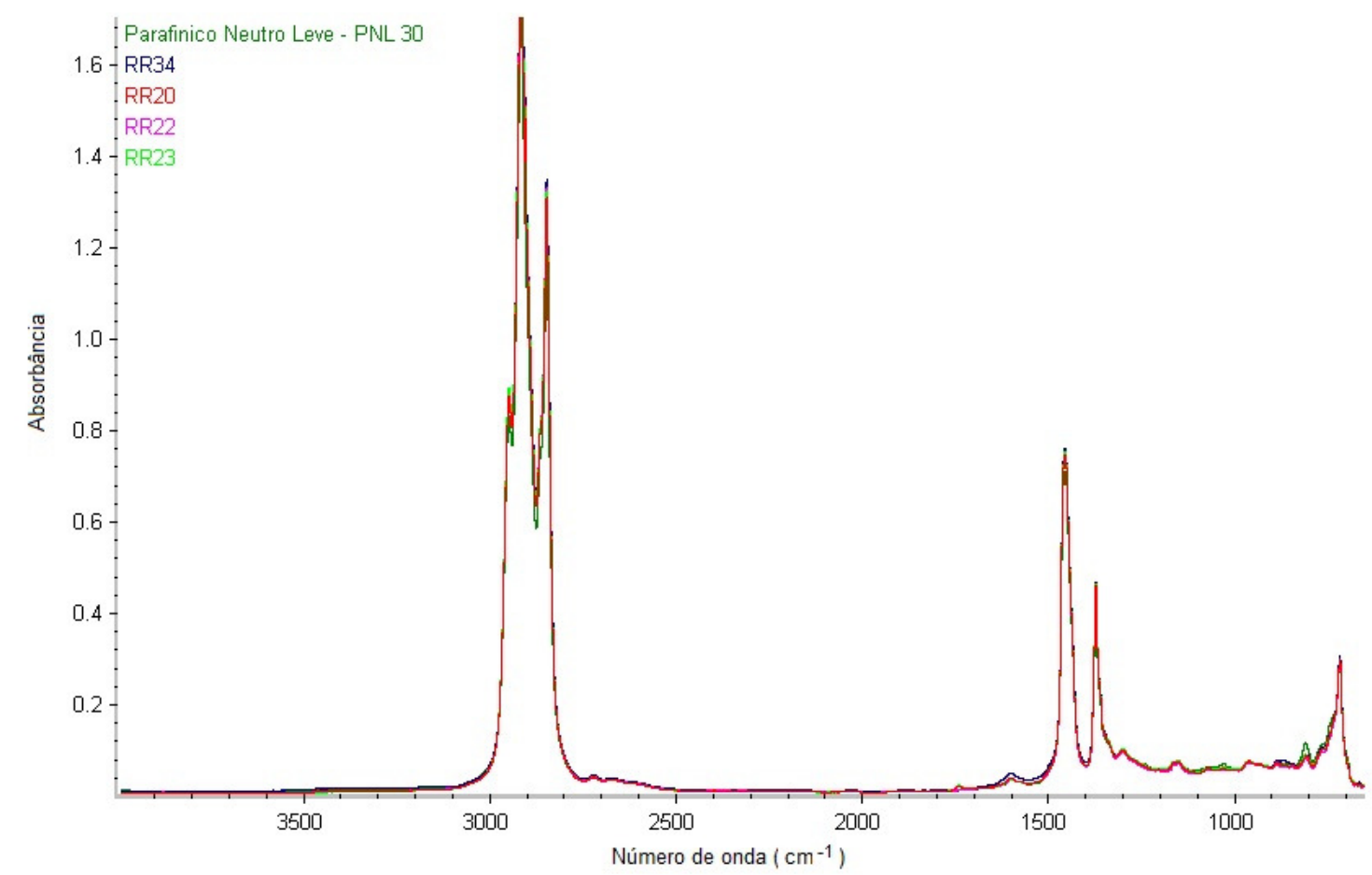

Espectros dos Óleos Rerrefinados Parafínicos Neutro Leves considerados conforme. 


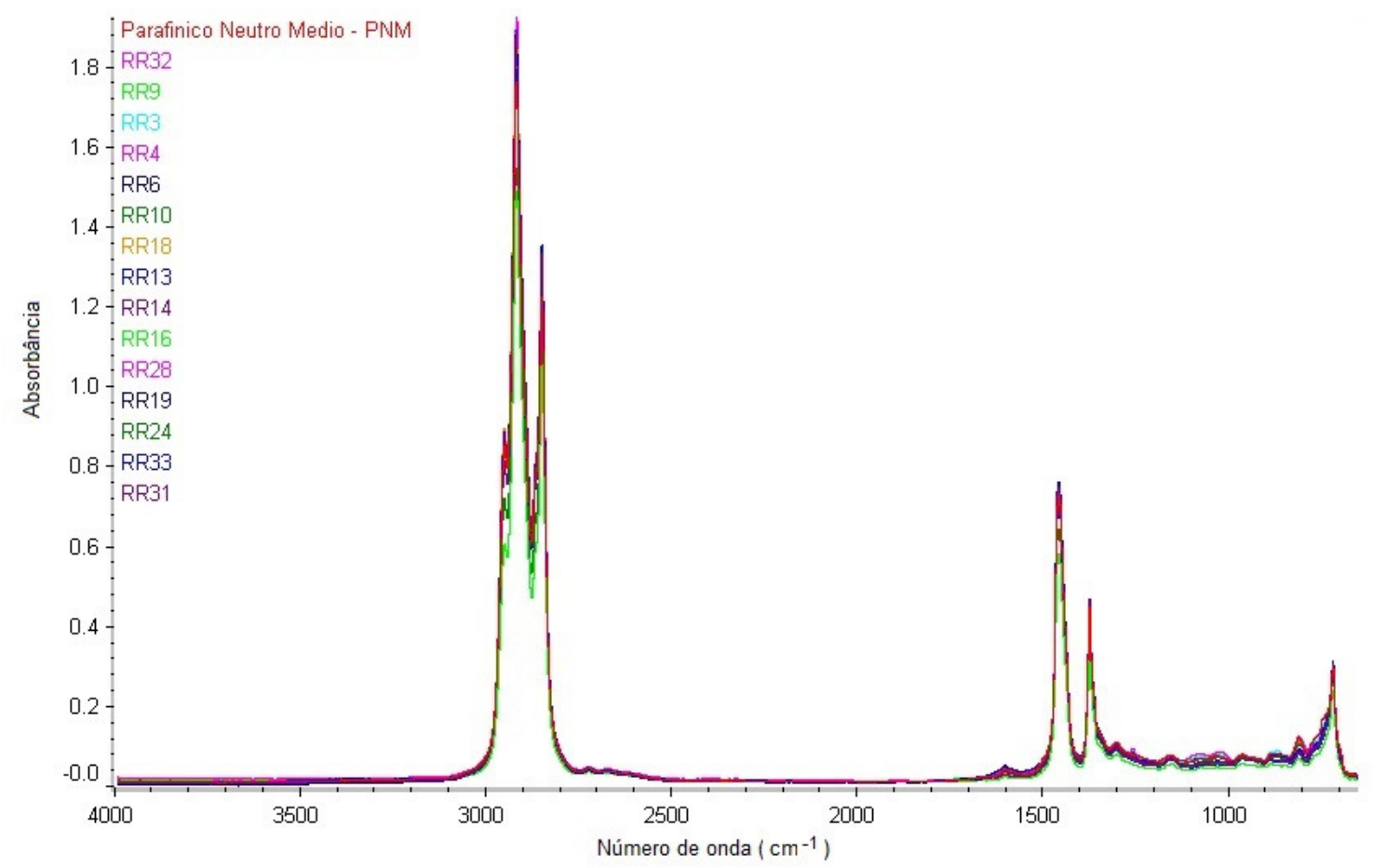

Espectros dos Óleos Rerrefinados Parafínicos Neutro Médios considerados conforme.

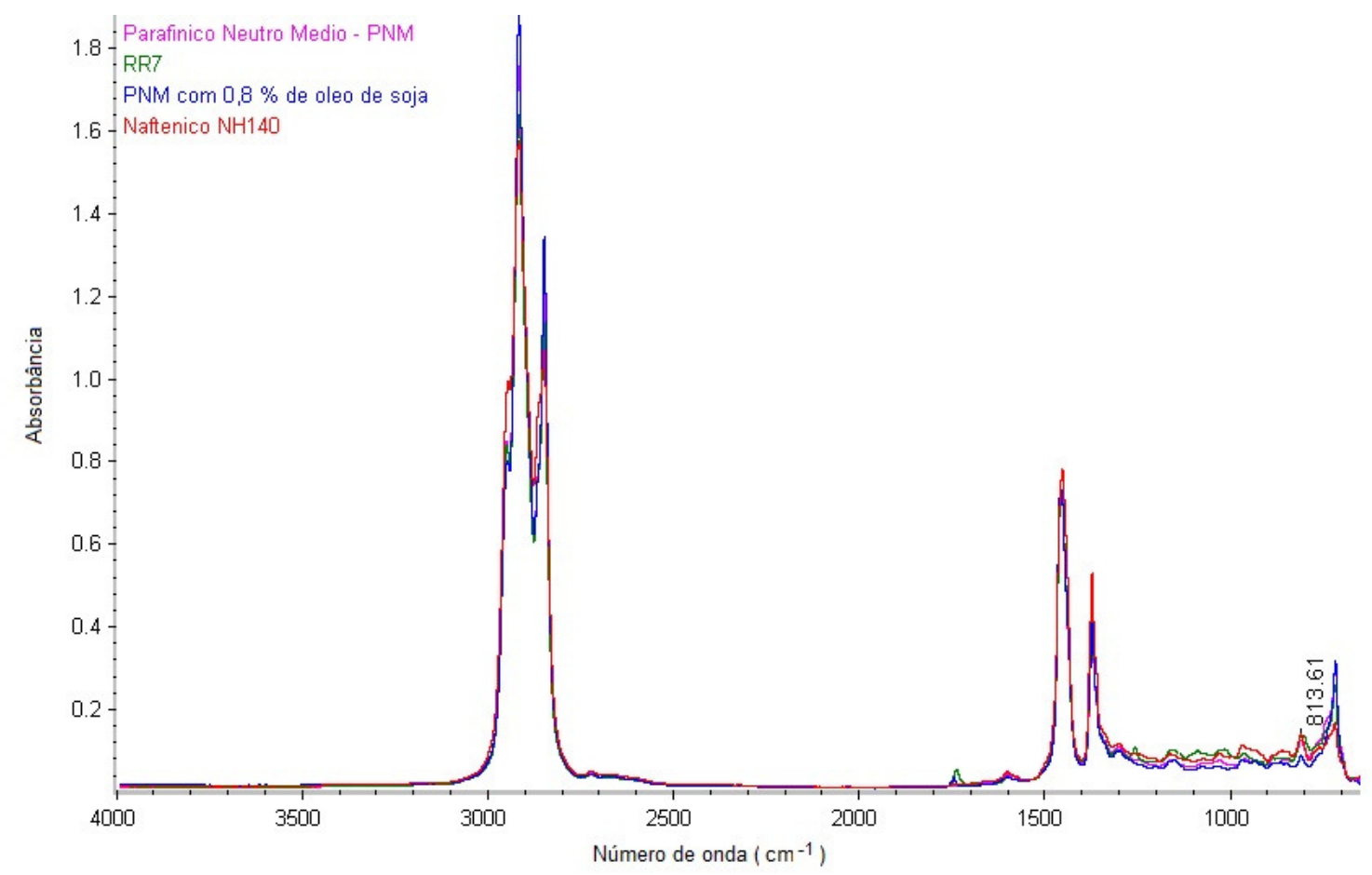

Espectro completo da Amostra RR7 


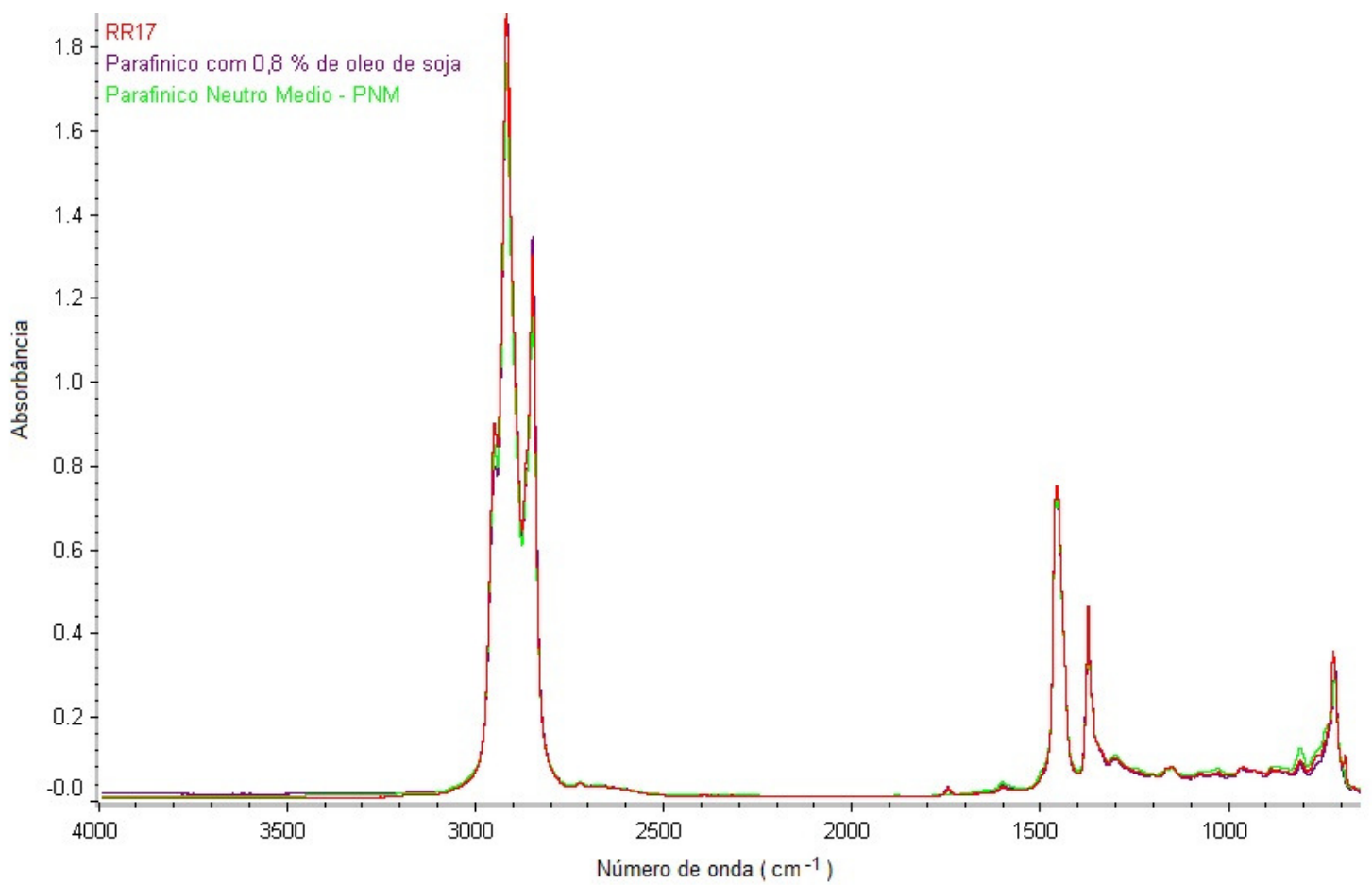

Espectro completo da Amostra RR17

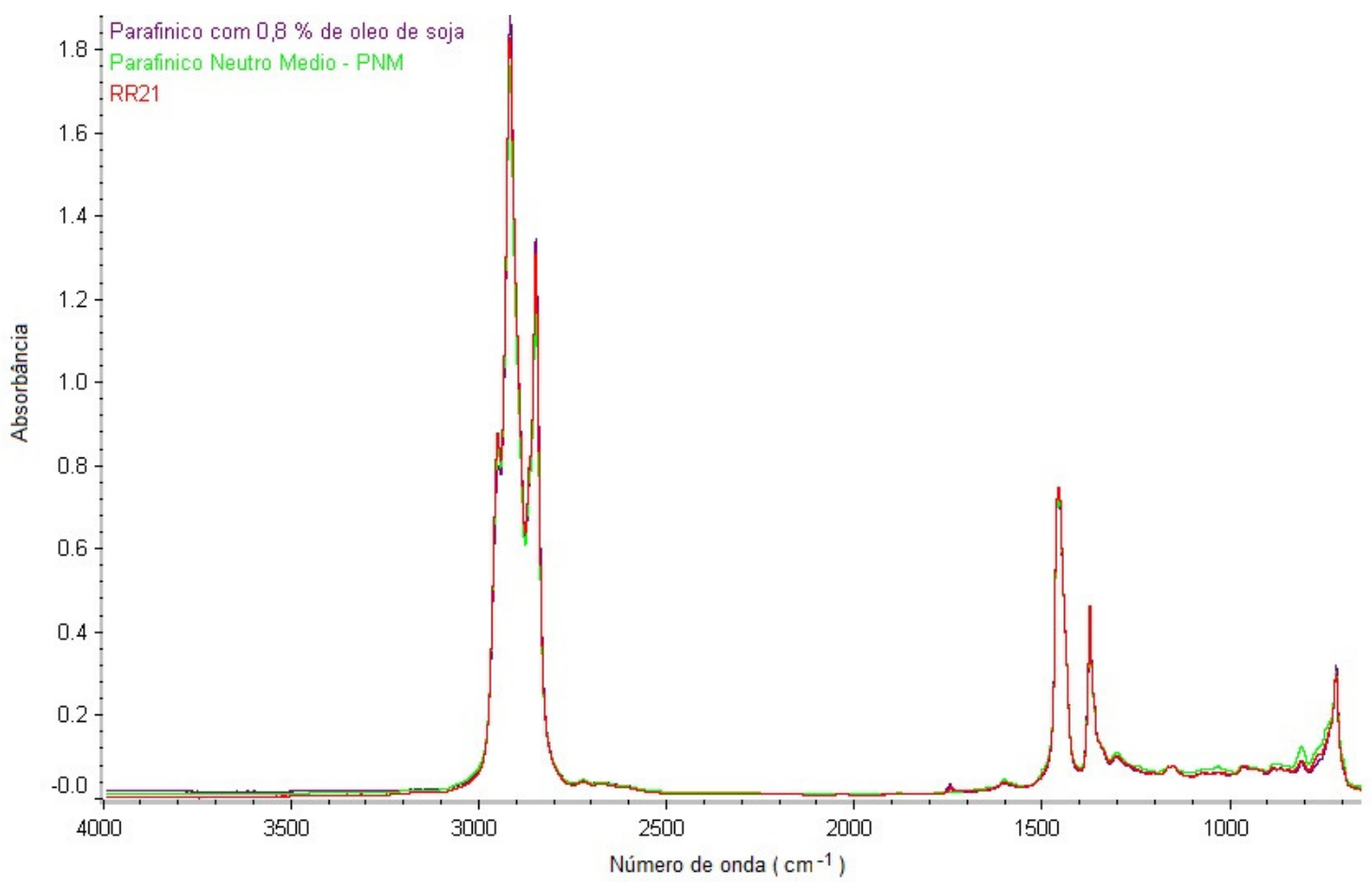

Espectro completo da Amostra RR21 


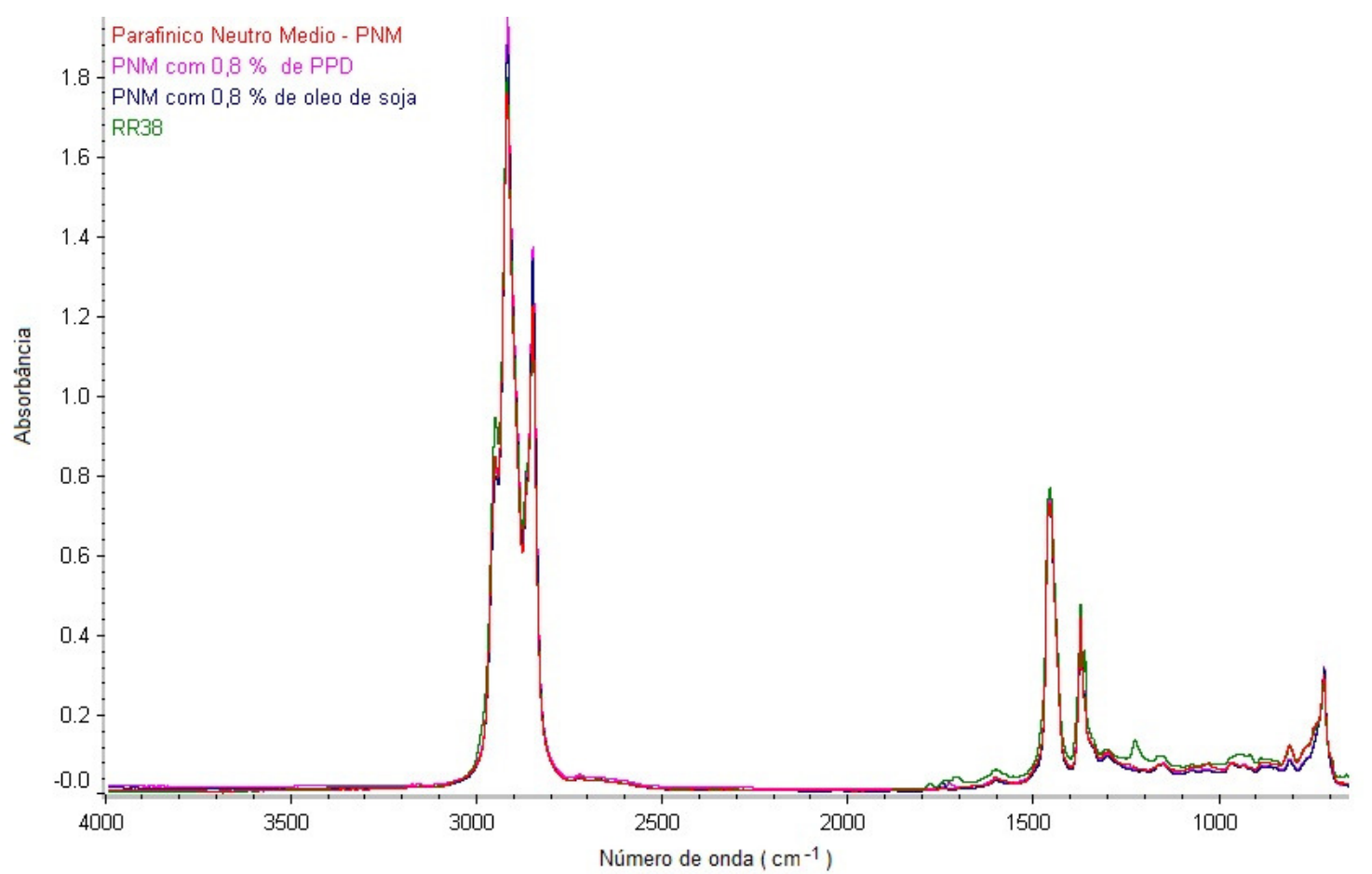

Espectro completo da Amostra RR38

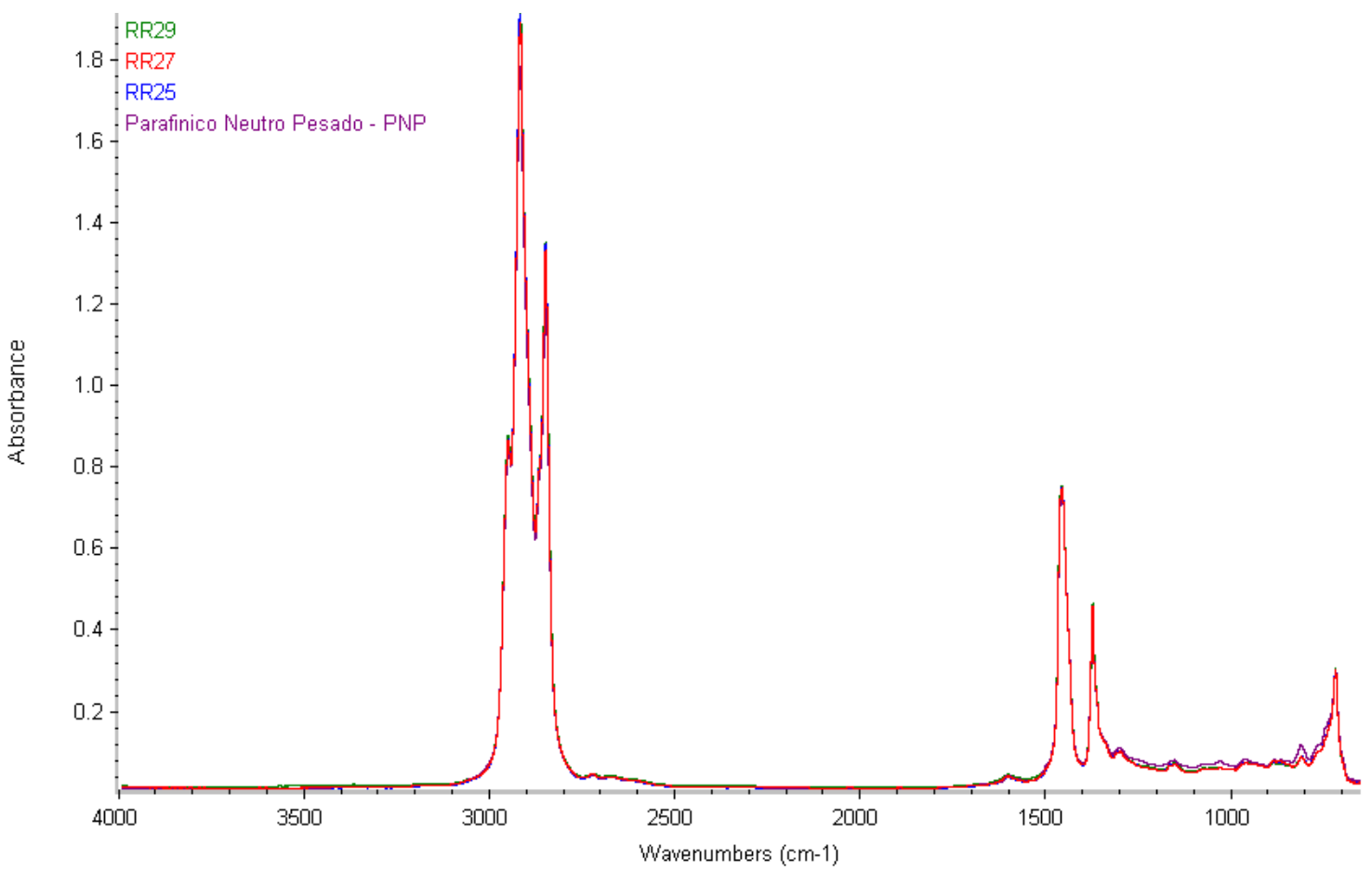

Espectros dos Óleos Rerrefinados Parafínicos Neutro Pesados considerados conforme. 


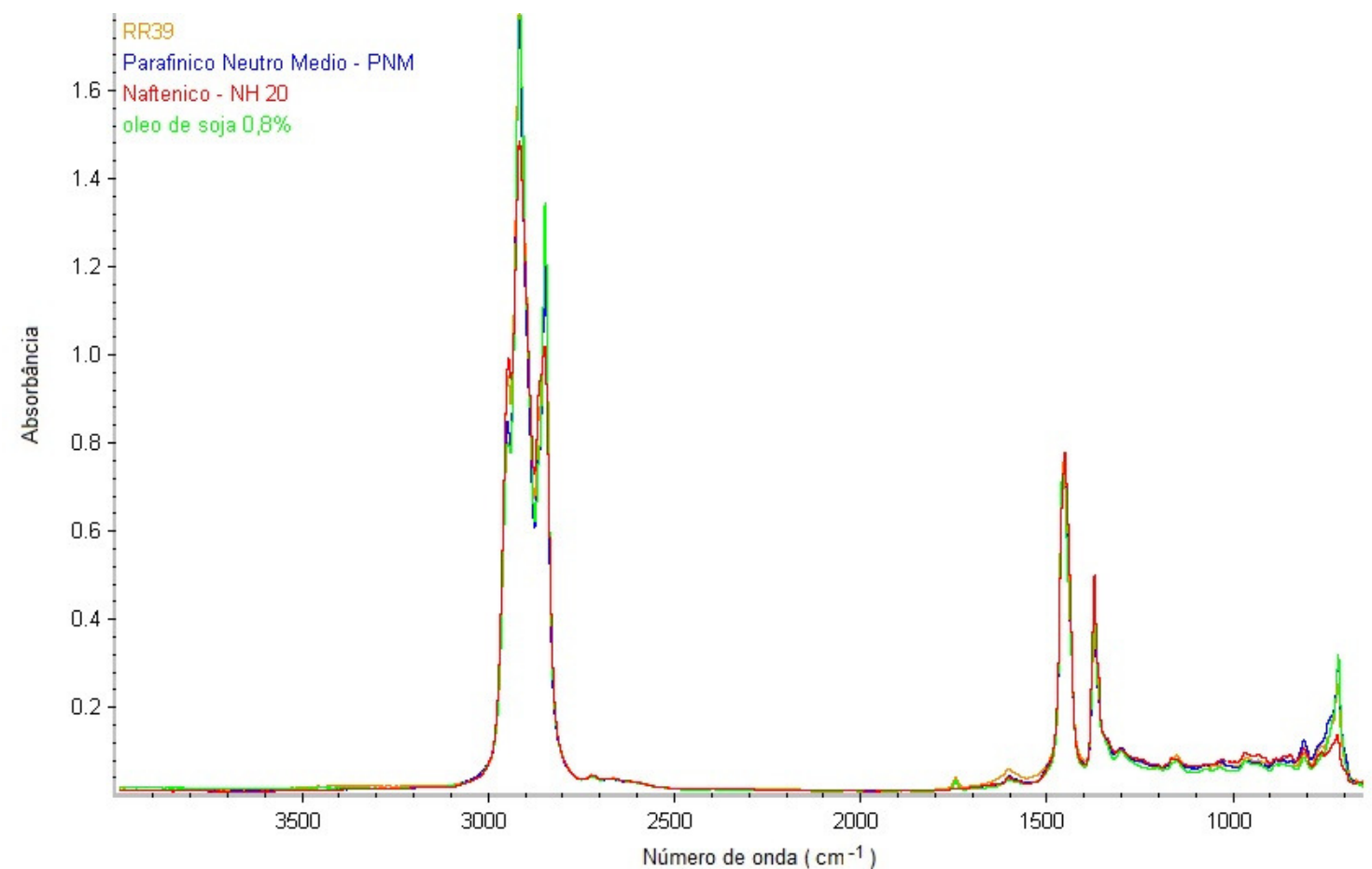

Espectro completo da Amostra RR39 


\subsection{Anexo 2 -Linearidade do Método PNM1 para o Ferro}

Teste de Resíduo Padronizado Jacknife

\begin{tabular}{ccccccc}
\hline Pontos & $\boldsymbol{x}_{\boldsymbol{i}}$ & $\boldsymbol{y}_{\boldsymbol{i}}$ & $\boldsymbol{e}_{\boldsymbol{i}}$ & $\boldsymbol{J}_{\boldsymbol{e}}$ & $\boldsymbol{r}_{\boldsymbol{i}}$ & $\boldsymbol{h}_{\boldsymbol{i}}$ \\
\hline 1 & 4,838 & 0,5367 & $-0,08$ & $-0,997$ & $-0,997$ & 0,108 \\
2 & 5,687 & 0,5369 & $-0,10$ & $-1,380$ & $-1,360$ & 0,106 \\
3 & 5,137 & 0,5706 & $-0,05$ & $-0,679$ & $-0,685$ & 0,108 \\
4 & 15,707 & 0,9568 & $-0,02$ & $-0,236$ & $-0,240$ & 0,078 \\
5 & 14,906 & 0,8785 & $-0,07$ & $-0,897$ & $-0,900$ & 0,080 \\
6 & 15,382 & 0,8867 & $-0,08$ & $-0,998$ & $-0,998$ & 0,079 \\
7 & 25,421 & 1,4432 & 0,14 & 1,897 & 1,820 & 0,058 \\
8 & 25,622 & 1,2393 & $-0,07$ & $-0,837$ & $-0,842$ & 0,057 \\
9 & 25,560 & 1,2953 & $-0,01$ & $-0,106$ & $-0,108$ & 0,057 \\
10 & 35,429 & 1,6569 & 0,02 & 0,299 & 0,303 & 0,042 \\
11 & 35,407 & 1,7004 & 0,07 & 0,855 & 0,858 & 0,043 \\
12 & 35,006 & 1,5859 & $-0,03$ & $-0,404$ & $-0,410$ & 0,043 \\
13 & 45,691 & 2,1119 & 0,14 & 1,774 & 1,713 & 0,034 \\
14 & 45,792 & 2,0478 & 0,07 & 0,868 & 0,872 & 0,034 \\
15 & 46,037 & 2,0755 & 0,09 & 1,120 & 1,115 & 0,033 \\
16 & 55,656 & 2,3821 & 0,08 & 0,939 & 0,941 & 0,031 \\
17 & 55,656 & 2,2878 & $-0,02$ & $-0,231$ & $-0,235$ & 0,031 \\
18 & 55,977 & 2,4498 & 0,13 & 1,703 & 1,651 & 0,031 \\
19 & 64,979 & 2,6914 & 0,07 & 0,923 & 0,926 & 0,035 \\
20 & 64,970 & 2,5704 & $-0,05$ & $-0,575$ & $-0,582$ & 0,035 \\
21 & 65,156 & 2,617 & $-0,01$ & $-0,076$ & $-0,077$ & 0,035 \\
22 & 75,025 & 2,8906 & $-0,06$ & $-0,766$ & $-0,771$ & 0,045 \\
23 & 75,255 & 3,088 & 0,13 & 1,657 & 1,611 & 0,045 \\
24 & 75,149 & 2,9457 & $-0,01$ & $-0,129$ & $-0,131$ & 0,045 \\
25 & 83,285 & 3,2945 & 0,07 & 0,846 & 0,850 & 0,058 \\
& & & & & & \\
27 & 84,598 & 3,2009 & $-0,07$ & $-0,884$ & $-0,887$ & 0,060 \\
28 & 95,128 & 3,6145 & $-0,01$ & $-0,092$ & $-0,094$ & 0,084 \\
29 & 95,487 & 3,5168 & $-0,12$ & $-1,534$ & $-1,500$ & 0,085 \\
30 & 94,891 & 3,6723 & 0,06 & 0,742 & 0,748 & 0,083 \\
31 & 105,542 & 3,9772 & 0,01 & 0,107 & 0,109 & 0,114 \\
32 & 104,730 & 3,8184 & $-0,12$ & $-1,652$ & $-1,606$ & 0,111 \\
33 & 104,680 & 3,8332 & $-0,11$ & $-1,415$ & $-1,392$ & 0,111 \\
\hline & & & & & &
\end{tabular}


Teste Ryan-Joiner - Normalidade dos resíduos

\begin{tabular}{|c|c|c|c|c|c|}
\hline Pontos & $p_{i}$ & $q_{i}$ & $\boldsymbol{e}_{\boldsymbol{i}}$ & \multirow{2}{*}{\multicolumn{2}{|c|}{$\begin{aligned} \text { Req } & =0,978271 \\
\text { Desvio da Normal : } & p>0,10\end{aligned}$}} \\
\hline 1 & 0,01938 & $-2,06673$ & $-0,12338$ & & \\
\hline 2 & 0,050388 & $-1,64111$ & $-0,11699$ & & \\
\hline 3 & 0,081395 & $-1,39575$ & $-0,10691$ & & \\
\hline 4 & 0,112403 & $-1,21385$ & $-0,10477$ & & \\
\hline 5 & 0,143411 & $-1,06512$ & $-0,07802$ & & \\
\hline 6 & 0,174419 & $-0,93685$ & $-0,0767$ & \multicolumn{2}{|c|}{ Valores Críticos de $R$} \\
\hline 7 & 0,205426 & $-0,82239$ & $-0,07036$ & Rcritico $(\alpha: 0,10)=$ & 0,972117 \\
\hline 8 & 0,236434 & $-0,71782$ & $-0,0701$ & Rcritico $(\alpha: 0,05)=$ & 0,965731 \\
\hline 9 & 0,267442 & $-0,62057$ & $-0,06661$ & Rcritico $(\alpha: 0,01)=$ & 0,951593 \\
\hline 10 & 0,29845 & $-0,52886$ & $-0,06141$ & & \\
\hline 11 & 0,329457 & $-0,44141$ & $-0,05277$ & & \\
\hline 12 & 0,360465 & $-0,35722$ & $-0,04658$ & \multirow{2}{*}{\multicolumn{2}{|c|}{$\begin{array}{l}\text { Conclusão } \\
\text { Os resíduos seguem a Normal }\end{array}$}} \\
\hline 13 & 0,391473 & $-0,27548$ & $-0,03268$ & & \\
\hline 14 & 0,422481 & $-0,19555$ & $-0,01886$ & & \\
\hline 15 & 0,453488 & $-0,11685$ & $-0,01876$ & & \\
\hline 16 & 0,484496 & $-0,03887$ & $-0,01044$ & & \\
\hline 17 & 0,515504 & 0,038872 & $-0,00855$ & & \\
\hline 18 & 0,546512 & 0,116853 & $-0,00733$ & & \\
\hline 19 & 0,577519 & 0,195551 & $-0,00617$ & & \\
\hline 20 & 0,608527 & 0,275482 & 0,008352 & & \\
\hline 21 & 0,639535 & 0,357216 & 0,024201 & & \\
\hline 22 & 0,670543 & 0,441412 & 0,058364 & & \\
\hline 23 & 0,70155 & 0,528865 & 0,067273 & & \\
\hline 24 & 0,732558 & 0,620568 & 0,068455 & & \\
\hline 25 & 0,763566 & 0,71782 & 0,069828 & & \\
\hline 26 & 0,794574 & 0,822394 & 0,074105 & & \\
\hline 27 & 0,825581 & 0,936847 & 0,075467 & & \\
\hline 28 & 0,856589 & 1,06512 & 0,089347 & & \\
\hline 29 & 0,887597 & 1,213847 & 0,12831 & & \\
\hline 30 & 0,918605 & 1,395747 & 0,132459 & & \\
\hline 31 & 0,949612 & 1,641107 & 0,137276 & & \\
\hline 32 & 0,98062 & 2,066729 & 0,143974 & & \\
\hline
\end{tabular}

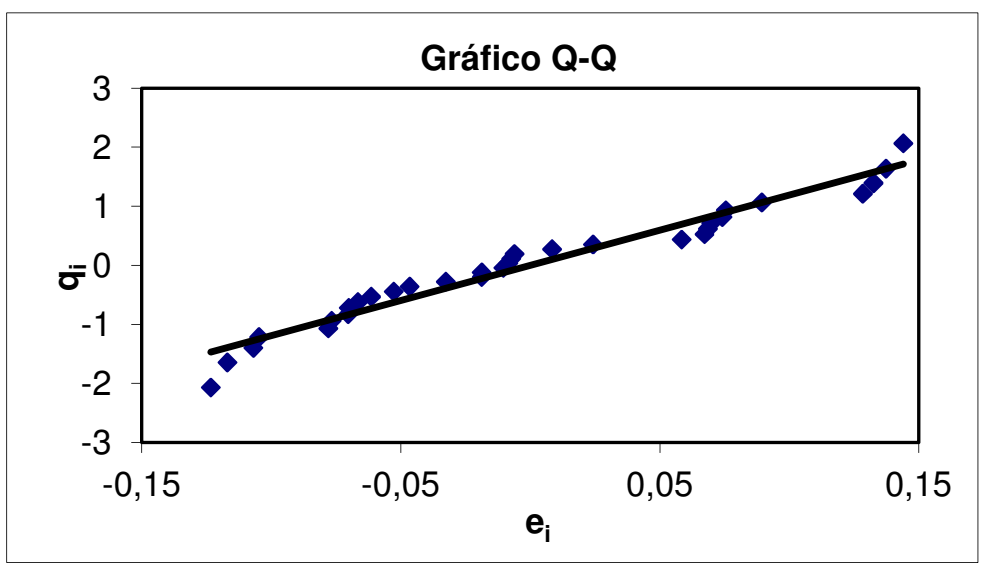

Teste de Durbin-Watson - Independência dos resíduos 


\begin{tabular}{|c|c|c|c|}
\hline Pontos & $\boldsymbol{e}_{i}$ & $\boldsymbol{e}_{i-1}$ & $e_{i}-e_{i-1}$ \\
\hline 1 & $-0,08$ & & \\
\hline 2 & $-0,10$ & $-0,08$ & $-0,03$ \\
\hline 3 & $-0,05$ & $-0,10$ & 0,05 \\
\hline 4 & $-0,02$ & $-0,05$ & 0,03 \\
\hline 5 & $-0,07$ & $-0,02$ & $-0,05$ \\
\hline 6 & $-0,08$ & $-0,07$ & $-0,01$ \\
\hline 7 & 0,14 & $-0,08$ & 0,22 \\
\hline 8 & $-0,07$ & 0,14 & $-0,21$ \\
\hline 9 & $-0,01$ & $-0,07$ & 0,06 \\
\hline 10 & 0,02 & $-0,01$ & 0,03 \\
\hline 11 & 0,07 & 0,02 & 0,04 \\
\hline 12 & $-0,03$ & 0,07 & $-0,10$ \\
\hline 13 & 0,14 & $-0,03$ & 0,17 \\
\hline 14 & 0,07 & 0,14 & $-0,07$ \\
\hline 15 & 0,09 & 0,07 & 0,02 \\
\hline 16 & 0,08 & 0,09 & $-0,01$ \\
\hline 17 & $-0,02$ & 0,08 & $-0,09$ \\
\hline 18 & 0,13 & $-0,02$ & 0,15 \\
\hline 19 & 0,07 & 0,13 & $-0,06$ \\
\hline 20 & $-0,05$ & 0,07 & $-0,12$ \\
\hline 21 & $-0,01$ & $-0,05$ & 0,04 \\
\hline 22 & $-0,06$ & $-0,01$ & $-0,06$ \\
\hline 23 & 0,13 & $-0,06$ & 0,19 \\
\hline 24 & $-0,010444202$ & 0,13 & $-0,14$ \\
\hline 25 & 0,06727277 & $-0,01$ & 0,08 \\
\hline 26 & $-0,070097799$ & 0,07 & $-0,14$ \\
\hline 27 & $-0,007328535$ & $-0,07$ & 0,06 \\
\hline 28 & $-0,116992785$ & $-0,01$ & $-0,11$ \\
\hline 29 & 0,058363536 & $-0,12$ & 0,18 \\
\hline 30 & 0,008351841 & 0,06 & $-0,05$ \\
\hline 31 & $-0,123378517$ & 0,01 & $-0,13$ \\
\hline 32 & $-0,106912527$ & $-0,12$ & 0,02 \\
\hline
\end{tabular}

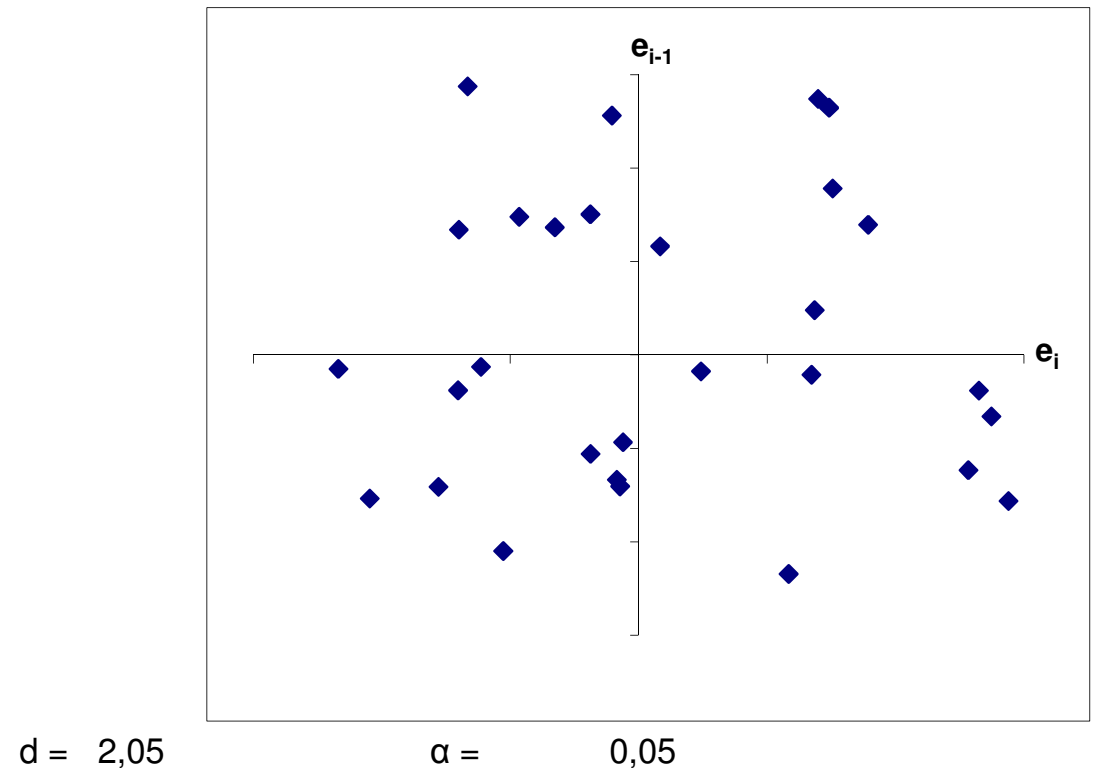




\begin{tabular}{llllllll}
\hline $\begin{array}{l}\text { Correlação } \\
\text { Positiva }\end{array}$ & Não & & \multicolumn{2}{l}{ Não há } & Não & & Correlação \\
& conclusivo & $\mathrm{dU}$ & correlação & $4-\mathrm{dU}$ & conclusivo & 4-dL & Negativa \\
\hline 1,37 & 1,50 & 2,04 & 2,50 & 2,63 & \\
\hline
\end{tabular}

Teste de Brown-Forsythe - Homoscedasticidade dos resíduos

\begin{tabular}{|c|c|c|c|c|c|c|}
\hline Grupo $k=1$ & Grupo $k=2$ & & & & & \\
\hline $\mathbf{e}_{1 j}$ & $\mathbf{e}_{2 \mathrm{j}}$ & $\left|d_{1}\right|$ & $\left|d_{2}\right|$ & Estatística & $k=1$ & $k=2$ \\
\hline$-0,077$ & 0,132459355 & 0,0579 & 0,0830 & $n_{k}$ & 17,0000 & 14,0000 \\
\hline$-0,105$ & 0,0741 & 0,0860 & 0,0377 & $\begin{array}{l}\mathrm{e}_{\mathrm{k}} \\
\text { (mediana) }\end{array}$ & $-0,0188$ & $-0,0089$ \\
\hline$-0,053$ & $-0,0466$ & 0,0340 & 0,0027 & $\mathrm{~d}_{\mathrm{k}}$ (média) & 0,0648 & 0,0544 \\
\hline$-0,019$ & $-0,0062$ & 0,0000 & 0,0525 & $S Q D_{k}$ & 0,0381 & 0,0308 \\
\hline$-0,070$ & $-0,0614$ & 0,0516 & 0,1372 & $\mathrm{~s} 2 \mathrm{p}$ & 0,0024 & \\
\hline$-0,078$ & 0,1283 & 0,0593 & 0,0016 & $\mathrm{tL}$ & 0,5913 & 0,5913 \\
\hline 0,144 & $-0,0104$ & 0,1627 & 0,0762 & $\mathrm{p}$ & 0,5589 & \\
\hline$-0,067$ & 0,0673 & 0,0478 & 0,0089 & \multirow{2}{*}{\multicolumn{3}{|c|}{ Conclusão }} \\
\hline$-0,009$ & & \multicolumn{2}{|l|}{0,0102} & & & \\
\hline 0,024 & $-0,0701$ & 0,0430 & 0,0016 & \multicolumn{3}{|c|}{ Não há evidência para rejeitar Ho } \\
\hline 0,068 & $-0,0073$ & 0,0872 & 0,1081 & \multicolumn{3}{|c|}{ Há homocedascidade } \\
\hline$-0,033$ & $-0,116992785$ & 0,0139 & 0,0672 & & & \\
\hline 0,137 & 0,0584 & 0,1560 & 0,0172 & & & \\
\hline 0,070 & 0,0084 & 0,0886 & 0,1145 & & & \\
\hline 0,089 & $-0,1234$ & 0,1081 & 0,0980 & & & \\
\hline 0,075 & $-0,1069$ & 0,0942 & 0,0089 & & & \\
\hline$-0,019$ & & 0,0001 & & & & \\
\hline
\end{tabular}

Análise de Regressão Linear

\begin{tabular}{ccrcrr}
\hline \multicolumn{2}{l}{ Estatísticas da regressão } & Estatísticas auxiliares & Coeficiente & \multicolumn{1}{c}{ Valor } & \multicolumn{1}{c}{$\boldsymbol{s}($ EP) } \\
\hline$R^{2}$ & $S_{x y}$ & $1,06 \mathrm{E}+03$ & Linear (a) & 0,4522 & 0,0287 \\
$n$ & $S_{x x}$ & $3,17 \mathrm{E}+04$ & Angular (b) & 0,03332 & 0,00046 \\
& $S_{y y}$ & $3,54 \mathrm{E}+01$ & & & \\
& $t_{c r i t i c o}$ & 2,042 & & & \\
& $J_{\text {critico }}$ & 2,045 & & & \\
\hline
\end{tabular}

ANOVA - Teste do desvio e significância da linearidade

\begin{tabular}{lcccccc}
\hline \multicolumn{1}{c}{$\boldsymbol{F V}$} & $\boldsymbol{G L}$ & $\boldsymbol{S Q}$ & $\boldsymbol{Q M}$ & $\boldsymbol{F}$ & $\boldsymbol{p}$ & $\boldsymbol{F}_{\text {critico }}$ \\
\hline Regressão & 1 & $3,52 \mathrm{E}+01$ & $3,52 \mathrm{E}+01$ & 5297,94 & $2,63 \mathrm{E}-35$ & 4,170877 \\
Resíduo & 30 & $1,99 \mathrm{E}-01$ & $6,64 \mathrm{E}-03$ & & & \\
Desvio da linearidade & 9 & $9,03 \mathrm{E}-02$ & $1,00 \mathrm{E}-02$ & 1,933 & $1,02 \mathrm{E}-01$ & 2,366048 \\
Entre níveis & 10 & $3,53 \mathrm{E}+01$ & & & & \\
Erro puro & 21 & $1,09 \mathrm{E}-01$ & $5,19 \mathrm{E}-03$ & & & \\
Total & 31 & $3,54 \mathrm{E}+01$ & & & & \\
\hline
\end{tabular}




\section{Ferro - PNM1}
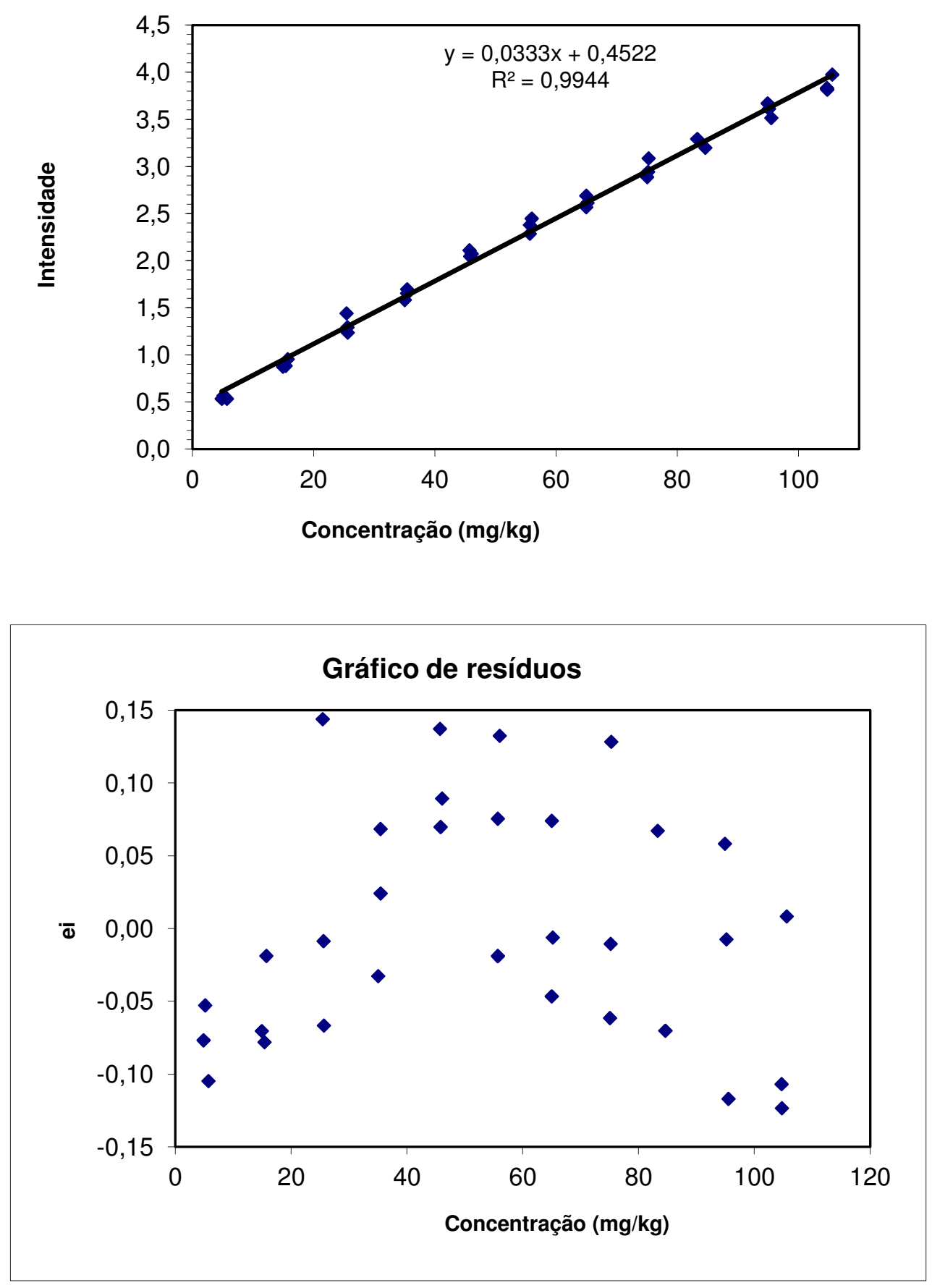


\subsection{Anexo 3 - Determinação do LD e LQ método PNM3 para o}

Ferro

\begin{tabular}{|c|c|c|}
\hline Replicatas & Concentração & \\
\hline 1 & $-1,457142857$ & \\
\hline 2 & $-2,939285714$ & \\
\hline 3 & $-2,571428571$ & \\
\hline 4 & $-1,835714286$ & \\
\hline 5 & $-2,521428571$ & \\
\hline 6 & 1,853571429 & \\
\hline 7 & $-2,128571429$ & \\
\hline 8 & $-3,721428571$ & \\
\hline 9 & $-2,296428571$ & \\
\hline 10 & $-0,896$ & \\
\hline$n$ & 10 & \\
\hline Média & $-1,851$ & LD 2,700189 \\
\hline$s$ & 1,517 & LQ 13,32063 \\
\hline
\end{tabular}




\subsection{Repetibilidade e Precisão Intermediária para o Ferro}

\begin{tabular}{ccc}
\hline Replicata & Concentração & Concentração \\
\hline 1 & 54,37142857 & 53,77857143 \\
2 & 54,83928571 & 54,42142857 \\
3 & 56,03571429 & 54,81785714 \\
4 & 56,10357143 & 54,86071429 \\
5 & 56,34642857 & 55,01071429 \\
6 & 56,43571429 & 55,075 \\
7 & 56,89285714 & 55,16071429 \\
8 & 59,90357143 & 56,14285714 \\
9 & 61,32857143 & 56,31071429 \\
10 & \multicolumn{2}{c}{5} \\
\hline MÉDIA & 56,917 & 0,782 \\
DESVIO-PADRÃO & 2,269 & 1,421 \\
C.V. (\%) & 3,986 & 2,2 \\
\hline LIM. REPETIBILIDADE & 6,4 & \\
\hline & & \\
MÉDIA DAS MÉDIAS & 55,991 & \\
DESVIO-PADRÃO & 1,310 & \\
C.V. (\%) & 2,340 & \\
LIM. PRECISÃO INTERMEDIÁRIA & 3,669 & \\
\cline { 1 - 2 } & \multicolumn{2}{c}{}
\end{tabular}




\subsection{Incerteza de medição para o Ferro método PNM3}

\begin{tabular}{|c|c|c|c|c|c|c|c|c|c|c|}
\hline \multirow{2}{*}{ Símbolo } & \multicolumn{3}{|c|}{ Fontes de incerteza } & \multirow{2}{*}{$\begin{array}{l}\text { Distribuição de } \\
\text { probabilidade }\end{array}$} & \multirow{2}{*}{ Divisor } & \multicolumn{2}{|c|}{$\begin{array}{l}\text { Coeficiente de } \\
\text { sensibilidade } c_{i}\end{array}$} & \multirow{2}{*}{$\begin{array}{c}\text { Incerteza } \\
\text { padrão } \\
u_{\mathrm{i}}\end{array}$} & \multirow{2}{*}{$\begin{array}{l}\text { Graus de } \\
\text { liberdade } v_{\mathbf{i}}\end{array}$} & \multirow{2}{*}{$\begin{array}{c}\text { Porcentagem } \\
\text { de } \\
\text { contribuição }\end{array}$} \\
\hline & Nome & $\begin{array}{c}\text { Valor } \\
(+/-)\end{array}$ & Unidade & & & Valor & Unidade & & & \\
\hline$U_{\text {solução } 1}$ & solução 1 da curva & 0,00023 & $\mathrm{mg} / \mathrm{kg}$ & normal & 2,00 & $1,00 \mathrm{E}+00$ & - & 0,000115 & infinito & 0,0000 \\
\hline$u_{\text {solução } 3}$ & solução 3 da curva & 0,00023 & $\mathrm{mg} / \mathrm{kg}$ & normal & 2,00 & $1,00 \mathrm{E}+00$ & - & 0,000115 & infinito & 0,0000 \\
\hline$u_{\text {solução } 4}$ & solução 4 da curva & 0,00023 & $\mathrm{mg} / \mathrm{kg}$ & normal & 2,00 & $1,00 \mathrm{E}+00$ & - & 0,000115 & infinito & 0,0000 \\
\hline$u_{\text {solução } 5}$ & solução 5 da curva & 0,00023 & $\mathrm{mg} / \mathrm{kg}$ & normal & 2,00 & $1,00 \mathrm{E}+00$ & - & 0,000115 & infinito & 0,0000 \\
\hline$u_{\text {solução } 6}$ & solução 6 da curva & 0,00023 & $\mathrm{mg} / \mathrm{kg}$ & normal & 2,00 & $1,00 \mathrm{E}+00$ & - & 0,000115 & infinito & 0,0000 \\
\hline$U_{\text {solução } 7}$ & solução 7 da curva & 0,00023 & $\mathrm{mg} / \mathrm{kg}$ & normal & 2,00 & $1,00 \mathrm{E}+00$ & - & 0,000115 & infinito & 0,0000 \\
\hline$u_{\text {solução } 8}$ & solução 8 da curva & 0,00023 & $\mathrm{mg} / \mathrm{kg}$ & normal & 2,00 & $1,00 \mathrm{E}+00$ & - & 0,000115 & infinito & 0,0000 \\
\hline$U_{\text {solução } 9}$ & solução 9 da curva & 0,00023 & $\mathrm{mg} / \mathrm{kg}$ & normal & 2,00 & $1,00 \mathrm{E}+00$ & - & 0,000115 & infinito & 0,0000 \\
\hline$U_{\text {solução } 10}$ & solução10 da curva & 0,00023 & $\mathrm{mg} / \mathrm{kg}$ & normal & 2,00 & $1,00 \mathrm{E}+00$ & - & 0,000115 & infinito & 0,0000 \\
\hline$u_{\text {solução } 12}$ & solução 12 da curva & 0,00023 & $\mathrm{mg} / \mathrm{kg}$ & normal & 2,00 & $1,00 \mathrm{E}+00$ & - & 0,000115 & infinito & 0,0000 \\
\hline$u_{\text {solução } 13}$ & solução 13 da curva & 0,00023 & $\mathrm{mg} / \mathrm{kg}$ & normal & 2,00 & $1,00 \mathrm{E}+00$ & - & 0,000115 & infinito & 0,0000 \\
\hline$U_{\text {solução } 14}$ & solução 14 da curva & 0,00023 & $\mathrm{mg} / \mathrm{kg}$ & normal & 2,00 & $1,00 \mathrm{E}+00$ & - & 0,000115 & infinito & 0,0000 \\
\hline$U_{\text {solução } 16}$ & solução 16 da curva & 0,00023 & $\mathrm{mg} / \mathrm{kg}$ & normal & 2,00 & $1,00 \mathrm{E}+00$ & - & 0,000115 & infinito & 0,0000 \\
\hline$U_{\text {solução } 17}$ & solução 17 da curva & 0,00023 & $\mathrm{mg} / \mathrm{kg}$ & normal & 2,00 & $1,00 \mathrm{E}+00$ & - & 0,000115 & infinito & 0,0000 \\
\hline$u_{\text {solução } 18}$ & solução18 da curva & 0,00023 & $\mathrm{mg} / \mathrm{kg}$ & normal & 2,00 & $1,00 \mathrm{E}+00$ & - & 0,000115 & infinito & 0,0000 \\
\hline$u_{\text {det. curva }}$ & curva analítica & 0,67995 & $\mathrm{mg} / \mathrm{kg}$ & normal & 1,00 & $1,00 \mathrm{E}+00$ & - & 0,679948 & infinito & 0,85 \\
\hline$U_{\text {verif. curva }}$ & verificação & 0,24000 & $\mathrm{mg} / \mathrm{kg}$ & normal & 2,00 & $1,00 \mathrm{E}+00$ & - & 0,120000 & infinito & 0,03 \\
\hline$u_{\text {prec. int. }}$ & precisão intermediária & 3,66910 & $\mathrm{mg} / \mathrm{kg}$ & normal & 1,00 & $1,00 \mathrm{E}+00$ & - & 3,669099 & 1 & 24,80 \\
\hline$u_{\text {repe }}$ & repetibilidade & 6,35224 & $\mathrm{mg} / \mathrm{kg}$ & normal & 1,00 & $1,00 \mathrm{E}+00$ & - & 6,352245 & 9 & 74,32 \\
\hline Incerteza & Distribuição de & \multicolumn{2}{|c|}{ Graus de liberdade } & Fator de abran & gência & \multicolumn{3}{|c|}{ Incerteza expandida (U) } & \multicolumn{2}{|c|}{ Unidade } \\
\hline
\end{tabular}




\begin{tabular}{|c|c|c|c|c|c|}
\hline $\begin{array}{c}\text { padrão } \\
\text { combina } \\
\text { da }\left(u_{\mathrm{c}}\right)\end{array}$ & probabilidade & $\left(v_{\text {eff }}\right)$ & $(k)$ & (Probabilidade $\cong 95 \%)$ & \\
\hline 7,368177 & normal & 8 & 2,37 & 17,4626 & $\mathrm{mg} / \mathrm{kg}$ \\
\hline
\end{tabular}

